\title{
Drawing: A Palimpsest for Architecture
}

By

Roberto Campos, B.A.S.

A thesis submitted to

The Faculty of Graduate Studies

In partial fulfillment of the requirements for the degree of

Master of Architecture

School of Architecture

Carleton University

Ottawa, Ontario

2004-2005

(C) Copyright

Roberto Campos 2005 
"With our minds fixed on the predominance of language we might even risk enclosing architecture within its own compound, denying it communication with anything else to preserve its integrity. This would be possible, yet it seems very unlikely to occur because, for architecture, even in the solitude of pretended autonomy, there is one unfailing communicant, and that is the drawing."

\section{- Robin Evans}

Translation From Drawing to Building

Drawing: A Palimpsest for Architecture
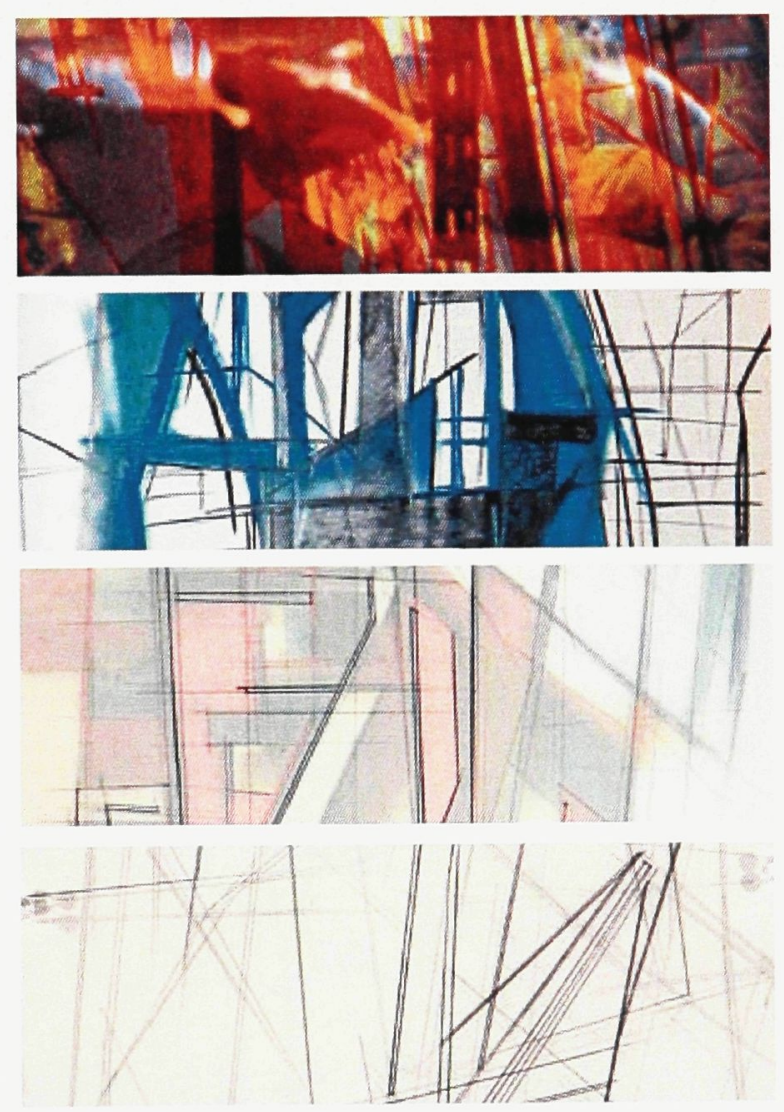

C) Roberto Campos 2005 


\begin{abstract}
The act of drawing and the drawing - as object - can be more than a capturing of a building onto paper. Rather, the drawing provides for a constituting of knowledge, in that, the drawing itself is a site for the imagining of new architecture. Through the act of their making, and the act of their coincidental readings, new architectural ideas are imagined. Understanding and ultimately taking advantage of this association can free the architect from the barriers established by the semantics of convention. Drawings can be established, not only as the site of production, but that of creative reception. Through academic research, and a speculative design project, the thesis will investigate the internal relationships of drawing; exploring them as a form of imaginative action. They are an "other" of architecture, an extension of an architectural idea and not just as a denotative to one.

The drawings developed through this thesis will use the imaginative capabilities of drawings to generate an architecture that explores new associative understandings of the Royal Architectural Institute of Canada, its' mandates, and their ability to advocate for the marketing of architecture in Canada.
\end{abstract}




\section{Acknowledgements}

I would like to thank my thesis advisor Professor Stephen Fai - not only for his continuous support and direction, but also for challenging this academic and professional journey. To my colleagues throughout the years for their daily constructive criticism and support, most importantly: Tony Sproul \& James Hayes for their daily and challenging dialogues on architecture and the values that guide it. Thanks to Rob Eland for contributing his editing and preparation support on more than one occasion. Patryk Illendo for struggling with me right to the very end. To my great friends Nathan Lockhart and Chris Foran from whom I learned a long time ago that life was not a race. To my parents Leticia Campos and Roberto Campos Sr. who've taught me the importance of hard work, generosity, humility and the unconditional support of family. To my brother and sister for putting up with me all these years. To Cil, for her incredible patience, and for always being there when I needed her the most. Yet, most of all for showing me that adventures are meaningless without having people to share them with. 


\section{Table of Contents}

$\begin{array}{ll}\text { Abstract } & \text { ii } \\ \text { Acknowledgements } & \text { iii } \\ \text { Table of Contents } & \text { iv } \\ \text { List of Illustrations } & \text { v }\end{array}$

$\begin{array}{ll}\text { Introduction } & 1\end{array}$

1 Objectification 5

2 Translation 17

The Poetics of Drawn Space 21

The Expressive and Emotive Aspects of the Poetic 23

3 Precedents 25

4 /Palimpsest/: The Process 35

4.1 Phase 1: Un-Learning How to Draw - Drawing a Palimpsest 39

4.2 Geometric Evolution 60

"No-Things" And Palimpsests $\quad 41$

Phase 2: First Revelation - As Chalk Drawing 60

Phase 3: Second Revelation - As Layered Drawing 62

Phase 4: Third Revelation - As Line Drawing 63

Chalk, Layered, Line $\quad 64$

4.3 Phase 5: The Layering of the Line Drawing 86

4.4 Programming by Palimpsest 88

Phase 6: Spatial \& Programmatic Evolution through Section 88

Program \& Site: The Royal Architectural Institute of Canada $\quad 88$

Phase 7: Spatial \& Programmatic Evolution through Plan 96

4.5 Phase 8: Formal Evolution through Axonometric Projection 106

4.6 Phase 9: R.A.I.C. Represented 113

$\begin{array}{ll}\text { Conclusion } & 118\end{array}$

$\begin{array}{ll}\text { Bibliography } & 120\end{array}$

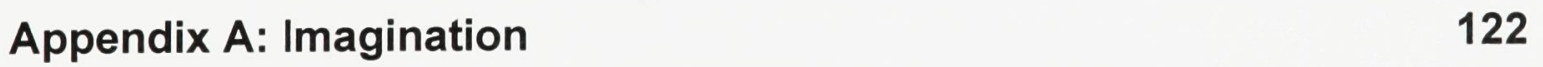




\section{List of Illustrations}

\section{All images by author unless otherwise noted.}

\section{Introduction}

1 Crisis of the Contemporary Architectural Drawing

1.1 J.-N.-D. Durand, Precis (1802-05), 'Courtyard Types'.

1.2 J.-N.-D. Durand, Precis (1802-05),

'Series of Building established by horizontal and vertical combinations.'

1.3 J.-N.-D. Durand, Precis (1802-05), 'Series of Orders'.

1.4 J.-N.-D. Durand, Precis (1802-05), 'Course to follow in the development of a project.

1.5 Etienne-Louis Boullee, Project for the Cenotaph for Sir Isaac Newton (1802-05), elevation and section.

\section{Precedents}

3.1 Office of Eisenman/Robertson Architects, University Art Museum of the California State University, 1986, Superimposed plans, Ink on Vellum

3.2 Office of Eisenman/Robertson Architects, La Villette Design Competition, 1986, Superimposed Plan diagrams, Ink on yellow vellum

3.3 Office of Eisenman/Robertson Architects, University Art Museum of the California State University, Ink and coloured pencils on vellum.

3.4 Daniel Libeskind, Little Universe (1978), from the Micromegas Series, Graphite on Paper.

3.5 Daniel Libeskind, Maldoror's Equation (1978), from the Micromegas Series, Graphite on Paper.
Daniel Libeskind, Chamberworks (1982), Graphite on Paper

3.6 Daniel Libeskind, Chamberworks (1982), Graphite on Paper 32

3.7 Daniel Libeskind, Between the Lines: Star Matrix - Site Plan (1988), Drawing for the Jewish Museum, Berlin.

3.8 Daniel Libeskind, Ground Floor Plan (1988), Drawing for the Jewish Museum, Berlin.

3.9 Daniel Libeskind, Between the Lines: Architectural Alphabet (1988), Drawing for the Jewish Museum, Berlin.

3.10 Daniel Libeskind, Jewish Museum, Berlin (1988-89), photograph by Helene Binet.

\subsection{Phase 1: Un-Learning How to Draw (The Projected Drawing)}




\subsection{Phase 2: Geometric Evolution}

4.2.1 Chalk Drawings (Displayed as Series) 60

4.2.2 Chalk Drawing Example $1 \quad 61$

4.2.3 Chalk Drawing Example 2 61

4.2.4 Layered Drawing Example $1 \quad 62$

4.2.5 Layered Drawing Example 2 62

4.2.6 Line Drawing Example $1 \quad 63$

4.2.7 to 4.2.171 "Chalk, Layered, Line" 64 - 85

4.3 Phase 4: The Layering of the Line Drawing

4.3.1 Layered Line Drawing \#1 87

4.3.2 Layered Line Drawing \#2 87

$\begin{array}{ll}\text { 4.3.3 Layered Line Drawing \#3 } & 87\end{array}$

4.3.4 Layered Line Drawing \#4 87

4.4 Phase 5: Spatial Evolution through Section

4.4.1 Section Exploration Drawing \#1 92

4.4.2 Section Exploration Drawing \#2 92

4.4.3 Section Exploration Drawing \#3 93

4.4.4 Section Exploration Drawing \#4 94

4.4.5 Section Exploration Drawing \#5 95

4.4.6 Section Exploration Drawing \#6 95

Phase 6: Spatial Evolution through Plan

4.4.7 St. Patrick St. Existing Elevation 96

4.4.8 Existing Pay Parking Lot 97

4.4.9 Existing Guigues Ave. Elevation 97

4.4.10 to 4.4.26 Plan \& Urban Exploration Drawings \#1 - $17 \quad 99$-104

4.4.27 Final Plan Exploration - Layered for Formal Development 105

4.5 Phase 7: Formal Evolution through Axonometric Projection

4.5.1 Axonometric Preliminary Exploration 108

4.5.2 Layered Plans for Axonometric Projection 108

4.5.3 Axonometric Drawing Exploration \#1 (1:150) 109

4.5.4 Axonometric Drawing Exploration \#2 - Layered with \#1 (1:150) 110

4.5.5 Axonometric Drawing Exploration \#3 (1:150) 111

4.6 Phase 8: R.A.I.C. Represented
4.6.1 Ground Floor Plan
$(1: 150)$
114
4.6.2 Second Floor Plan
$(1: 150)$
115
4.6.3 Section Moment @ Main Stair
116
4.6.4 Section Moment @ Library \& Archives Above Gallery 116
4.6.5 Section Moment @ RAIC Syllabus Gallery
117
4.6.6Plan Moment @ St. Patrick St.Pavilion 


\section{Introduction}

"With our minds fixed on the predominance of language we might even risk enclosing architecture within its own compound, denying it communication with anything else to preserve its integrity. This would be possible, yet it seems very unlikely to occur because, for architecture, even in the solitude of pretended autonomy, there is one unfailing communicant, and that is the drawing." 1

The act of drawing and the drawing - as object - can be more than the representing of a building onto paper. Rather, the drawing provides for a constituting of knowledge, in that, the drawing itself can be the site for the imagining of new architecture. Therefore, through the act of their making, and the act of their coincidental reading, new ideas are alluded; developing the idea of architecture, through their unique communicable capabilities. Drawing is a material and psychological practice that has traditionally developed into the representation of an object. Yet, it can simultaneously become an extended idea or an architectural object itself. Understanding and ultimately taking advantage of this association can free the architect from the semantic barriers established by architectural conventions.

"Whether explanatory or exploratory, drawing as both verb and noun is an inscription of architecture, an interpretation open to interpretation."2

Through an understanding, and a re-exploration of drawing (verb), can the drawing (noun) be used as a physical extension of the imagination? If so, can it generate (imagine) architecture, and not solely become a representation of it? Through academic research, and a speculative project, the thesis will explore these questions by investigating the internal relationships of drawing, more specifically, the interactions between the author, the viewer, and the drawing 
itself. This will frame how the thesis drawings are used as a generative process. By understanding these associations, the project drawings will become an "other" of architecture; an extension of an architectural idea, and not just as a denotative to one. Drawings will develop into a mode of thinking, and not just the formalization of a preconceived, complete thought.

The research chapters of the thesis will explore how drawing techniques, established during the Enlightenment, objectified the design process; influencing the use of the drawing in contemporary architectural practice. This will allow us to move beyond its efficient and economical appropriation. The thesis will explore instead the potentials for drawing itself, and its ability to fluctuate the established "meanings" governed by convention through their translation. ${ }^{3}$ Since imagination is developed by knowledge, there will always be an inherent association to the established conventions that currently guide architecture and its modes of representation. Appendix 1] Even through the translation of meaning, we can never fully free ourselves from this relationship. In fact, we require it in order to evaluate the proposal as "architectural".

The thesis project will generate architectural ideas through an intense exploration of making and reading drawings that strongly suggest or - as the thesis will imply - "imagine" the possibility for spatial experiences, program, urban strategies, materials and craft. These drawing will be a form of resistance by challenging the "commodification", ${ }^{4}$ and standardization of design development, program and form making. They confront the established conventions of architectural semantics. 
The research and drawing explorations will frame how the thesis will generate the design project, which is proposing a new permanent headquarters for the Royal Architectural Institute of Canada (R.A.I.C.). The design of the project will test the proposals of the thesis; developing the project based on a layered association within drawing(s), and how architects can reveal program and spatial experiences through them. The R.A.I.C., established in 1907, is a voluntary national association representing more than 3,000 architects, faculty and graduates of accredited Canadian Schools of Architecture. The R.A.I.C. is the voice for architecture, and its practice in Canada provides the national framework for the development and recognition of architectural excellence. ${ }^{5}$ The specific site for the project is located at the corner of Parent Ave. and St. Patrick St. in the Ottawa By Ward Market. Currently it is an empty parking lot directly east of the Notre Dame Basilica, and where the Canadian Conference of Catholic Bishops (C.C.C.B.) building was recently demolished.

The drawings will explore new associative understandings of the R.A.I.C., its' mandates, its' programmatic relationships (internal and external) and its ability to encourage the marketing of architecture in Canada. 


\section{Introduction Endnotes}

1 Evans, Robin. "Translation from Drawing to Building". Translation from Drawing to Building. Cambridge, Mass.: MIT Press, c1997. p. 154.

2 Kahn, Andrea. "Disclosure: Approaching Architecture." Harvard Architectural Review. n. 8 (1992): 4.

Emphasis added. Kahn continues: "Only when drawing is seen to inscribe its own architectural ground is it possible to accord it both a definitive role in shaping the conception of architecture and a substantive tectonic relationship to built form." p. 18.

${ }^{3}$ Evans, Robin. p. 154.

4 Marx, Karl. The Communist Manifesto: Annotated text / Karl Marx; prefaces by Marx and Engels; Edited by Frederic L. Bender. New York: W.W. Norton, 1988.

5 "The Royal Architectural Institute of Canada: The Voice of Architecture and its Practice in Canada." RAIC.org. 2005. Royal Architectural Institute of Canada. 20 June 2005 <http://www.raic.org/index_e.htm> 


\section{Objectification}

The shift from an "approximate and gestural world" to a "universe of machine and precision" during the eighteenth and nineteenth centuries signaled the end of Classical architectural theory. ${ }^{1}$ Replacing Firmitas, Commoditas and Venustatis - rational thought, efficiency, and economy were established as the new values of architecture. Industrialization, the transformation of public and religious institutions, and new paradigms of scientific knowledge all contributed to the social revolution that, by extension, transformed the practice and theory of architecture. $^{2}$ Evidence of this transformation can be seen in the changing relationship between architecture and engineering.

Up until this period, with the exception of land planning (a practice primarily executed by engineers), the role of the engineer was complementary to that of the architect. ${ }^{3}$ The growing middle class, however, influenced by social and technological change, aligned themselves with the economic imperatives embraced by the engineering profession. ${ }^{4}$

"Engineers were distinguished from architects in the eighteenth century, and began then to exert a considerable influence upon the design of space. By deploying a network of new institutions, by codifying their knowledge and practice, they deployed a system which was to pose an increasingly serious threat to the architects and, indeed, to wrest some of their traditional prerogatives from them. ${ }^{.5}$

With the closing of the old design academies, whose pedagogy was highly influenced by Classical theory, and the establishment of new institution like the l'Ecole Polytechnique in 1794, architectural practice and theory were reconfigured to address these changing attitudes. ${ }^{6}$ The architectural drawing 
and the new, rational modes of its application were understood as a key to developing a "new architecture".

In this chapter, we explore how these new drawing techniques objectified the design process and how they have influenced the use of drawing in architectural practice today. Specifically, we will consider the argument put forward by Jean Nicholas-Louis Durand (1760-1834); an argument influenced by the descriptive geometry pioneered by French Engineer Gaspard Monge (17461818).

Durand's founding of l'Ecole Polytechnique in Paris, and his teaching of architecture there between 1795 and 1833, established a new pedagogical system for training architects and engineers within the zeitgeist of a new epoch. ${ }^{7}$ His strategy was to teach students a rational method of design that could be applied to any building type. This was a critique of architecture's dependency on traditional techniques of differentiation, including the application of decoration. Durand argued that these traditions, labelled by him as "vicious", ignored the true rules of composition that were based on arithmetical proportion. ${ }^{8}$ [III. 1.1]

His use of Monge's descriptive geometry was instrumental in developing a system of architectural drawing and production that was socially relevant. ${ }^{9}$ This system was structured to facilitate the scientific construction of buildings through a categorization of building typologies and a rationalization of design development. These building types, their appropriate style, function, and propriety, were determined by economy and efficiency - the new values of architecture. ${ }^{10}$ 
The idea of convenance was a major point of consideration for Durand in the development of his theory. ${ }^{11}$ For a building to demonstrate convenance, it had to be stable, healthy and convenient. This influenced the choice of site, proportion, and materiality. Since architecture was the most expensive of all the arts, Durand argued that "it should not be whimsical or guided by prejudice or routine." ${ }^{12}$ To elaborate the rules of convenance, Durand's Recueil et Parallele des Edifices de Tout Genre. Anciens et Modernes (1801) and Précis des lecons d'architecture données à l'Ecole Polytechnique (1802) began to lay out rational and immutable rules for the proper manifestation of architecture through drawing. Science and rationality - the foundations of modern engineering, were used to guide the development of architecture by the application of a rational system of architectural drawing.

"There was no need to look for explanations outside the field of the new theory, a theory of architecture postulated for the first time as autonomous, self-sufficient, and specialized, composed exclusively of truths evident to mathematical reason. Durand thought that the means by which architecture reached its objectives were no longer difficult to identify; architecture, created by men for mankind, could find these means within its own way of being." ${ }^{13}$

Love, well-being, and an aversion to pain were the precepts of Durand's epistemology. Since these principles were the premises for the ethical and aesthetic development of technology, buildings were to be convenient (solid, healthy and comfortable) and economical. Transcendental sources of meaning derived from metaphor or narrative were irrelevant; they did not contribute to revealing the new architecture.

In order to illustrate the new architecture through drawing, Durand developed three primary tools. First, he promoted the use of grids and axes on 
transparent paper, and a universally established scale with precise decimal measurements. Secondly, Monge's descriptive geometry was adapted to accurately translate buildings and details into two dimensional representations. ${ }^{14}$ Third, through a formal systemization of plans, elevations and sections (now conventional orthographic projections), Durand transformed the design of architecture into an arrangement of standardized modules and procedures associated with specific building typologies. [III. 1.1, 1.2] New compositions in architecture relied on the syntactic relationship of parts, guided by the notions of economics and convenience. ${ }^{15}$ Through the use of a common scale and a rational, systematic use of drawings, architects could evaluate objectively their architecture against the criteria established by Durand's value system. ${ }^{16}$

According to Durand, the rules of composition, which were misunderstood in other theories of architecture, had a central role to play in rationalizing design. However, these rules needed to be standardized. [III. 1.3, 1.4] Appropriate composition lay in reconciling the formal analysis of the parts of the building (walls, floors, roofs, porches, courtyards, vestibules and rooms) with the subsequent synthesis of the object (the overall building form). ${ }^{17}$ While Durand employed circular and square forms, their use was never predicated on transcendental sources of meaning but on geometric economy.

Unlike his master, Boullée, whose architectural forms were derived through the intersection of solids, ${ }^{18}$ [III. 1.5] Durand's volumes were the result of relationships between logical plans and elevations. By exploiting the semiotic capacities of drawings, he was able to emphasize the possible similarities 
between architecture and engineering and portray the projects from an objective and logical point of view. This led to his critique of any medium or technique that represented architecture subjectively, including watercolours and compositions based on Renaissance point perspectives. ${ }^{19}$

Durand proposed the use of the grid as a system for arranging architectural components. It not only allowed for a systemized combination and definition of architectural objects, it also provided "a neutral and isotropic space which eluded the rules of perspective and consequently the subjectivity of a privileged spectator" ${ }^{20}$ The Cartesian grid system of coordinate points became a template for the economical and efficient development of all architectural typologies. In creating this kind of open system, the grid layouts gave architecture autonomy within its own rules for formal composition. This extricated it from the values of any external influences that did not contribute to the parameters of economy and convenience and encouraged the use of drawings as measured representations of building ideas. ${ }^{21}$

"The assumption that architecture can derive its meaning from functionalism, formal games of combination, the coherence or rationality of style understood as ornamental language, or the use of type as a generative structure in design marks the evolution of Western architecture during the past two centuries." ${ }^{22}$

The systemization of architectural design devalued the architectural drawing by reducing it to a codified and closed language. Alberto Perez-Gomez argues that this has contributed greatly to the "banal" and "formalist" approaches of contemporary architecture. ${ }^{23}$

"Traditional theories were, to his way of thinking, nothing but imaginary tales lacking scientific value; their sole purpose was to prove that the objective of architecture, being an art of imitation, was to please 
the eye. This obvious assumption however was a mistake. For Durand was unable to realize that the mythical dimension was actually the realm where the transcendent justification of architecture had to be found. It was only in the context of the new positivistic world that reactionary architects who questioned the power of reason could be considered mere decorators." 24

The richness and ambiguity engendered by transcendental sources of meaning, once fundamental principles of pre-enlightenment architecture, have given way to Durand's economy and efficiency as the only acceptable values of architecture. ${ }^{25}$ This attitude of comfort over meaning has reduced the clarity of "the architect's role in society as well as a misunderstanding of the very essence of architecture itself." $^{26}$ The significance of transcendental dimensions of architecture and geometry directly challenges Durand's empirical approach. Furthermore, revealing the need for drawings - and their relationship with the constructed buildings - "to speak to something else apart from the technological process that produced it." ${ }^{27}$

The drawing, then, can do more than demonstrate a rational process of development. It can also move beyond its exclusivity as scaled references to be used as instructions for the construction of a building. ${ }^{28}$ By only appropriating the orthographic system of drawing established by Durand, the relationship between drawing and the building has, today, been reduced to an equation. The "construction" drawing does have a pivotal role in the making of architecture, and its capabilities cannot be excluded. However, the drawing (noun) and drawing (verb) have the potential to explore the "other" of architecture and according to Perez-Gomez, the first crucial step in re-evaluating the role of the drawing is to 
acknowledge that the conception and realization of architecture is related to the very tools of its representation. ${ }^{29}$

"An uncritical use of these devices therefore will always result in yet more reductive products: the question "how" cannot be answered with a methodology. Can a recording of traces again be translated (rather than transcribed) in built architectural projects? Does the transition between sample and building necessitate a further representational mediation, and how can this mediation act as a generative process evolving from an existing sample." ${ }^{30}$

By understanding the implications of Durand's rationalism and its contribution to the "crisis" of European science ${ }^{31}$ the architect might see the possibility of an alternative use of the architectural drawing beyond that of objectification. The drawing can reconcile the relationship between the architectural idea and the building. Perez-Gomez argues further that this could contribute to the creation of new, metaphorically rich architecture that is able to move beyond Durand's niceness and pleasures. ${ }^{32}$ Through drawing, architecture can, therefore, set up, outside of its own technological make up and mathematical rationale, a reference point by which it can be evaluated in its contribution to society. 

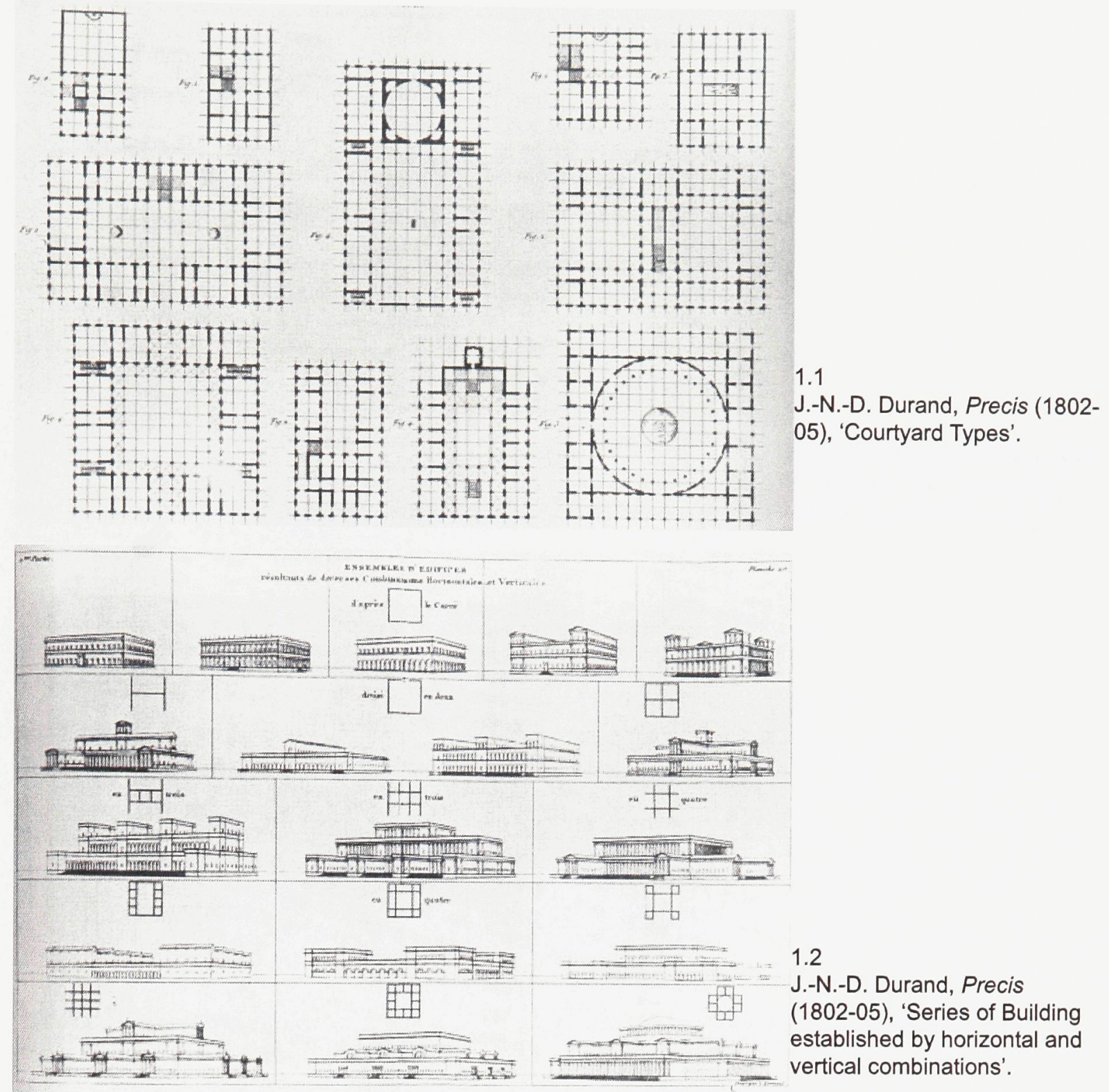

1.2

J.-N.-D. Durand, Precis (1802-05), 'Series of Building established by horizontal and vertical combinations'.

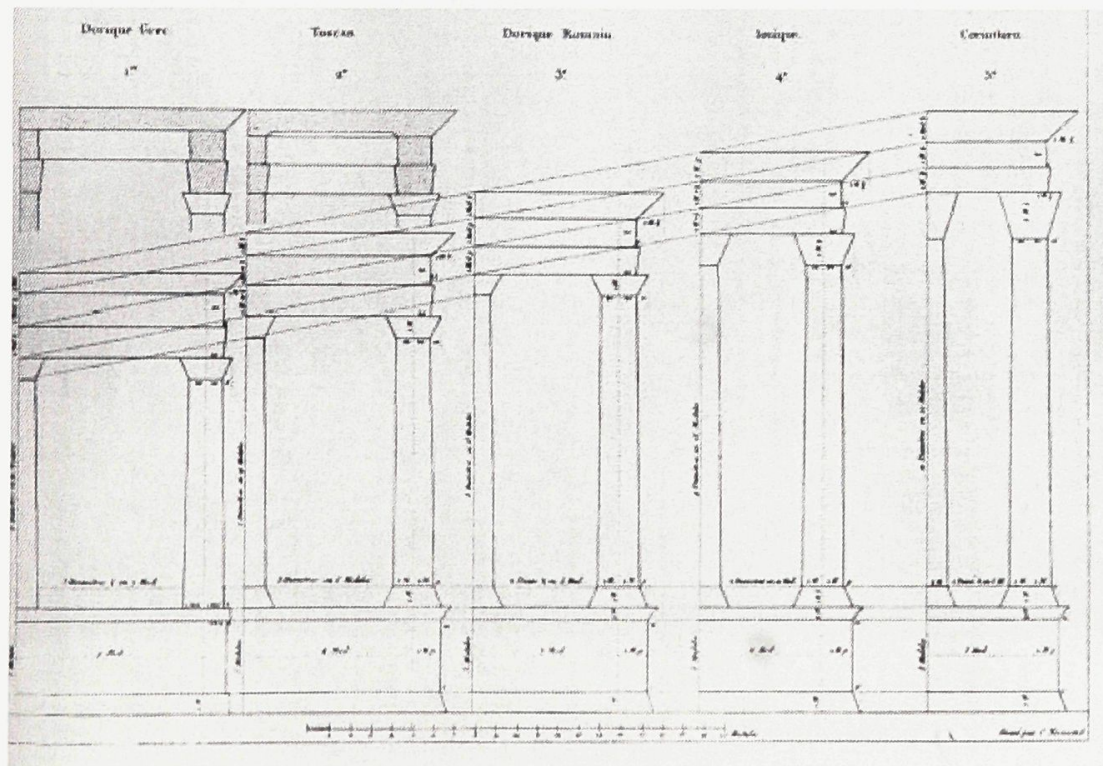

1.3

J.-N.-D. Durand, Precis (180205), 'Series of Orders'. 


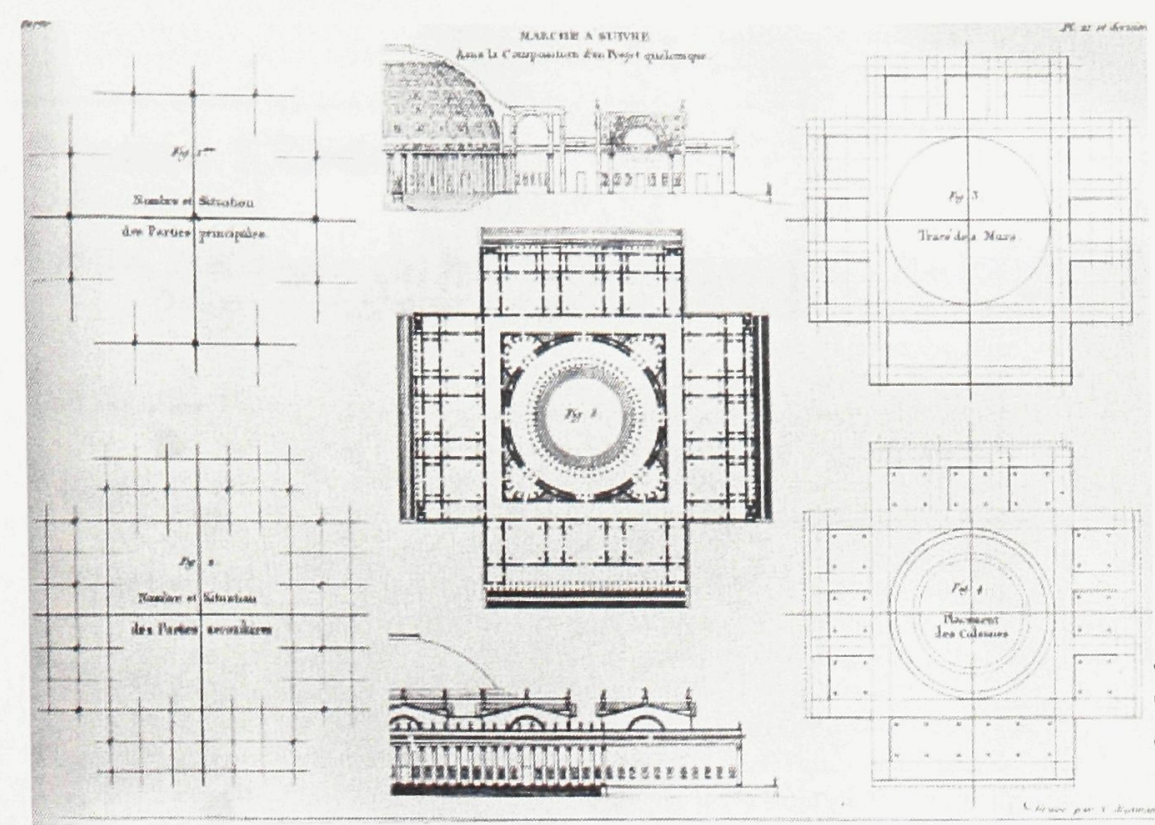

J.-N.-D. Durand, Precis (180205), 'Course to follow in the development of a project.
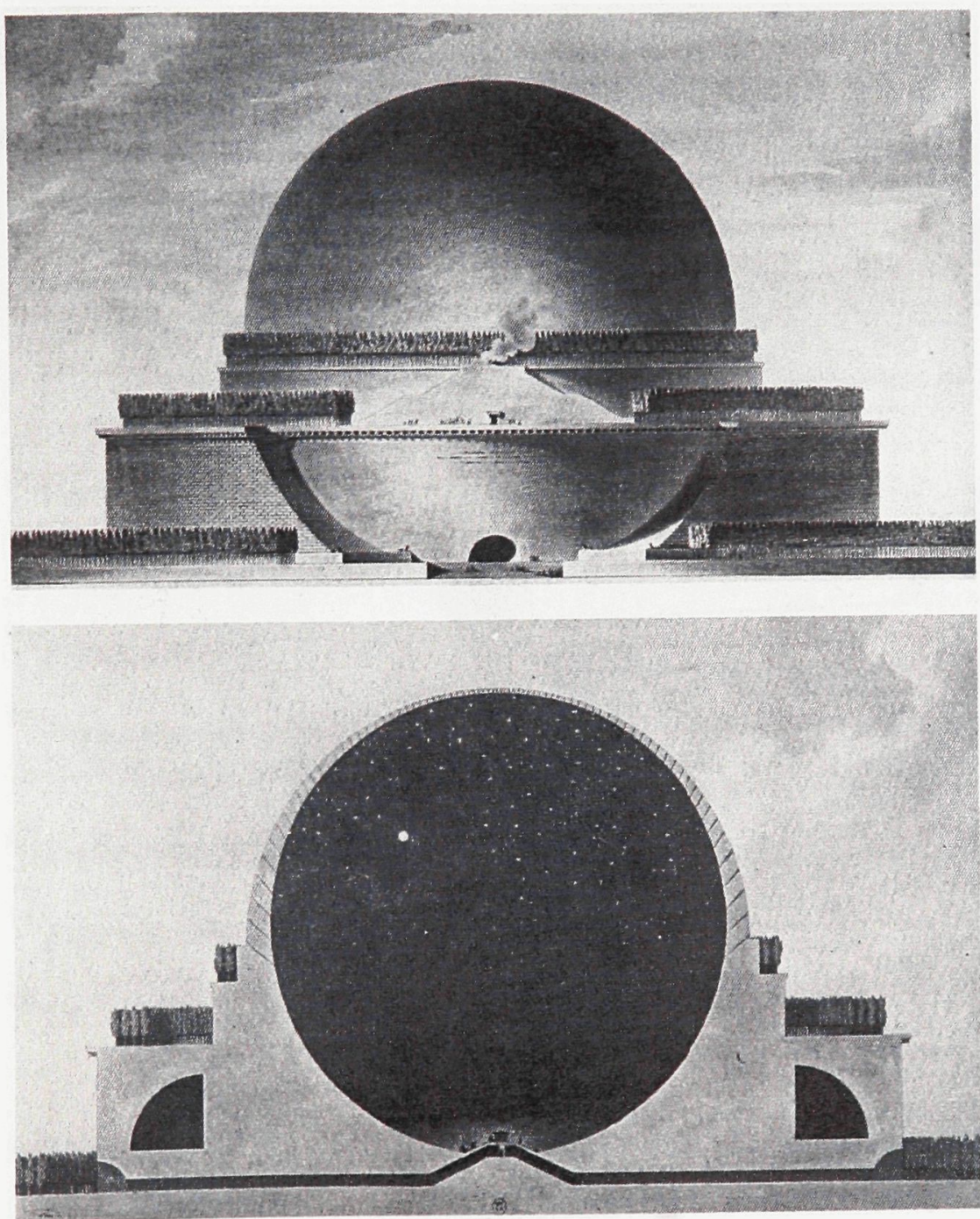

1.5

Etienne-Louis Boullee, Project for the Cenotaph for Sir Isaac Newton, elevation and section.(1802-05), 


\section{Section 1 Endnotes:}

1 Picon, Antoine. French Architects and Engineers in the Age of Enlightenment. Trans. Martin Thom. Cambridge: Cambridge University Press, c1992. p. 7.

2 Picon, p. 10.

3 Picon, p. 2

4 Picon, p. 10

5 Picon, p. 2

6 Picon, p. 4

${ }^{7}$ Picon, p. 322.

${ }^{8}$ Picon, p. 322.

${ }^{9}$ Descriptive geometry: The technique of accurately representing objects by means of drawings and of solving graphically all problems related to their form and position. Descriptive geometry provides the theoretical basis for technical drawings. Descriptive geometry deals specifically with the graphical representation on a plane (the drawing surface) of the basic geometrical elements and the solution of space problems connected with their representation.

Watts, Earle F., and John T. Rule. Descriptive Geometry. Englewood Cliff's, N.J.:

Prentice-Hall, Inc., c1946. p. 1-2.

10 Perez-Gomez, Alberto, and Louise Pelletier. "Prelude - Mapping the Question: The Perspective Hinge (Translation vs. Transcription)". Architectural Representation and the Perspective Hinge. Cambridge, Mass.: M.I.T Press, c1997. p. 3.

11 Picon, p. 85.

12 Perez-Gomez, Alberto. "Durand and Functionalism". Architecture and the Crisis of Modern Science. Cambridge, Mass.: M.I.T. Press, c1983. p. 299.

13 Perez-Gomez, "Architecture and the Crisis of Modern Science". p. 299.

14 Picon, p. 326.

15 Perez-Gomez, Alberto, and Louise Pelletier. "Variation Three - The Image without an Observer: The Perspective Hinge". Architectural Representation and the Perspective Hinge. Cambridge, Mass.: M.I.T Press, c1997. p. 298.

16 Picon, p. 326.

17 Picon, p. 323. 
18 Braham, Allen. "Part Two: Buildings of the 1760 s and Their Architects". The Architecture of the French Enlightenment. Berkley and Los Angeles: University of California Press, c1980. p.117.

19 Linear Perspective: The means by which the appearance and spatial relationship of forms are suggested on a plane surface. As the axonometric drawing orients itself toward the object, the perspective orients to the viewer, depicting the specific viewpoint. The viewing position is clearly located by a perspective drawing, such that one is able to find the exact spot on a site that allows one to see the lines of a building as represented by the lines of a drawing.

Fraser, lain, and Rod Hemni. "Perspective Drawings". Envisioning Architecture: An Analysis of Drawing. New York: Van Nostrand Reinhold, 1994. p. 59.

20

Picon, p. 326

21

Picon, p. 326.

22 Perez-Gomez, "Introduction". Architecture and the Crisis of Modern Science. Cambridge, Mass.: M.I.T Press, c1983. p. 4.

${ }^{23}$ Perez-Gomez, "Architecture and the Crisis of Modern Science". p. 305.

${ }^{24}$ Perez-Gomez, "Architecture and the Crisis of Modern Science". p. 300.

25 Perez-Gomez, "Architecture and the Crisis of Modern Science". p. 303.

${ }^{26}$ Perez-Gomez, "Architecture and the Crisis of Modern Science". p. 313.

27 Perez-Gomez, "Architecture and the Crisis of Modern Science". p. 313.

${ }^{28}$ Perez-Gomez, Alberto, and Louise Pelletier. "Architectural Representation and the Perspective Hinge". p. 3.

${ }^{29}$ Perez-Gomez, Alberto, and Louise Pelletier. "Architectural Representation and the Perspective Hinge". p. 3

${ }^{30}$ Perez-Gomez, Alberto, and Louise Pelletier. "Architectural Representation and the Perspective Hinge". p. 329.

${ }^{31}$ Perez-Gomez, "Architecture and the Crisis of Modern Science". p. 311.

32 Perez-Gomez, "Architecture and the Crisis of Modern Science". p. 299. 


\section{Section 1 Image notes:}

1.1 J.-N.-D. Durand, Precis (1802-05), 'Courtyard Types'.

Picon, Antoine. French Architects and Engineers in the Age of Enlightenment. Trans.

Martin Thom. Cambridge: Cambridge University Press, c1992. p. 322.

1.2 J.-N.-D. Durand, Precis (1802-05), 'Series of Building established by horizontal and vertical combinations'.

Picon, Antoine. p. 322.

1.3 J.-N.-D. Durand, Precis (1802-05), 'Series of Orders'.

Picon, Antoine. p. 322.

1.4 J.-N.-D. Durand, Precis (1802-05), 'Course to follow in the development of a project.

Picon, Antoine. p. 322.

1.5Etienne-Louis Boullee, Project for the Cenotaph for Sir Isaac Newton, elevation and section.(1802-05),

Braham, Allen. "Part Two: Buildings of the 1760s and Their Architects". The Architecture of the French Enlightenment. Berkley and Los Angeles: University of California Press, c1980. p.118. 


\section{2}

\section{Translation}

"To discuss appropriate alternatives to the ideological stagnations plaguing most architectural creation at the end of the second millennium, the first crucial step is to acknowledge that value laden tools of representation underlie the conception and realization of architecture."1

As discussed in the last chapter, architectural drawing has come to be used primarily as an economical mode of communication - a means of relaying predetermined information for the efficient completion of an architectural project. Drawing conventions such as sketches, shop drawings and construction documents are a means of registering codified information for the production of a built work. Since architects have come to accept the instrumental role of the drawing as representing something to be, this has led, generally speaking, to a complacency towards drawing in architectural practice. ${ }^{2}$ Architects seem unwilling or are unable to employ drawing as a means of invention, because they assume that concept and reality have a one to one relationship. In other words, ideas (usually represented through drawing or model) are to be rendered verbatim into a building. Contemporary architectural drawings have become bridging devices that communicate, rather than extricate, architectural ideas into architectural projects. They are used to project, not generate, a future piece of architecture.

Robin Evans argues that the theory of translatory motion, where something is moved without altering its original meaning, allows the language of architectural drawings to carry more than one meaning. During the act of translation, the foundations that structure language can lose their sense of 
continuity as "things can get bent, broken or lost on the way". ${ }^{3}$ It is at that moment that "other" possible interpretations are suggested. However, if any new knowledge is to be gained through the deviation of its translation, there must be a kinship or an acknowledgment of the original semantics of the drawing. ${ }^{4}$ Therefore, since drawings maintain some affinity to their original intent, built architecture is always implied by the conventions of architectural drawing.

"I would like to suggest that something similar occurs in architecture between the drawing and the building, and that a similar suspension of critical disbelief is necessary in order to enable architects to perform their tasks."

Translation, then, requires a suspension of disbelief to imagine the relationship between drawings and buildings. Traditionally, as advocated by Durand, conventions have guided the architectural drawing during translation in order to prevent any ambiguities. Yet it is these ambiguities that allow the drawing to also be used as a means of invention. The potential for drawing lies not solely with its similarity to that which it is intended to represent (the final building), but also with its dis-similarity from it. ${ }^{6}$

If we begin to fully grasp the potential of each (drawing and building) as forms of action, the difference between the two suggests the possibilities of "other" in the exploration of architecture. Used strategically, drawings can suspend signification in a semantic flux that encourages us to use them as a way of imagining (discovery) what "might be". When viewed through the frame of the conventions of architectural drawing, these "might be" drawings can be read as a kind of fictional architecture - a drawing of what "could be". 
An accepted signifier-signified relationship is necessary for construction drawings in order to construct a building efficiently and economically. In this case, drawings are a means for the architect to relay such things as the sequence of construction and the amount and locations of materials. The primary role of these drawings is not intended to be exploratory, but referential. Communicating clearly through conventions is expected of these drawings.

In order to use the drawing as a generative tool, a relationship - not unlike the one that is to exist between drawing and building as Evans has suggested must be explored within drawing itself. The drawings developed as part of this thesis explore these existing kinships. Considering both the semiotic conventions of architectural drawing and the ambiguities of architectural metaphor and narrative, a complex set of inter-relationships exist between the author, the viewer and the drawing.

"They do not inform, but rather persuade or entrance the onlooker. They lead into optative landscapes, into discourses of open, floating meaning; they are sustained by the magic of the indefinable."

The following section of this chapter will discuss in more depth the interactions between the author, the viewer, and the drawing itself, in order to frame how the thesis drawings are used as a generative process.

Traditional communication models, including architectural drawings, are based on an 'addresser' relaying a 'message' to an 'addressee'. The "author" (addresser) is the first determinant in how a drawing is developed and eventually read. The contribution of the author is an artifact of representing the author's intentions and mediated by skill, education, and experience. For example, the author determines the appropriate method for how a drawing is developed. 
These methods include determining a suitable technique (style) and medium selection. Line drawings on vellum will relay information differently than if the same content is expressed using chalk or pastels. Therefore, the explicit choices of the author in making the drawing create the content for a reading to occur, and to develop the first set of possible signifiers.

The "reading" of drawings and our understanding of them as information is determined by the relationship of the reader (addressee) and the drawing itself. It is based on the experience and knowledge [Appendix A] of the addressee and their ability to understand the information, in relation to content, media and context of that drawing. These associations determine how the messages of a drawing are ultimately received. This allows architects to understand the relationship between a drawing and a building, either as a reference to it or as an extension of it. Understanding drawings as "messages" relayed in forms of codified language is intrinsic to how we read the information of any architectural drawing. Romand Jakobson's argument - published in Thomas Seboak's book Style in Language $^{8}$ (1960) - explores the different capacities and functions of language. The thesis has applied these principles to explore further the reading of drawings.

The Referential function of drawing is oriented toward the context of the message. ${ }^{9}$ Every message requires a context in order for the language to refer to something. Construction documents, or working drawings as they are commonly known, are dependent on this condition. An architect prepares drawings for the construction of a building and gives them to a contractor to 
"read" as instructions for the construction process. The Connotative function induces action, such as a command, and is geared towards the addressee or the reader of the drawings. ${ }^{10}$ Again, construction drawings rely on this condition in order to allow them to work as a series of instructions for making. The Metalingual is drawing that speaks about drawing. ${ }^{11}$ Its function is oriented towards a code and establishes convention. This is prevalent in such things as the graphic standards that govern the conventions of architectural drawings. The Emotive is an act of relaying an expressive condition. ${ }^{12}$ Its function is oriented towards, not only the addressee, but also the addresser (the author) of the drawing. This mode of communication typically has difficulty functioning in drawings using architectural conventions because construction documents are intended to limit subjective interpretation by the readers. In order for working drawings to operate, they require little to no ambiguity. The Poetic function of drawing is concerned with meaning, or meaningfulness. ${ }^{13}$ The poetic is less about "what" something means than "that" something means. Together these functions show us how drawings communicate. It is important to keep in mind that they are not exclusive in that all or some may be operating simultaneously. The most significant for our discussion, however, is the Poetic.

As discussed the communicating function of an architectural drawing is associated with the context of its making and the context of its reading. Understanding this allows us to explore the "poetry" of drawing through the specificities of the various drawing media, intentions and the various readings that they may initiate. If through the referential function of architectural 
conventions, drawing conveys the instruction for the translation of the architectural drawing into a building, the poetic function creates a space of imagination, the space of the architectural idea before it is recognized as "building".

Wolfgang Meissenheimer suggests in his essay The Functional and the Poetic Drawing, that the poetic drawing, unlike "referent" drawings, has the potential to explore the "indefinable". ${ }^{14}$ Incapable of being absolutely precise, the indefinable can still translate the immediate perceptions of an object. It suggests the characteristics of an author, a particular culture, place, time and triggers an interpretive and emotional response. The indefinable requires the inherent participation of the viewer's imagination in order to fill the gaps that the drawings may not have revealed through the conventions of architectural semiotics. [Appendix A]

"This situation is different in those drawings which attempt to express the indefinable; traces of the memory and the dreams of the drawer, outbreaks of temperament and wit, provocations of the observer, riddles, vague evocations or gestures of philosophical theses. Drawing of this type - I would call them poetic." 15

Unlike conventional drawings, whose foremost architectural purpose is to communicate the true and objectified relationships between architectural idea and building, the poetic drawing explores more intensely the expressive, emotive and appellative features of its assembly. ${ }^{16}$ These drawings attempt to explore the indefinable of architecture through the drawing itself. Characteristics relating to the drawing's communicable denotations are therefore expressed on the surface. Their usefulness opens themselves up to an unlimited arrangement of ambiguities that can allow the drawings to go beyond the exclusivity of 
construction rationale. Poetic function lies primarily with the emotive aspects of the drawing. The expressive or emotive development of any architectural drawing is a reflection of the architects' subjective-ness, since the power of the imagination is directly related to a culmination of one's knowledge. ${ }^{17}$ Knowledge is where a lifetime's worth of memories, experiences and educations are stored until they are needed by consciousness for such things as engaging the imagination. Knowledge is acquired from the sub-conscious. Therefore, the 'making' of architectural drawings is subject to the imagination of the architect.

\section{[Appendix A]}

But how do we evaluate critically, the success of a "subjective" drawing? The thesis argues that any successes can only be evaluated based on the intent of the drawings. In the case of the functional drawing, this is very easy. A functional drawing is guided by the conventions of its use and is successful if clarity, the value that guides these drawings, is expressed.

For the poetic function of drawing, the criteria are, as we have discussed, significantly different. But the architectural drawing relies on both the functional and the poetic to reveal an architectural idea. If a new and different understanding of the architectural drawing, one that suggests a learned understanding of architectural conventions can reveal itself through the act of its making and through the persuasion and engagement of the reader, then it can explore the imagining of architecture. An exploration not governed by style, signification or typology, but by the process of its making and by the process of its reading. 


\section{Section 2 Endnotes}

1 Perez-Gomez, Alberto, and Louis Pelletier. "Prelude - Mapping the Question: The Perspective Hinge / Translations vs. Transcription". Architectural Representation and the Perspective Hinge. Cambridge, Mass.: M.I.T. Press, c1997. 3.

2 Perez-Gomez, "Translation vs. Transcription". p. 3.

3 Evans, Robin. "Translation from Drawing to Building". Translation from Drawing to Building. Cambridge, Mass.: MIT Press, c1997. p. 154.

4 Evans, p. 154.

${ }^{5}$ Evans, p. 154.

${ }^{6}$ Evans, p. 154.

${ }^{7}$ Meissenheimer, p. 111.

8 Jakobson, Romand. "Linguistics and Poetics: Closing Statement". Style in Language. Ed. Thomas Sebeok. Cambridge: Technology Press of Massachusetts Institute of Technology, 1960. p. $350-377$.

9 Jakobson, p. 353.

10 Jakobson, p. 355.

11 Jakobson, p. 356.

12 Jakobson, p. 354.

13 Jakobson, p. 356.

14 Meissenheimer, Wolfgang. "The Functional and the Poetic Drawing". Daidalos. September 1987.

${ }^{15}$ Meissenheimer, p. 111.

16 Meissenheimer, p. 111.

17 Sartre, Jean-Paul. "Description - Part 2. The Probable: The Nature of the Analogon in the Mental Image". Trans. Jonathan Webber. The Imaginary: A Phenomenological Psychology of the Imagination. London: Routledge, c2004.p. 57-67. 


\section{Precedents}

In this chapter, we discuss two architects and their use of drawing as a means of developing an architectural idea: Peter Eisenman's and Daniel Libeskind's. Both Eisenman and Libeskind have used drawing to challenge the conventions of architectural representation and, ultimately, our perception of architecture. Using very distinct strategies, the drawings of these architects not only investigate possibilities of a referenced architecture, but the drawings themselves are explored as an extension of an over-riding examination of architecture set out by the author. The drawings are an exploration of the "other" of architecture.

\section{Eisenman: Formalization through Drawing}

The drawings of Peter Eisenman attempt to explore the "discursive interiority of architecture". By creating architecture that is free from "exterior" influences such as politics, social conditions and cultural values, Eisenman's drawings search for an architecture that is self referential. ${ }^{2}$ He argues that conventional architectural discourse (including contemporary forms of representation) revolves around it being a motivated sign system. Attaching external relationships to it (metaphors, narratives) in order to fulfill our desire "to have architecture be meaningful and to communicate." ${ }^{3}$ Traditionally, the drawing - in relationship to architecture - was to take the internal motivations of architecture and transform them into external desires. ${ }^{4}$ These motivations are what create the relationship between sign and the signified perceptions of 
architecture. Eisenman attempts to reverse these roles by taking external sources of motivation (subjects that may have nothing to do with the program or even architecture, such as mathematics, physics and biology) and transforming them, through the drawings, into new internal motivations. These new and seemingly arbitrary drawings become the instigators for the imagining of an architectural idea. This creates a condition where Eisenman does not know the ends of his research or the shape of the final project. ${ }^{5}$

"In this context, function, traditional aesthetics, social concerns, and metaphors of machines were for me always pallid justifications for a do-what-you-want expressionism. My use of the diagram proposed a different rationale, one that could be both more logical and more involved with a process of architecture somewhat distant from the design process of the traditional author-architect."

By evolving into the primary motivator in the design process, the drawing acts as a tool for writing architecture, rather than having architecture itself being an explicit and external sign function. ${ }^{7}$ Eisenman argues that any becoming in architecture is really about the becoming of presence and the drawings attempt to manifest "non-presence" as a "new presence". ${ }^{8}$ These presences attempt to remove the communicating significations associated with the approaches of architectural conventions and replace them as an index condition.

\section{Micromegas: the Space of Daniel Libeskind's Encounters}

The Micromegas of Daniel Libeskind investigates the potential of architecture to be a medium for generating meaning through the interpretive participation of the viewer. Libeskind's strategy exploits our traditional understanding of architecture that is developed through a semantic and semiotic condition. Rather than participating in a unified vocabulary and syntax that is 
equivalently understood through universal convention, Libeskind's drawings operate as a form of almost mystical translation. This allows the drawings to imply, and simultaneously defer meaning. His heterogeneous syntax fragments references into questions.

"Drawing is not mere invention; its efficacy is not drawn from its own unlimited resources of liberty. It is a state of experience in which the other is revealed through mechanisms that provoke and support objective accomplishments and the one who draws upon them. Being neither pure registration nor pure creation, these drawings (Micromegas) come to resemble an explication or a reading of a text $-a$ text both generous and inexhaustible."

Micromegas [III. 3.4, 3.5] is a series of lightly rendered line drawings that explore an intense, refined and multifaceted expedition of lines and the spaces they allude to. Architecture (our conventional understanding of it) does not impose itself, despite the architectural nature of the drawings. An endless series of layered projections suggests a series of three-dimensional perceptions that imply spatial moments. However the viewer is denied the possibility for a direct reading of an object, as the compositions are set up by a homogenous structure that resists their automatic readability. Instead the drawings create a series of endlessly intertwining relationships that challenge the reader to search for other references, as the hierarchal conventions of architectural representation are now homogenized. The drawings mediate recognizable forms against new possibilities that are created by the imagination of the reader.

"These drawings seek to reflect on a deeper level of consciousness the inner life of geometrical order whose nucleus is the conflict between the voluntary and the involuntary. Once again this duality appears as an unsurpassable condition pointing to a dynamic ground, which testifies to an experience that receives only as much as it is capable of giving, draws only that which allows itself to be drawn into." ${ }^{10}$ 
The Micromegas explore the relationship that exists between the intuitions of geometric structures created through pre-objective experience and their objective formalization initiated by our perception of them in the subjective sphere. ${ }^{11}$ The drawings begin to formalize a means of imagining not only through their making by the author, but through the required engagement of the viewer as well. Intention is no longer oriented solely from the author and through an exploration of the interiority of geometry, Libeskind reflects on a conflict between the voluntary and the involuntary acts of drawing. ${ }^{12}$ Through an ambiguous exploration of orthographic projection, these drawings "disrupt the homogeneous, continuous space of axonometry and isometry into a multitude of conflicting spaces." 13 Through drawing, Libeskind explores pictorial fragmentation that similar to his later drawings such as the Chamberworks Series [III.3.6] - begins to reveal the possibilities of architecture.

"In describing how opaque they are to frontal interpretation, how they refuse to make manifest a meaning that lies behind them, we must look in front for the things that the drawing might yet suggest, might lead to, might provoke: In short, for what is potent in them rather than what is latent." ${ }^{14}$

These drawings, though having no direct correlation to an actual built work of architecture, do begin to initiate an attitude by Libeskind towards the making of his future buildings. Architecture must not be understood as a represented object, but as "a hub of activity whose epicentre is the drawing and the act of its making." 15 This is an important realization, for, unlike the Micromegas Series or even his future Chamberworks Series, the development of the drawings for the Extension to the Berlin Museum (1988-99) is initiated from four specific metaphoric sources of meaning that have a direct relationship to the history of 
$20^{\text {th }}$ century Berlin. ${ }^{16}$ The design is based on a process of connecting lines between locations of historic events and locations of Jewish culture in Berlin. They begin to expose, through an architectural expression, the contributions and ultimate disappearance of Jewish culture in the city during the $20^{\text {th }}$ century. These internal motivators, as apposed to the external motivational sources employed by Peter Eisenman, are represented as lines that are layered or interconnected; initiating the development of a formal building tectonic and the final aesthetic of the Museum. [III. 3.7 to 3.10] Meaning may be employed as an initiating element, but is abstracted through its layered representation. Libeskind attempts to create a new perception of the history and future of Berlin, extended through a building form that continues to instigate the voluntary and involuntary perceptions of the viewer. The initial motivators for the development of the building's tectonics are left to Libeskind himself and the multiple publications of the work. Whether, through an architectural exploration of Schoenberg's unfinished opera Moses and Aaron, or through the relationship of Jewish Berliners and their inevitable deportation and/or execution during the Second World War, or even as a challenge to the semantics of architecture, Libeskind's drawings attempt to "search for something." 17

The drawings by Eisenman and Libeskind explore, challenge and ultimately exploit the viewer's (including the author's) conventional perception of architectural drawing. Yet, with the exception of Libeskind's Micromegas and Chamberworks which have no direct correlation with a programmed building, the drawings in relationship to their buildings, establish a one-to-one reference. This 
may explain why many of their projects are often criticized negatively when it comes to the experience of their spaces. Drawings become their primary exploration of architecture, and the building is the formal reference of that exploration. By not understanding that the perception of a "building" can be diverse yet related to the drawings and instead perceiving architecture as belonging solely to one, their drawings can be understood as self-referential. As Robin Evans has suggested, these buildings may have been discarded as unfortunate aftermaths. ${ }^{18}$ 


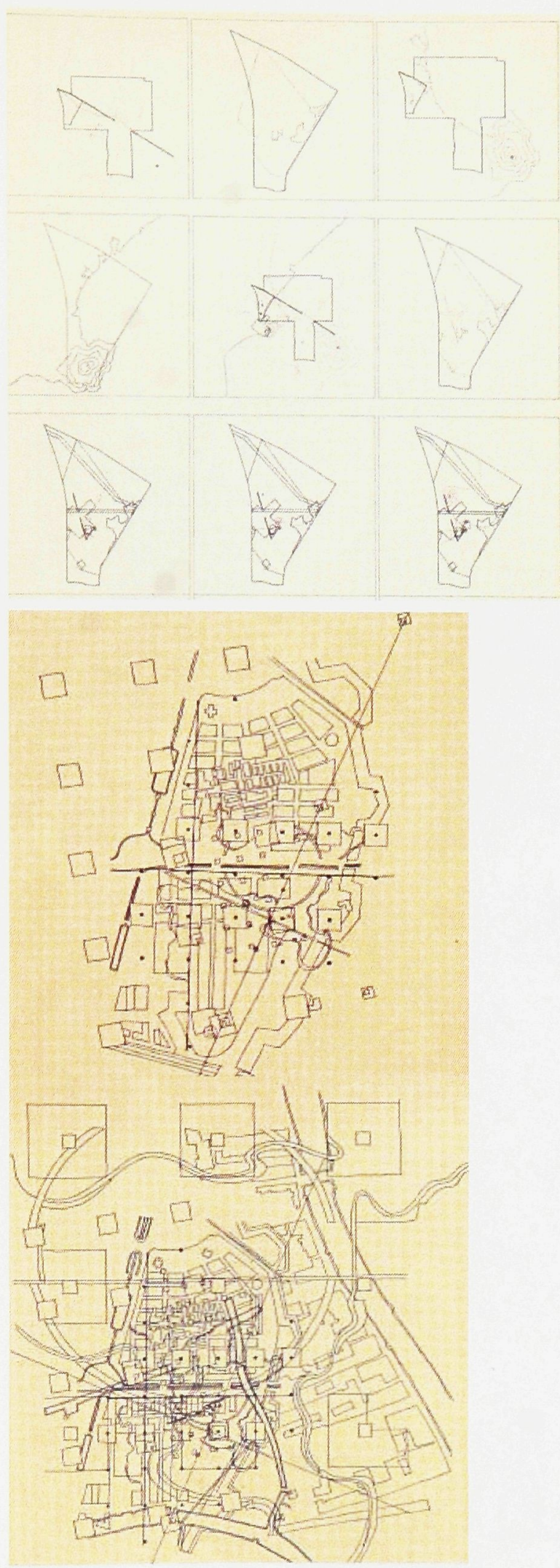

3.2 Office of Eisenman/Robertson Architects, La Villette Design Competition, 1986, Plan sketches for showing various formal superimpositions such as: previous Cannaregio project, scale shifts, and various grid systems. Black ink on yellow trace paper.
3.1 Office of Eisenman/Robertson Architects,

University Art Museum of the California State University, 1986, Diagrams of superimpositions, including: land divisions, coast lines, ranches, scale shifts and museum site.Pen and black ink, colour pencils, and red filt tip pen on vellum.

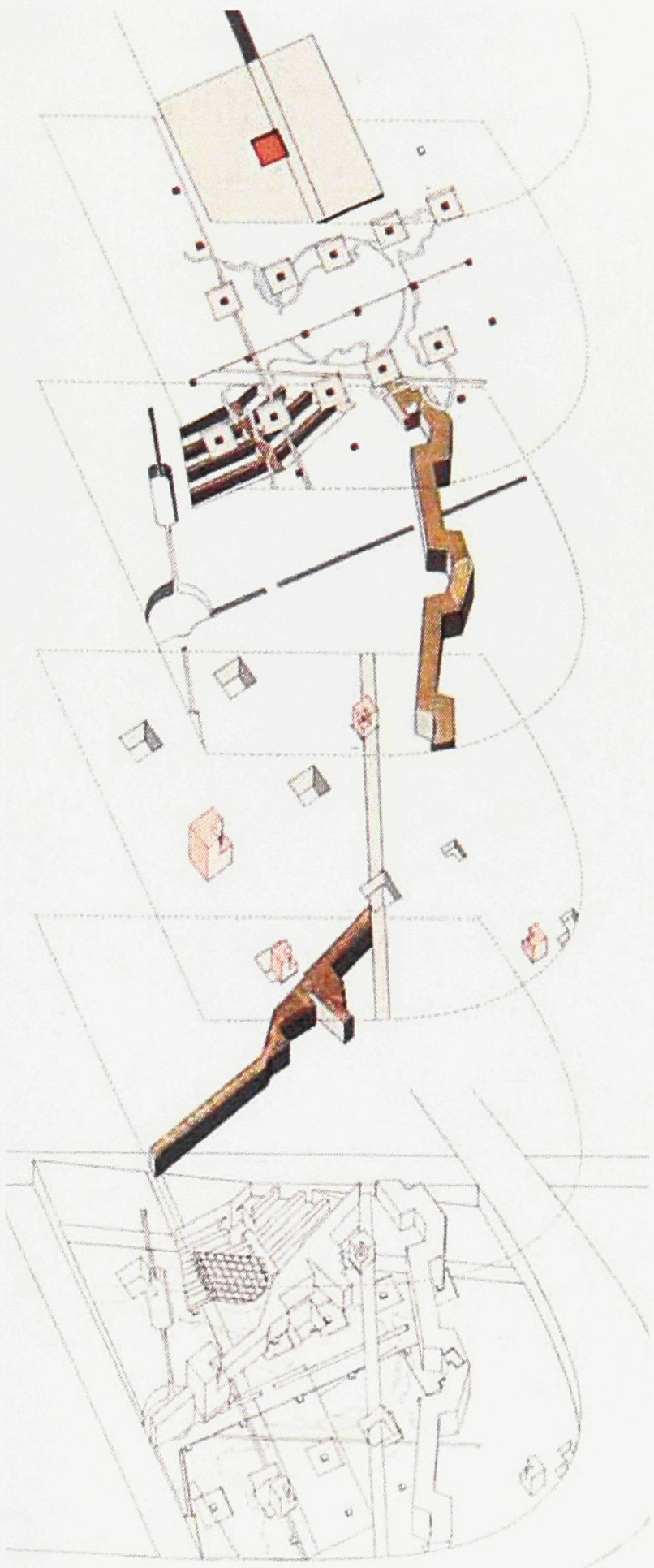

3.3 Office of Eisenman/Robertson Architects,

University Art Museum of the California State University, 1986, Diagrams of superimpositions, including: land divisions, coast lines, ranches, scale shifts and museum site.Pen and black ink, colour pencils, and red filt tip pen on vellum. 


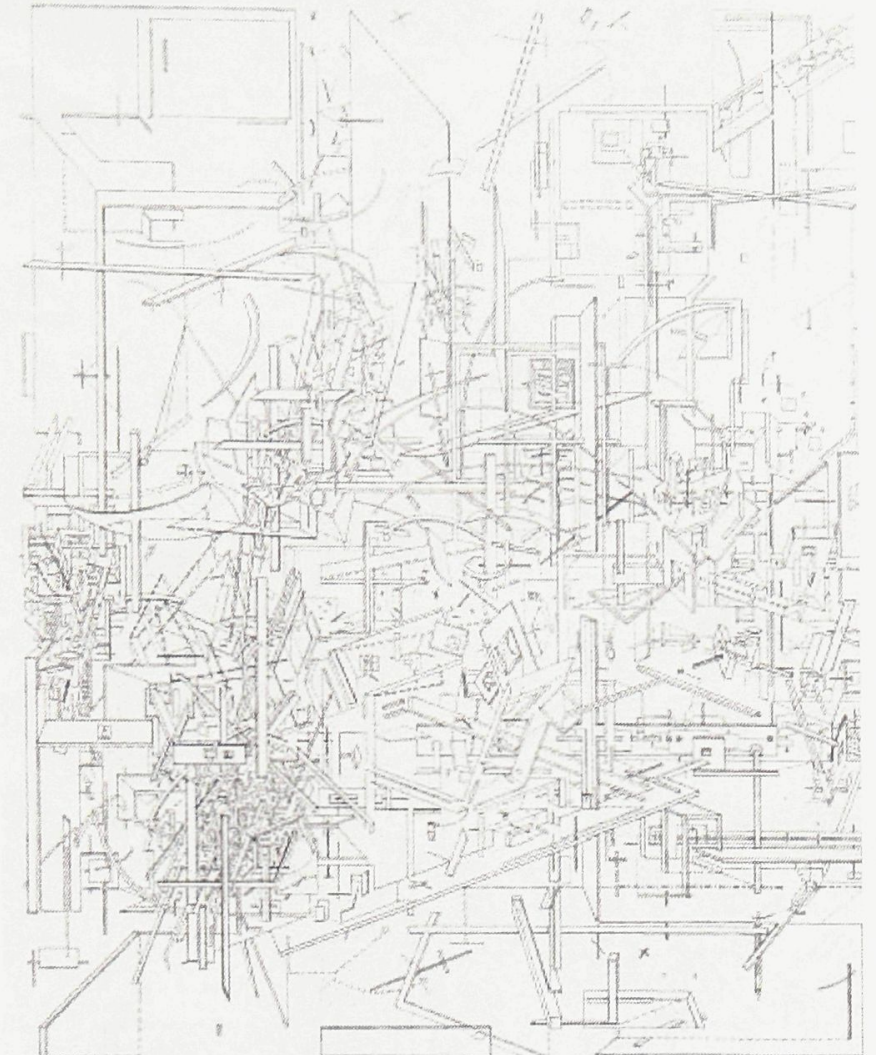

3.4 Daniel Libeskind, Little Universe, 1978, from the Micromegas Series, Graphite on paper.

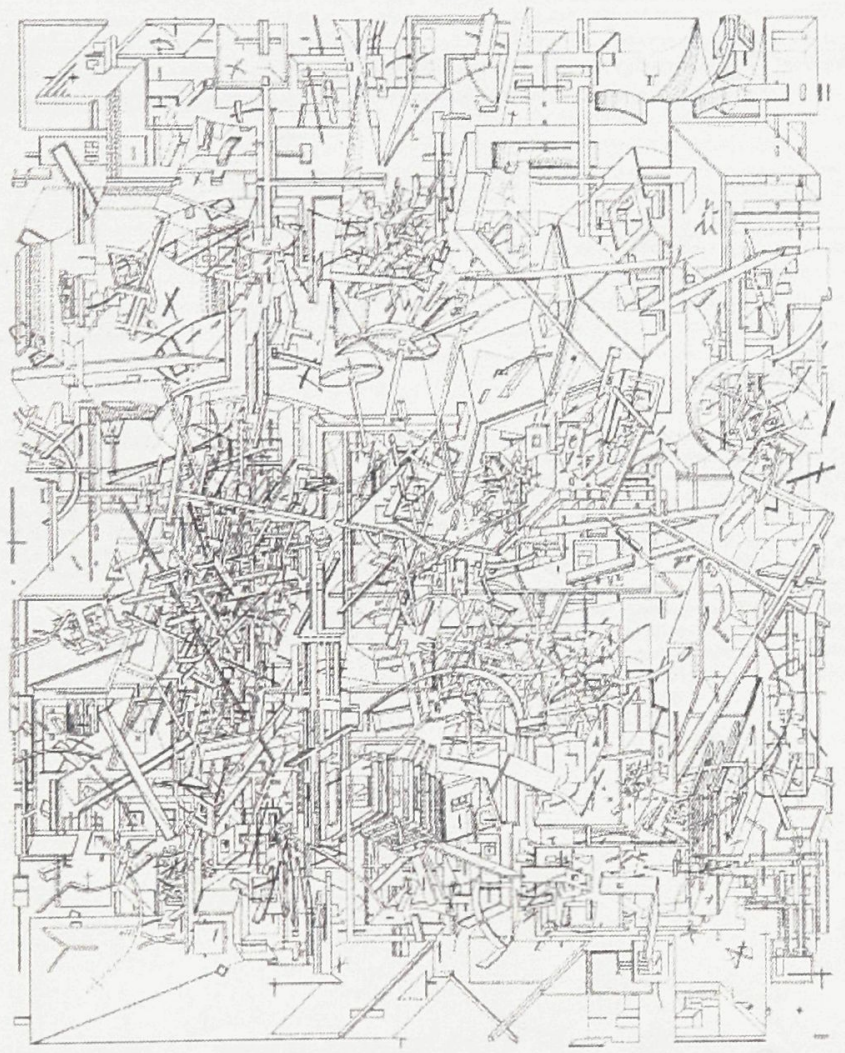

3.5 Daniel Libeskind, Maldoror's Equation, 1978, from the Micromegas Series, Graphite on paper.

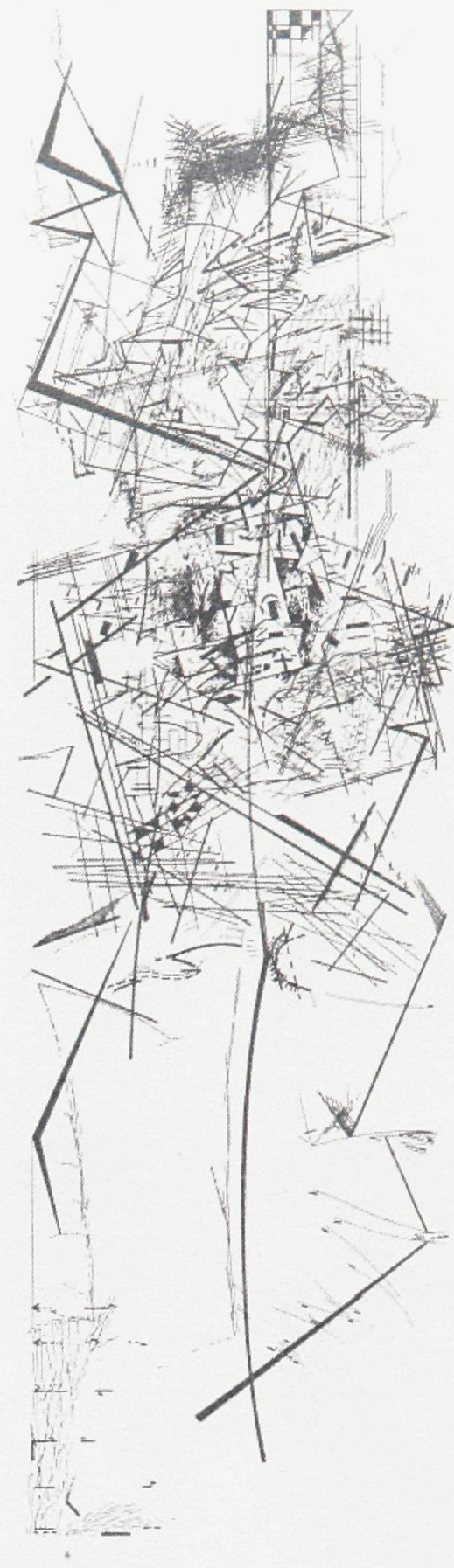

3.6 Daniel Libeskind, Chamberworks, 1982, Graphite on paper. 


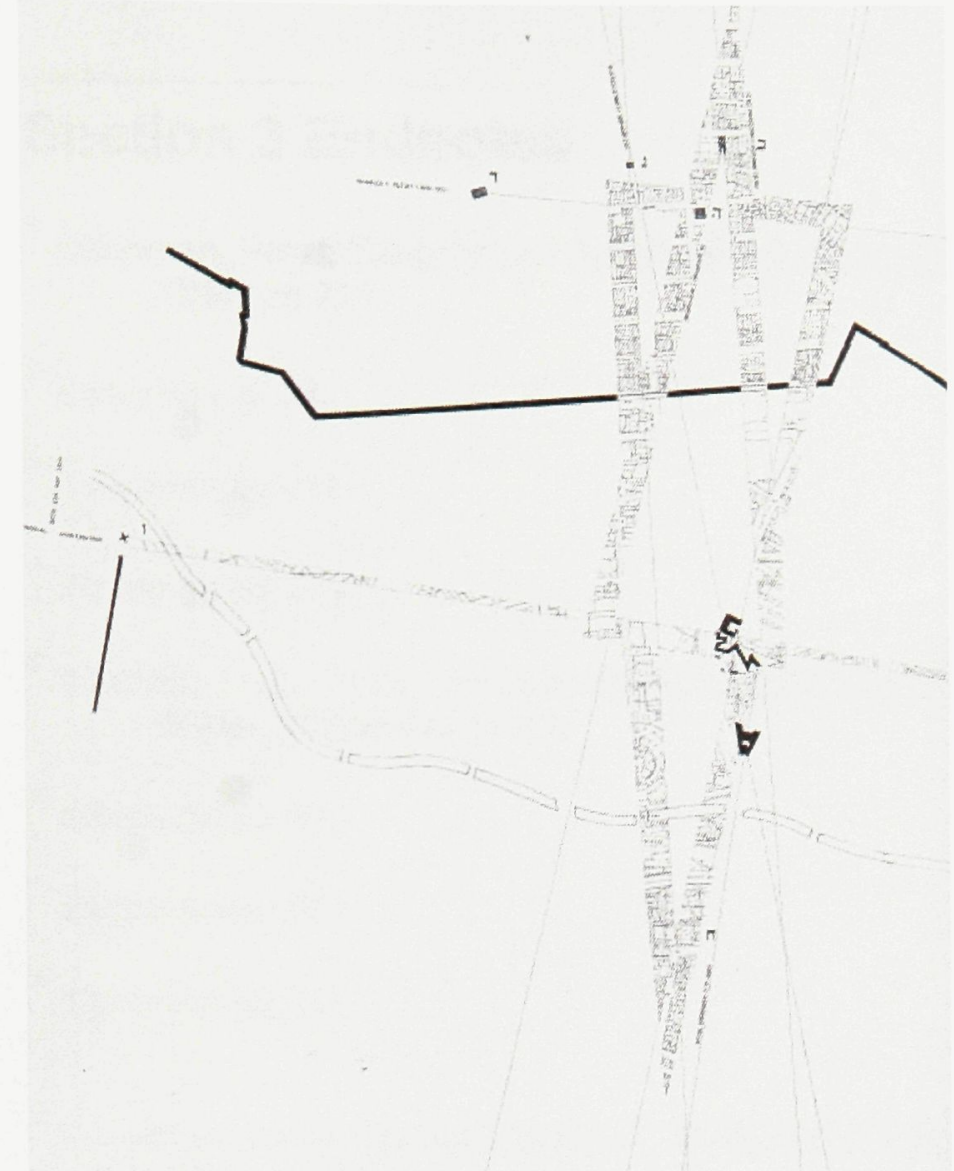

3.7 Daniel Libeskind, Between the Lines: Star Matrix - Site Plan, 1988-99, Drawings for Jewish Museum, Berlin.

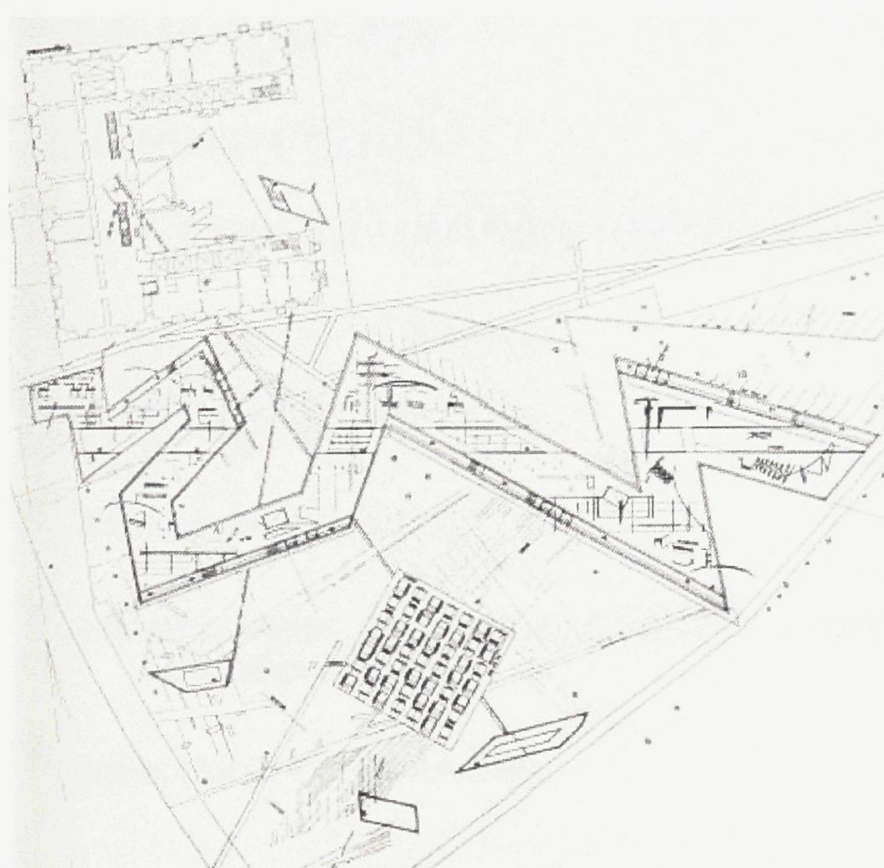

3.8 Daniel Libeskind, Ground Floor Plan, 1988-99, Drawing for Jewish Museum, Berlin.

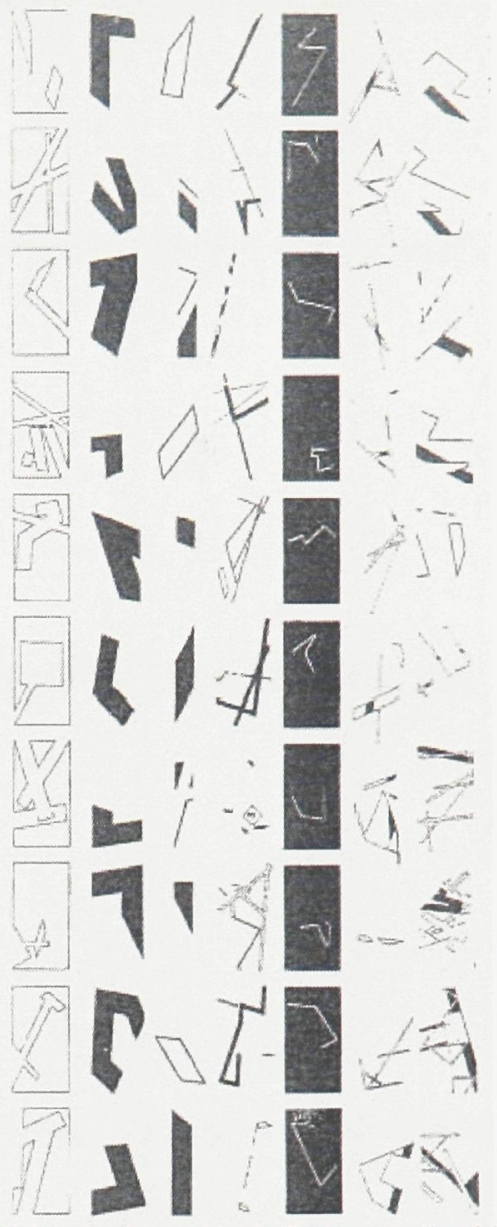

3.9 Daniel Libeskind, Between the Lines: Architectural Alphabet, 1988-99, Drawings for Jewish Museum, Berlin.

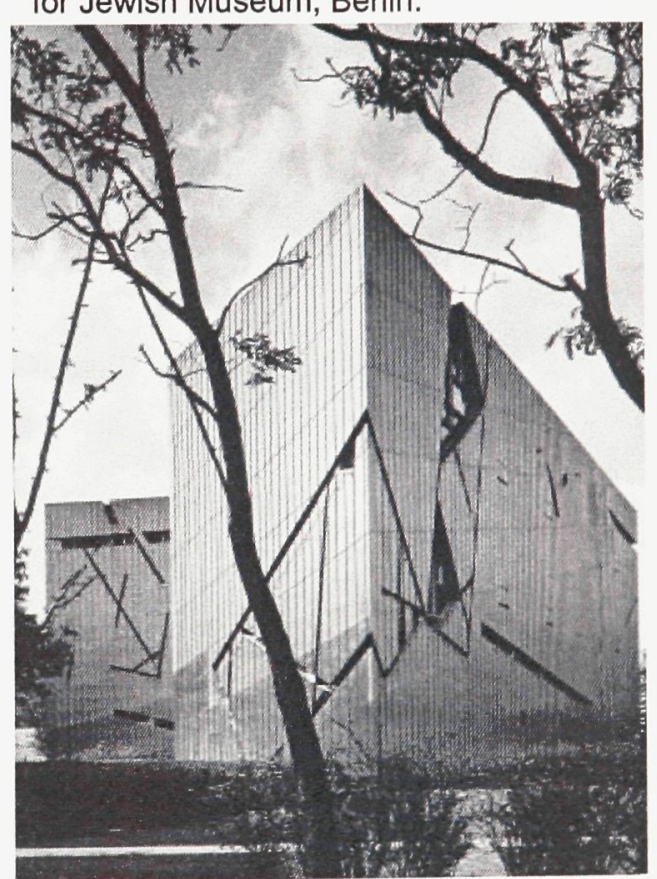

3.10 Daniel Libeskind, Jewish Museum, Berlin.1988-99, Photograph by Helene Binet. 


\section{Section 3 Endnotes}

1 Eisenman, Peter. "Diagrams of Anteriority." Diagram Diaries. New York: Universe Publishing. 1999. pg 211

2 Eisenman, p. 37.

${ }^{3}$ Eisenman pg 211

${ }^{4}$ Eisenman pg 211

5 Galofaro, Luca. "How Eisenman Works." Digital Eisenman: An Office of the Electronic Era. Berlin: Birkhäuser. p. 43.

${ }^{6}$ Eisenman pg 49

${ }^{7}$ Eisenman pg 213

${ }^{8}$ Eisenman pg 213

${ }^{9}$ Libeskind, Daniel. Daniel Libeskind: The Space of Encounter. New York: Universe Publishing. 2000. p. 84.

${ }^{10}$ Libeskind, Daniel. p. 87.

${ }^{11}$ Libeskind, Daniel. p. 84.

12 Libeskind, Daniel. p. 87.

13 Evans, Robin. "In Front of Lines that Leave Nothing Behind." AA Files 6 (May 1984): p. 90

${ }^{14}$ Evans, Robin - p. 93 AA files

${ }^{15}$ Evans, Robin - p. 93 AA files

16 Libeskind, Daniel. p. 26-27.

17 Libeskind, Daniel. Jewish Museum Berlin: Architect Daniel Libeskind. Berlin: G+B Arts International. p. 143.

${ }^{18}$ Evans, Robin - p. 96 AA files. 


\section{0}

\section{/Palimpsest/ - The Project}

Drawing as imagining requires a suspension of the physical, the psychological mental and the deliberate intentions that usually guide the conception of an architectural drawing. In the same manner that drawings are thought to come before architecture, "idea" is thought to precede drawing. Imagination is defined by its intention. [Appendix 1] The thesis presented here proposes that the architectural imagination, idea and drawing can be inverted or manifested concurrently.

To test this thesis, we established a strategy reminiscent of a palimpsest where drawings are over written with new drawings. This process was an appropriate strategy in that it allowed the drawings to reveal themselves as poetic moments that hinted at, and then denied architectural convention. This notion of palimpsest was, a way of structuring and revealing the architectural possibilities of the drawing. By suspending any knowledge of the product anticipated through the act of drawing.

Originally a palimpsest was a parchment or other surface on which writing has been applied over earlier writing that had been erased. It is something reused or altered, but still bearing the visible traces of its earlier form, and making it impossible to determine which layers were first inscribed. ${ }^{1}$ The meaning is explicit in the original Greek word palimpsestos, which is a combination of palin, "again" and psestos, "rubbed smooth". ${ }^{2}$ The palimpsest introduces erasure as part of the layering process creating a fluid relationship 
between the layers of its development. Drawings, projections and erasures are superimposed to bring about "other" drawings, projections or erasures. The drawing, the projections and the erasures merge to become one. My interest is in the dual role; filling the gap between traditional drawing surfaces and the ability to redevelop it through its re-use. The palimpsest fulfils both these roles, conserving traces, while still being receptive to the possibility for new architecture.

"A sheet of paper preserves indefinitely but is quickly saturated. A slate, whose virginity may always be reconstituted by erasing the imprints on it, does not conserve traces." ${ }^{3}$

Similar to the medieval palimpsest, the thesis drawings are re-written, or re-inscribed with each new layer of development. The layers are transparent or translucent and can be seen below the surface of the image. The connections between layers are developed sequentially in time, and are primarily about their juxtaposition in space. Drawings from one layer might dominate images from an earlier layer or vice versa. They might leave blank areas with no drawing at all and these juxtapositions suggest previously unimagined architectural ideas. The development of these ideas and subsequent readings are the source for an invention of architecture. This poetic understanding of drawings, as discussed in the previous chapter, provides a model for the exploration of space.

The drawings that represent the subject of this investigation are informed by each subsequent layer while continuing to reference earlier intentions; including the images that initiated the project. The drawings subvert the idea of one sole source or path of development and defer the "meaning" of the work along a long chain of significations. Each layered phase attempts at "draw"-ing 
out the particulars required for the development of a new architectural idea, including: drawings as action, geometries, space, sections, contextual planning, building form, programmatic experiences and human interaction through detail. This stratified process of drawing conjures the manifestation of architecture as an "other" within an over-riding architectural proposition. The drawings are the beginnings of this proposition. By establishing a fluid source of reference in the development of the drawings we temporarily free ourselves from the confines of the conventions of architectural production. If the drawings, first, refer to themselves, as architectural drawings, rather than instructions for building, we can understand them as representing the imagining of architecture. It is our reading of the drawings as space or form - with all the associated semantics of architectural convention - that later return the drawings back to the architecture of buildings. This includes ephemeral experiences, tectonic compositions, and programmatic relationships. In the case of the thesis project, the aim of the process is to develop, through drawing, a proposal for a permanent headquarters for the Royal Architectural Institute of Canada (RAIC). 


\section{Section 4.0 Endnotes}

${ }^{1}$ Kleinhenz, Christopher. "Palimpsest". Medieval Manuscripts and Textual Criticism. Chapel Hill, N.C.: University of North Carolina Dept. of Romance Languages, 1976.

p. 287.

2 Kleinhenz, Christopher. p. 287.

${ }^{3}$ Derrida, Jacques. The Truth in Painting. Trans. by Geoff Bennington \& lan Mcleod. Chicago: University of Chicago Press. 1987. p. 222. 


\section{1}

Phase 1: Un-Learning How to Draw (Drawing a Palimpsest) How to draw no-thing?

Drawing "no"-thing allows for the exploration of a drawing through the act of its making. If we can agree that to draw "something" is to intentionally make marks that have some resemblance or coded reference to a "thing", then to draw "nothing" would be to make marks that are intentional but do not have a resemblance or make reference to a thing. In order to do this, the subject of the drawing must be disconnected from the conditions of historical experience, physical comfort, knowledge of and/or collected memories; a disconnection from anything that might enclose the explorations as a reference for something. Yet, "nothing" still requires an impartial guide through the process, in this case the palimpsest, in order to reference the drawings back as the initiator for an architectural proposition.

The palimpsest here is constructed of two (2) overlapped, projected images. The content of the individual images is irrelevant; they where not originally photographed by myself and I had no other knowledge of their original intent or content. The selection of each slide was an act of chance. As the projectors were turned on, and the projected lights overlapped, a new unpredictable and undecipherable image was created. This projected image was the guide to this first set of drawings.

In order to allow the drawings to develop without time for reflection, chalk on white bond paper was selected as the drawing medium. Tacked directly to the 
wall, the paper substituted itself as the screen for the projections. The act of drawing was done on this screen and directly over the newly projected image. The two week process was an intense exercise in producing newly conceived images that are drawings of no-thing, made from light.

The process of slide selection, drawing, photographic documentation, and quick note taking was rigorously enforced following the completion of each drawing. Following documentation, each drawing was filed and not seen again until the entire exercise was completed. In total $65\left(2^{\prime} \times 3^{\prime}\right)$ individual drawings were completed within a 15 day span. These drawings were the reference point for the next phase of the process. Once all of the drawings were documented, they were analysed in conjunction with the notes taken during their making. A small descriptive, if occasionally ephemeral, text was developed.

The following pages document each drawing developed through this process. As indicated in the introduction of this chapter, the drawings will be described in a manner more fitting to the images themselves, as a palimpsest. Continuing with the notion of drawing as palimpsest for architectural space; these drawings are accompanied with a complementary text.

Note: Drawings (with projections) 1-5 (day 1) were not documented; therefore the section will begin with drawing \#6. 
No-Things And Palimpsests

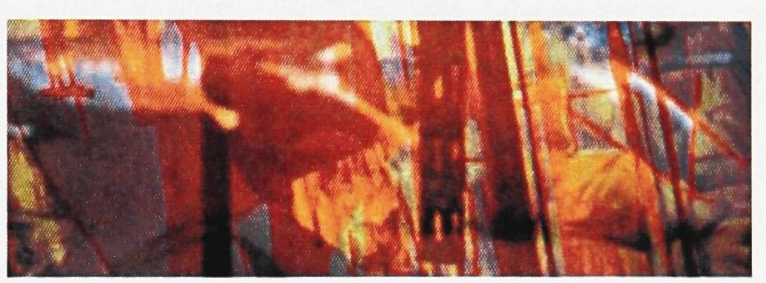




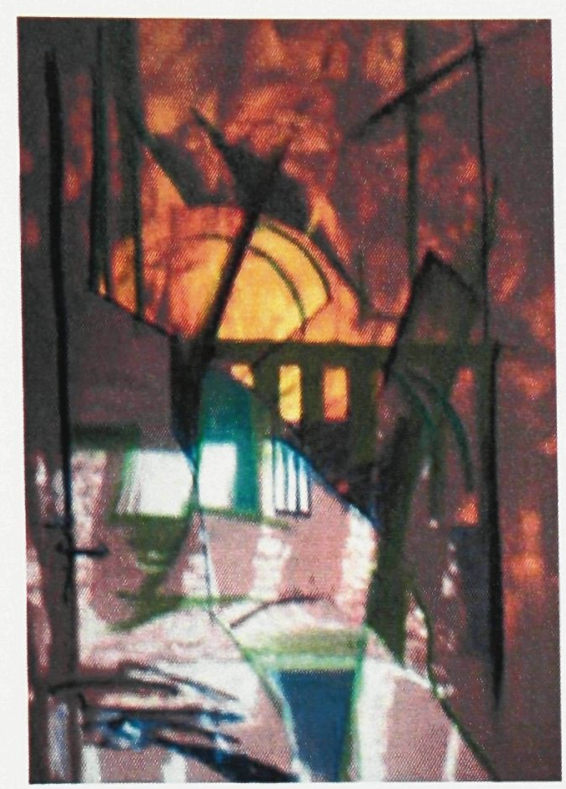

\subsubsection{Drawing \# 6 (Day 2)}

Searching ... and searching ...

$$
\text { Seeking ... and seeking ... }
$$

Finally a moment of pause. Two worlds in divergence are embraced through the overlap of a new. Finally, after a fear of unknowingness - identity.

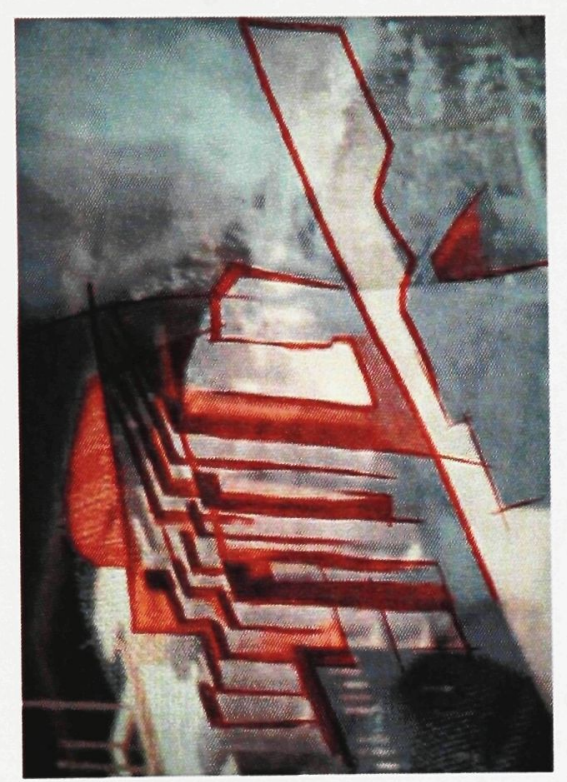

\subsubsection{Drawing \# 9 (Day 2)}

Layers of inequity are now given a just existence.

Defined and strategic gestures reveal the real truth of the image. Ephemoral forms mislead us, causing us to believe that which is not true.

Red is the liberator.

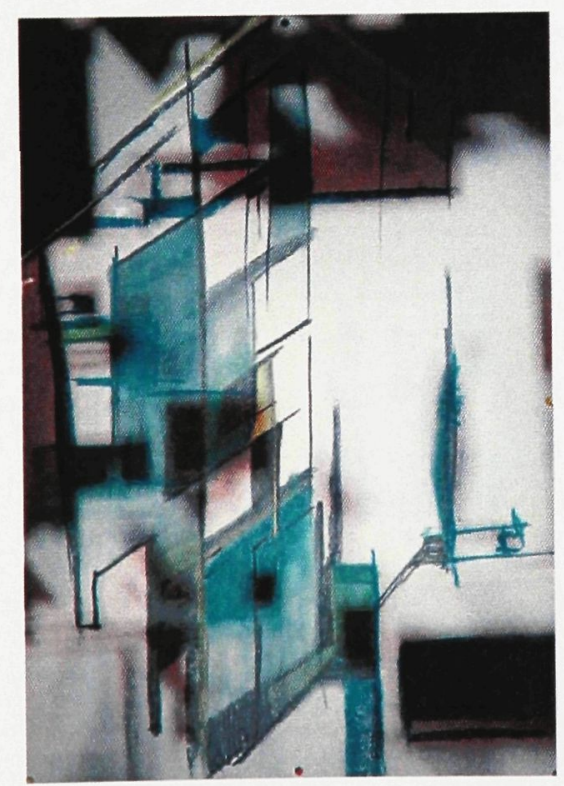

\subsubsection{Drawing \# 10 (Day 2)}

The indefineable, forces structure.

Blue enhances the implicitness of void, surfaces, verticality and the structured skewed.

Vague memory is now given a tactile reality as clarity is created from the elusiveness. 


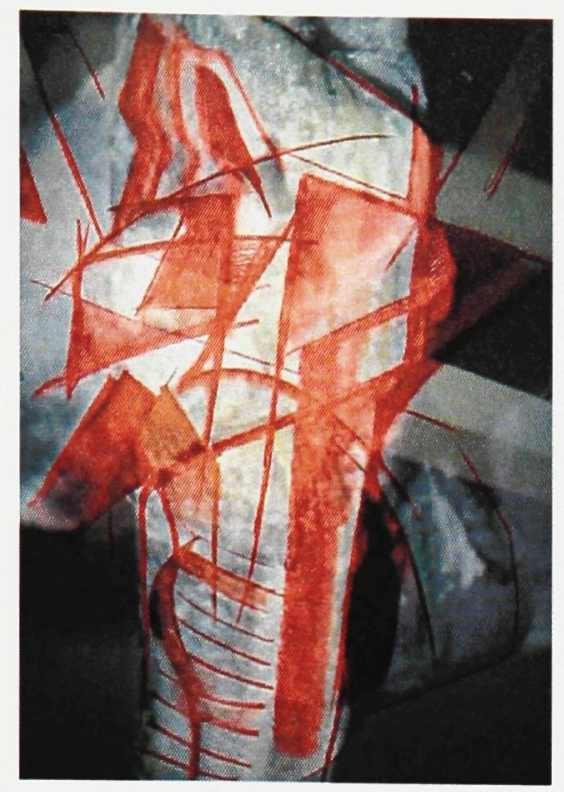

\subsubsection{Drawing \# 11 (Day 3)}

Strange conversations erupt between structure and surface, though it's impossible to carry it with all this noise.

Questions are asked and answered as Red is in simultaneously exchange with the facts of each other's biased viewpoint.

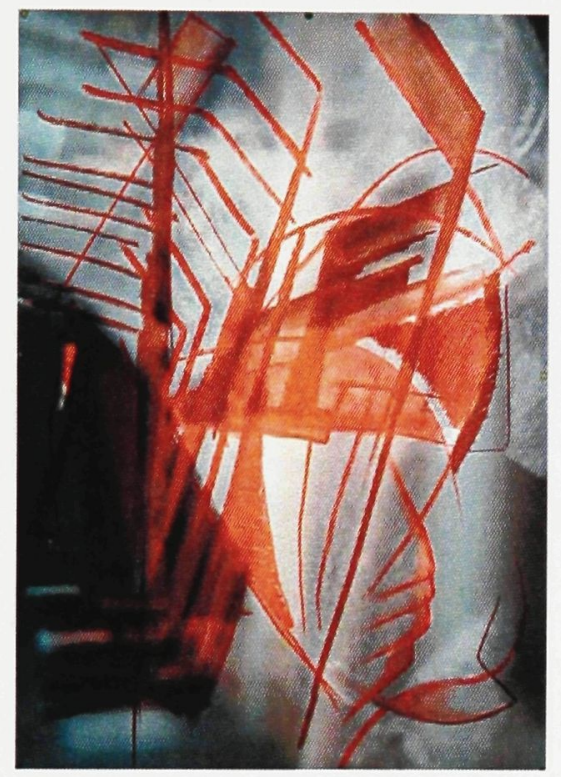

\subsubsection{Drawing \# 12 (Day 3)}

An eruption of evocation and dialogue between particular ways of considering and particular ways of seeing is manifested.

Pressure forces our movement through the image to a forced moment. First, seemingly beyond our reach but now in the midst of our perception.

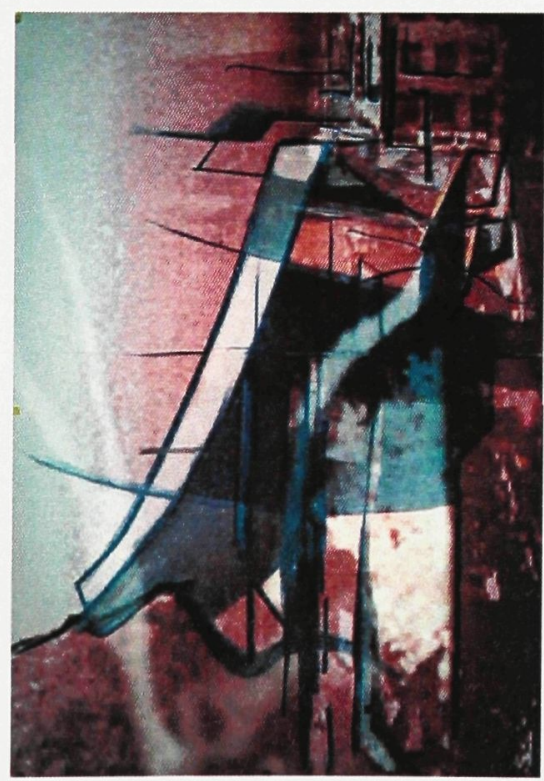

\subsubsection{Drawing \# 13 (Day 3)}

Confused line and tonal relationships are claritied through the homogeneity of colour.

Blue establishes intentionally, a becoming.

Involving itself in a difficult situation, improving and preventing it from getting worse. 


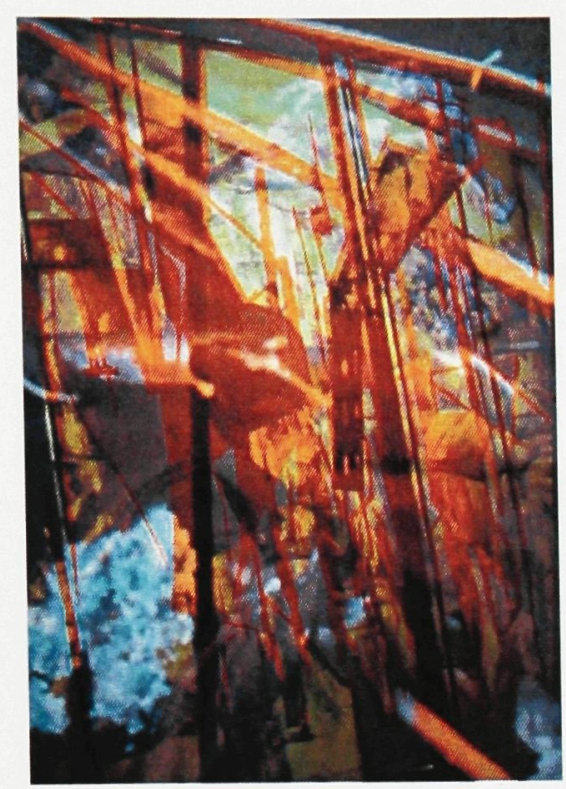

\subsubsection{Drawing \# 14 (Day 3)}

Hierarchy of media no longer exists; accentuation of three distinct planes simultaneously engaging the viewer, the projected image itself, and the possibilities of beyond. Orange becomes a true arbitrator, trying to give the schizophrenic image a grounded reality. One can only begin to imagine the possibilities of a future revelation.

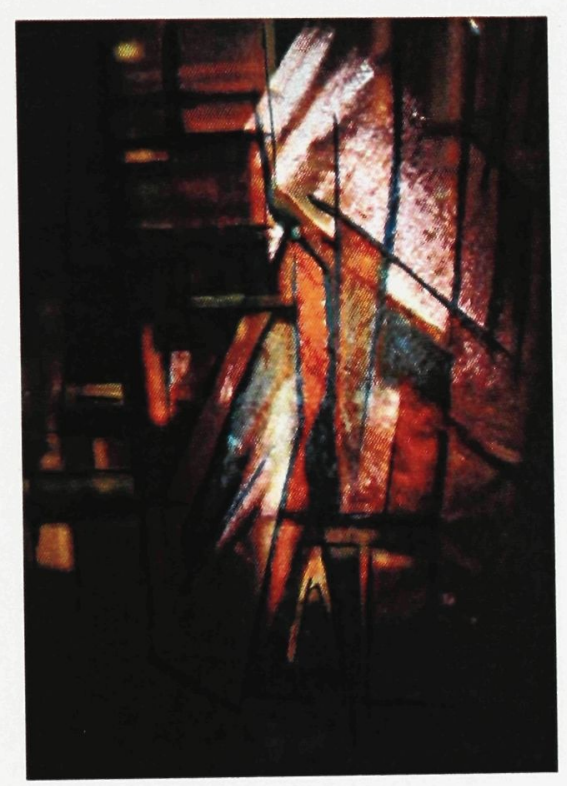

\subsubsection{Drawing \# 15 (Day 3)}

True and perceived visibility evocates chance through contrasting copper and blue, exposing known ephemeral planes and indicative structure. Darkness becomes the true generator of future disclosures; forbidding us to see what the drawing may reveal later.

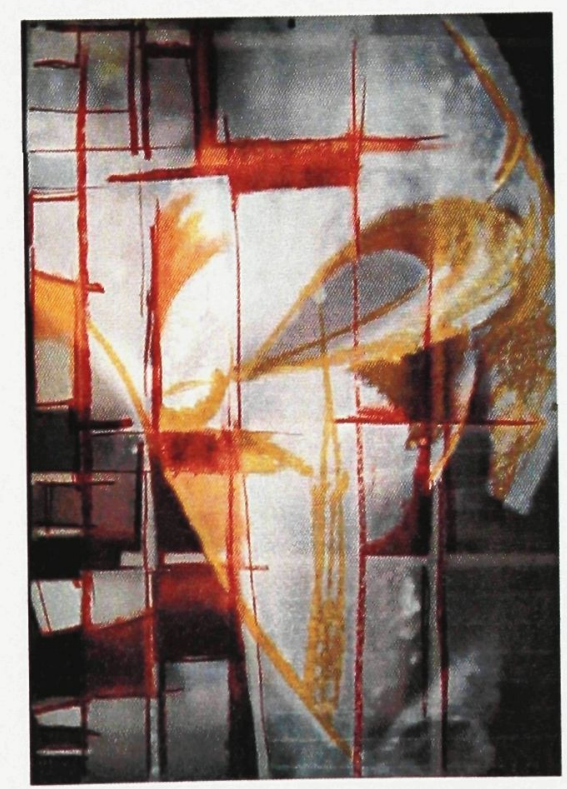

\subsubsection{Drawing \# 16 (Day 4)}

Structured order and fluidic motion are bridged by the overlaps of divergent colours. Red rules the image's order, enhanced further through the exposure of the original projected structure. Yellow, like the transient, bridges the gaps. Overwhelming brightness gives clear indications of future likelihood from this bipolar projection. 


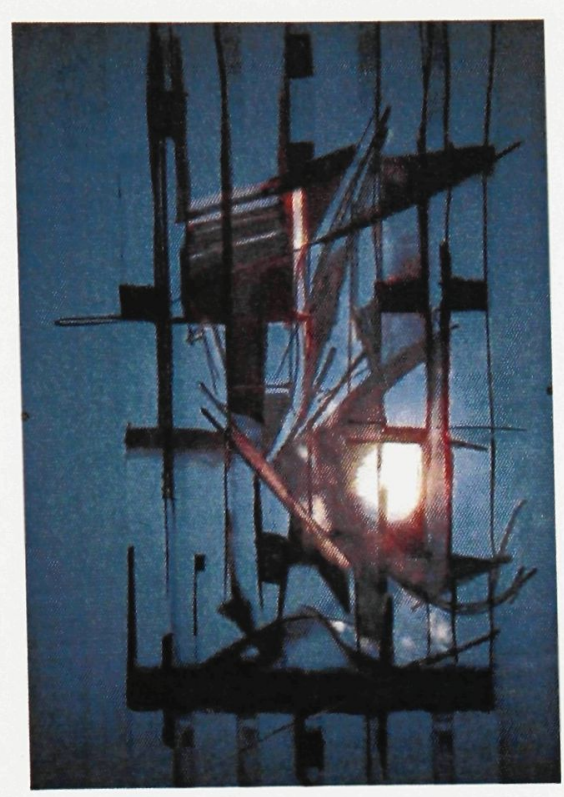

\subsubsection{Drawing \# 17 (Day 4)}

Parasistic embodiedment through rigorous lines, as an apparent entity lives in and around its structured host, obtaining nourishment without killing it. Unlike traditional parasitic entities, this one glorifies its host; allowing it to become one as well.

Structure struggles back.

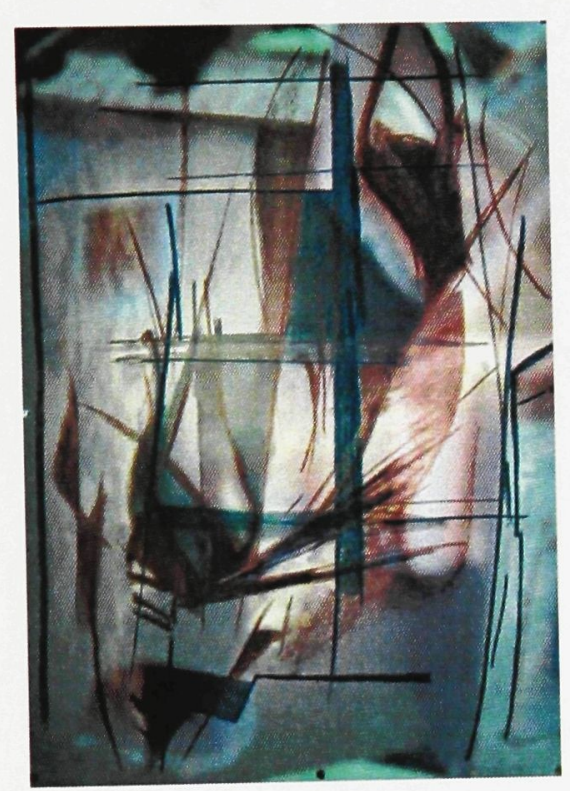

\subsubsection{Drawing \# 19 (Day 4)}

Cutting across...

An overlap of the 'other', a set of elements shared by two or more given sets, establishes a series of points or locus moments where line, surface, or solid cross one another. Cohesion can only exist through a perception of the whole.

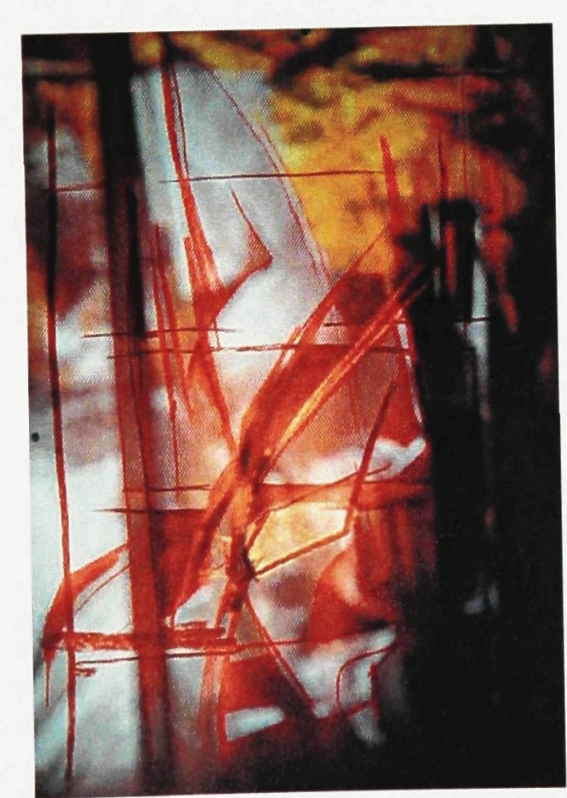

\subsubsection{Drawing \# 20 (Day 4)}

In a state of being tranlated.

A body in motion, in which every point of that body moves parallel to and with the same gestures as every other point of that body. It is now given a tangible reference point through light. 


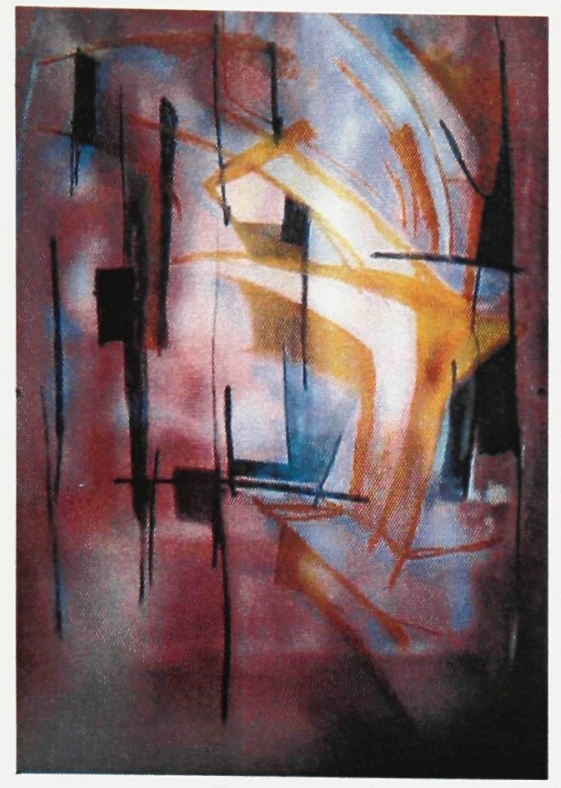

\subsubsection{Drawing \# 21 (Day 5)}

Thoughts of light are now made objective, external and concrete.

A focus of attention through drawn feelings, thought, or action creates a new object of contempt.

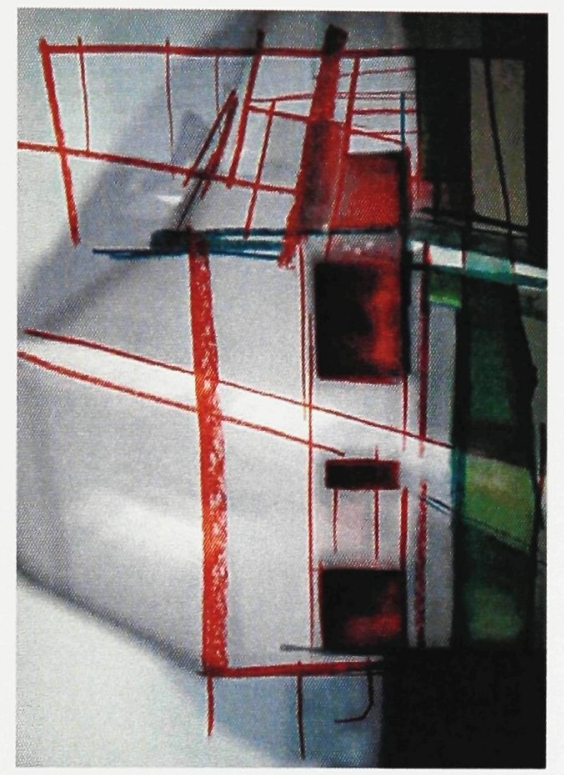

\subsubsection{Drawing \# 22 (Day 5)}

Preliminary expressive meanings are exaggerated to a point of extinction. Instead they are given new formal dimensions, shape and a new appearance of something 'other' than the initial. A new interpretive reflection is revealed dominated by the intensity of line, plane and colour.

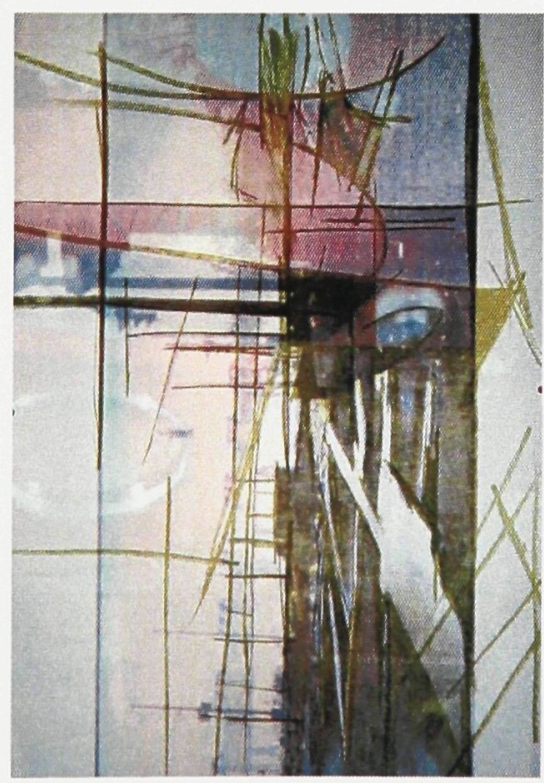

\subsubsection{Drawing \# 23 (Day 5)}

The exaggeration of a recognized macro scaled condition against apparent detailed and micro scaled images begins to mediate revealed scale shifts. A threshold is established as homogeniety provides a reference to this moment. 


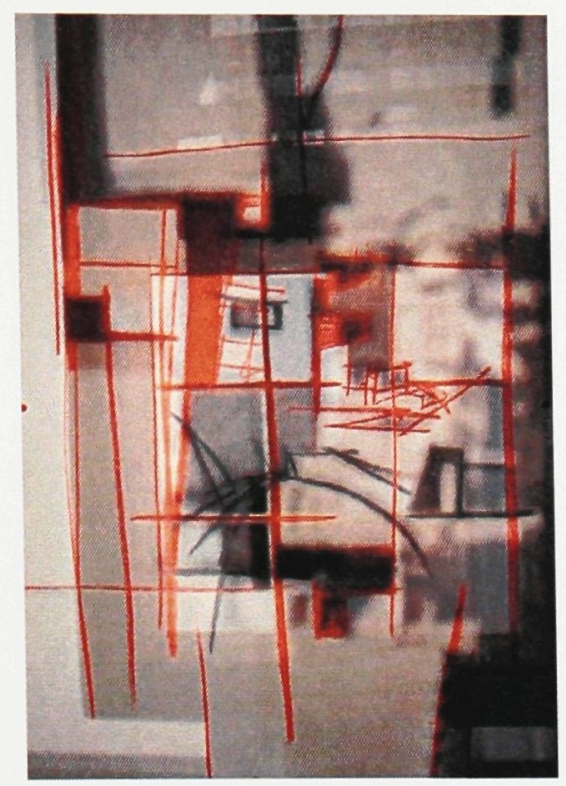

\subsubsection{Drawing \# 24 (Day 5)}

Exaggerated through an outlining of their placement, area or space. Voids and emptiness, are transgressed from a state of non-existence to physical authorities. Formal rectilinear patterns emerge as the dominant nature of a vagueness struggling to emerge.

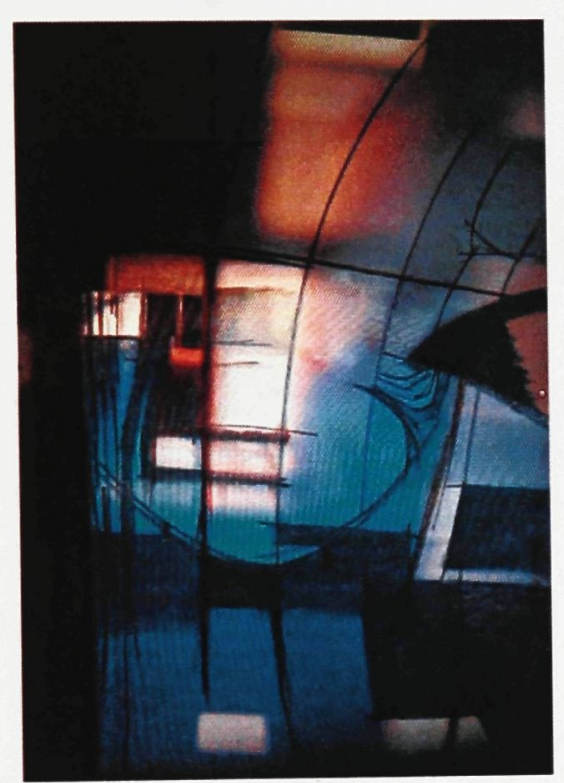

\subsubsection{Drawing \# 26 (Day 6)}

Imbued and saturated experience of colour engage vague forms into taking a defined position. The impregnation of tone begins to equal out colour against the sharpness of void in an effort to unify space.

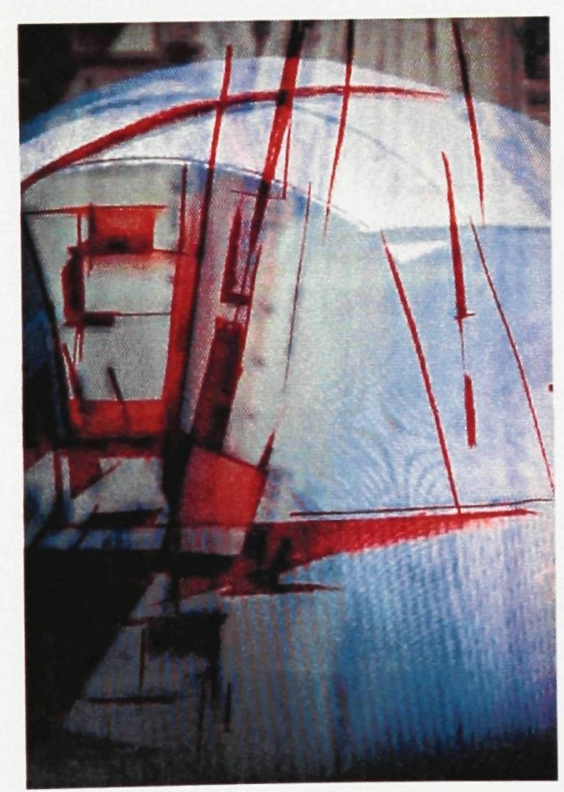

\subsubsection{Drawing \# 27 (Day 6)}

Dark, direct and harsh red lines and planes bridge the diverging worlds of planned structure and occurrence. A single vault - a simulation of the ephemeral - reconciles the overlapped and makes them all become one. 


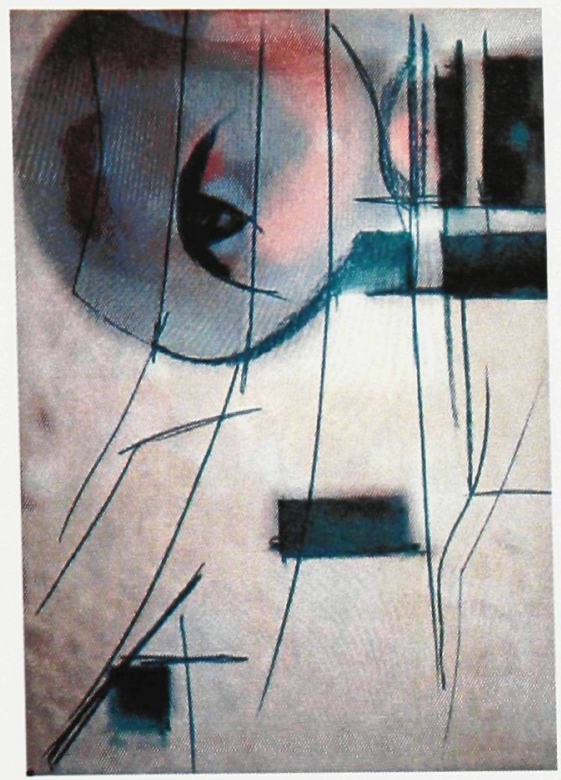

\subsubsection{Drawing \# 28 (Day 6)}

Gestured lines enhance the clear significant micro patterns, defining the true nature of experience. Dark and defined rectilinear blue voids become moments in which these identifying patterns are not only captured, but indicate the important characteristics of a future not yet defined.

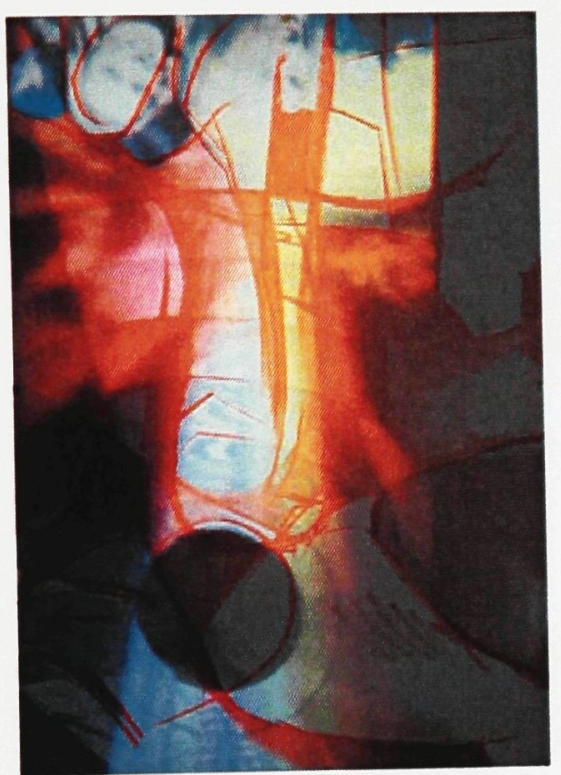

\subsubsection{Drawing \# 29 (Day 6)}

Colour draws out the hidden patterns of a convoluted experience. The outlining of complex micro images creates a homogenous, yet seemingly suitable space. Enhanced by the plays of linked voids, surfaces and planes, Orange gives this moment cohesion.

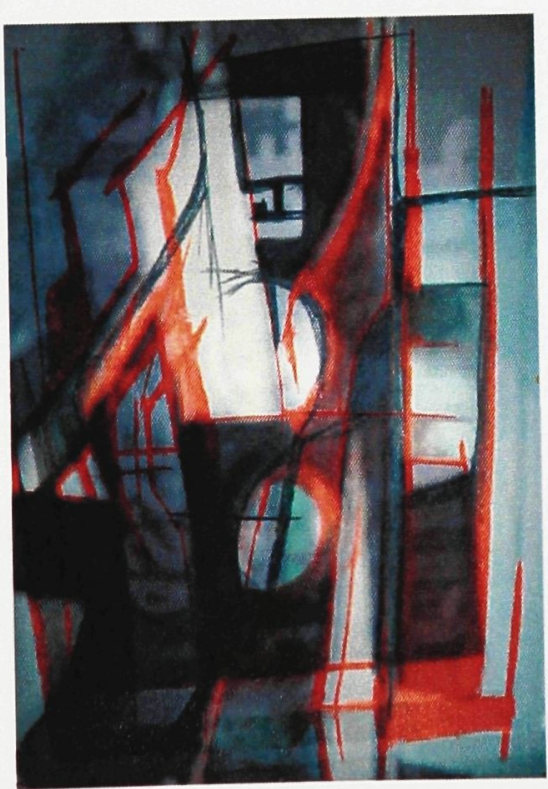

\subsubsection{Drawing \# 30 (Day 6)}

The spatial arrangement of something as distinct from its substance is established. Planes, line and colour become greater, more serious or more extreme. They inaugurate something new from something pre-existence; a 'becoming' of the real. 

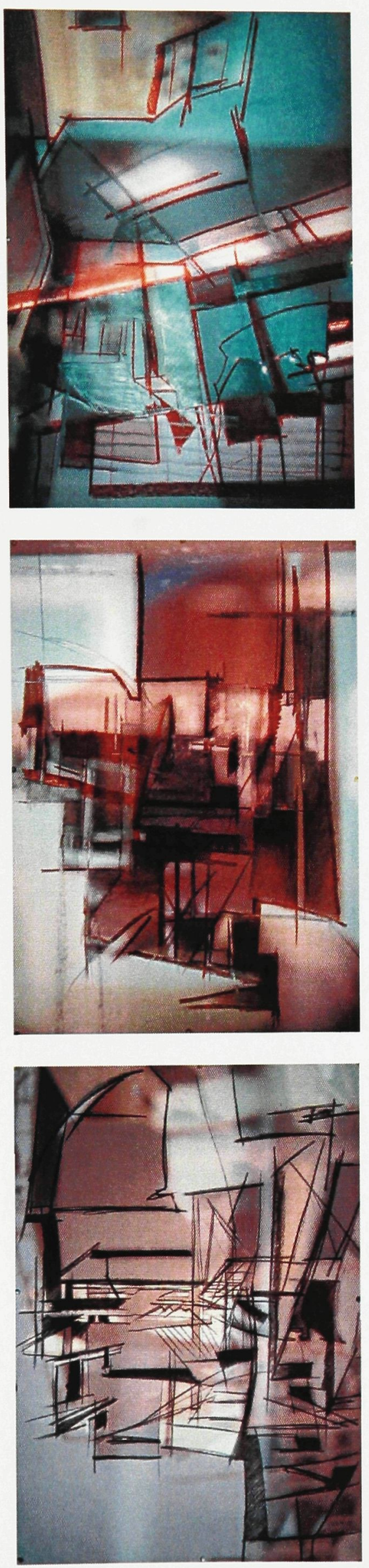

\subsubsection{Drawing \# 31 (Day 7)}

Guiding lines, planes and the colour of the initial, develop into a subservient of the created. Opening projections exaggerate established moments of depth that begin to reveal the profundity that spaces can insight into our existence.

\subsubsection{Drawing \# 32 (Day 7)}

Vestiges of colour leave evidence or an indication of the former presence or existence of something "other". To ascertain the successive stages in the development or progress of space, brown delineates references for the true understanding or possible interpretation of place.

\subsubsection{Drawing \# 33 (Day 7)}

Pure tonal possibilities establish a strategy of homogeneity through heterogeneity that begins to reveal the exploitations of line and void; engaging the viewer's mental image and establishing references in order to complete the physical. 


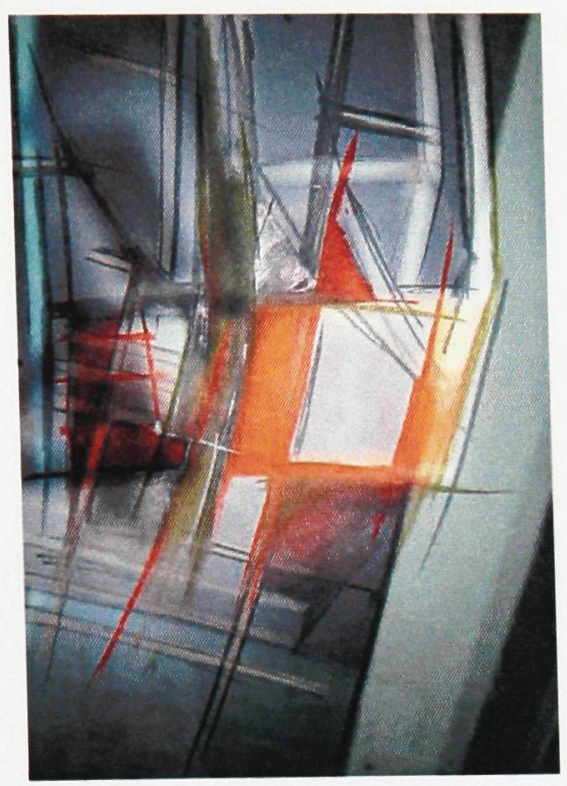

\subsubsection{Drawing \# 34 (Day 7)}

A new strategy augments the relationship between the physical and projected realities of light and colour. One becomes indecipherable from the other as an exaggeration of planes and lines establishes dependency through an exploitation of apparent movement and stability.

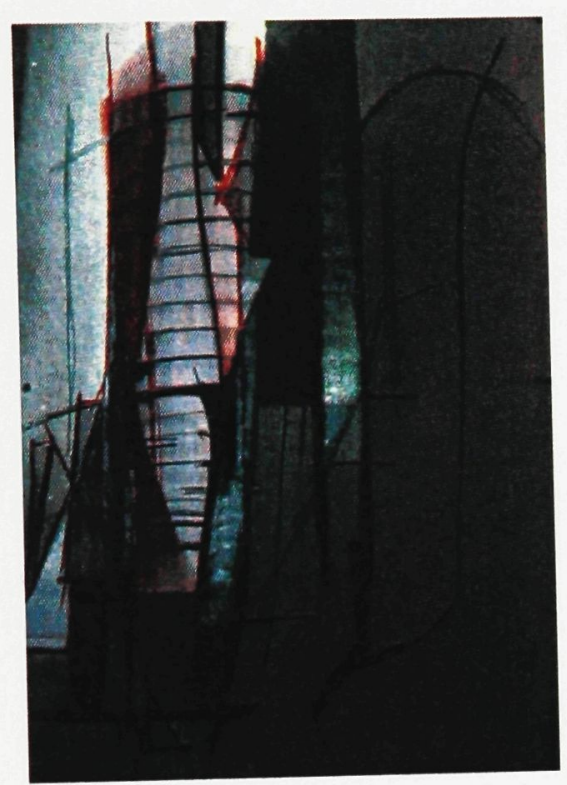

\subsubsection{Drawing \# 36 (Day 8)}

The distinctly visible and utterly undecipherable are mediated by lines and planes exaggerating the characteristics of elevation. Bleeding into darkness; lines are guided only by slight tonal variations that are perceived as intensity of colour is also removed. Recognizable forms give new connotation.

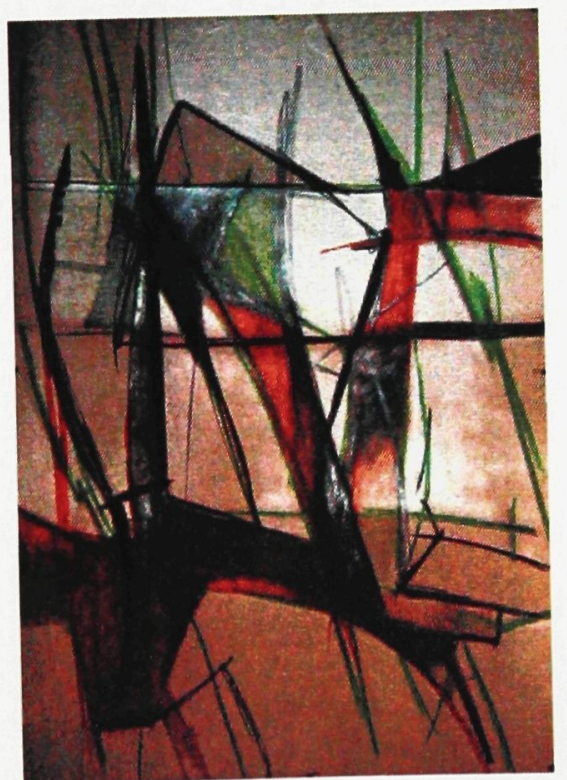

\subsubsection{Drawing \# 37 (Day 8)}

Intensive and deep, strength through moments of colour establishes itself. Based on the degree of difference from the grey of the same brightness, saturation is given its strength, drawing an interpretation of the projected images that are similar to an emotional response. 


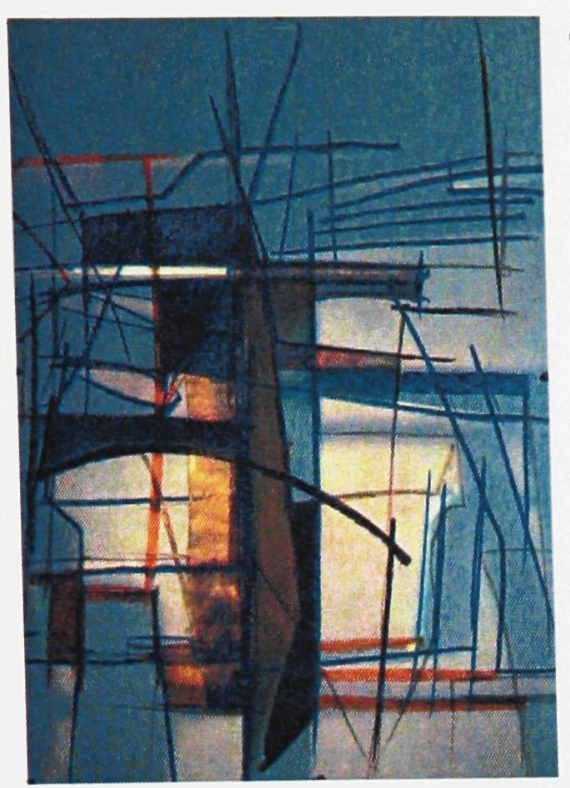

\subsubsection{Drawing \# 38 (Day 8)}

The clarity of objects and the ambiguity of coloured landscapes, deliberate through an apparent supernatural experience. Activity through line and tone ultimately culminates in a decisive, though equally intangible, exposure of form and depth.

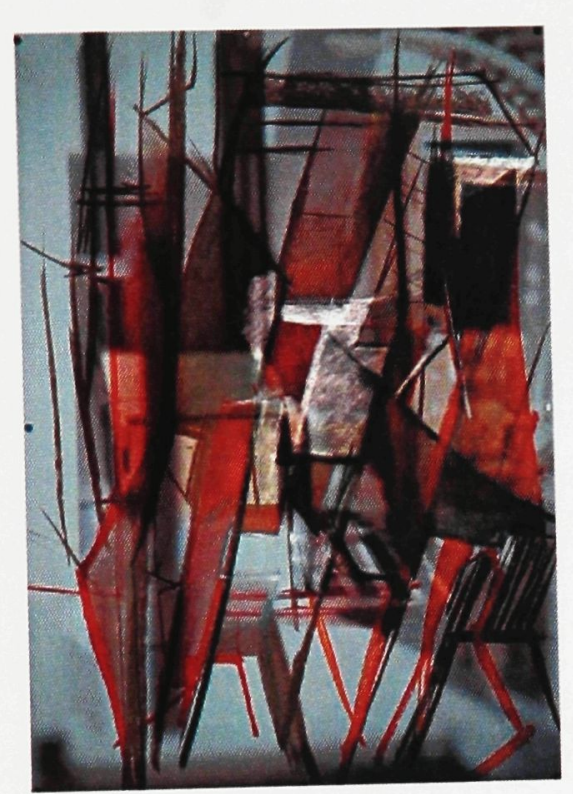

\subsubsection{Drawing \# 39 (Day 8)}

An exploitation of geometric planes and surfaces, such that if any two points are joined by straight lines, they are contained themselves wholly within these surfaces. Overlap allows for a movement beyond the purely outward appearances of a two dimensional composition, ascertaining an infinite array of depth.

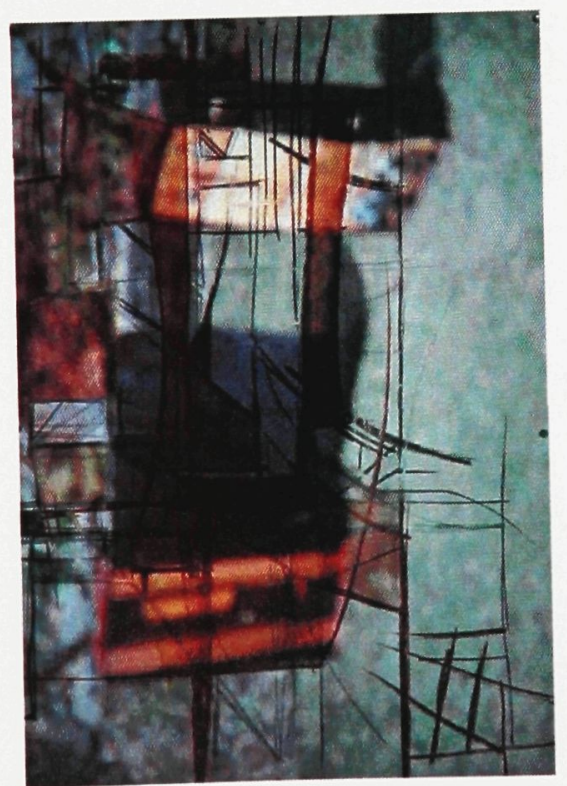

\subsubsection{Drawing \# 40 (Day 8)}

Lines attempt to compose clarity from the blurred. Once something confused in form or outline achieves a reversal of the autonomic function of the newly projected lines. Something once used for measuring, dividing and giving intelligibility has itself become illegible. 


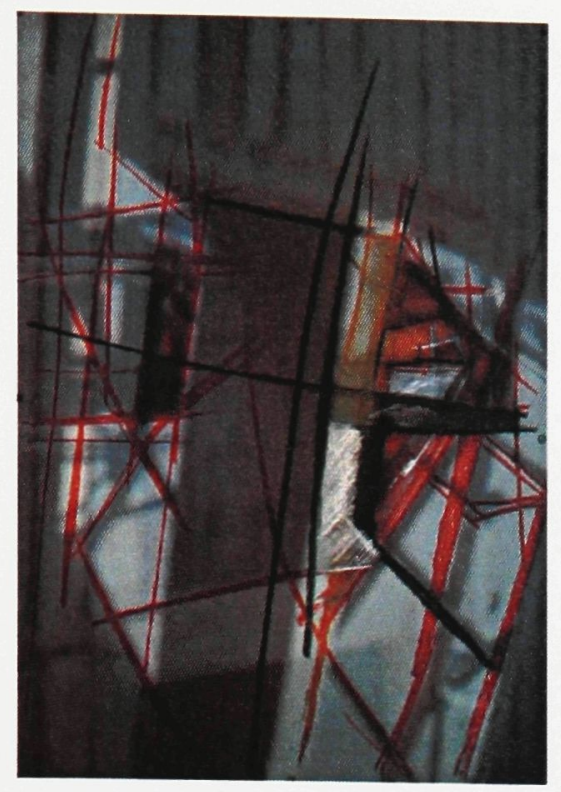

\subsubsection{Drawing \# 42 (Day 9)}

A moment of clarity exposes itself through defined line and tone. Everything is now amenable through a detailing of the vague. We can get what we want if we follow the lines and only when we seize from wanting and thinking the original clarity will be seen.

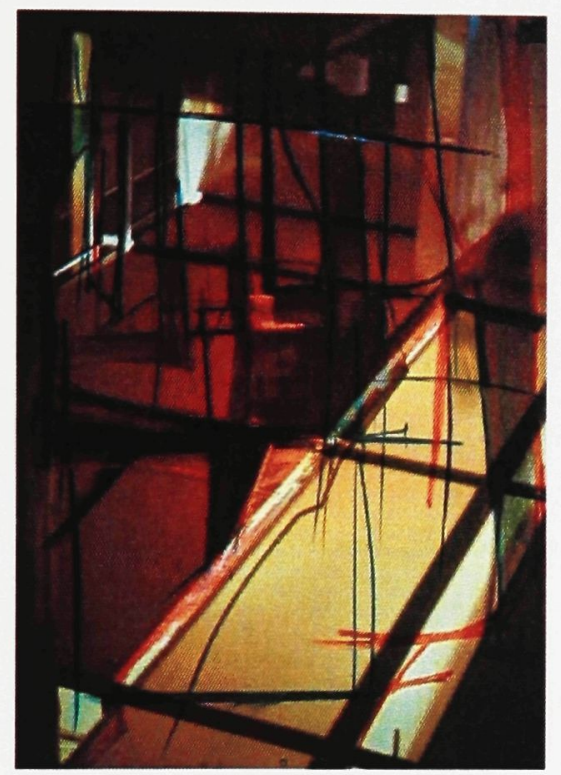

\subsubsection{Drawing \# 43 (Day 9)}

Play, colour and light struggles with the powers of darkness. Forms experience difficulty and make a great effort in order to manifest something, anything. It is an energetic attempt to achieve space through a crowd of obscurity; a real struggle and a battle for recognition.

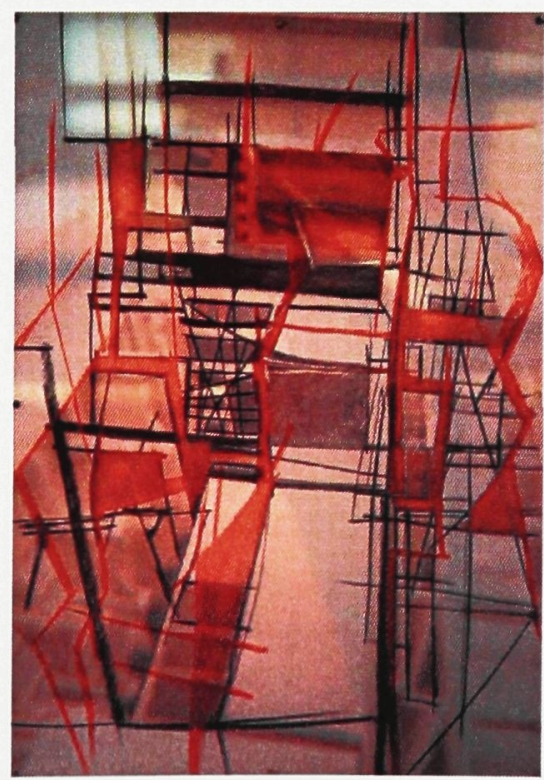

\subsubsection{Drawing \# 44 (Day 9)}

Furcation, space divides itself between juxtaposed line and planes that branch out from the route of perception. Place designates itself simultaneously as the end and the beginning of an endless journey where reality's painful path is scattered until a series of moments grounds it into instances where these disparate worlds finally merge. 


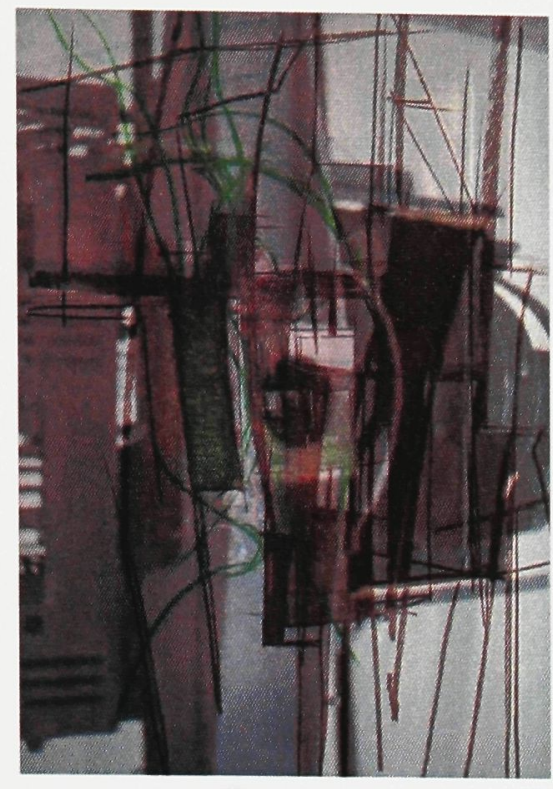

\subsubsection{Drawing \# 45 (Day 9)}

Line and plane explore a relationship between two distinct moments in which each provides for the other the conditions necessary for its continued existence. This affiliation of colour, plane and moving line diverge at a concentrated condition - giving one a moment's brief spatial relief.

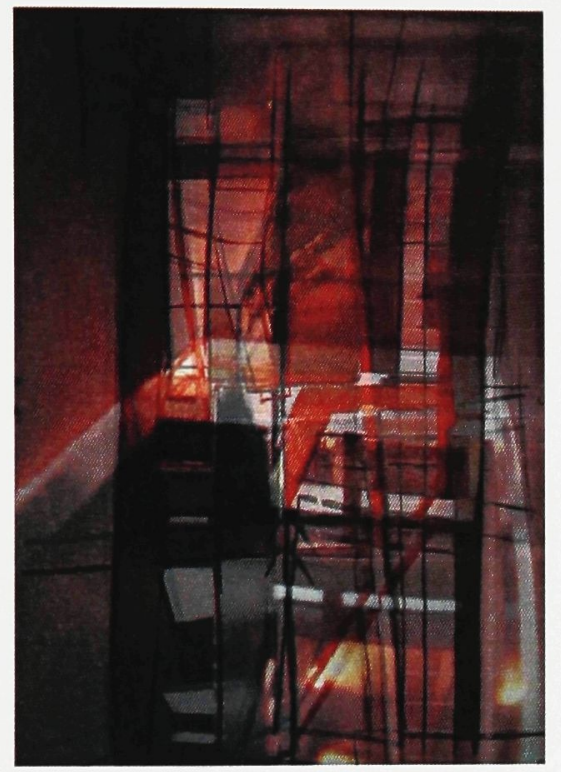

\subsubsection{Drawing \# 46 (Day 10)}

A particular way of considering 'something' exposes our perspective towards space. Endlessness through tonal shifts instigate a tightness of the body, shape and experience of a ghostly space. The spirit of experience is now given an apparent form that can now be seen.

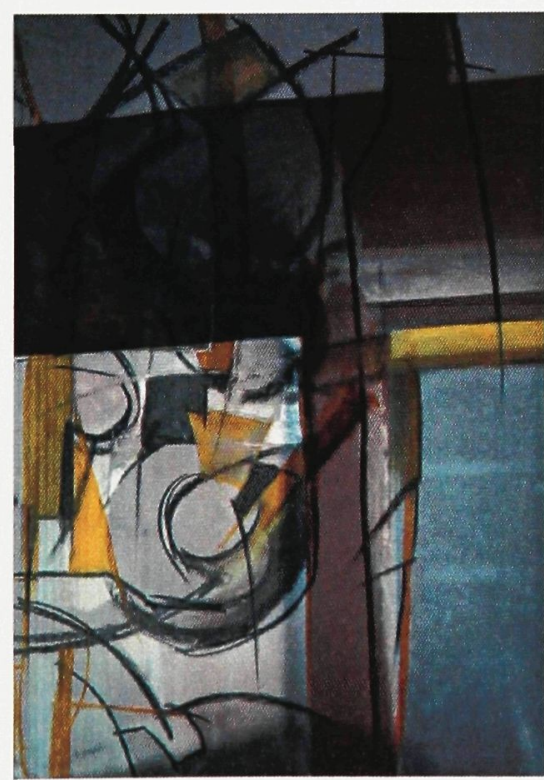

\subsubsection{Drawing \# 47 (Day 10)}

Line, plane and colour battle an oppressing void that cancels or simply annuls their existence. New touches without sense and revoked without reason, intensifies the importance of that which has been spared. Faith in a future reversal of this trend is all we have left. 


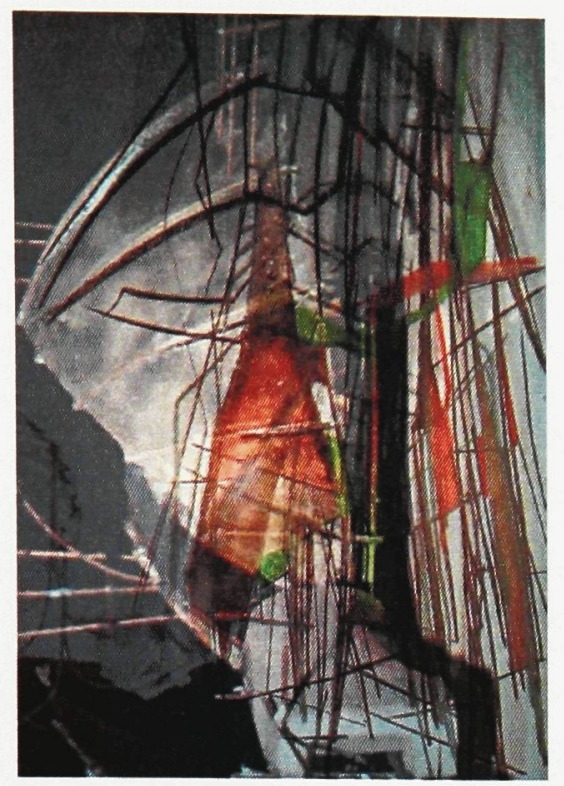

\subsubsection{Drawing \# 48 (Day 10)}

Bionic appendages of lines in movement exploit themselves as things added and attached to a greater entity of importance. The adjunct moments of colour stabilize these attachments like limbs joined to the axis or trunk of a body. Their connection adds new function to the moments to which they are endlessly linked.

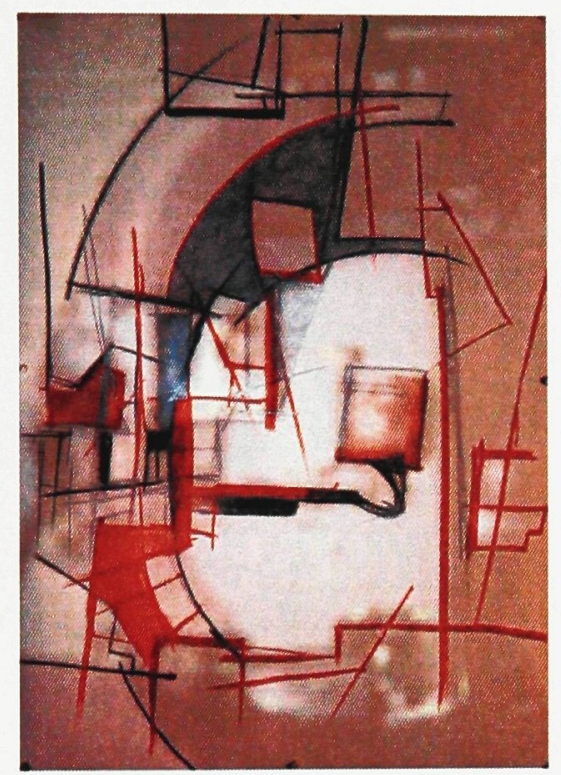

\subsubsection{Drawing \# 49 (Day 10)}

Divorced elements and individual figures of experience change form and undergo a development of morphemic reunification. Existing and meaningful linguistic units consisting of lines, grey and orange, are given a greater cohesive importance through the beneficial use of smaller yet meaningful parts.

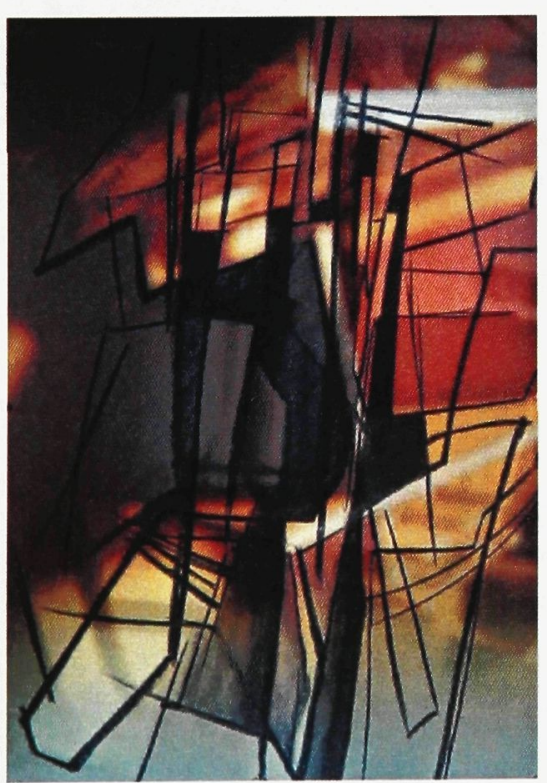

\subsubsection{Drawing \# 50 (Day 10)}

Long and narrow depressions in the surface of light expose depth through a series of fissure moments. Cracks of colour, voids of darkness and the overlay of projected lines intertwine to create forms and spaces inherently related to the deep furrows of the image. Architecture is created through the exploitation of subgroups, factions and schisms. 


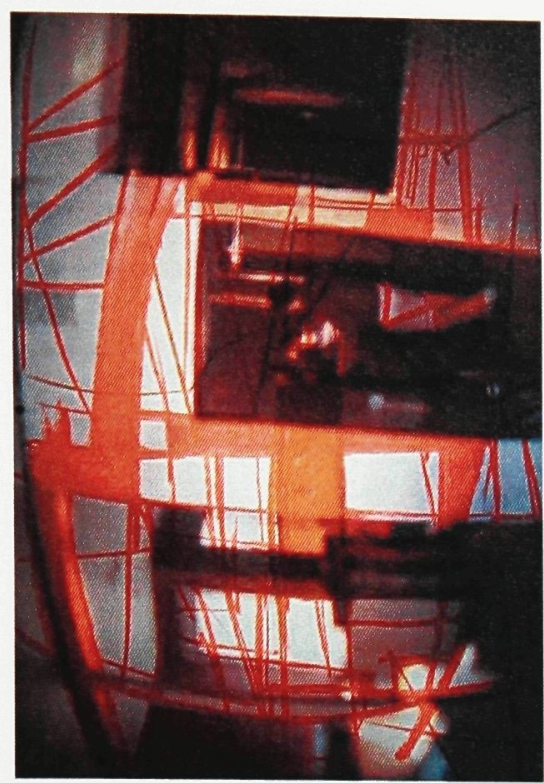

\subsubsection{Drawing \# 51 (Day 11)}

Peripheral ambivalence, manifested as equally immersed elements of composition, force the perception of space through various simultaneous conditions of depth. Moments of diverse states of emotion are now given a unified whole through colour, tone and intense projection.

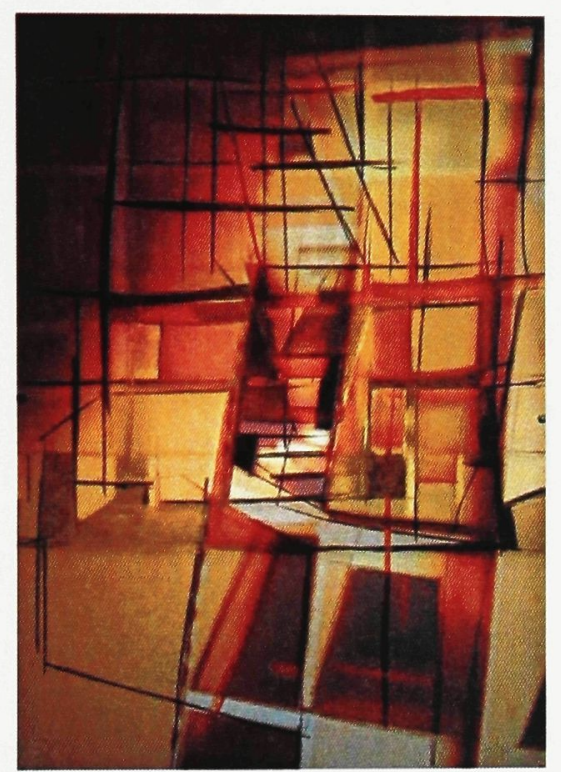

\subsubsection{Drawing \# 52 (Day 11)}

The process organization of space reveals something made up of interstitial elements. Each varied with functions that contribute to the whole composition - the collective functions of plane and depth - and to the multi lateral explorations of individual meanings. Architecture is situated within the small, diverse spaces that mediate line and projection.

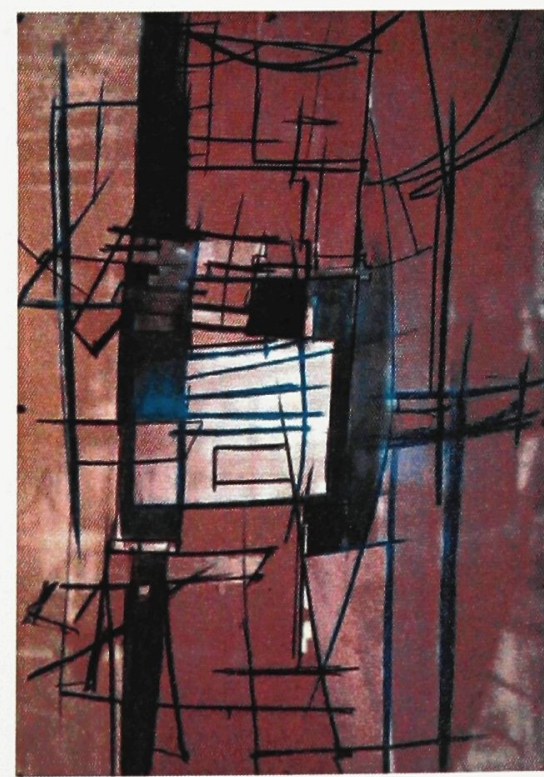

\subsubsection{Drawing \# 53 (Day 11)}

Through the combining of separate elements or substances, a coherent whole is formed. Reasoning from the particular to the general; line, colour and void reference the nature of an all ready well defined spatial resolution. intervention gives the image a sense of irresputable definition. 


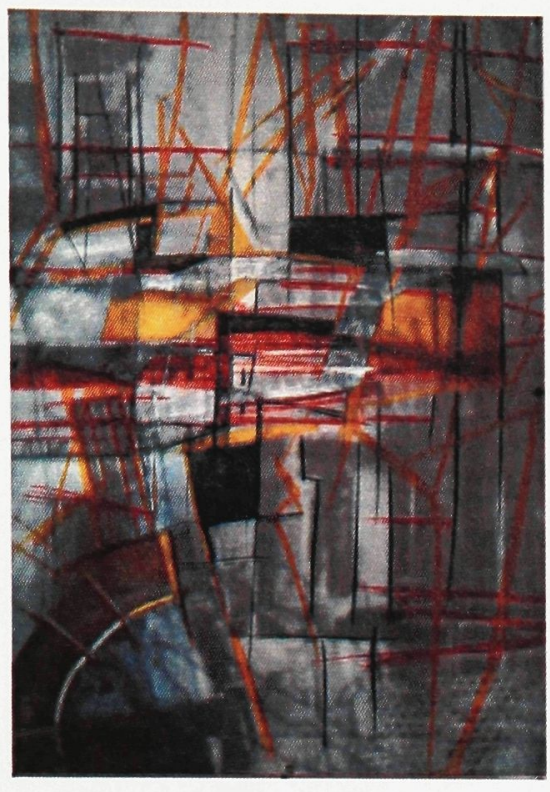

\subsubsection{Drawing \# 54 (Day 11)}

Drawing begins to draw out stability from a condition of great turmoil and confusion. This disordered state of unformed definition and infinite space are drawn out from moments of colour and gestural lines. Yellow is the tool for realizing this stability. It is the only trully defined link to both worlds.

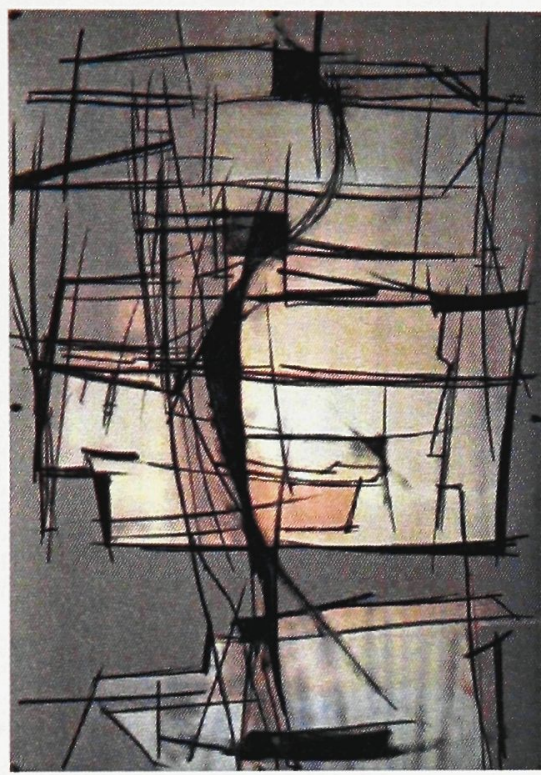

\subsubsection{Drawing \# 55 (Day 11)}

To cause to regain consciousness; antithetical lines and voids express the assumed intentions of projected light. Not only do they define boundaries and the limits of illumination. Black - once defined as without light - now gives form a sentient understanding of consciousness.

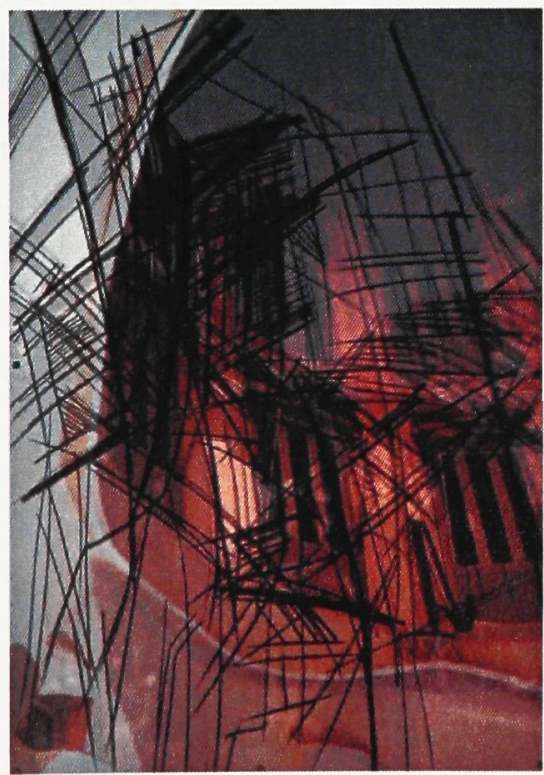

\subsubsection{Drawing \# 56 (Day 12)}

Like the act of moving the limbs or body, gestural definitions of line establish the expressive meaning of the image thought. Like a mirage engagement, homogenous black and a strong inclination for line establish the true relationship between projection, new image and reactionary drawing. 


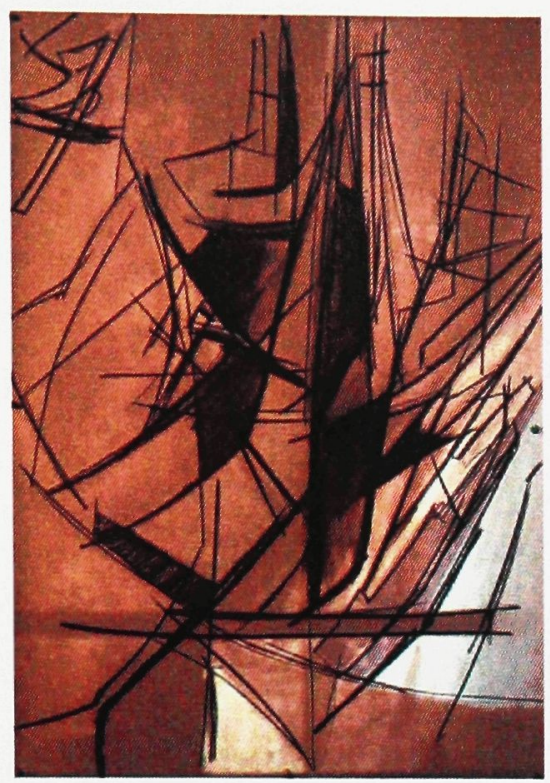

\subsubsection{Drawing \# 57 (Day 12)}

Dialogues between the unascertained and the methodically defined begin to reveal, from this claustrophobic experience, the possibilities of an opening and that of intelligibility. Metaphorically or literally, lines and tone initiate the clarity of the real from the ambiguous illusory. Drawing begins to define the imagination.

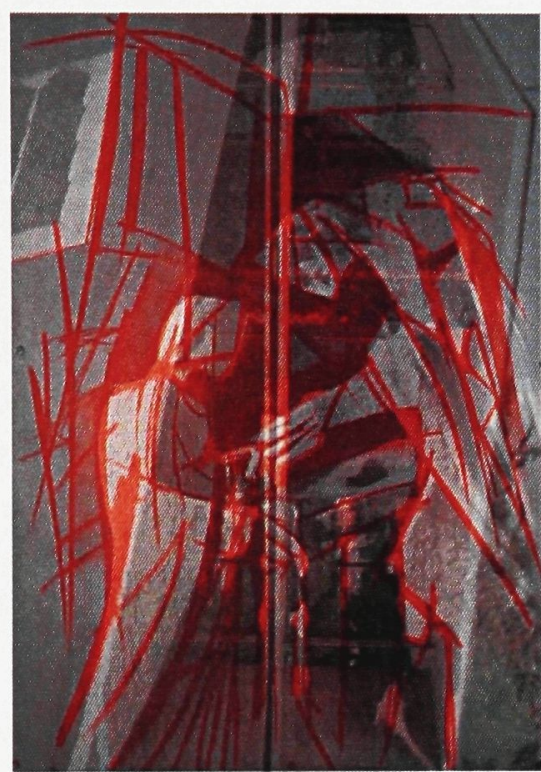

\subsubsection{Drawing \# 58 (Day 12)}

Tone becomes a character of distinct pitch, quality, and duration. Colour, a kind of note that gives cohesion to undecipherable patterns and the recurring alternations of contrasting elements within the original. Red is the tone that gives the convoluted a unity of rhythm through the regular and harmonious patterns created by intervening lines and forms.

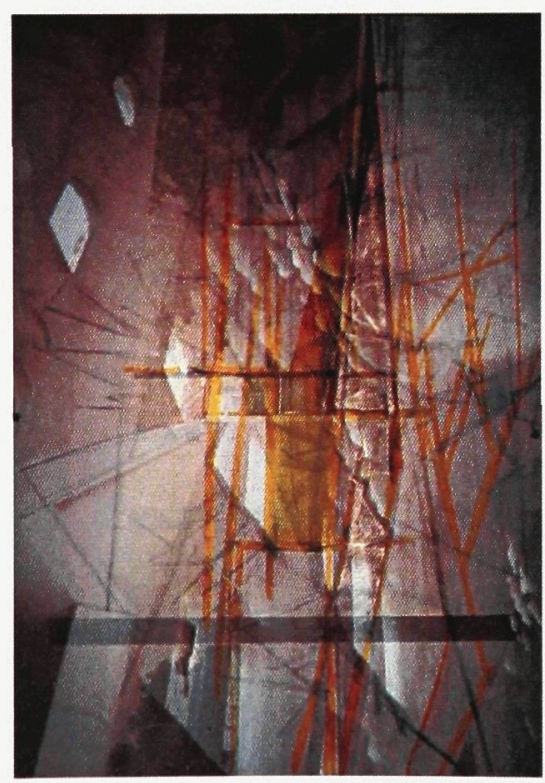

\subsubsection{Drawing \# 59 (Day 12)}

The spectre reveals various apparitions, constantly flowing between the real and the imaginary. Sudden and unusual sights of structure, form and light are in constant and ambiguous flux that even the real of new colour and line are engulfed by the unreal. Space exists only in the moments of perception. 


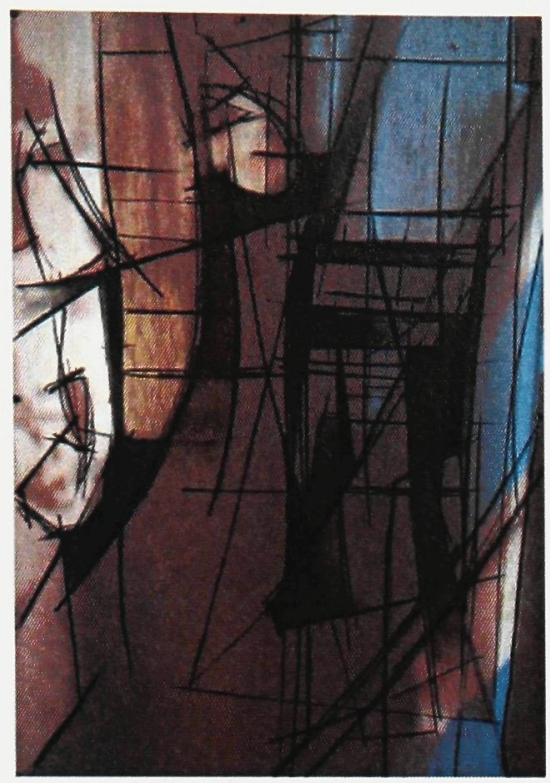

\subsubsection{Drawing \# 60 (Day 12)}

The semantics of the presented sacred is given new and disparate meaning through homogenization. Drawing, specifically the tedious use of black, allows for new fluidic exchanges. Perceived \& deceptive space is no longer seen through its original content, but through the new languages associated with the line and plane.

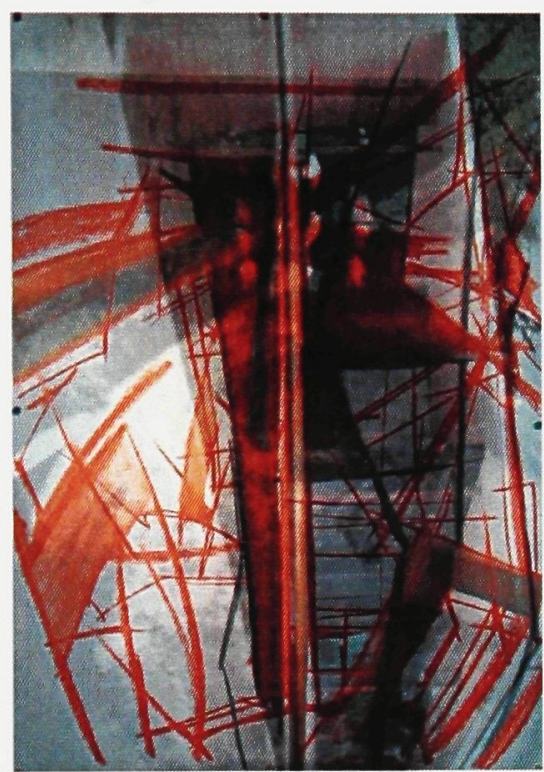

\subsubsection{Drawing \# 62 (Day 13)}

An assemblage of diverse elements creates a collage of conflicting memories: the strong definition of image and the intense definition of orange. Each one, with its intent on hierarchy, somehow unknowingly work in conjuntion, establishing a strong response to drawing.

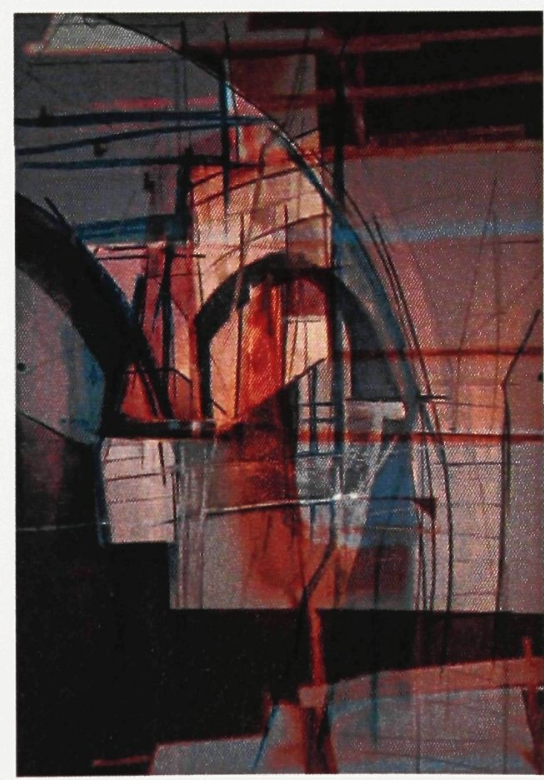

\subsubsection{Drawing \# 63 (Day 13)}

Through the collection of diverse colours, lines, material and image; the possibilities for new moments are now revealing themselves; places in which each element is no longer graded or ranked. The hierarchy of values from the drawing or images is now irrelevant as spaces defines itself by the appropriation of both. 


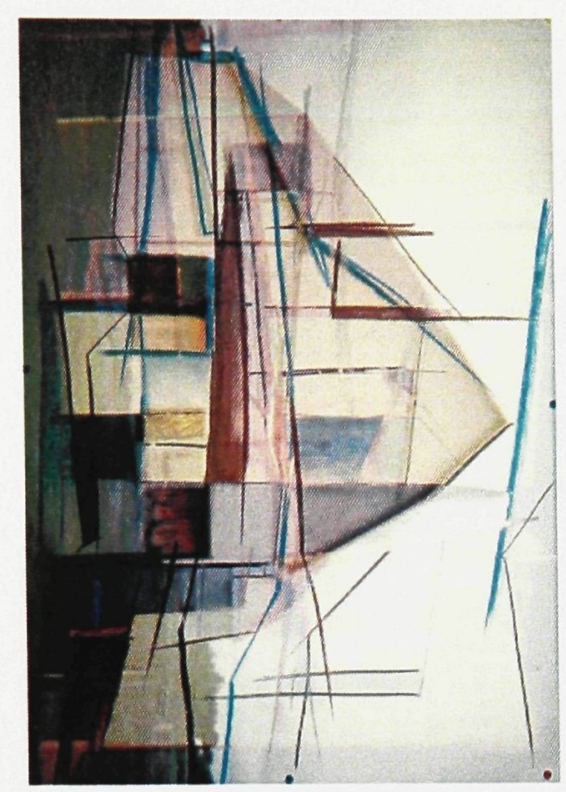

\subsubsection{Drawing \# 64 (Day 13)}

Drawing defines itself by its perceived presence under the circumstances of a specified place. Lessening our perception of an understood condition; colour and volumetric conditions draw out an 'other' that is hazy and indistinct to sight and mind.

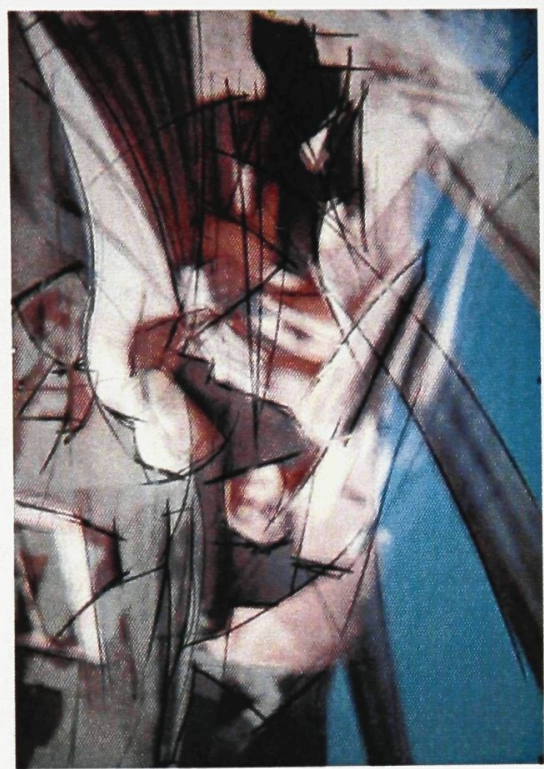

4.1.53 Drawing \# 65 (Day 13) 


\section{2}

\section{Phase 2: First Revelation As Chalk Drawings}

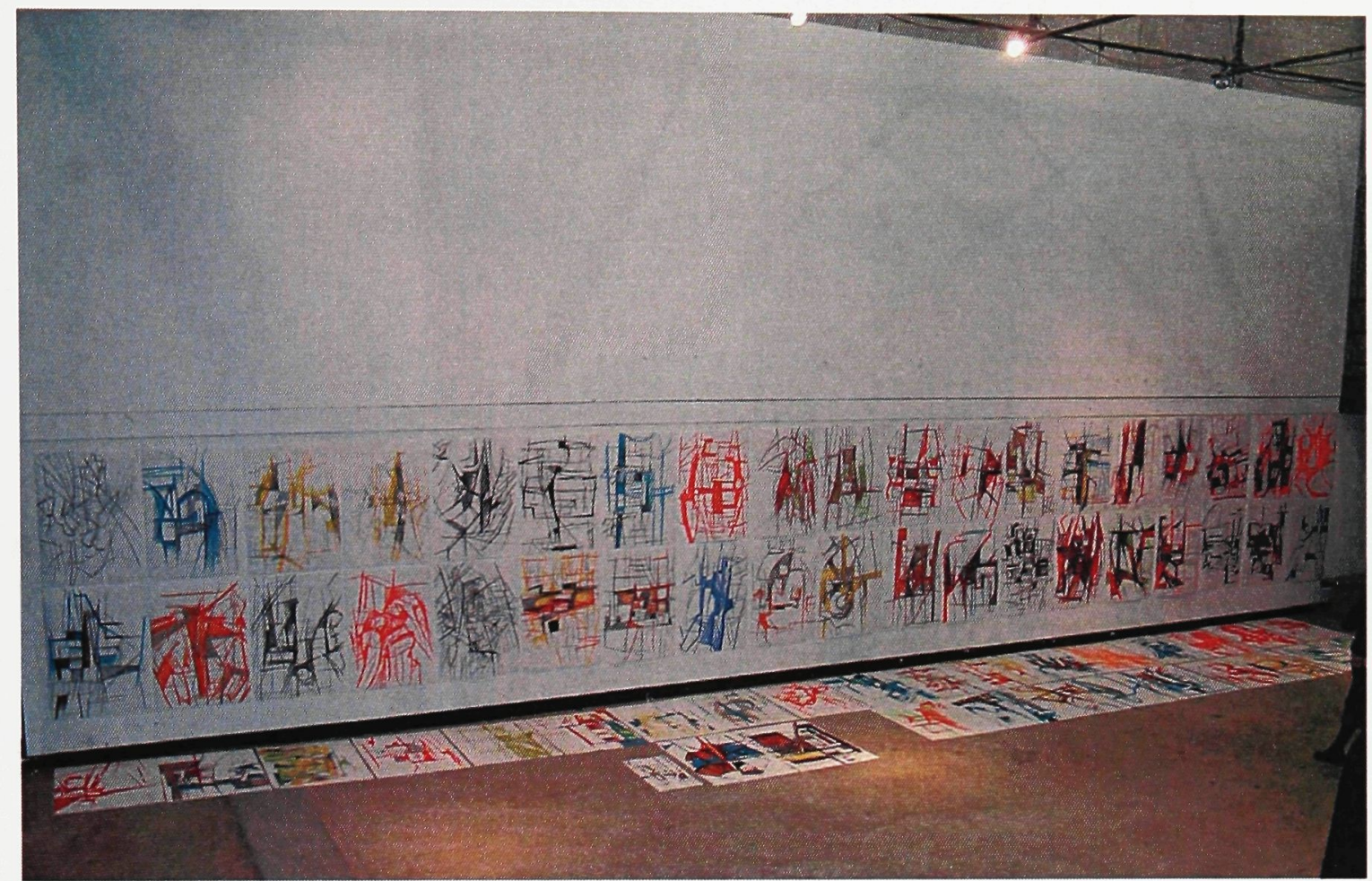

4.2.1 Chalk Drawings (Displayed as Series)

After the completion of this phase of the project, the drawings were pinned up sequentially in order to read any patterns or disjunctions of thought that the images revealed. By understanding the drawings in a larger context, issues that may not have been revealed during the process of making became clear.

In the absence of the original projections, the drawings begin to reveal new relationships between apparent structure and surface plane associations. The drawings also begin to reveal the patterns associated with the actual making of the drawings, as certain clustered sections begin to express the days in which particular strategies may have been employed, including: colour selections, their homogenization, gestured moves, hierarchal choices and the intensity of the drawings themselves.

Each approach had some drawings that were more successful than 


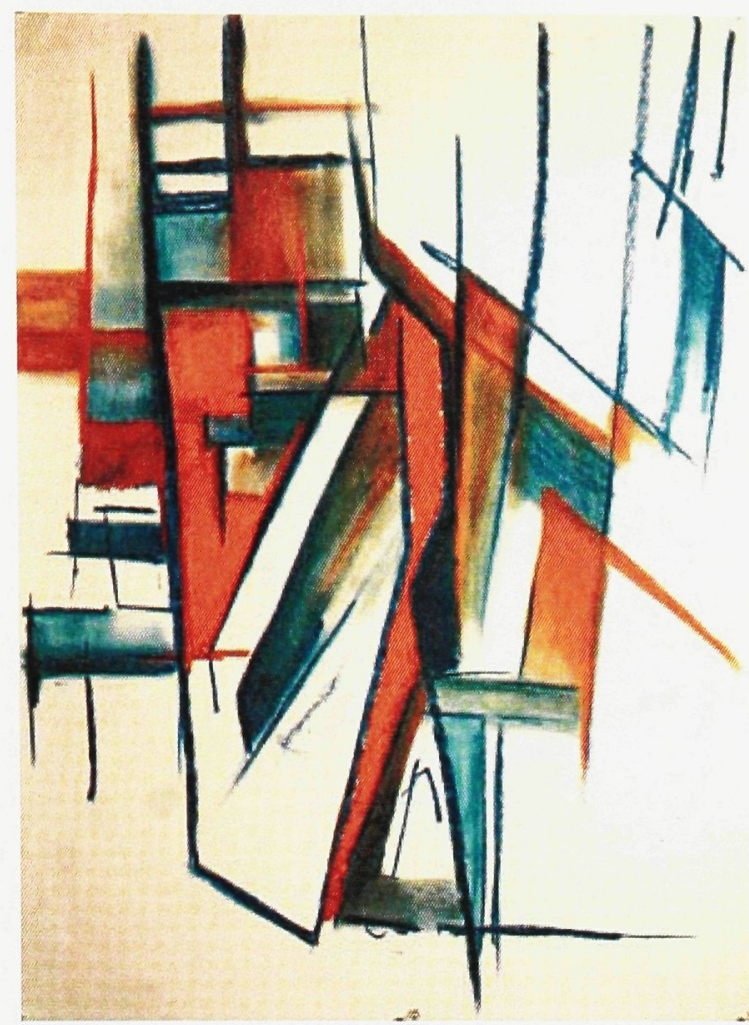

4.2.2 Chalk Drawing Example 1

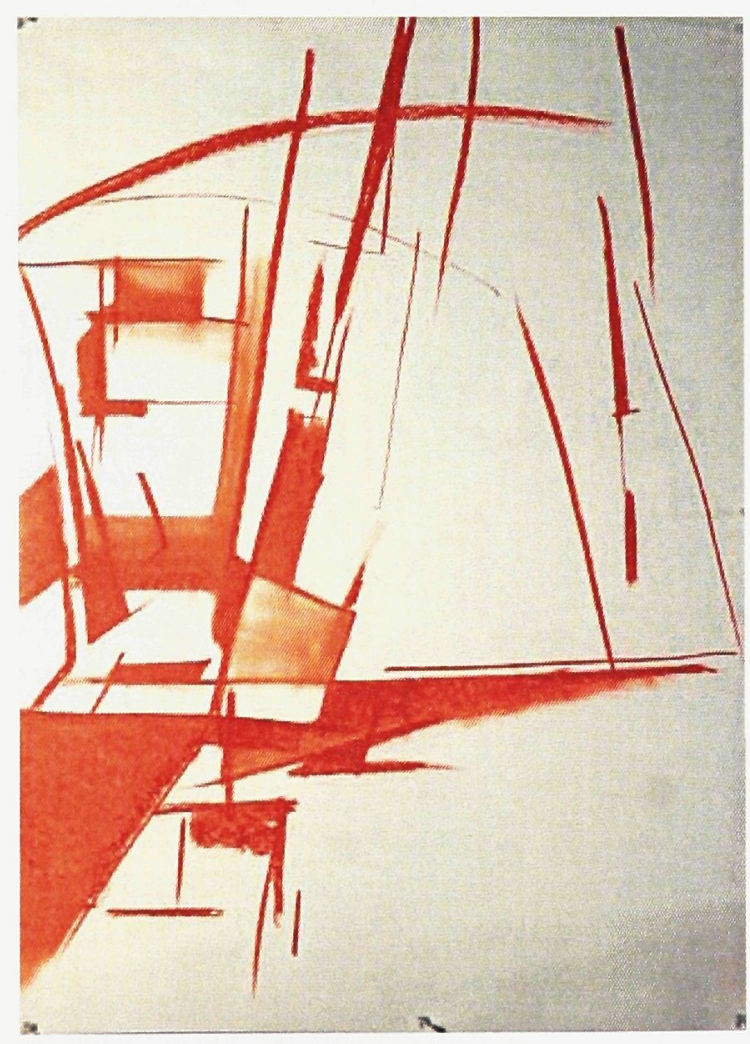

4.2.3 Chalk Drawing Example 2

others, based on our immediate perception and an inherent condition with this mode of development. It is this realization of simultaneous success, failure, chance and strategy that allows the drawings to participate in "imagining" architecture as their fluctuation prevents them from referencing solely any specifics.

The next phase of the project took these drawings to a natural next step and drew out basic geometries. As discussed earlier, each drawing phase is strategically established to explore certain intentions, yet always allowing them the possibility of revealing something other that may not have already been predicted. By developing the geometries of the drawings in the next phase, they could begin to move beyond the purely gestural to the beginnings of an architectural proposition. 


\section{Phase 3: Second Revelation as "Lavered" Drawings}

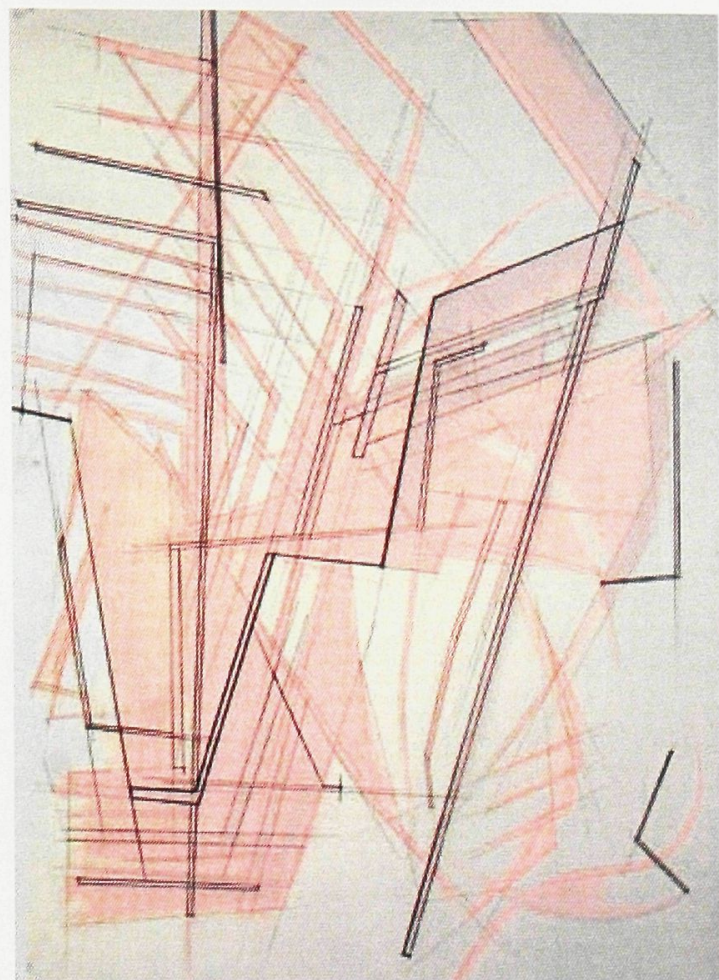

4.2.4 Layered Drawing Example 1

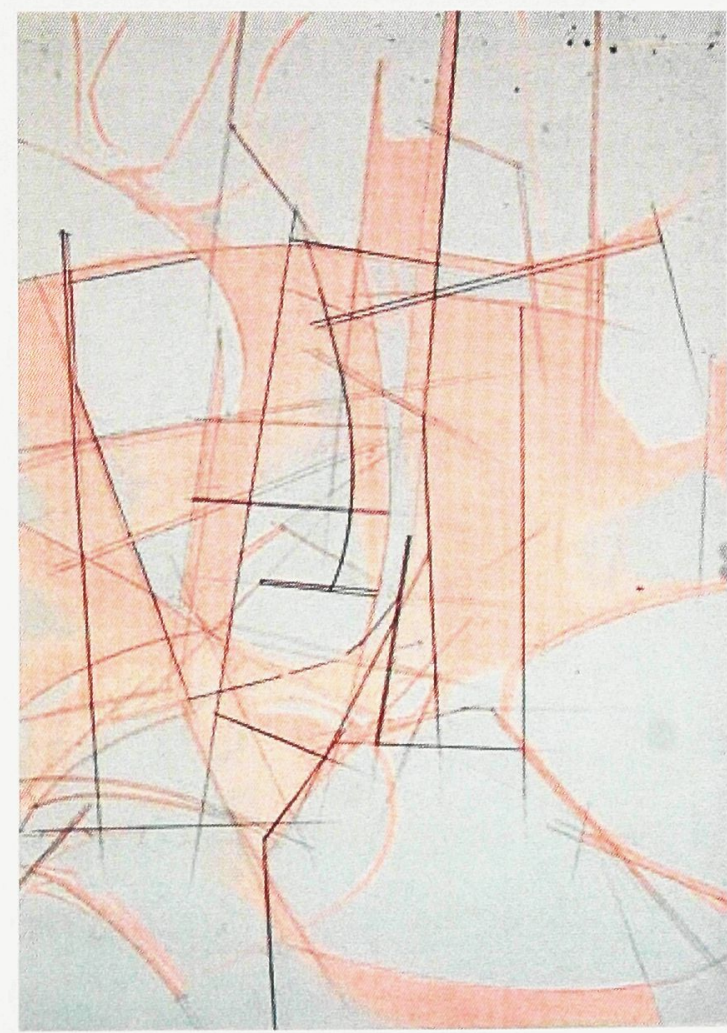

4.2.5 Layered Drawing Example 2
In order to clarify inherent geometries, all drawings from phase I were scaled down from 36 " x 24 " using digital reproduction. Similar to the first phase of the project, where the projected images provided a reference for the chalk drawings, here the newly scaled down images provided the reference point for new hardline, graphite drawings. Again the palimpsest metaphor continued, as an equally sized 11 " $\times 17$ " sheet of vellum was placed over the newly printed reductions, and the process began again. The strategy for this phase was not only to draw out apparent geometries but to set up a natural relationship between the graphite line interventions and the coloured chalk drawings which guided their making. This allowed the new drawing to exist, as both in a relationship to its navigator, but also to reveal itself again as something other. Each drawing was filed away on completion until all drawings in the series were completed.

In order to maintain consistency and to prevent any subjective and predetermined 
conceptions as to their selection, each new drawing was developed in the same order set out by the original projected drawings.

These newly layered drawings begin to reveal a spatial relationship between graphite line and coloured chalk. Unlike the phase one images, these drawings began to establish a clearer rapport between foreground and background as depth revealed itself between the two distinct, yet related processes.

\section{Phase 4: Third Revelation as "Line" Drawings}

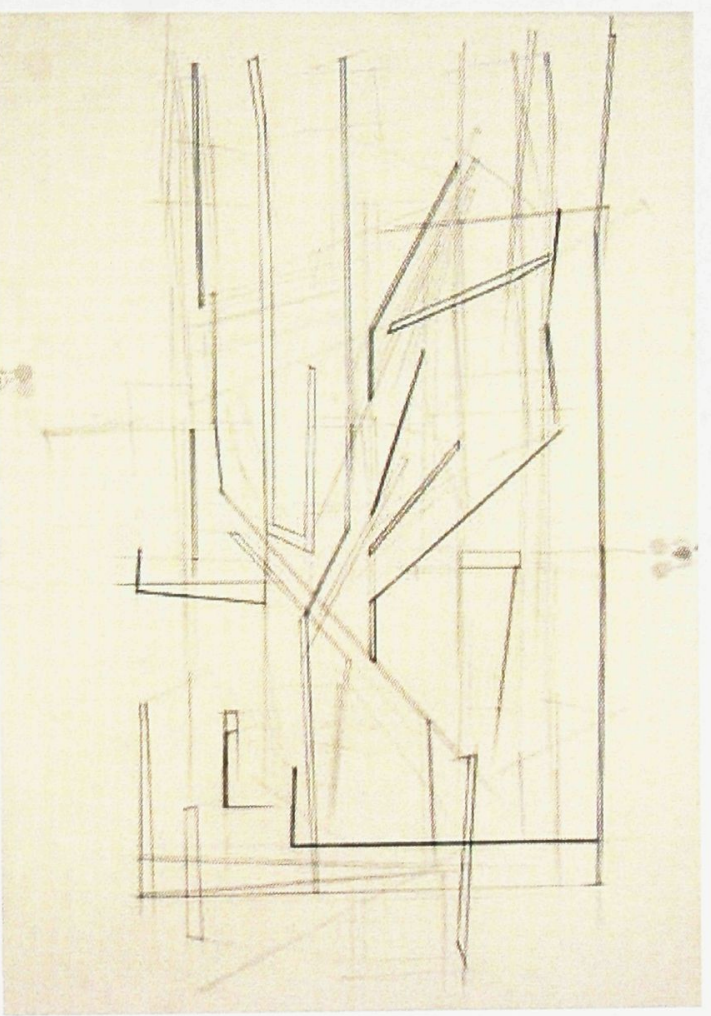

4.2.6 Line Drawing Example 1
The line drawings began to expose themselves in a manner more affiliated with traditional architectural drawings; representing geometric relationships. What was revealed by analyzing the entire phase as a whole were consistent patterns of overlapping lines and planes. This suggests a strategy that could be employed in the future development of the project. Formal elements were clearly defined and established, yet their directional projections suggested a recognition of their existence beyond their structured end.

This begins to imply a possible metaphorical depth that can be transformed into a formal strategy of layering the architectural program through the layering of tectonic elements. The natural extension would be then to overlay these line drawings together in order to rigorously explore the potentials for this new tectonic evolution. 


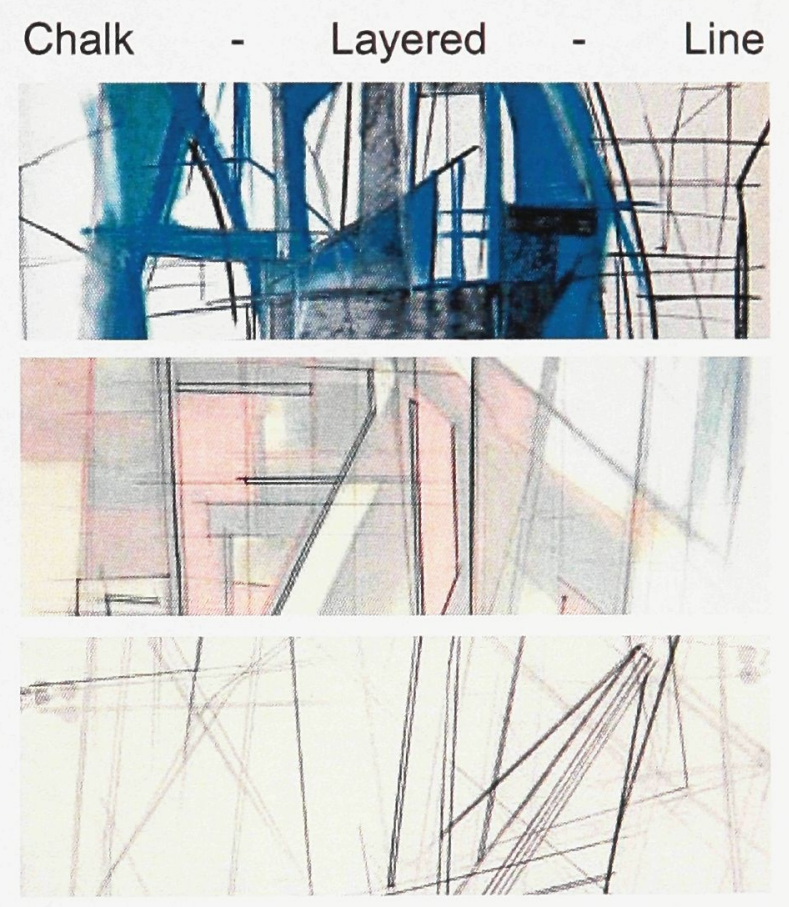



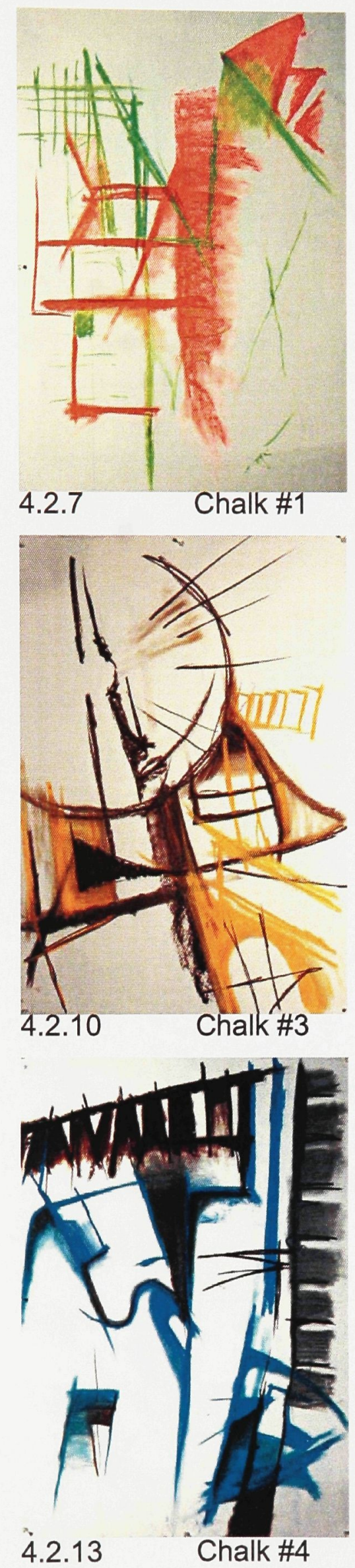
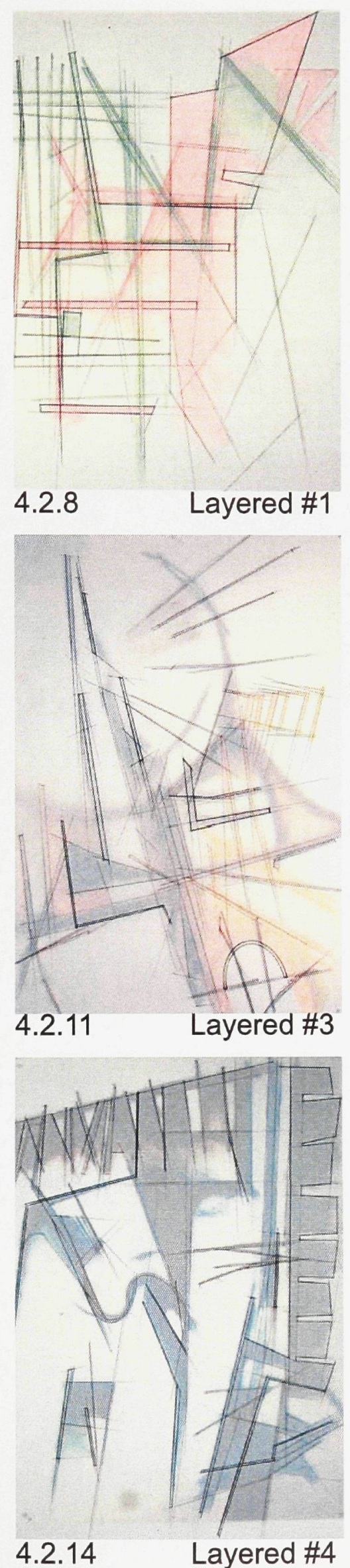
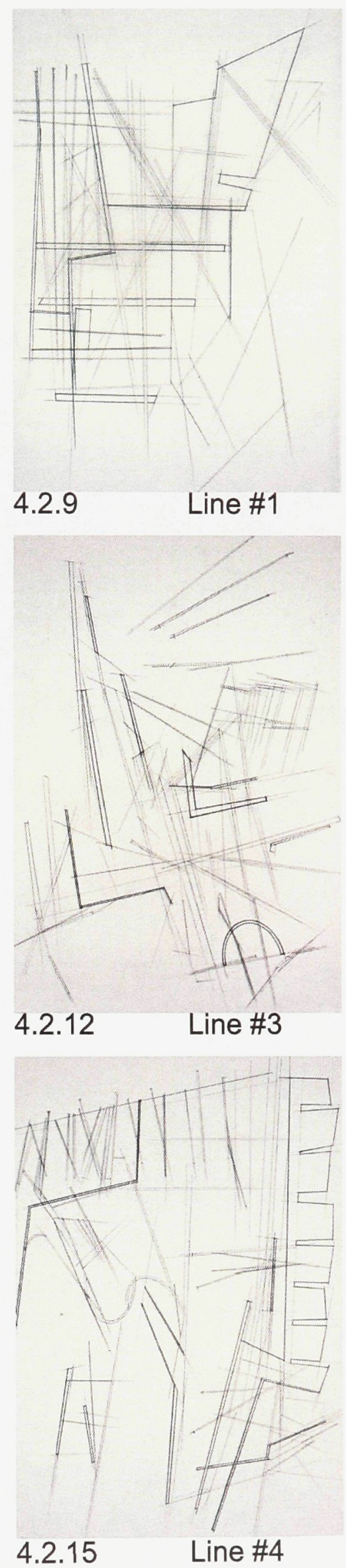


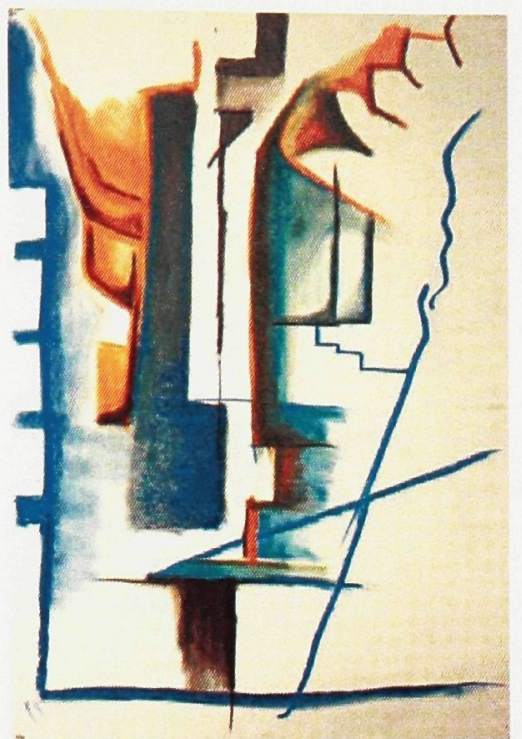

4.2.16

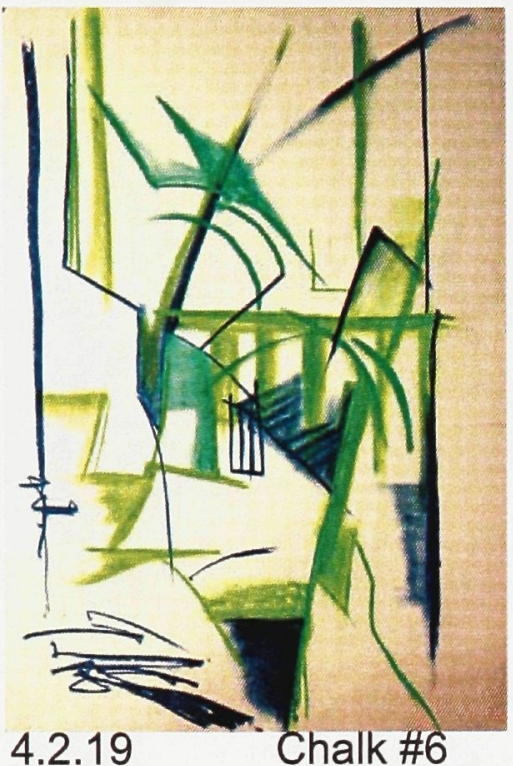

4.2.19 Chalk \#6

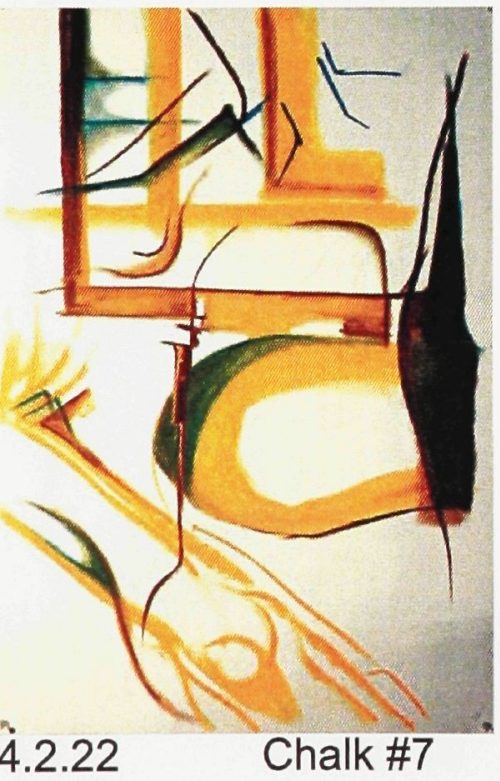

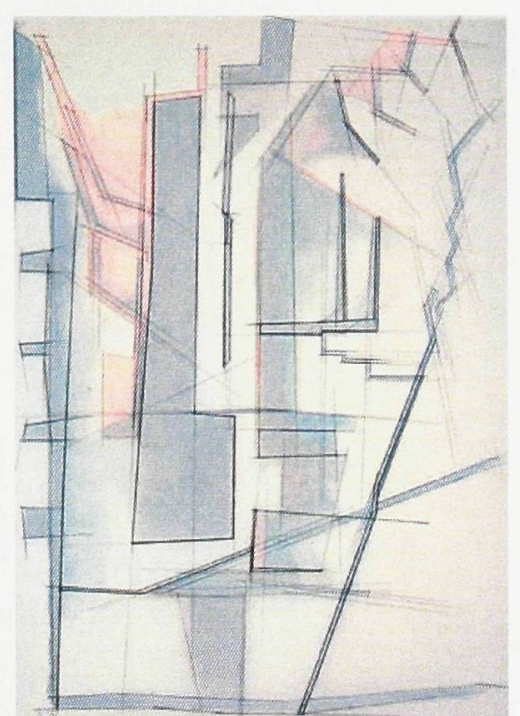
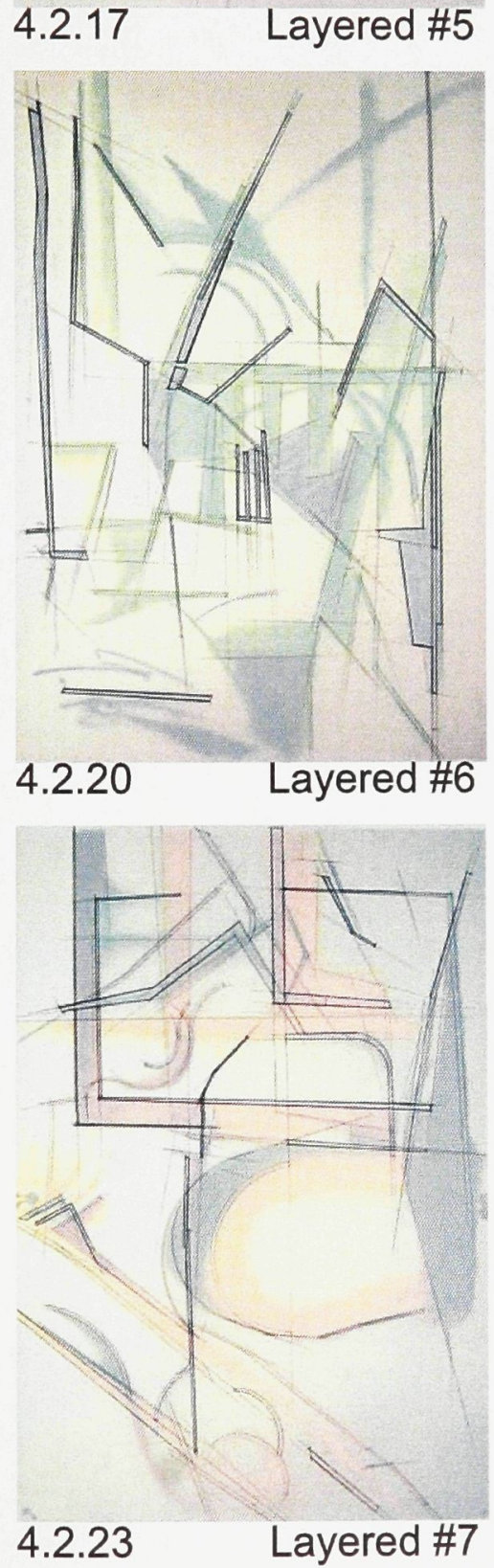

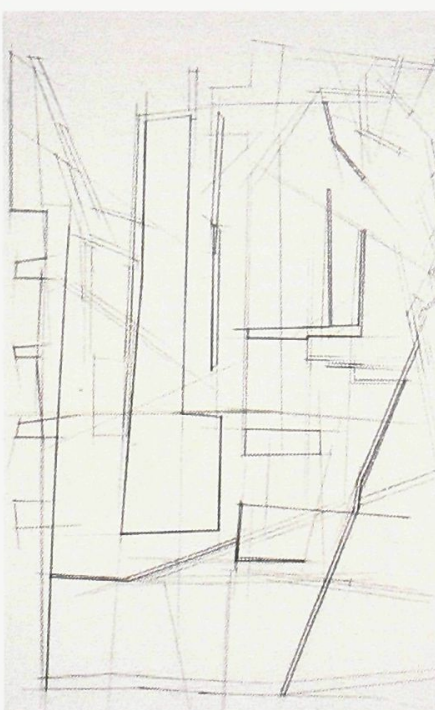

4.2.18 Line \#5

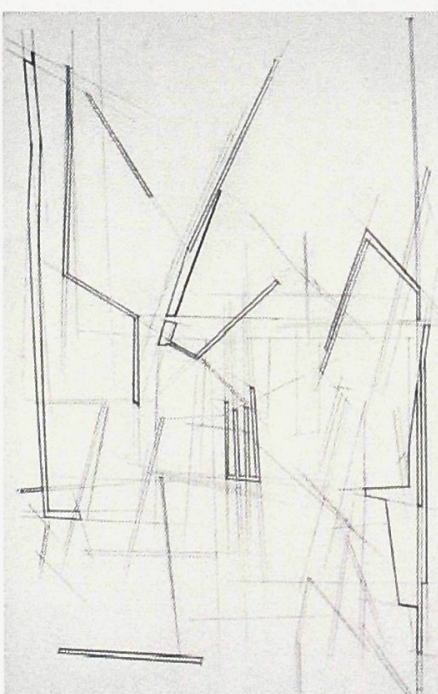

4.2.21 Line \#6

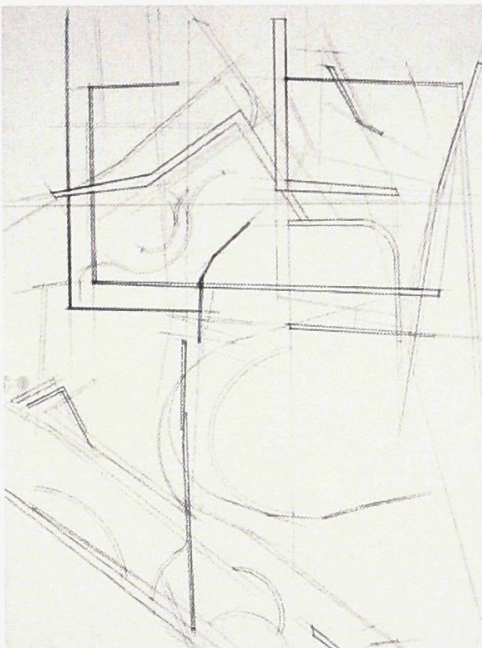

4.2.24 Line \#7 

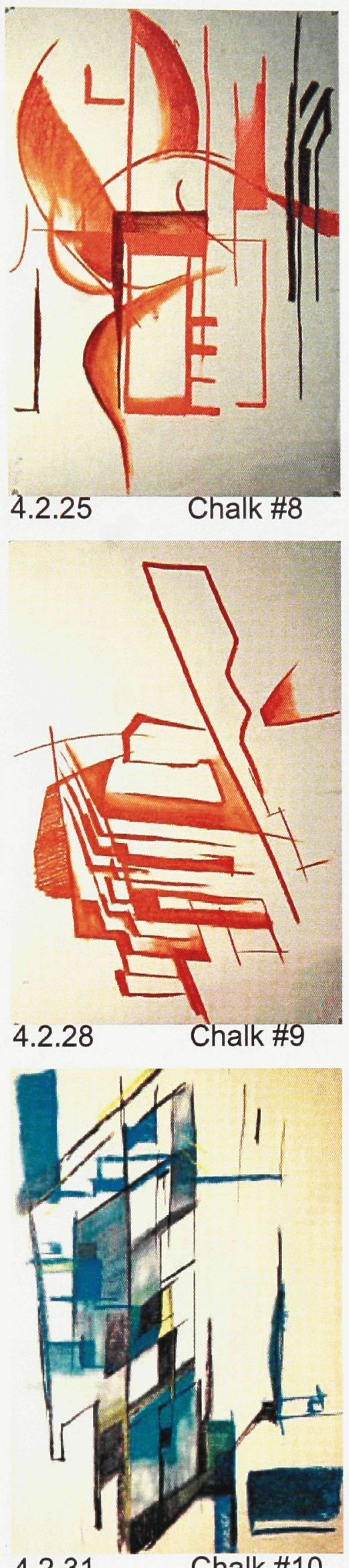

4.2.31
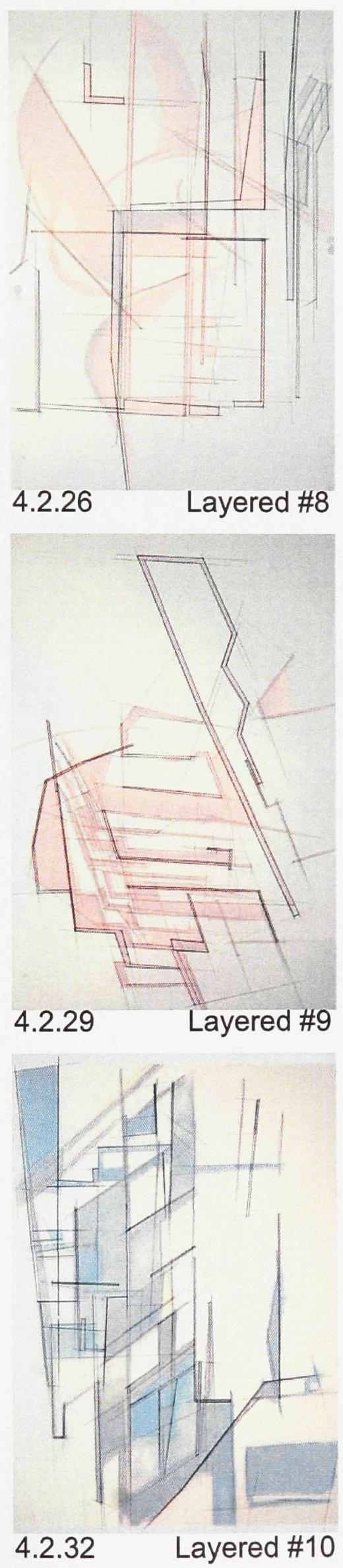
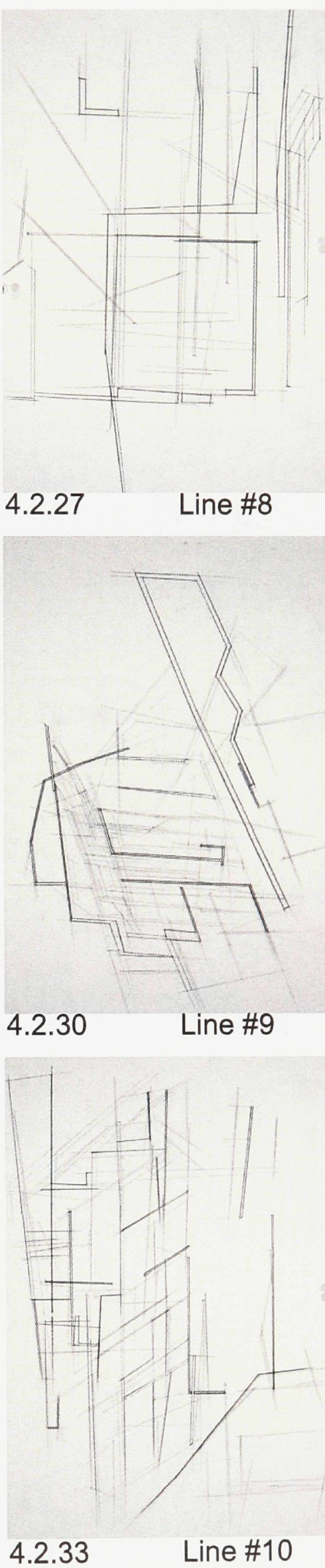

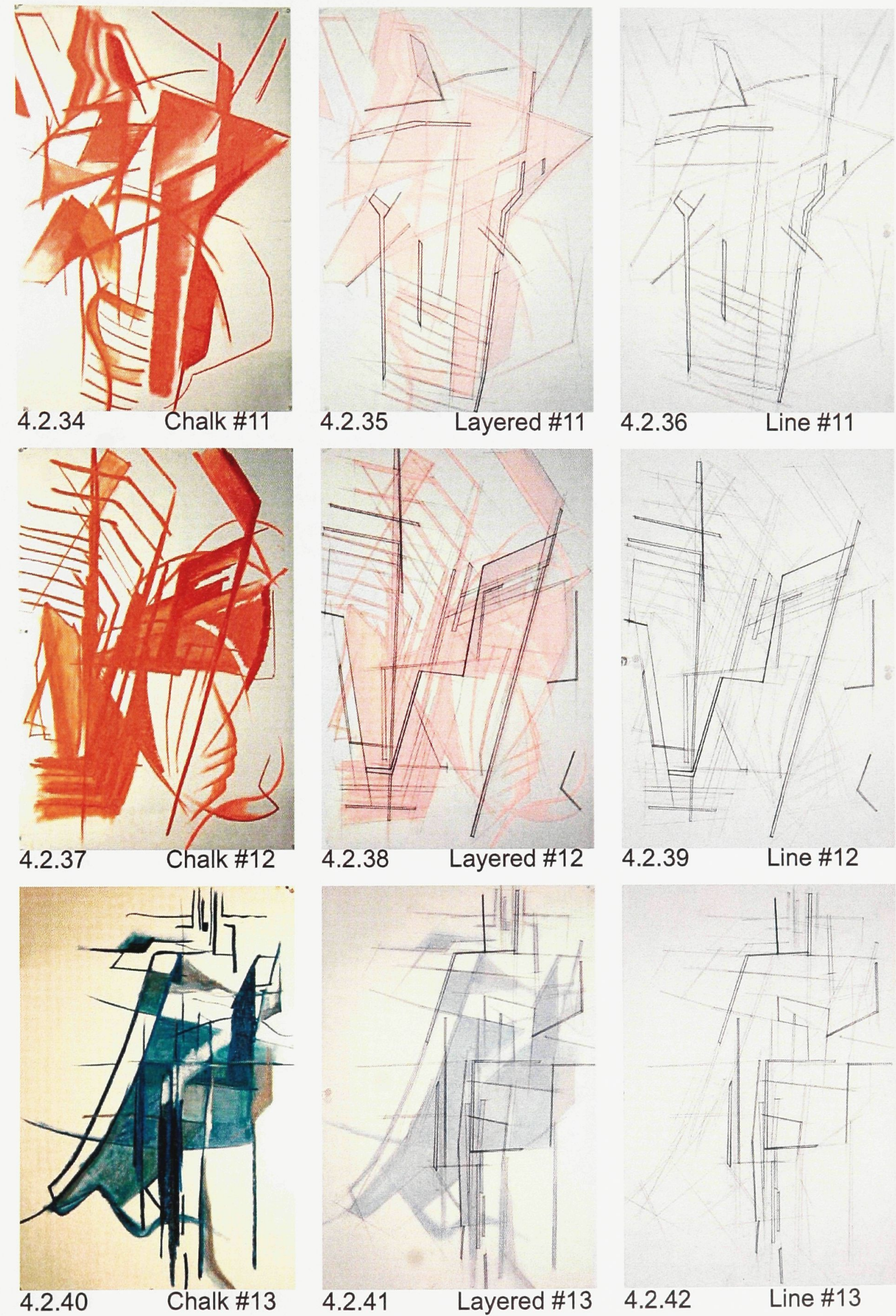

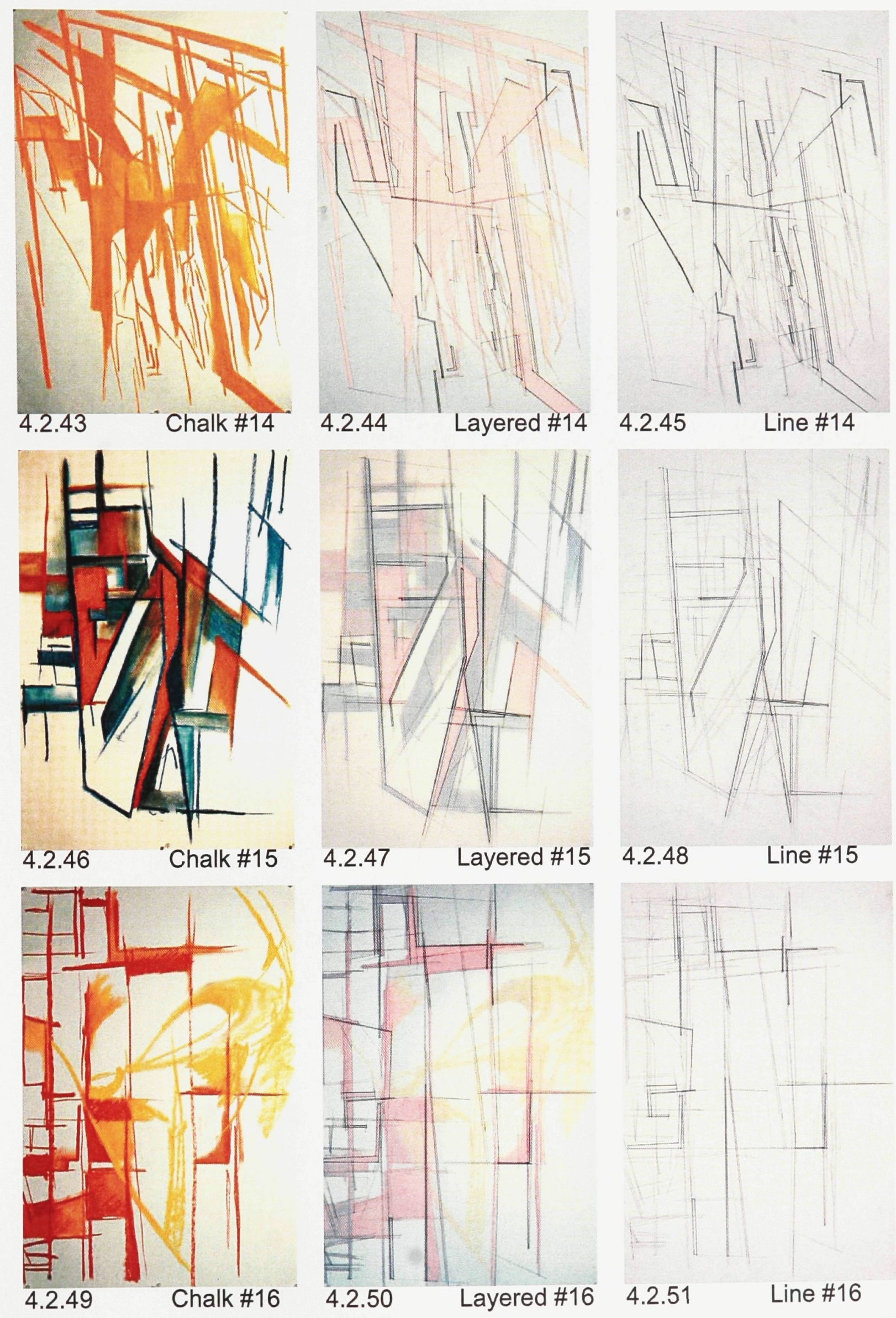

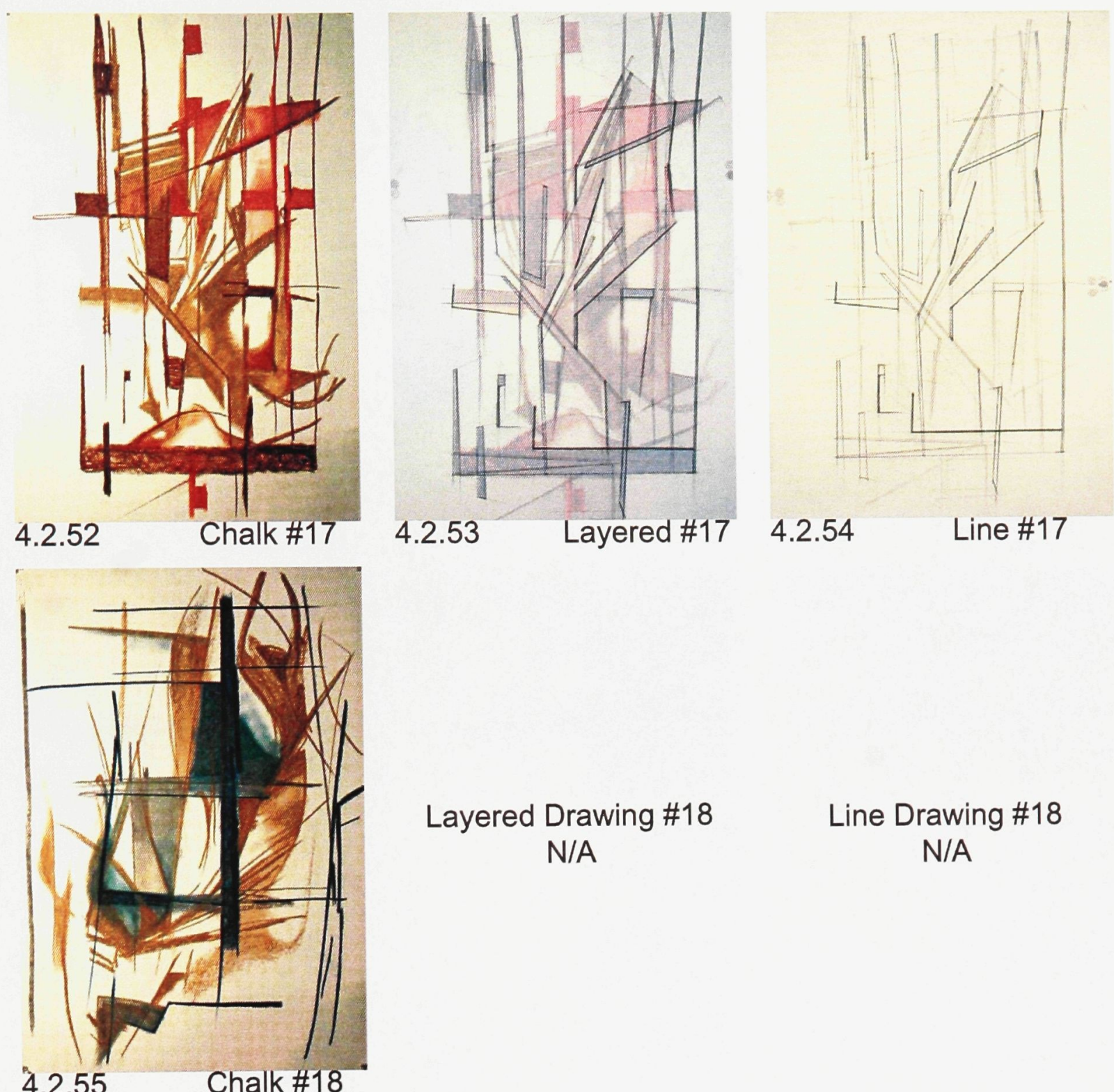
Layered Drawing \#18 N/A
Line Drawing \#18 N/A

\section{Layered Drawing \#19} N/A

\section{Line Drawing \#19} N/A 

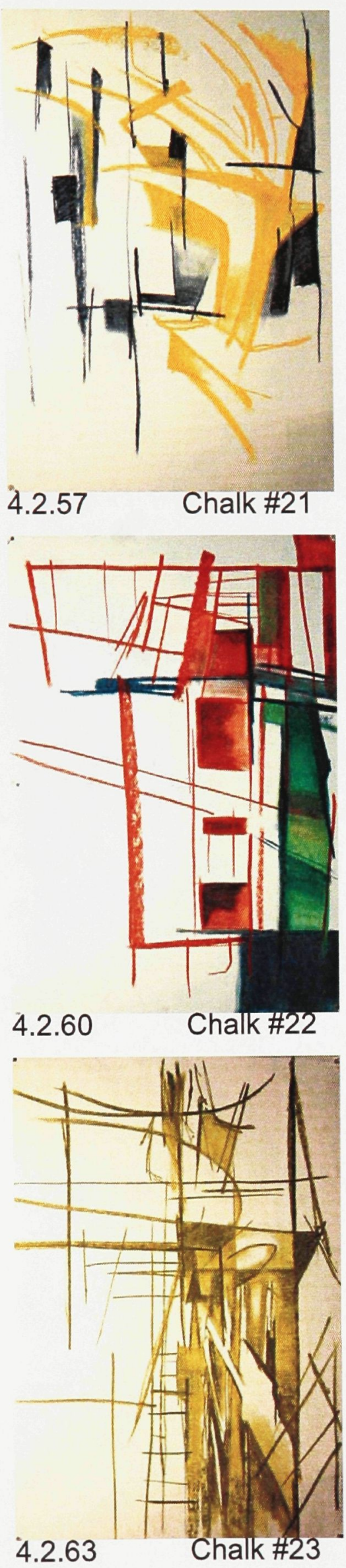
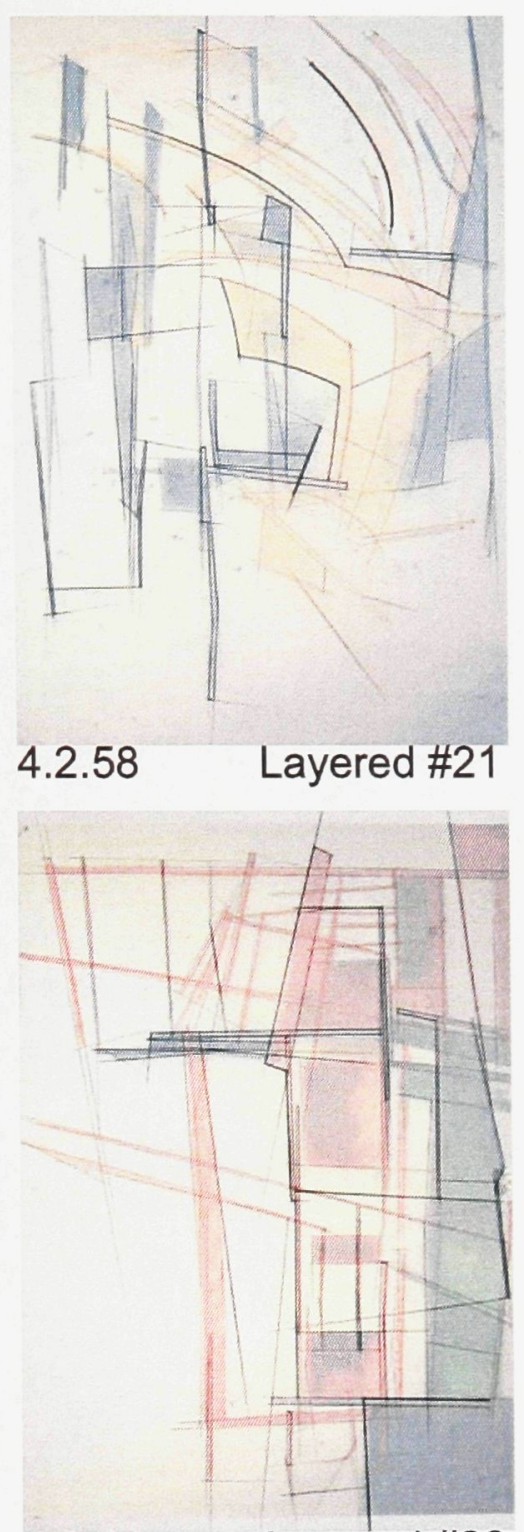

\subsubsection{1}

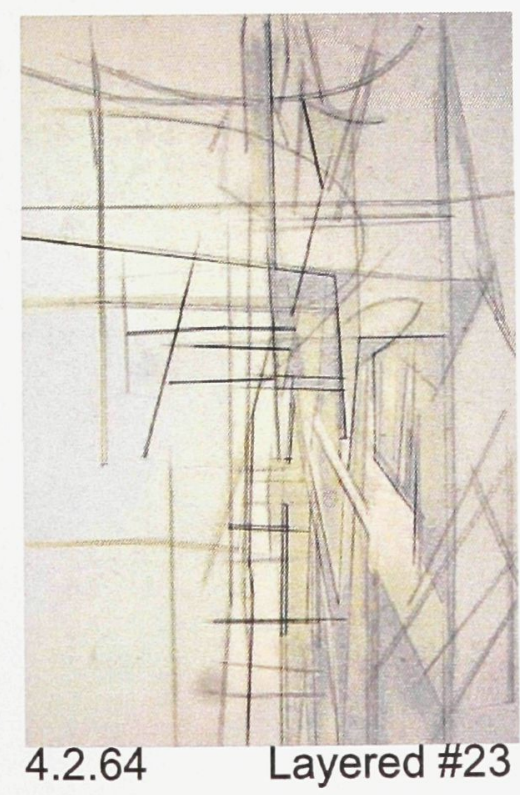

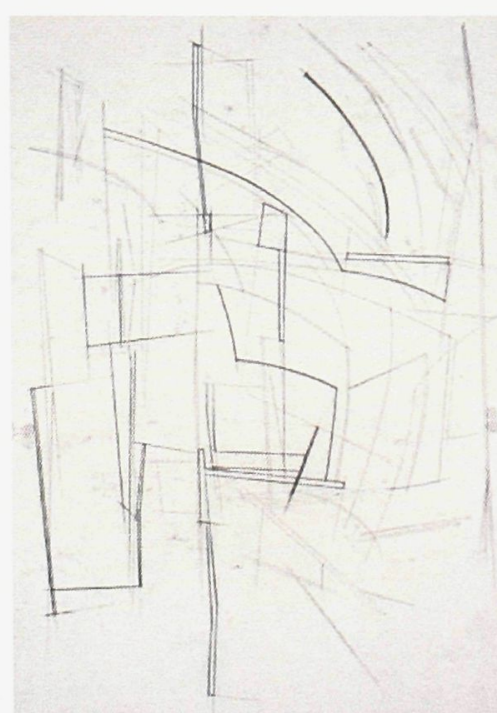
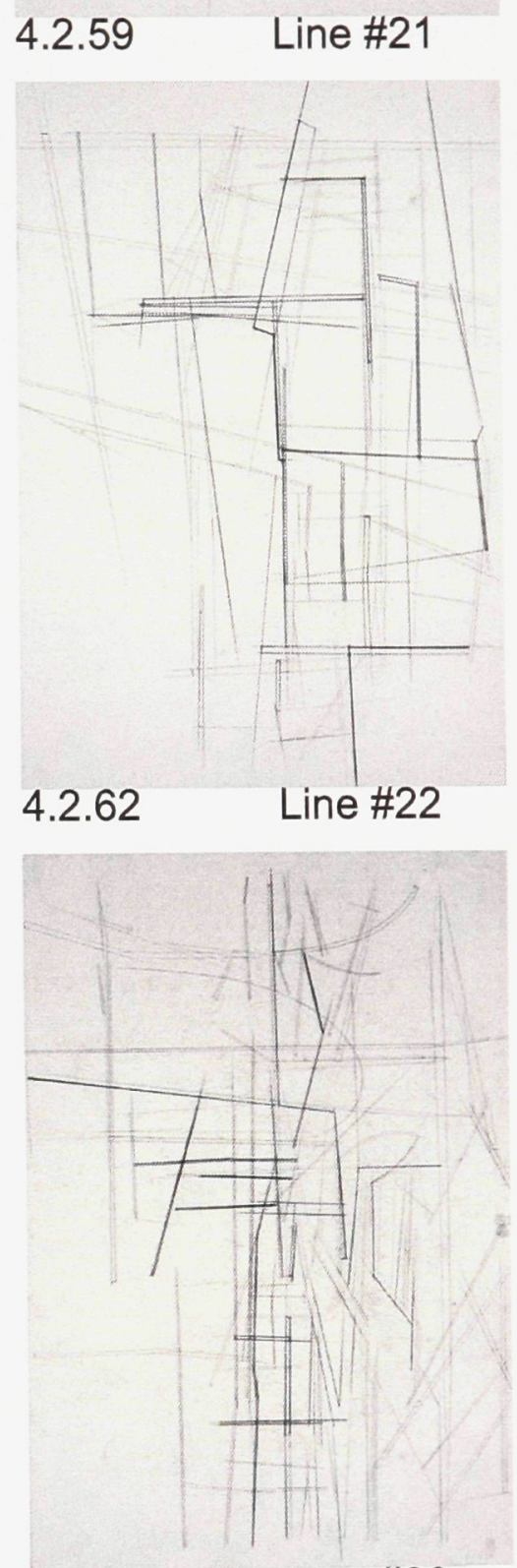

4.2.65 Line \#23 


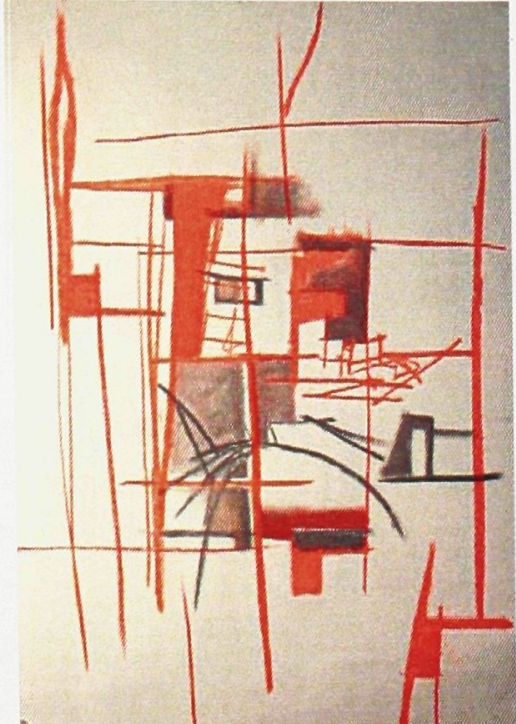

4.2 .66
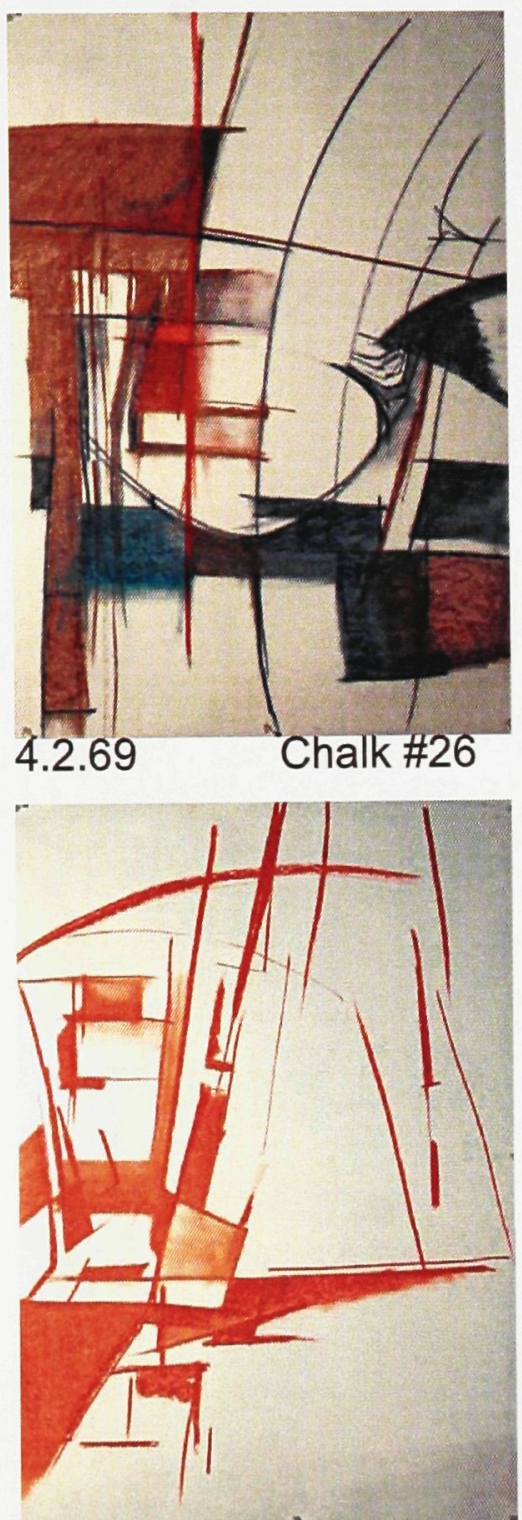

4.2.70 Čnalk \#27
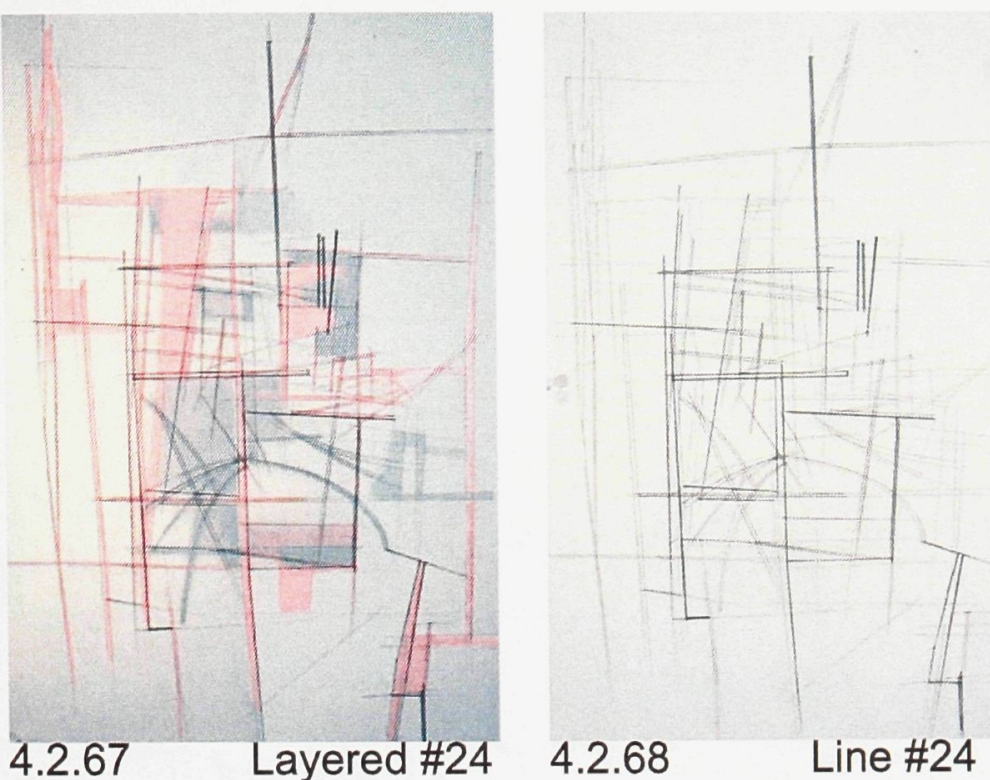

Layered Drawing \#26 N/A

Line Drawing \#26 N/A

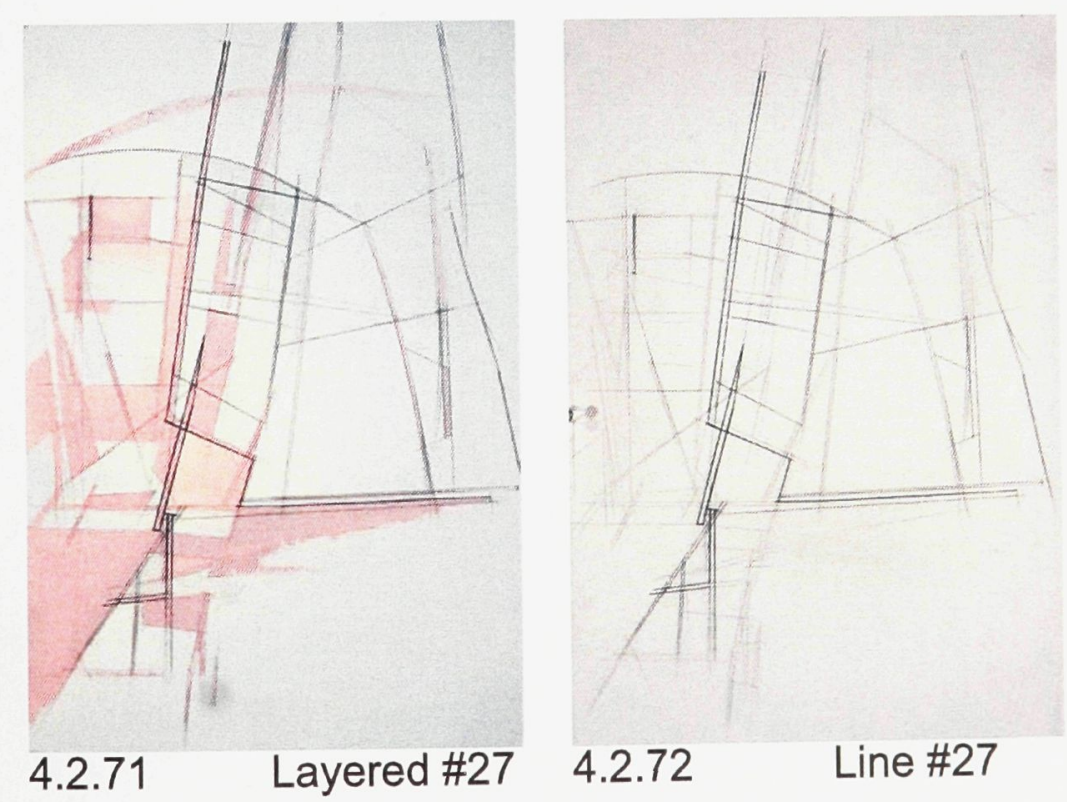



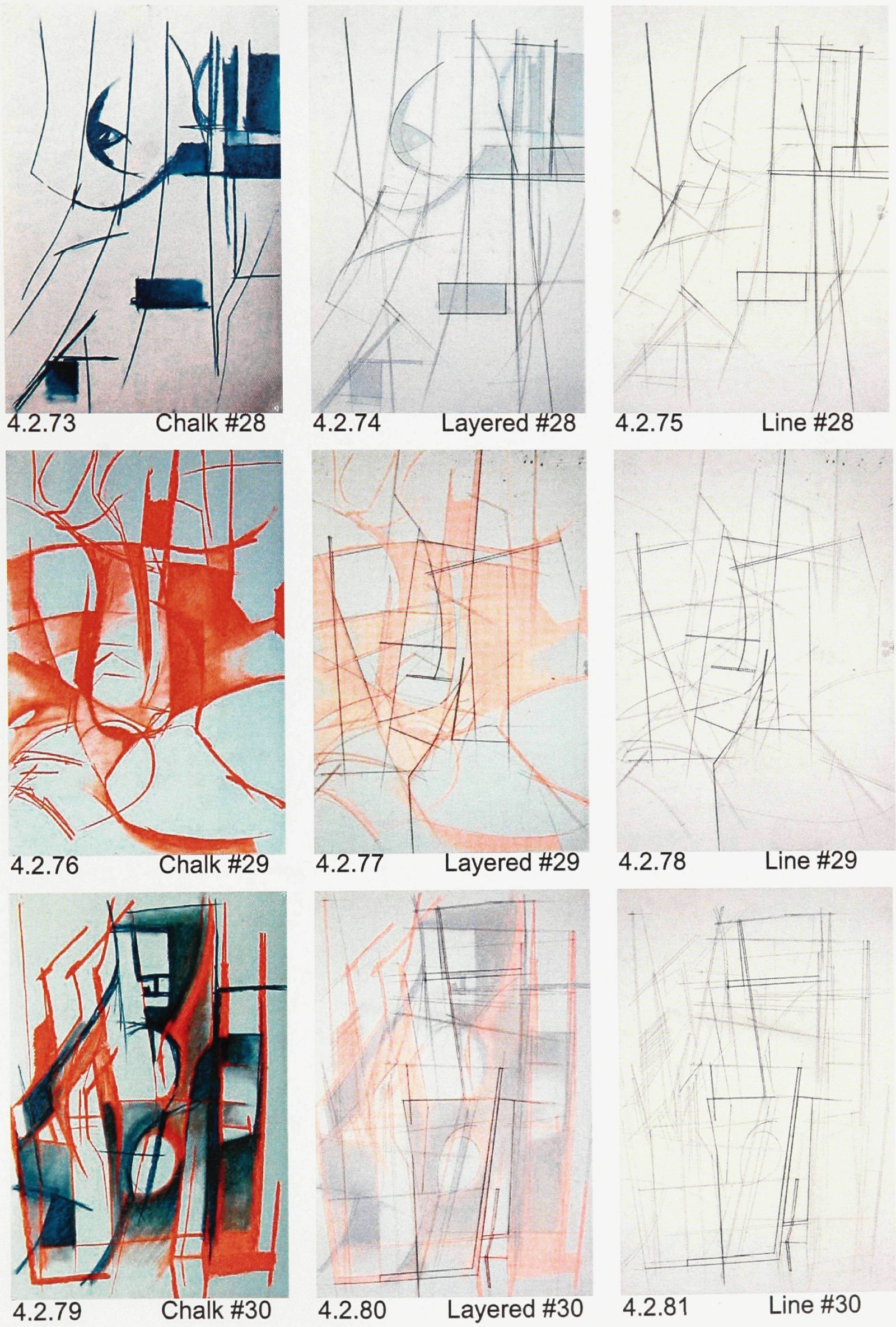


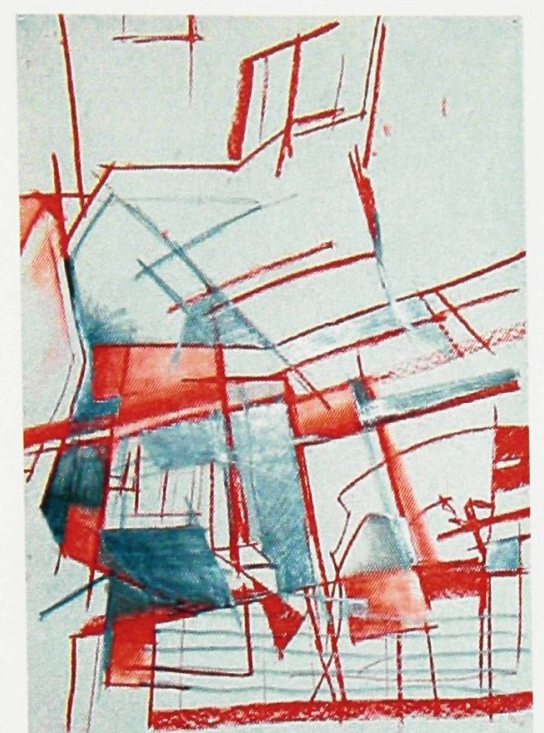

4.2 .82

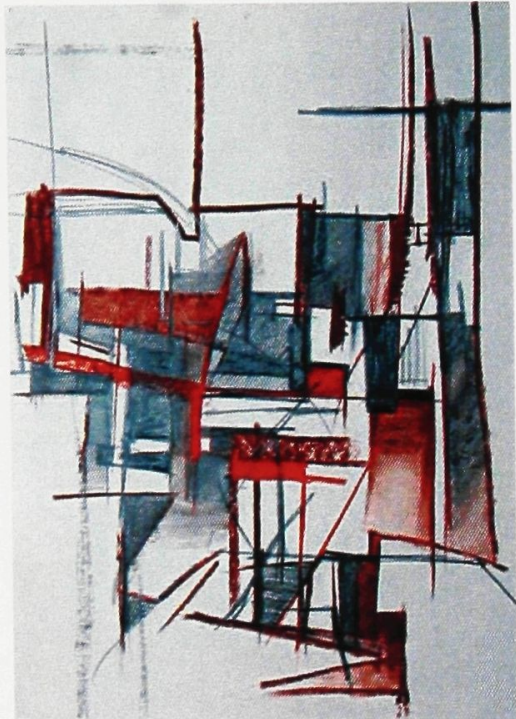

4.2.85 Chalk \#32

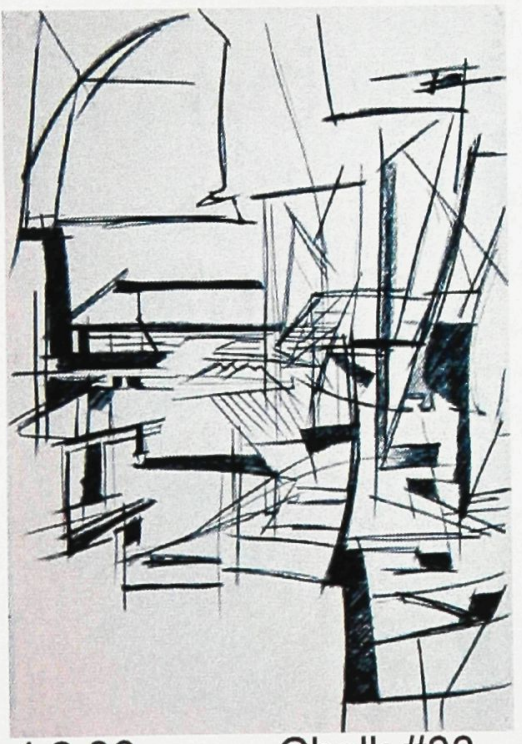

4.2 .86
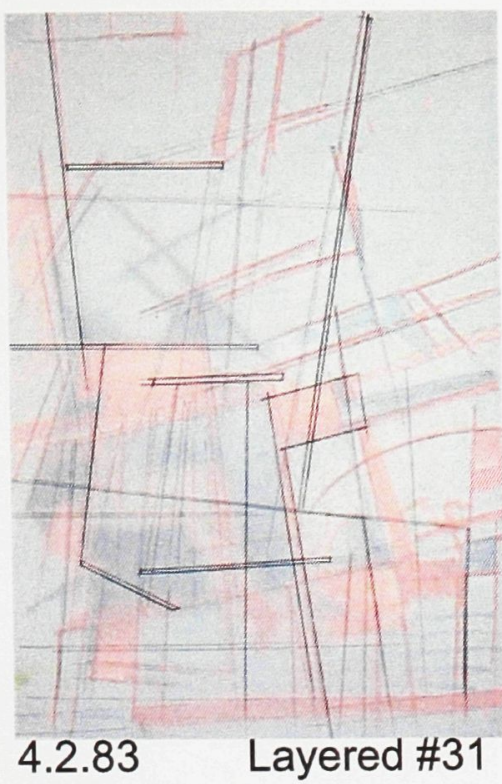

Layered Drawing \#32 N/A

Line Drawing \#32

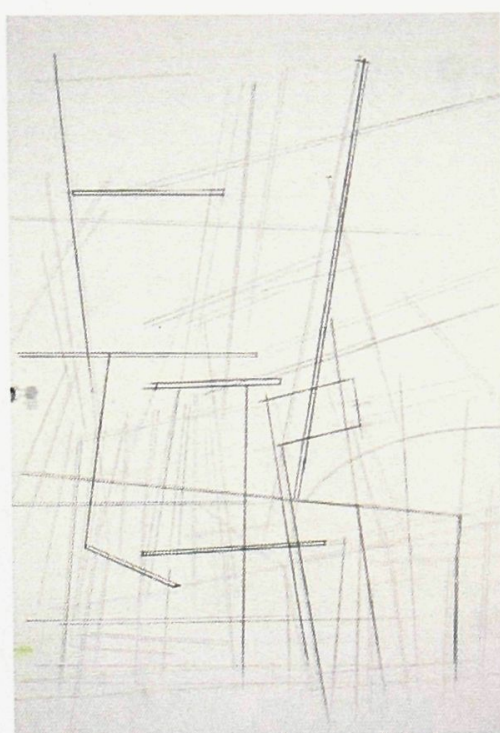

4.2.84 Line \#31

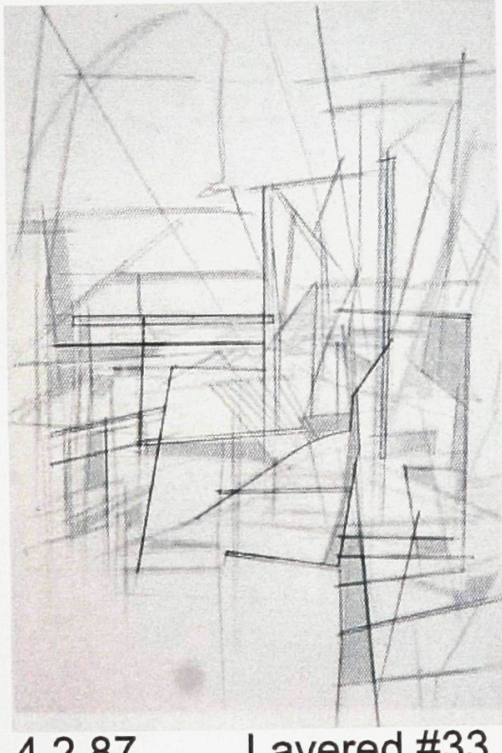

4.2 .87
N/A

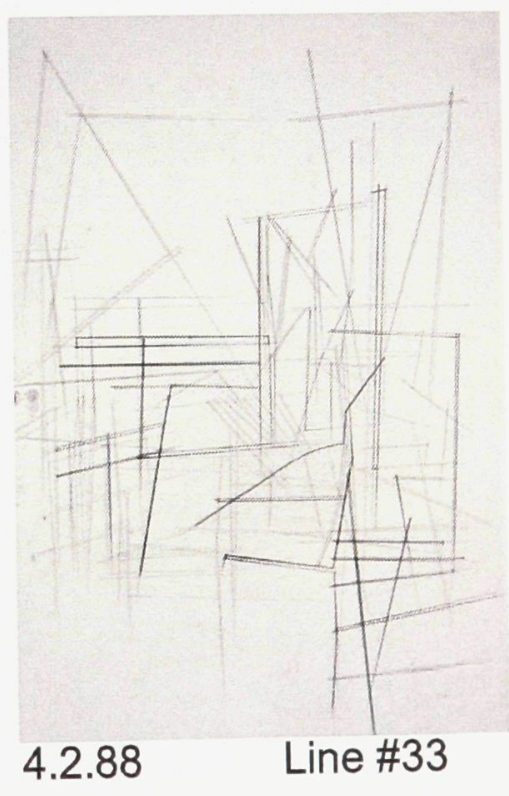



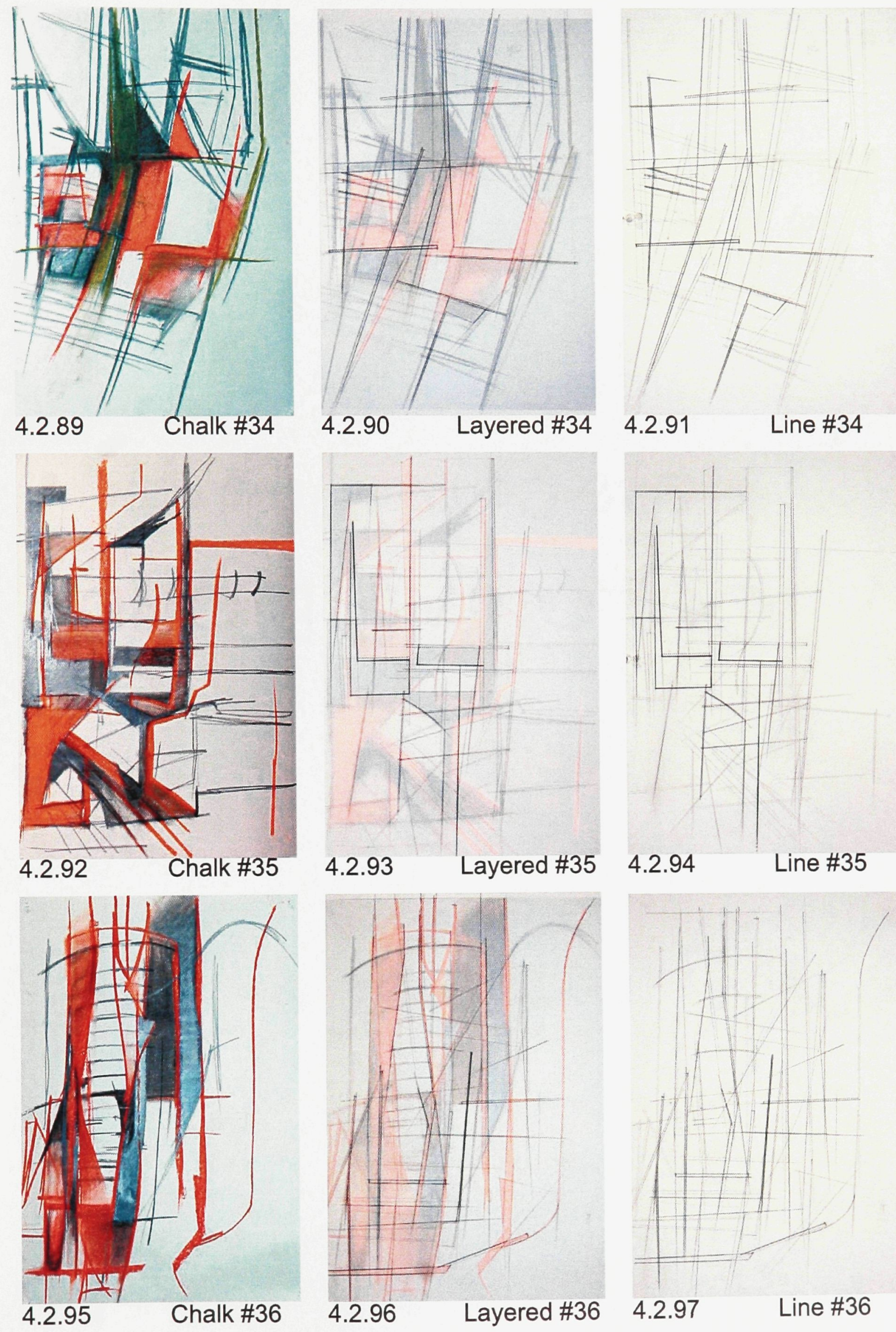

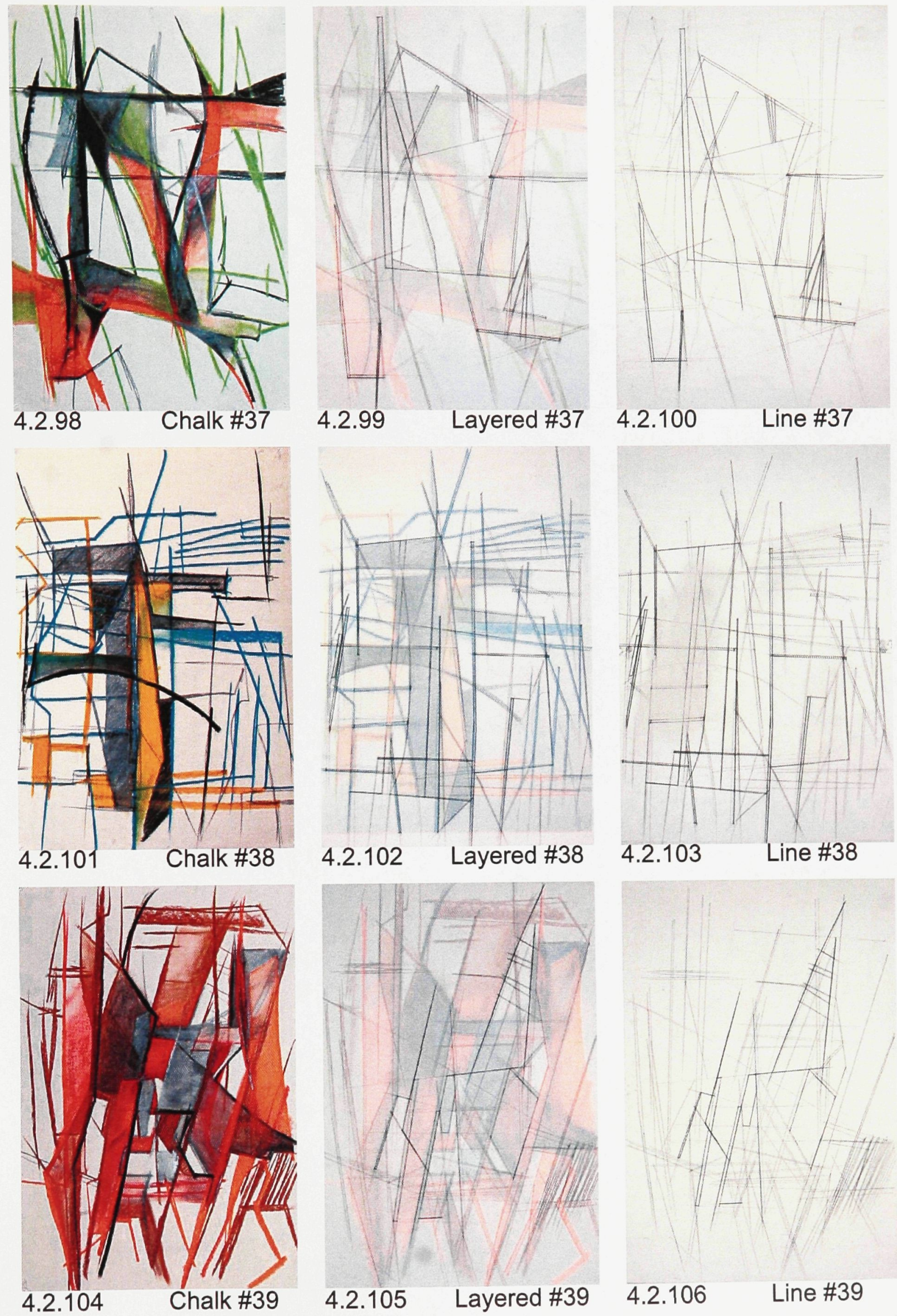

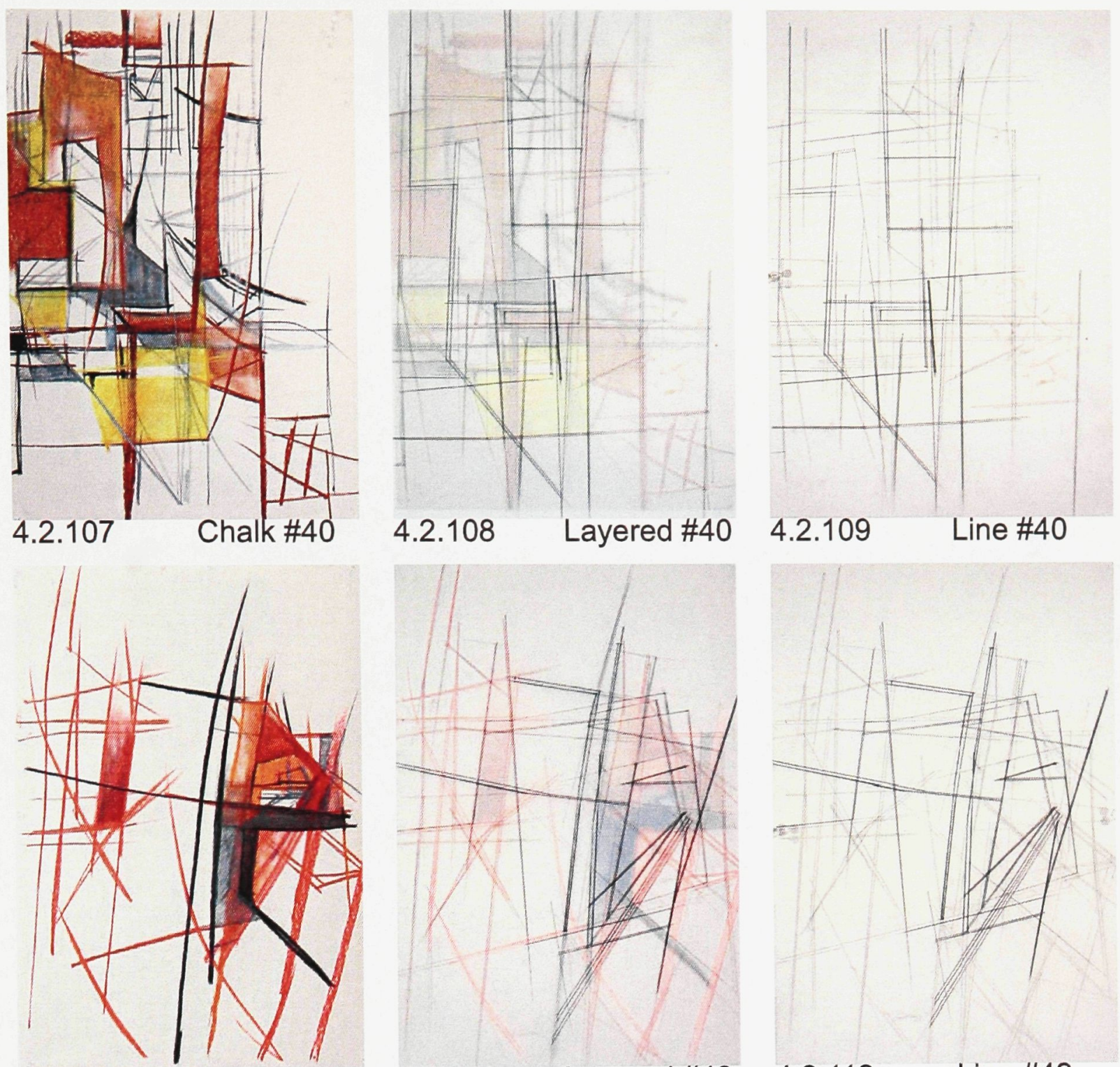

4.2.110

Chalk \#42

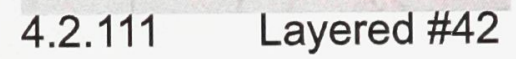

\subsubsection{Line \#42}
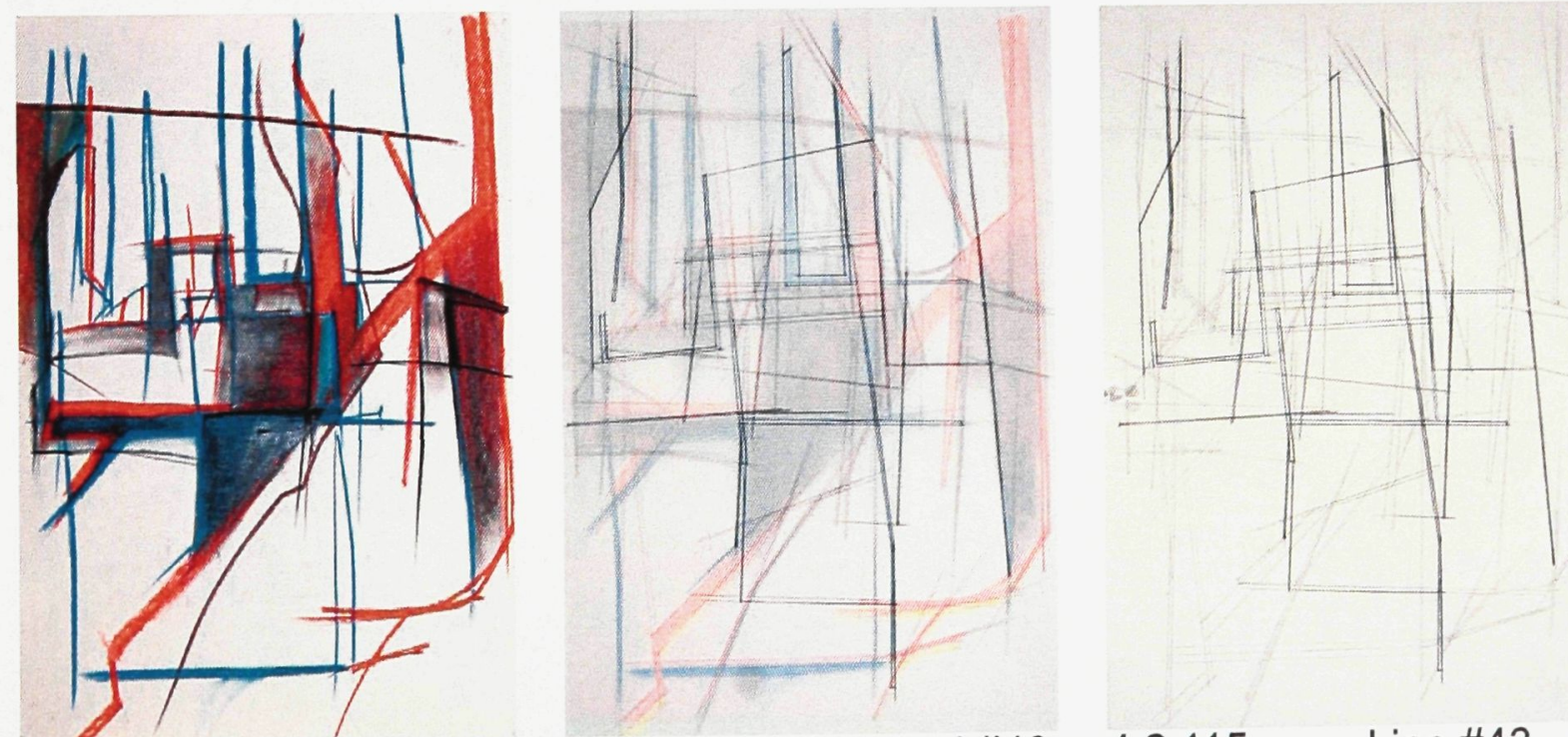

4.2.113 Chalk \#43

4.2.114 Layered \#43

4.2.115

Line \#43 

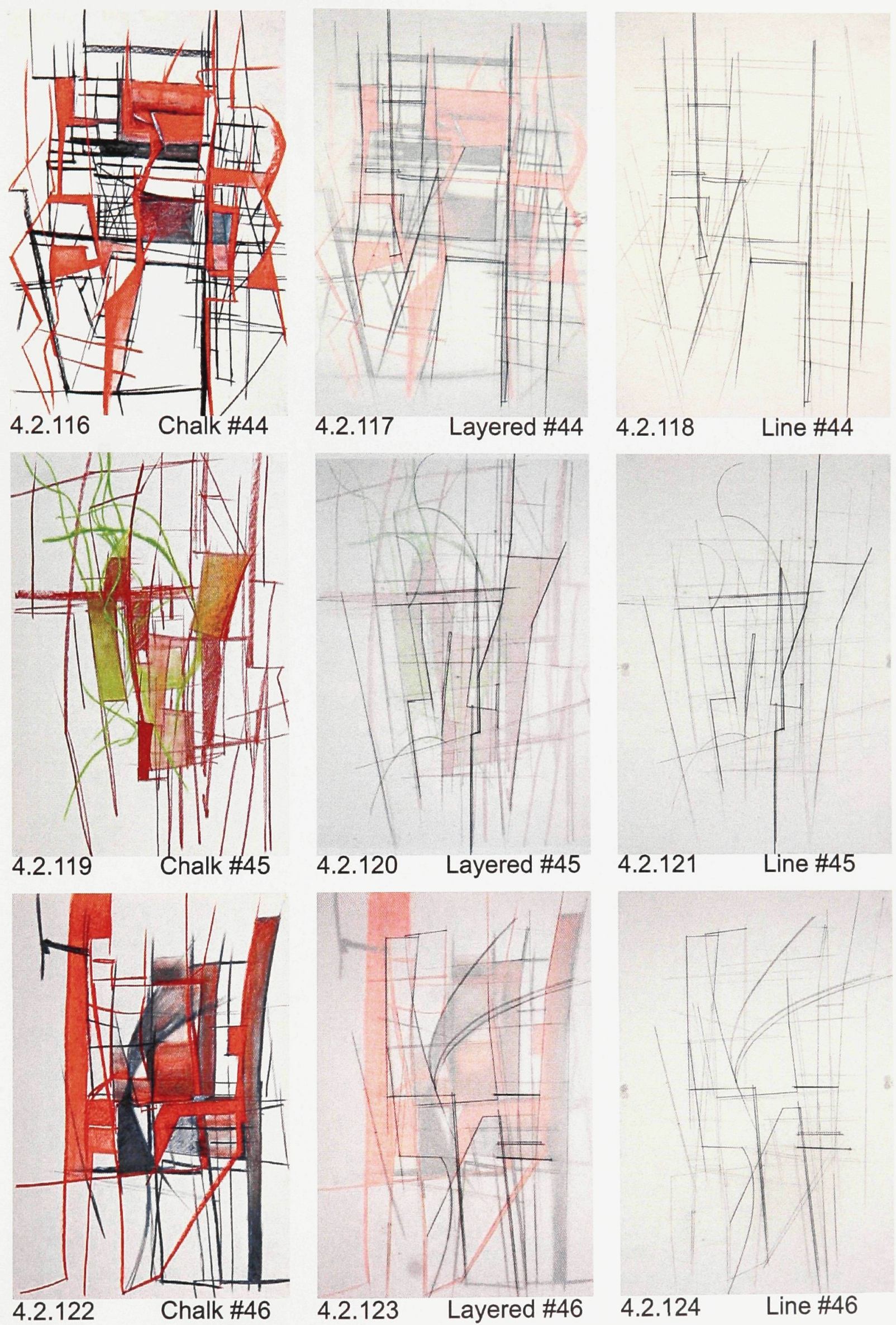

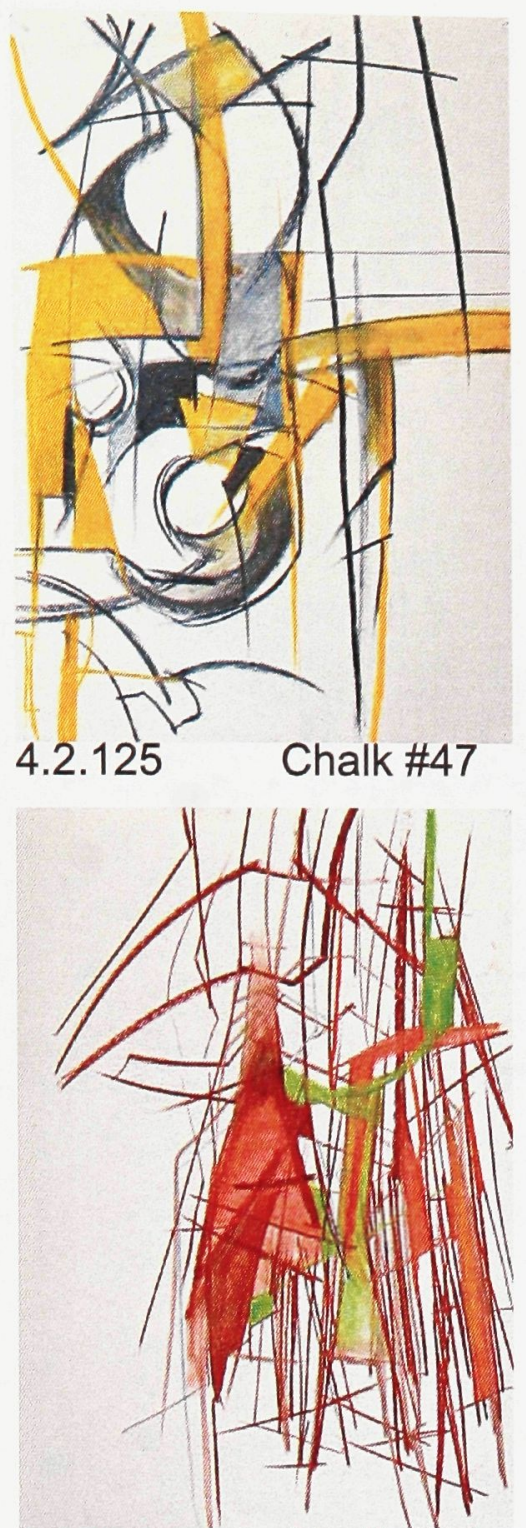

4.2.128 Chalk \#48

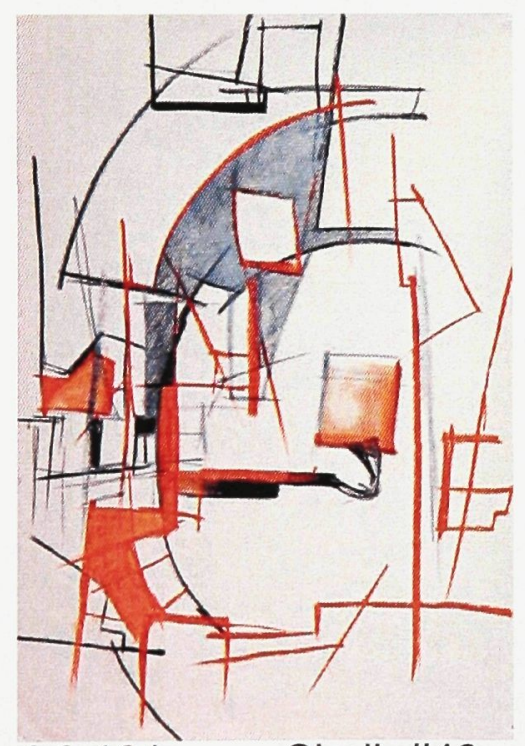

4.2.131 Chalk \#49

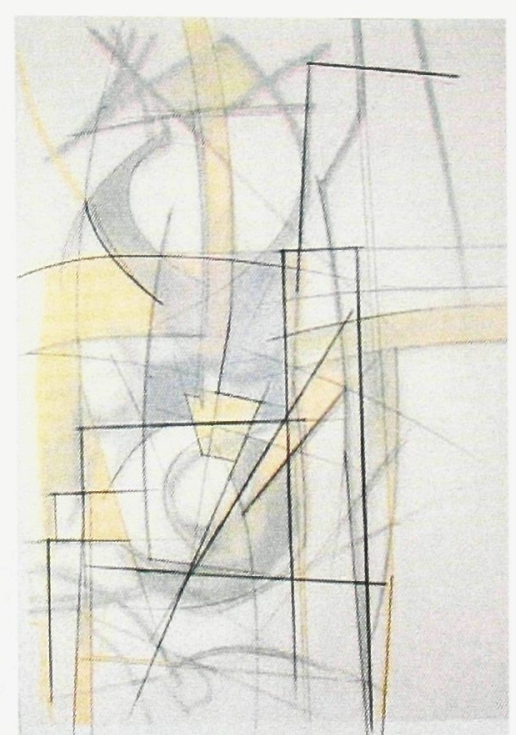

4.2.126 Layered \#47
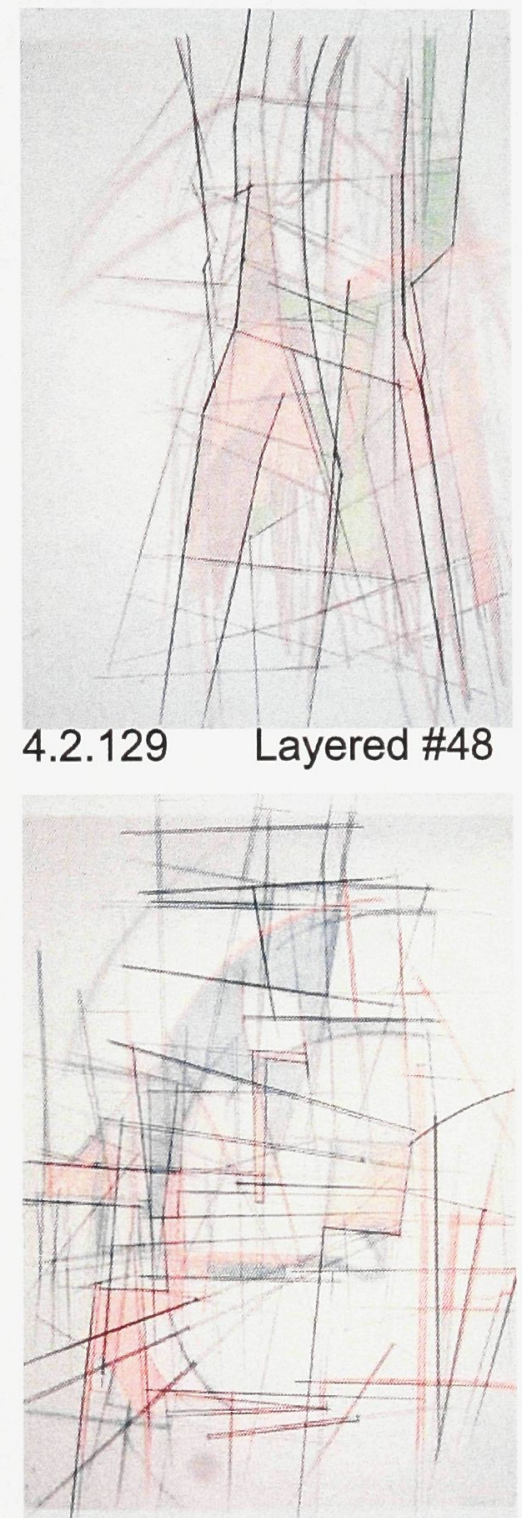

4.2.132 Layered \#49

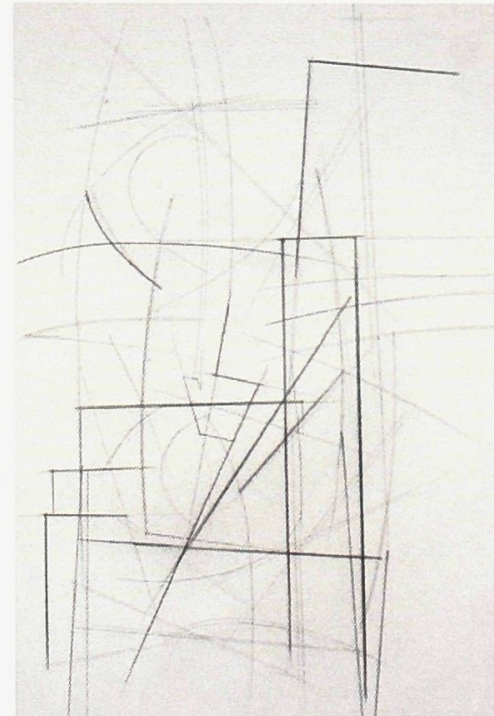

4.2.127 Line \#47
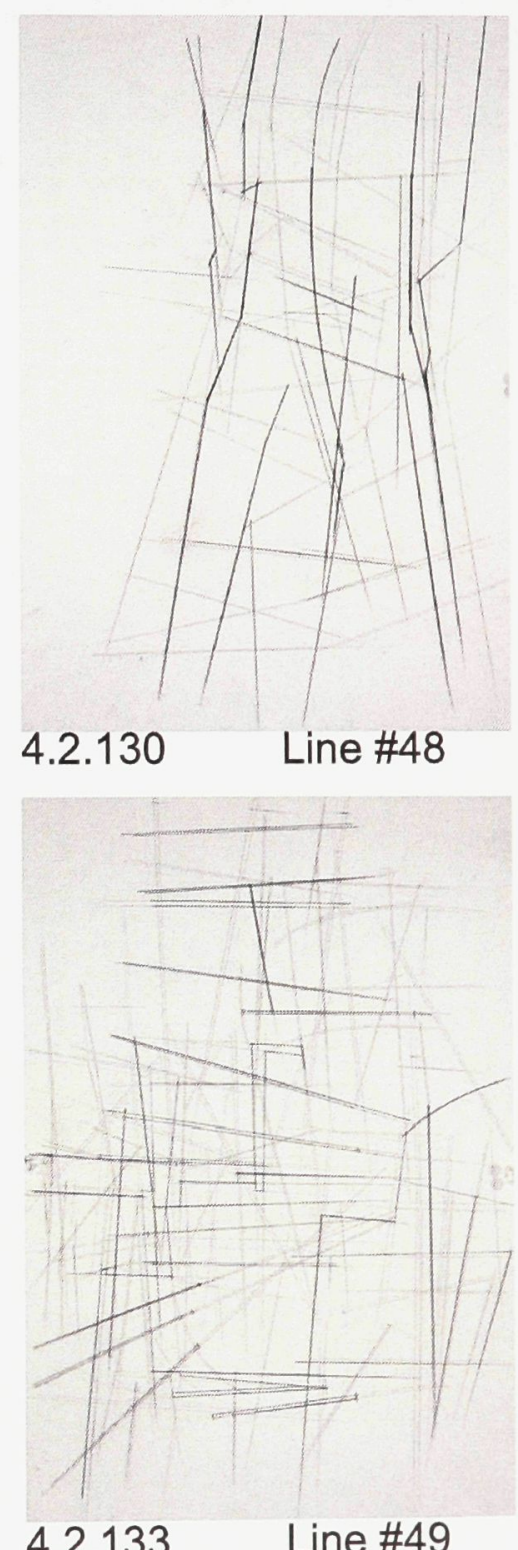

4.2.133 Line \#49 

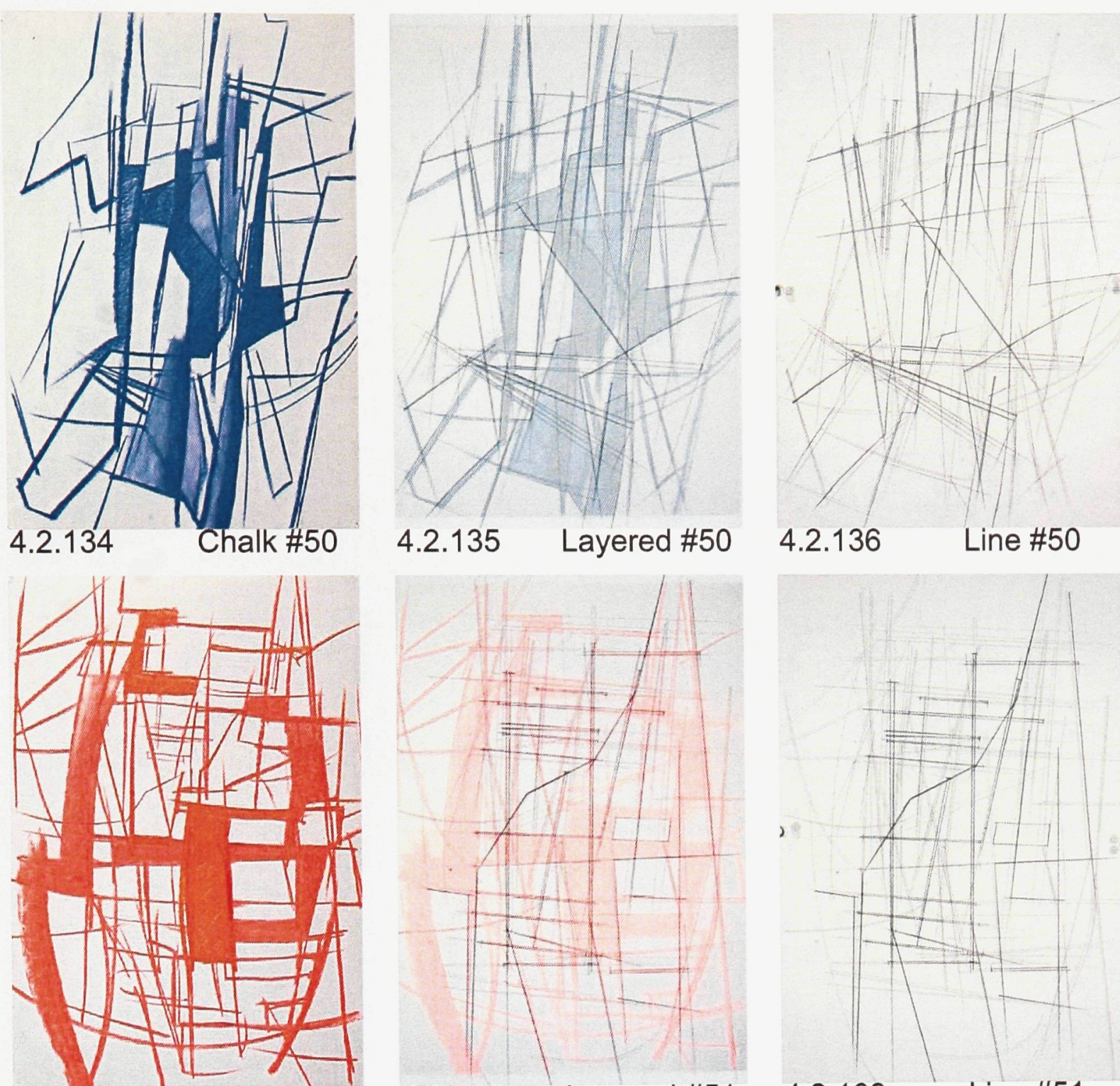

4.2.137
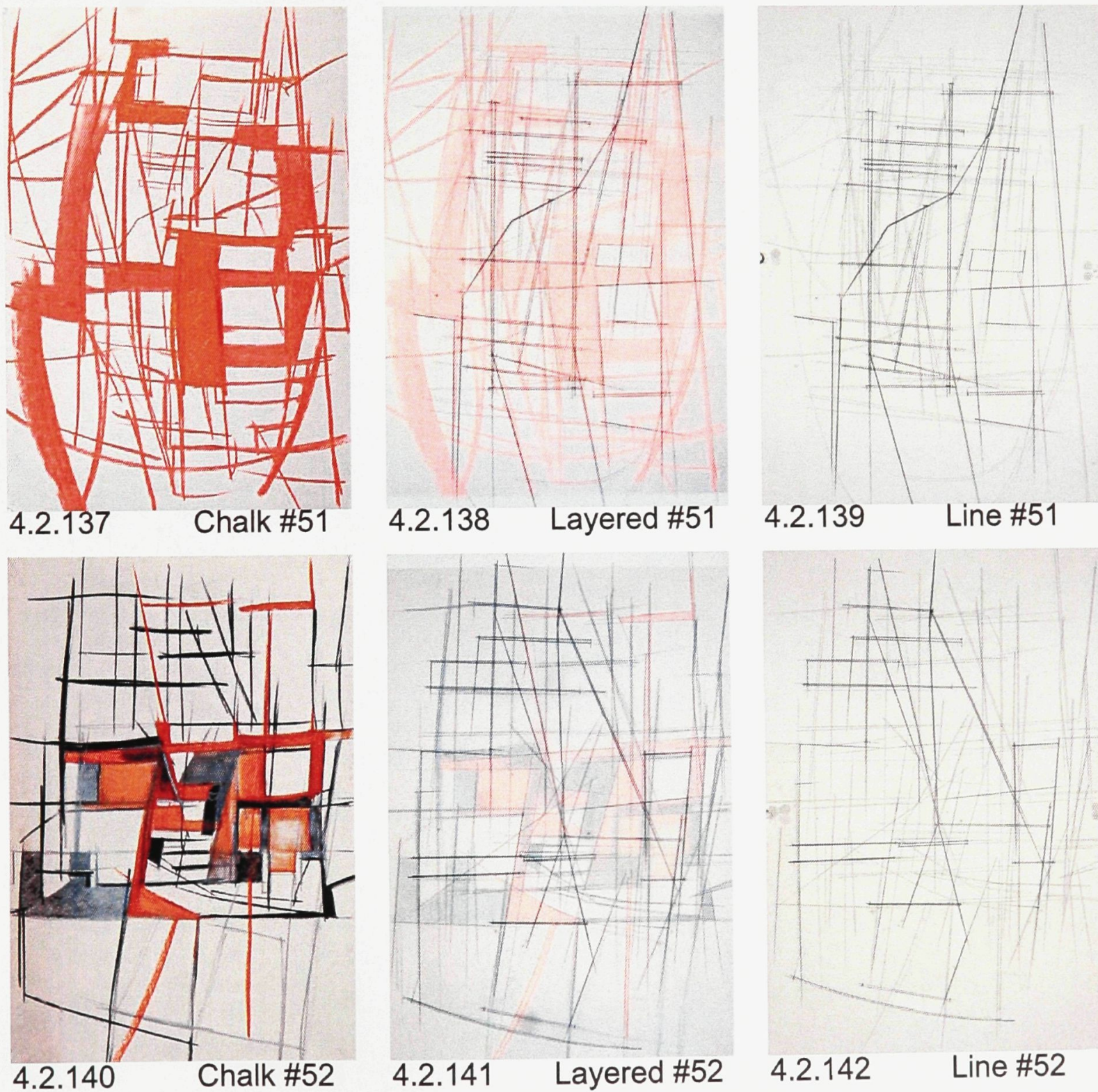


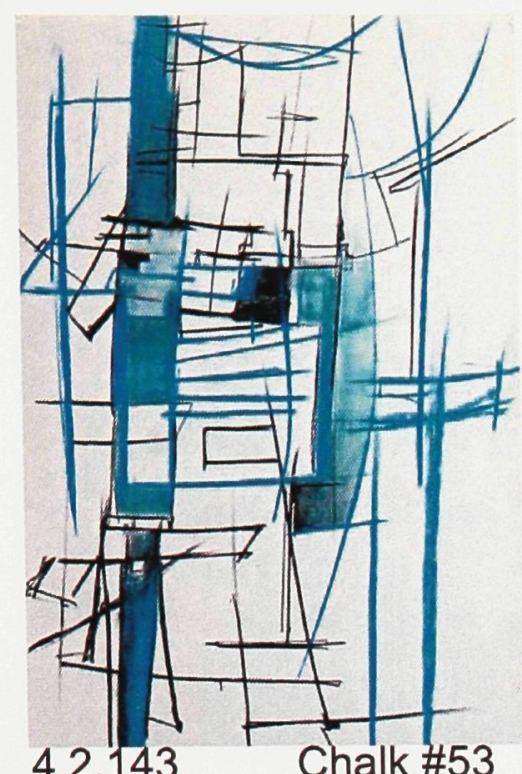

Layered Drawing \#53 N/A
Line Drawing \#53 N/A
Layered Drawing \#54

N/A
Line Drawing \#54

N/A
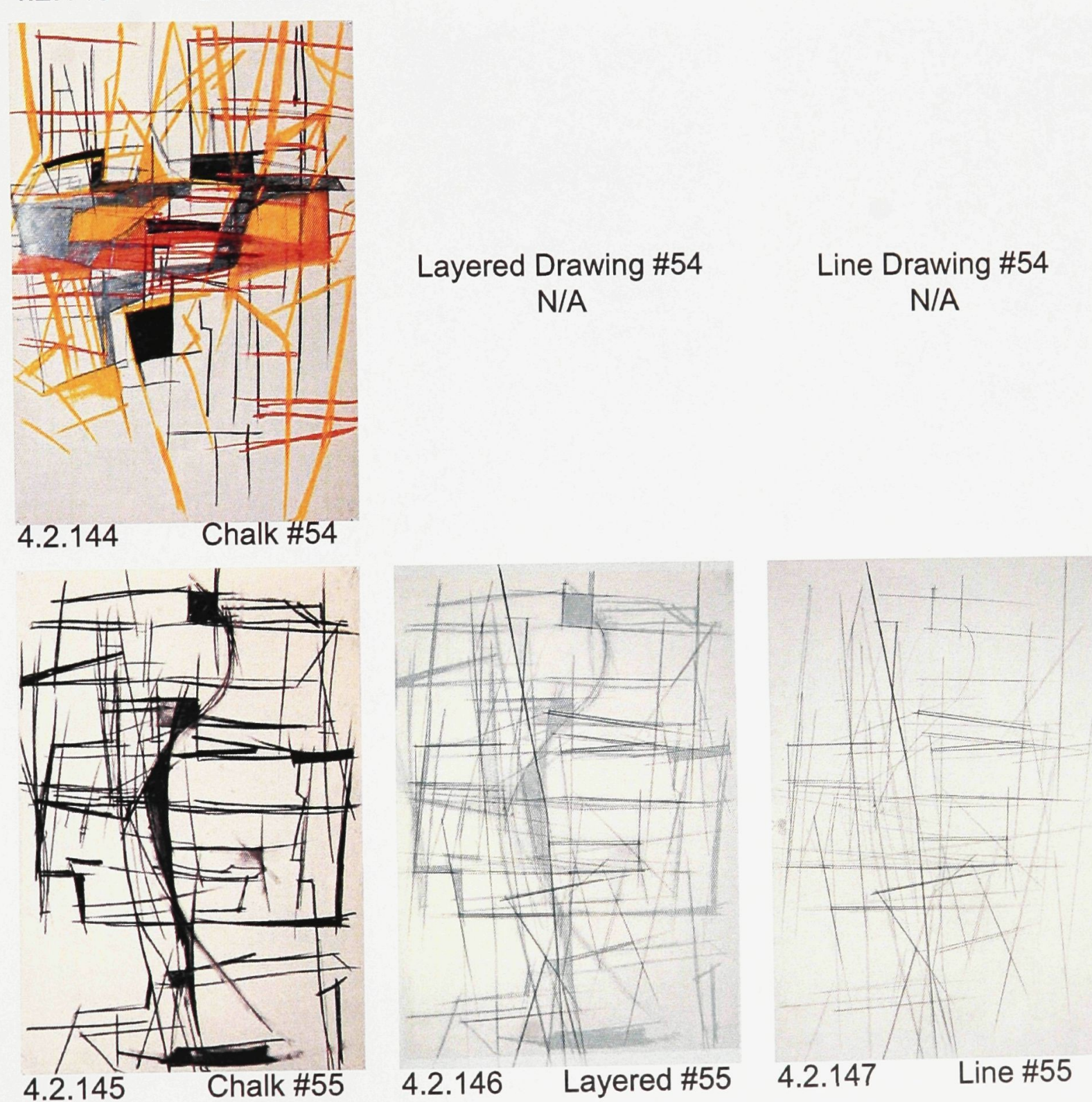

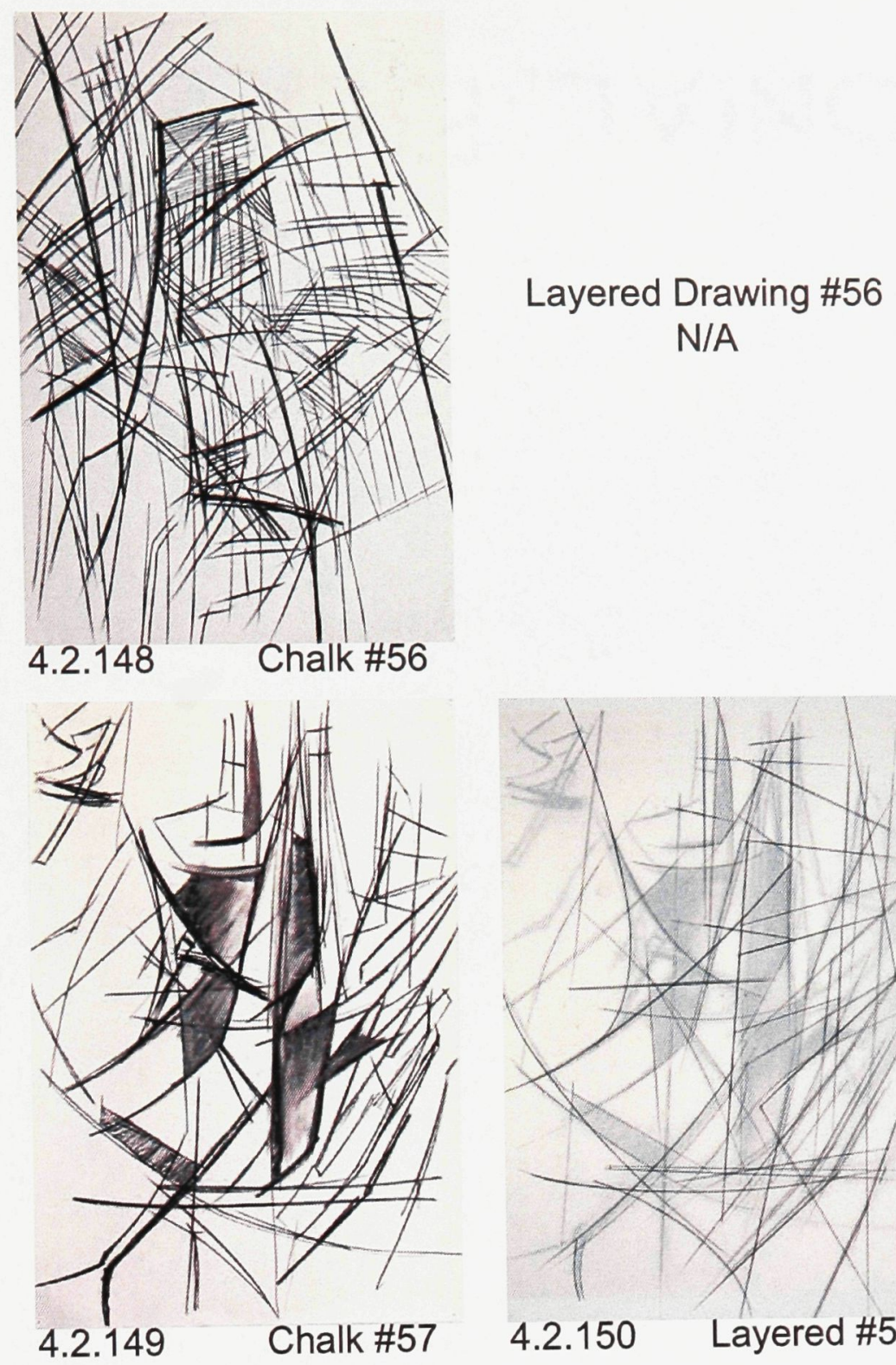
Line Drawing \#56 N/A
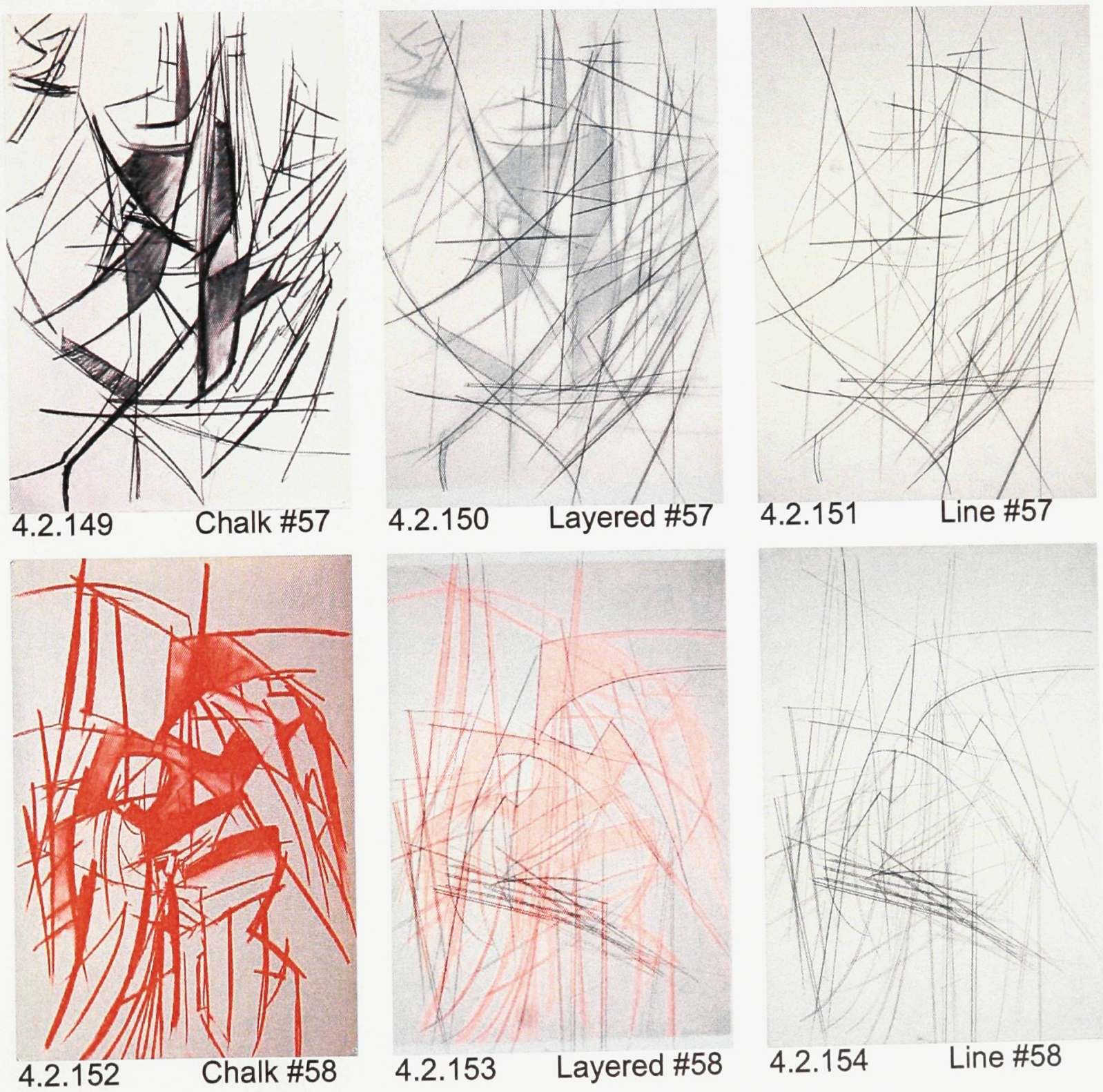

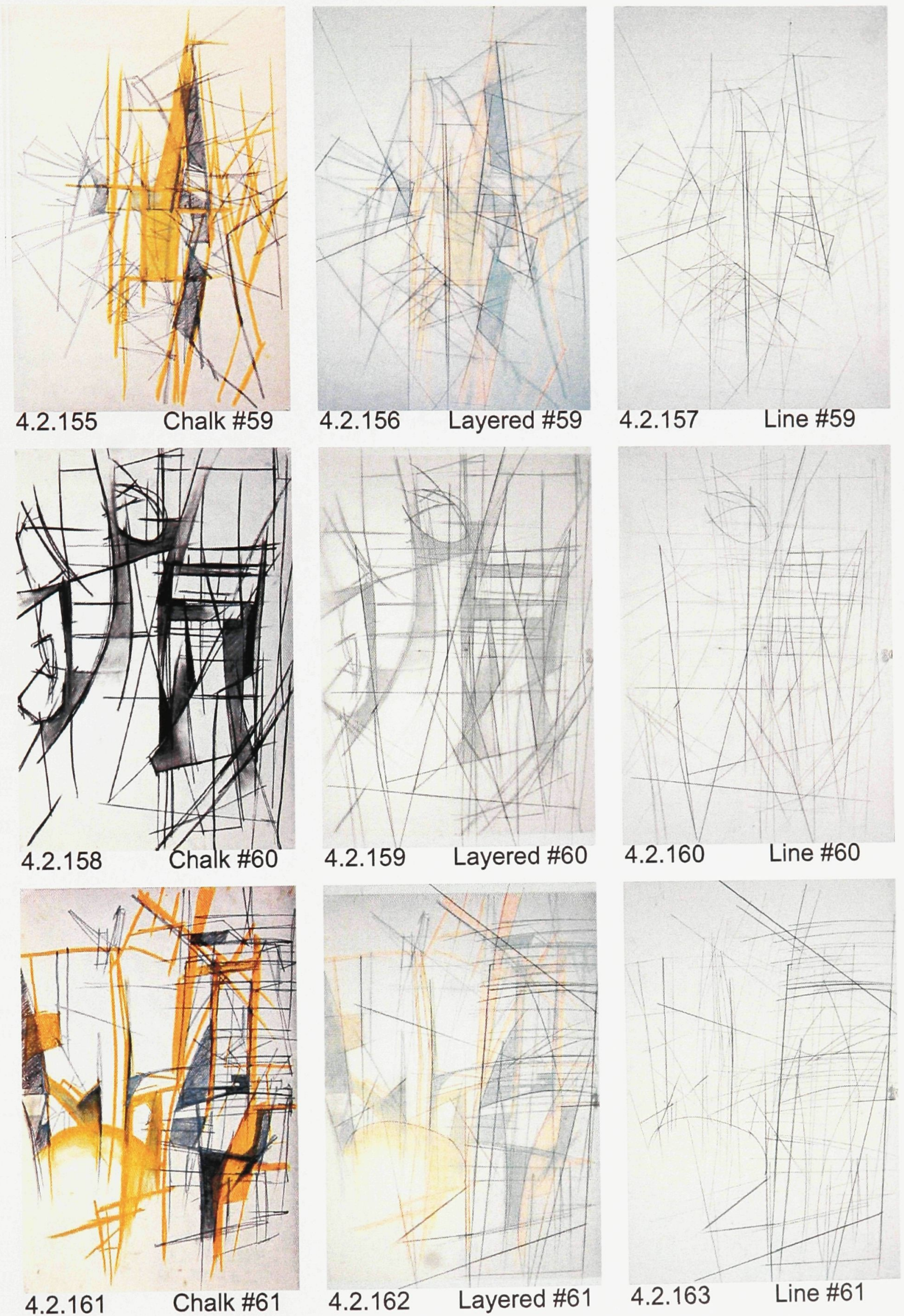

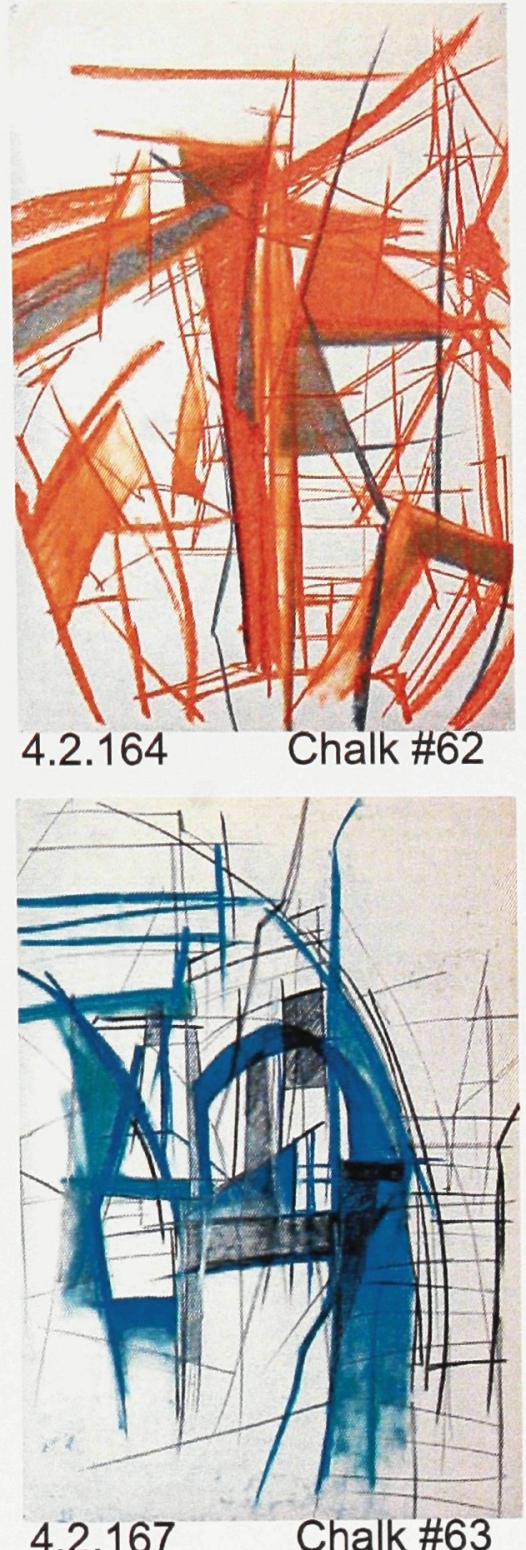

4.2.167 Chalk \#63

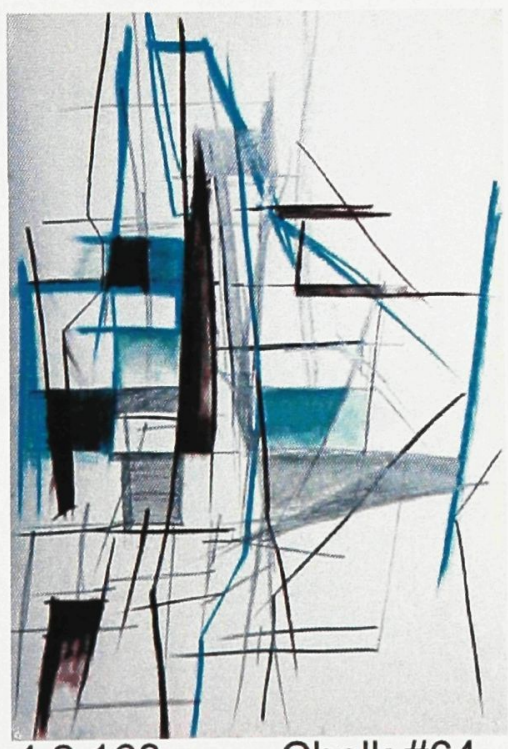

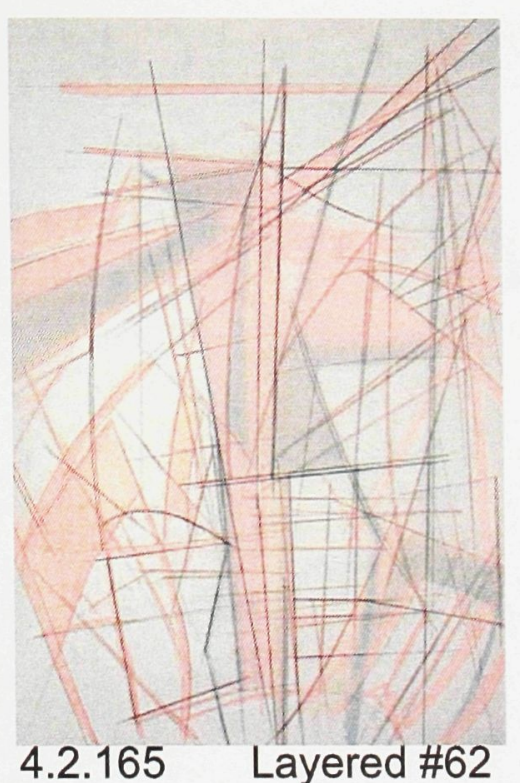

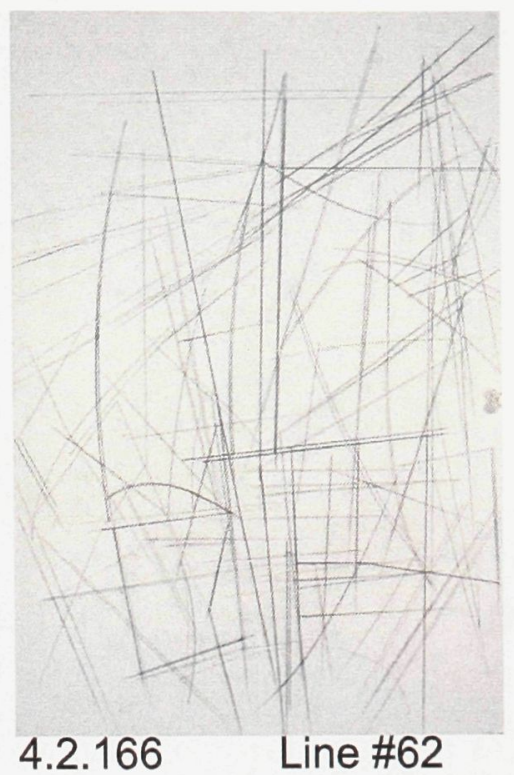

Layered Drawing \#63 N/A

Line Drawing \#63 N/A
Layered Drawing \#64 N/A
Line Drawing \#64 N/A 

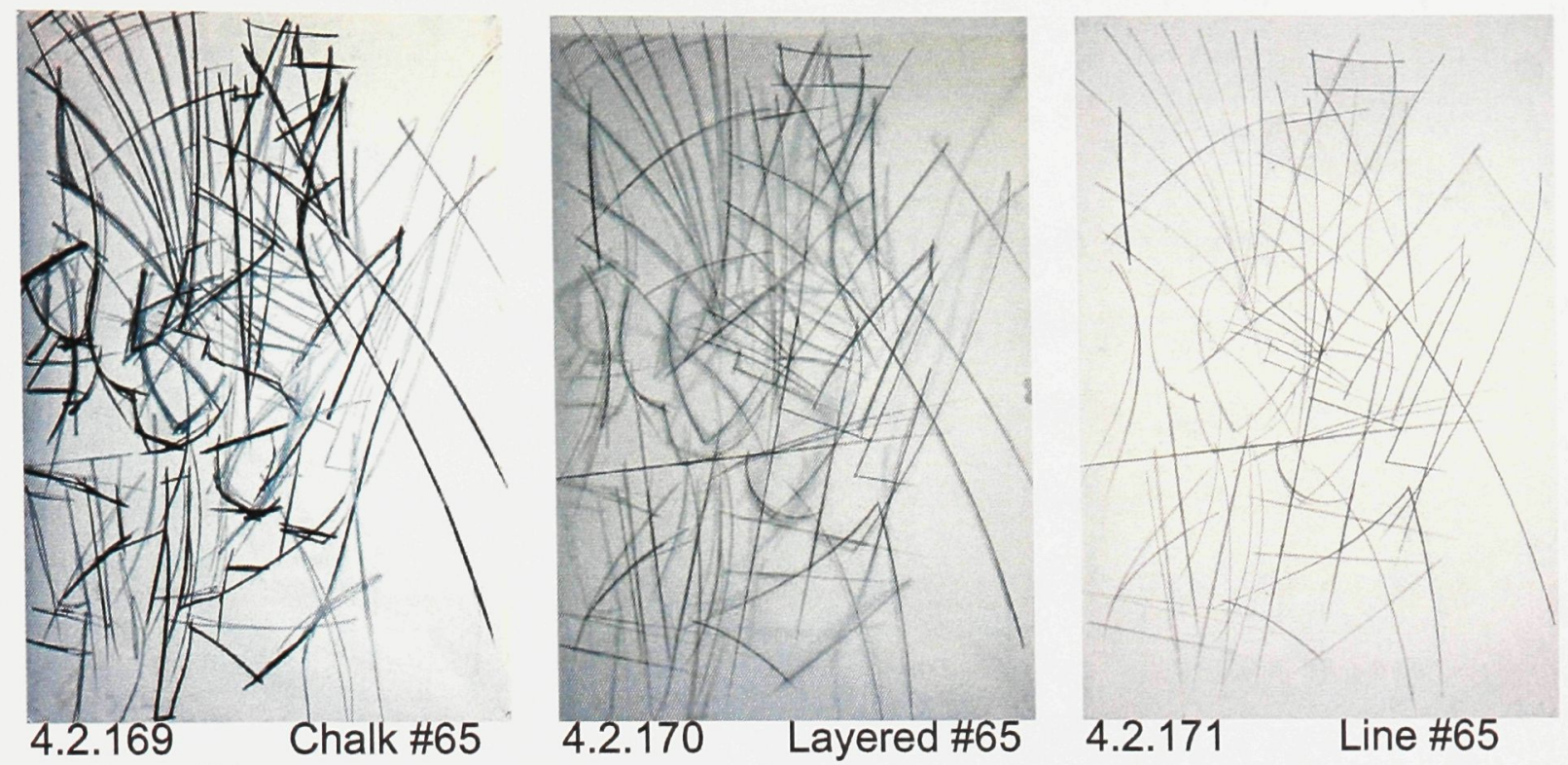

Drawing Sets:

- \#1, \#20, \#25 and \#41 Not Available 


\section{3}

\section{Phase 5: The Layering of the Line Drawings}

This phase of the project involved "reading" the line drawings. They were over-laid, using digital technology, to draw out architectural space. The introduction of Photoshop allowed for an effective and thorough engagment with the line drawings with each other. The drawings were created only out of their layered and translucent relationships and at no point were new physical interventions added through digitization. Only through a process of revealing or erasing did the next phase of images develop. [III. 4.3.1, 4.3.2, 4.3.3]

By the overlaying of these drawings, new spaces engage in formal dialogues that begins to expose new, interpretive sections or plans. The operative word "or" is still relevant as these experiences were still devoid of specific programmatic conditions or even formal structural referrals. The drawings continue as an "imagining" at this phase of the process. 


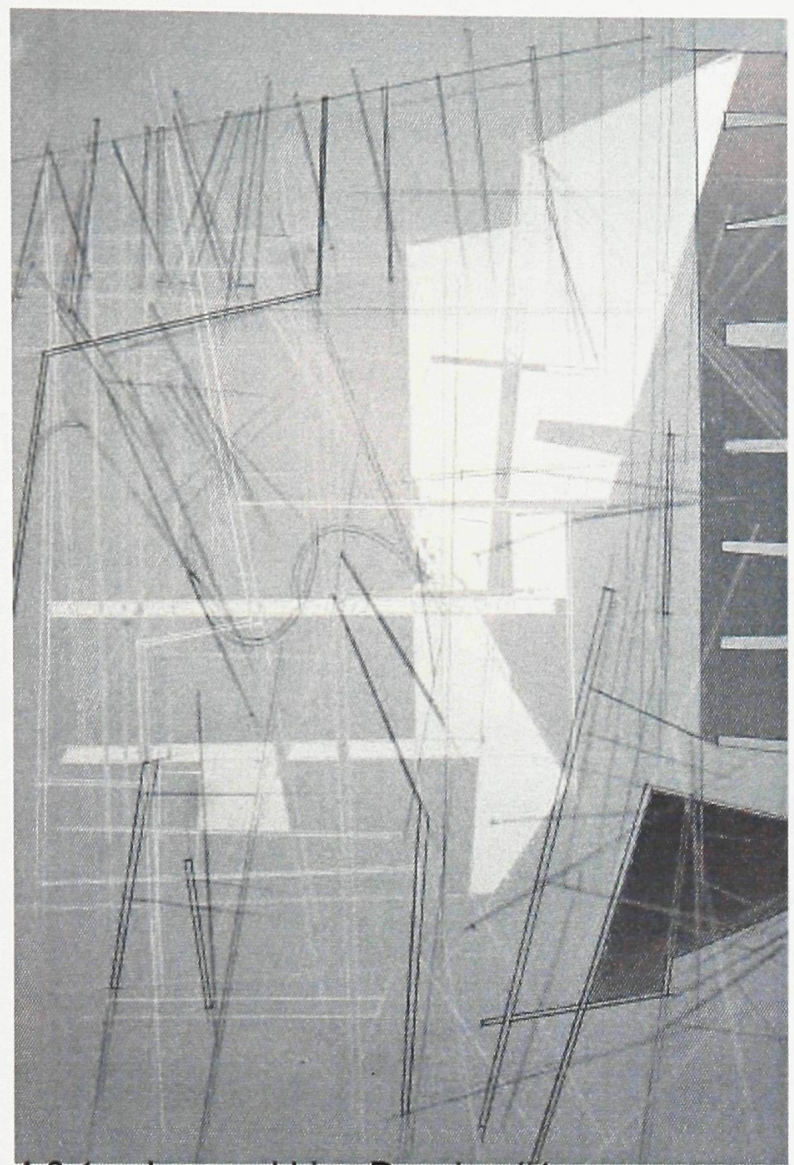

4.3.1 Layered Line Drawing \#1

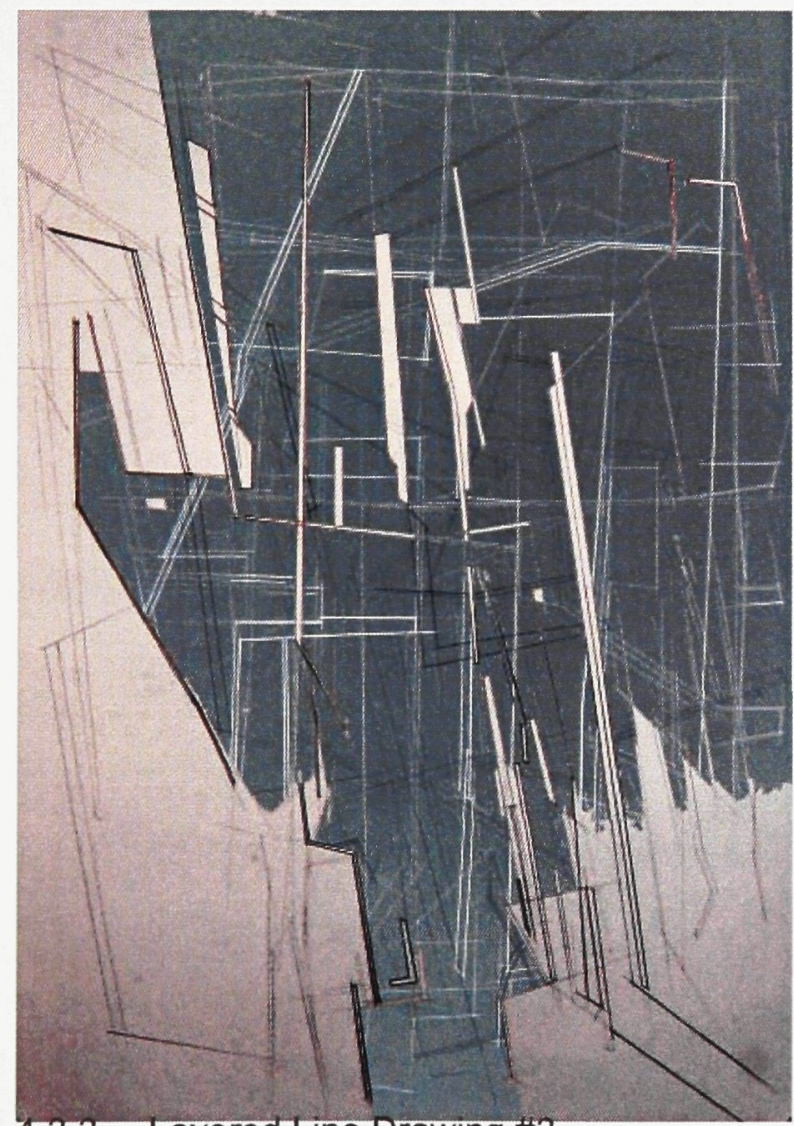

4.3.3 Layered Line Drawing \#3

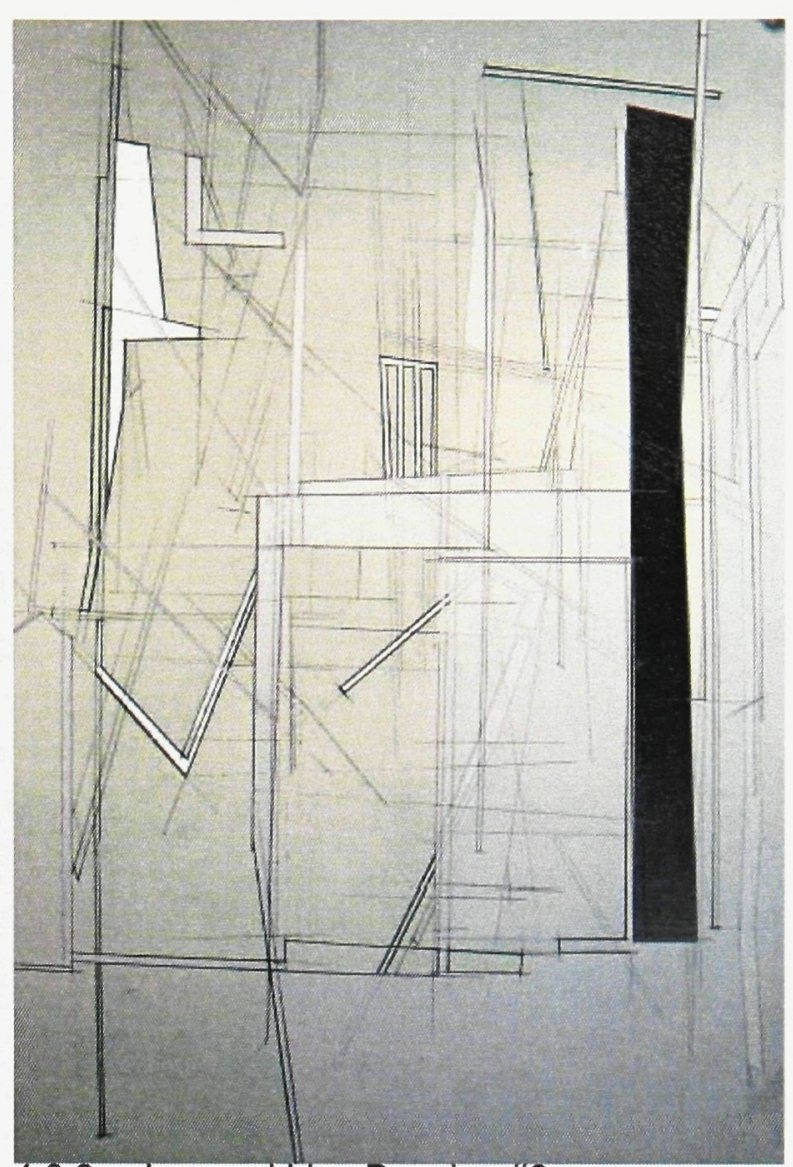

4.3.2 Layered Line Drawing \#2

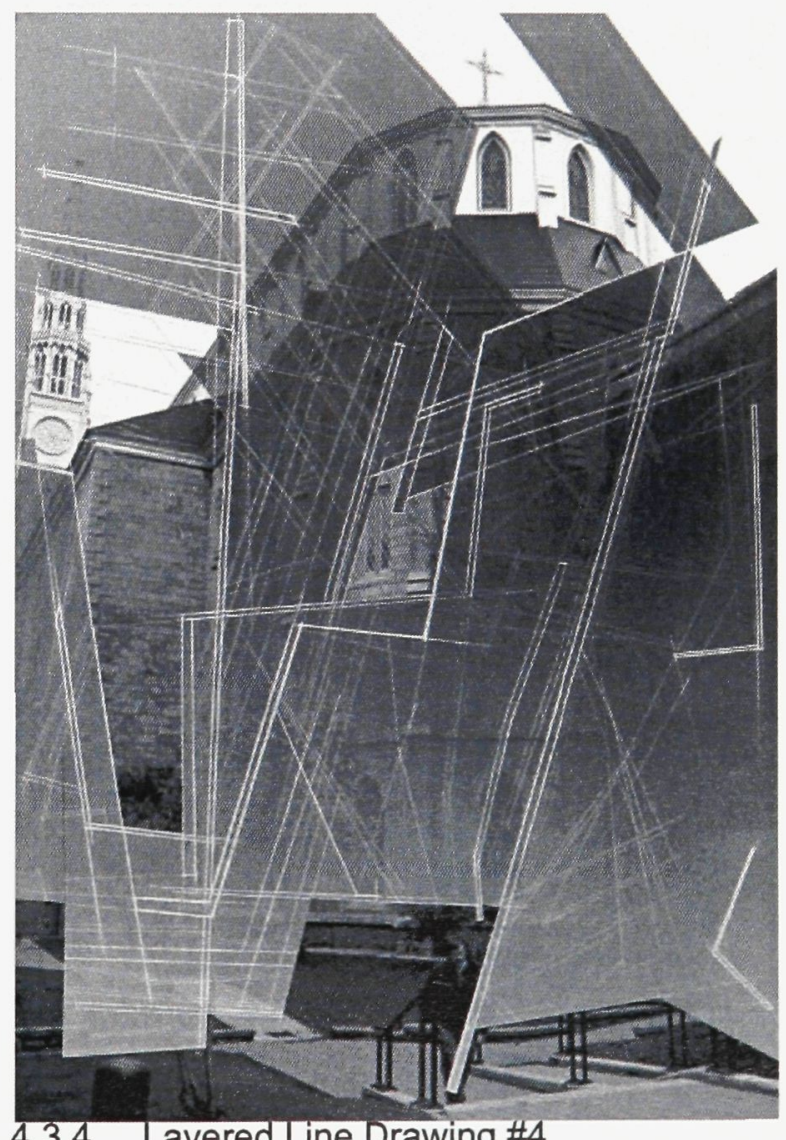

4.3.4 Layered Line Drawing \#4 


\section{4}

\section{Programing by Palimpsest}

\section{Phase 6: Spatial Evolution Through Section}

This phase of the project was set up as a means of revealing the potential for spatial and sectional relationships and how they can reveal potential program.

This is an opportune time to explain the programmatic development for the proposed R.A.I.C. It was not developed in the traditional manner of knowing the programmatic requirements prior to the its design development. The entire program of the building was developed based on a layered (maintaining the palimpsest metaphor) relationship between the spaces that can encourage a new associative understanding of the R.A.I.C., its' mandates and programs (social or administrative), and their affiliation with how the drawings begin to reveal the potential for these spatial relationships to happen.

In order to reveal a certain level of programmatic understanding, an initial analysis was made that could allow for a flexible development of its spaces. This analysis revealed three major conditions within and around the facility, and one condition related to the siting in Ottawa. The following section explores those moments of interaction.

The Headquarters of the Royal Architectural Institute of Canada was understood to address four distinct audiences:

\section{Employees of the R.A.I.C.}

- They require conditions that engage dialogue with members of the profession, themselves and the public.

- They require spaces that provide services for architects, including the contribution to training and professional proficiency, and provide information and advice. 
- They require experiences that engage debate, not to resolve personal bureaucratic issues, but to engage the policy making aspects of the profession.

- They require experiences of "Architecture". Spaces that exploit interpretation and the imagination of the spectator. A constant cue of who they are and what they are supposed to represent; a united representation of the profession.

\section{Members \& Fellows of the R.A.I.C.}

- They require environments that encourage further educational development, both professional and academic.

- They require environments that expose architectural achievements, including: the exposure of Canadian architecture, architecture in Canada and work by Canadian architects around the World.

- They require tactile and metaphoric experiences of architecture that can expose students to the poetry of concept and its refinement through tactile moments.

- They require experiences of "Architecture"; spaces that exploit interpretation and the imagination.

\section{Students \& Interested Members of the Public}

- They require environments that encourage public opinion.

- They require surroundings that expose the various stages of the profession and its services.

- They require experiences that allow an exploitation of a curiosity that they may not have been aware existed. 


\section{Citizens of Ottawa \& Tourists}

- The specific site proposal for the project is at the corner of Parent Ave. and St. Patrick St., currently an empty parking lot directly adjacent to, and east of the Basilica in the By Ward Market. The site was specifically chosen for its proximity to 3 distinct urban zones diverging on the site that can help strengthen the possible overlapping of social interaction through the developed R.A.I.C. program.

- The Market's mixed use conditions consists of people who may not necessarily reside in the area, but are exposed to the urban context on a regular basis. They are the workers and / or owners of businesses located in the immediate surroundings and those who live outside of the Market but visit the area for multiple reasons (business or pleasure).

- The residential zones in the immediate surroundings can provide an opportunity to expose architecture and the R.A.I.C to the local population and possibly provide them with more engaging community services.

- The converging ring known as Confederation Boulevard and the sites immediacy to National landmarks, such as the National Gallery, can provide opportunities for the program to expose architecture at a national level and to the millions of tourists that visit the city of Ottawa every year.

The R.A.I.C. headquarters does more than fulfill administrative requirements. In order for our profession to make a stronger statement to the public, the building must demonstrate what architecture can bring to urban development and society as a whole.

In developing the program, the drawings are not only layered in relationship to each other, but in order to reveal spatial experiences. Scale and context help guide the formalities of developing the sectional environments. It 
is these moments that begin to reveal not only the formal relationships between solids, voids, structure, and surface, but also inform the development of the building's layered programs.

The sections were developed using a general strategy, with minor variations. The first exploratory sections were developed through the layering of the line drawings in PhotoShop (Adobe Publishing Software). Some were developed through a relationship of one or two other line drawings, and others developed using one line drawing, replicated two to three times within the same image. Both techniques resulted in similar results of revealing very fluid and transparent experiences. 

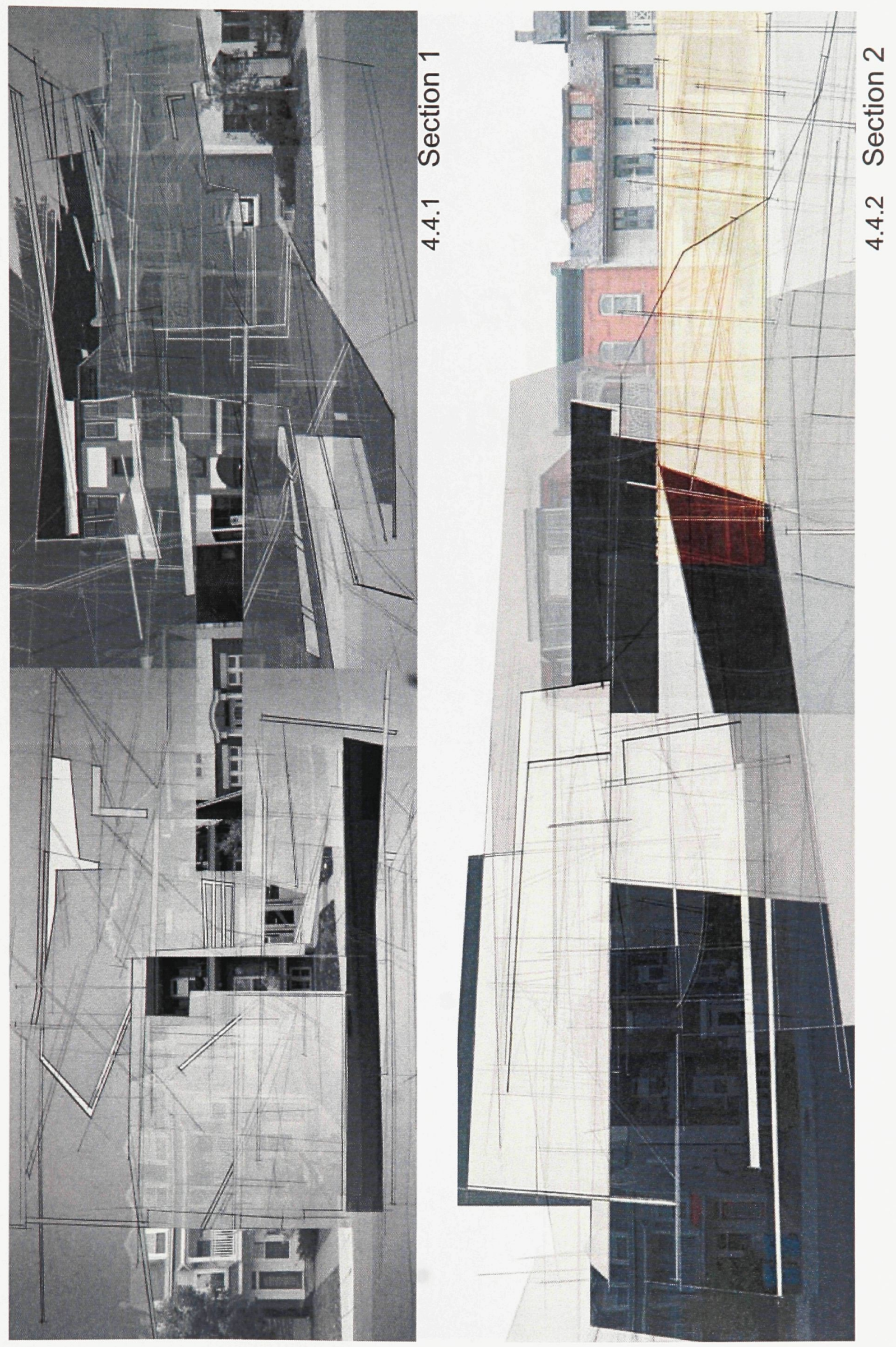


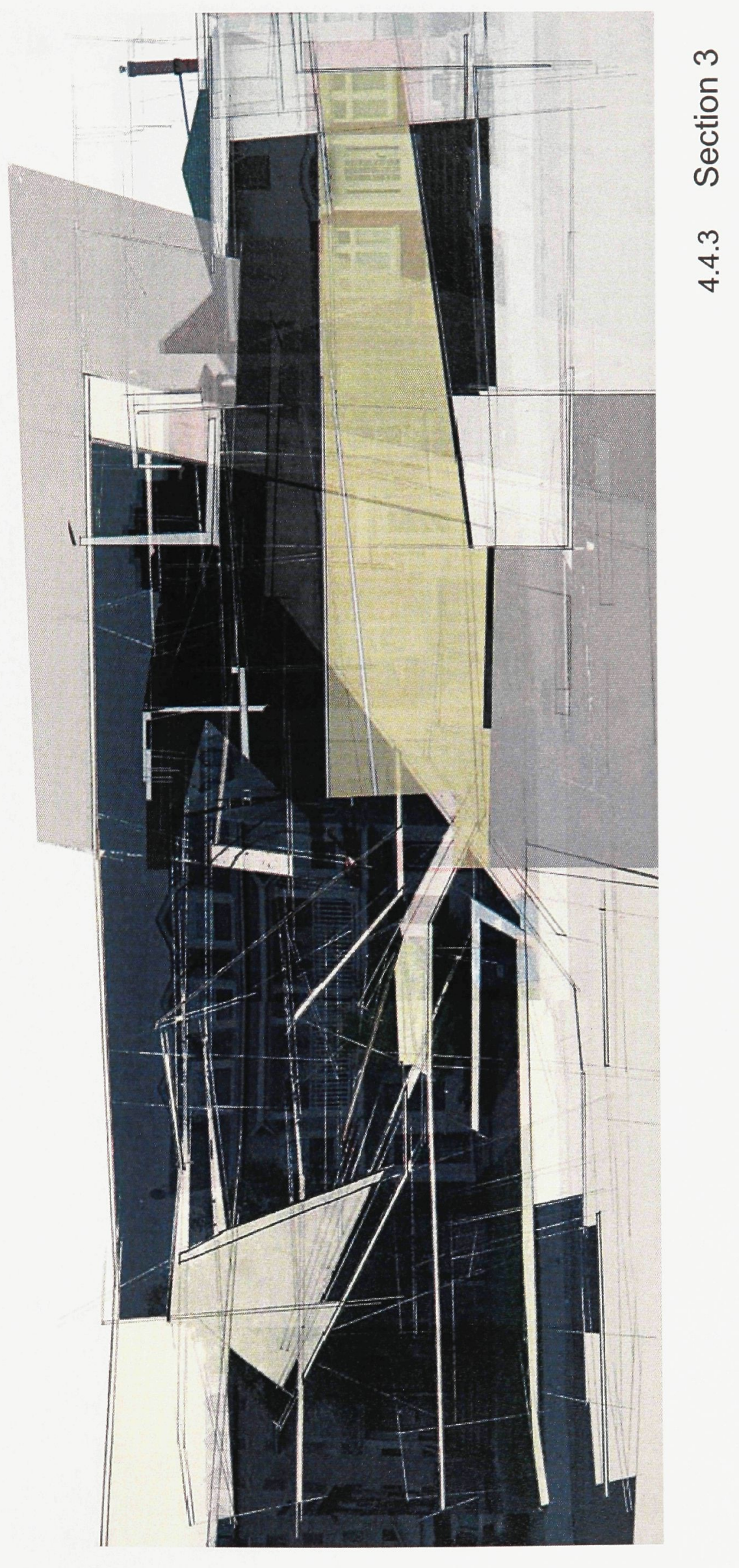




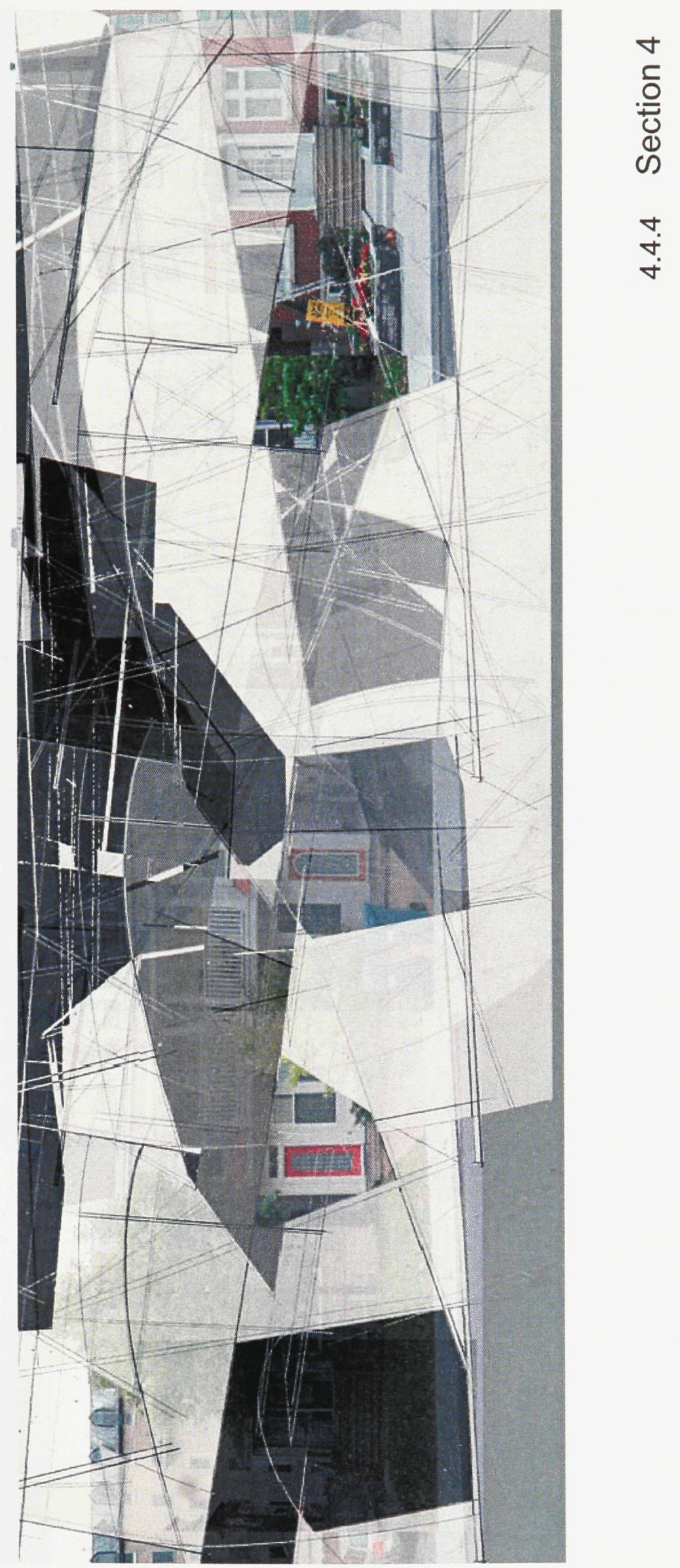



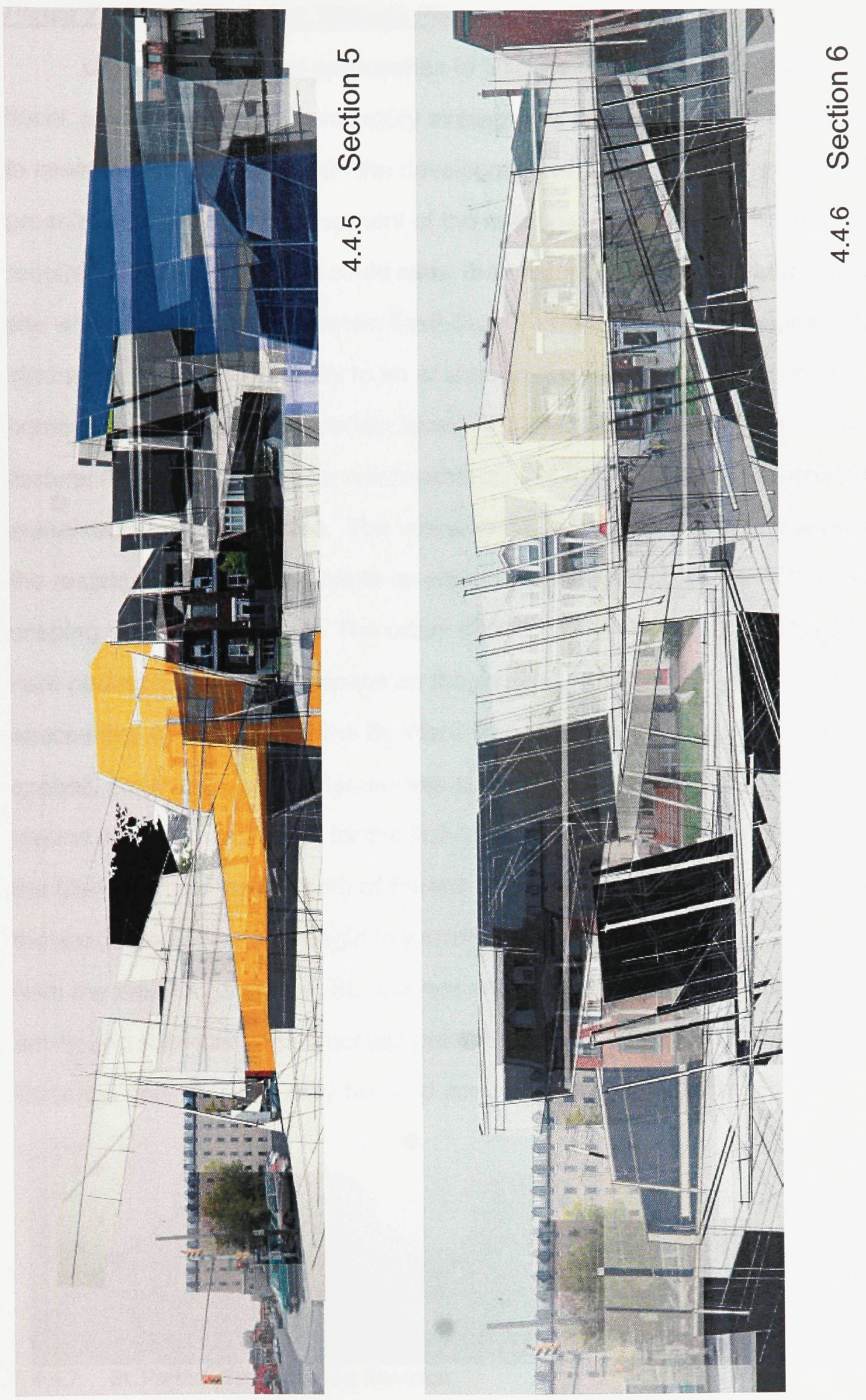


\section{Phase 7: Spatial Evolution Through Plan}

Unlike conventional approaches to plan that attempt to reconcile the functional, programmatic, and circulatory strategies of a program, these plans attempt to associate the drawings with the development of the program. In a similar approach taken with the development of the sectional explorations, the drawings required a formal guide that could allow their natural progression on the selected site while still permitting a certain flexibility. Therefore, a series of simple urban strategies, related specifically to an analysis of the site and the surrounding urban context were to direct, to a certain level, the development of the plans. The architectural response would be a relationship between these urban strategies and the actual drawings themselves. The interpretation of the drawings is what reveals the responses to these moments as either formal architectural tectonics, landscaping, or even metaphor. The urban strategies include: maintaining a predominant pedestrian and public space on the south side of the site, providing exterior spaces that could continue the By Ward Market attitude towards public exterior spaces, providing a pedestrian access to the underground parking facility, and a natural main entrance point for the R.A.I.C. as the socially enriched elements of the Market are primarily south of Parent. Ave. This allows public engagement of the space and could also begin to transform the way vehicles approach the site from the east on St. Patrick St. Current traffic planning have this one-way western bound street as a main access point to the Champlain Bridge leading towards Gatineau and often has very fast and congested vehicular traffic.

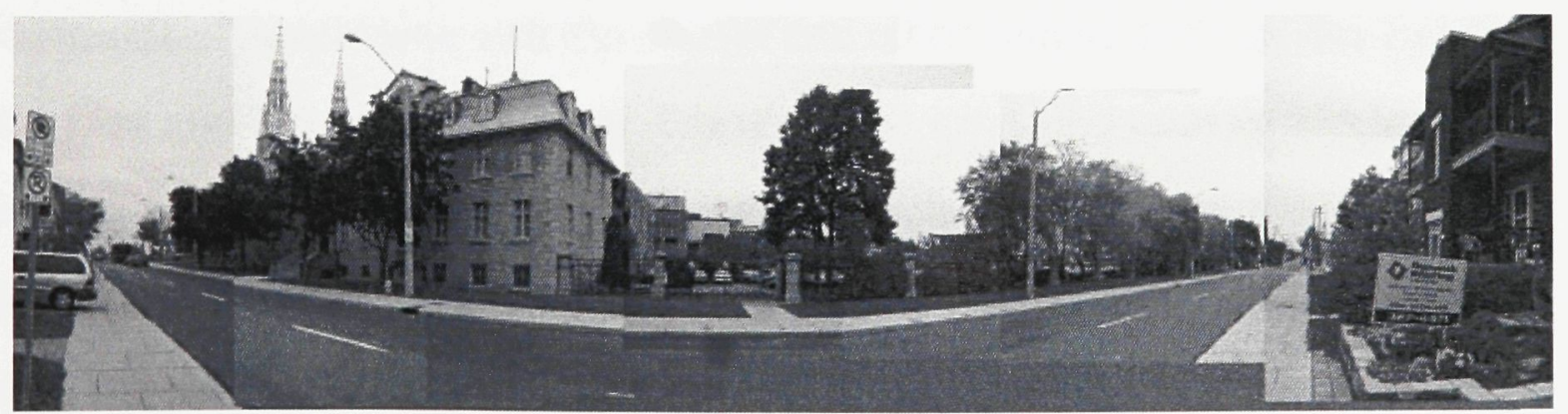

4.4.7 St. Partrick Street Existing Elevation 
The next strategy would be, as stated, a natural introduction to the R.A.I.C. at the south east corner of the site. This intersection - St. Patrick St and Parent Ave. - is the natural first perceived moment of the space as a pedestrian and is the most visible marker when approaching the building from the east or the south

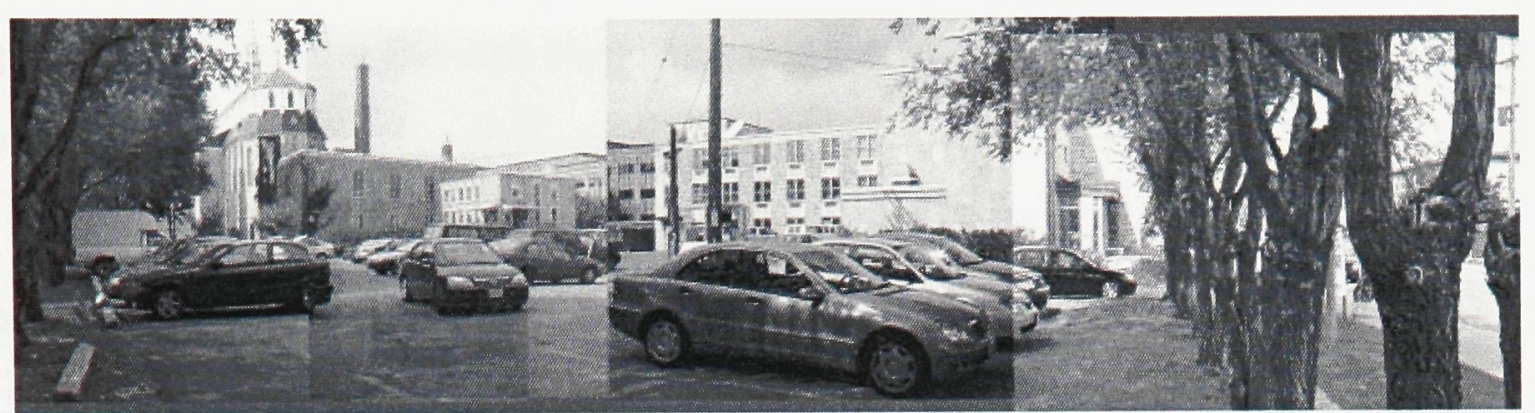

4.4.8 Existing Pay Parking Lot

from at least two blocks away. The building could then begin to engage the urban context from a much larger position.

The north side of the site - Guigues Ave. - is a one way street running east and has a dramatically different feel than the busier St. Patrick St. on the south. Traffic movement is slower but is still fairly busy with the multiple parking meters on the north side of the street; making it a natural parking destination for the

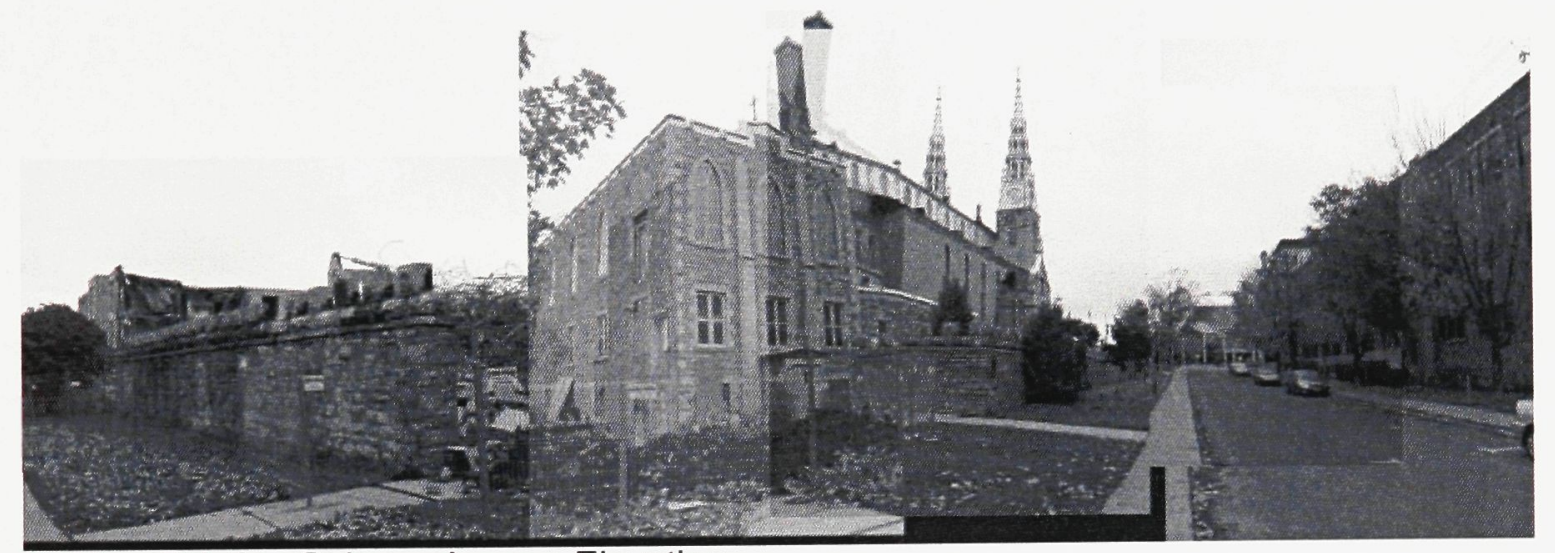

4.4.9 Existing Guigues Avenue Elevation

hundreds of people who visit the market and other venues such as, the Basilica, the Mint and the National Gallery. Entrance and exit to the underground parking facility would be an appropriate strategy for this north side of the site. It could also provide a possible second entrance point to the building. The last flexible strategy guiding the project's development through plan is the site itself and its 
immediacy to the Basilica and its supporting buildings. This is by far the most flexible as it will be left to the development of the drawings themselves to reveal the possible moments of spatial connection, separation or metaphoric dialogue (urban and historical palimpset) that can reveal itself between the existing neogothic buildings, the Byward Market, and the contemporary tectonic approaches of the new R.A.I.C.

As with the sections, the explorations of the plans followed a similar approach of layering the various line drawings (using Adobe Photoshop software). Once a series of about 25 different explorations were completed, those that seemed to be the most dynamic or successful (choice made completely based on author's subjectivity) were then layered once again through another series of abstractions. The final plan drawing was then used as the guide for the next development of the project, explored primarily through axonometric projection. 


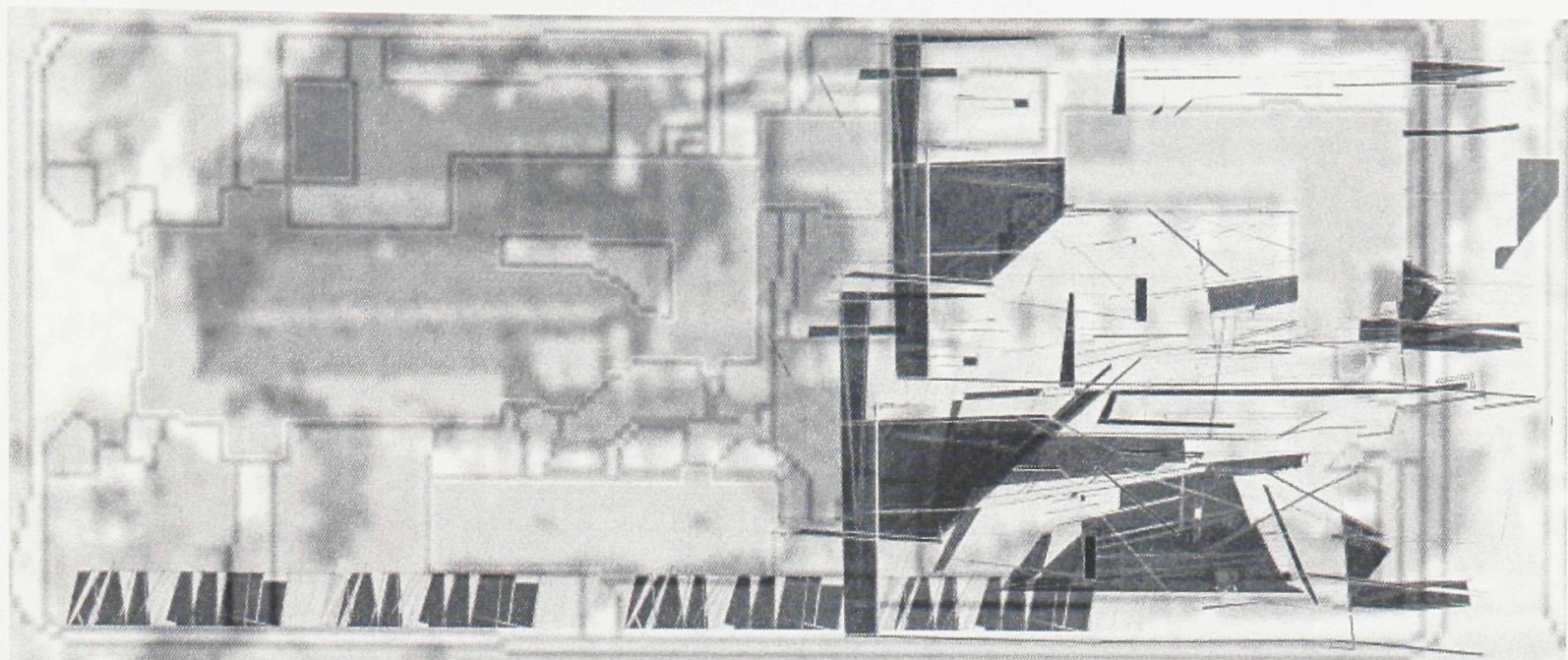

\subsubsection{Plan Exploration \#1}

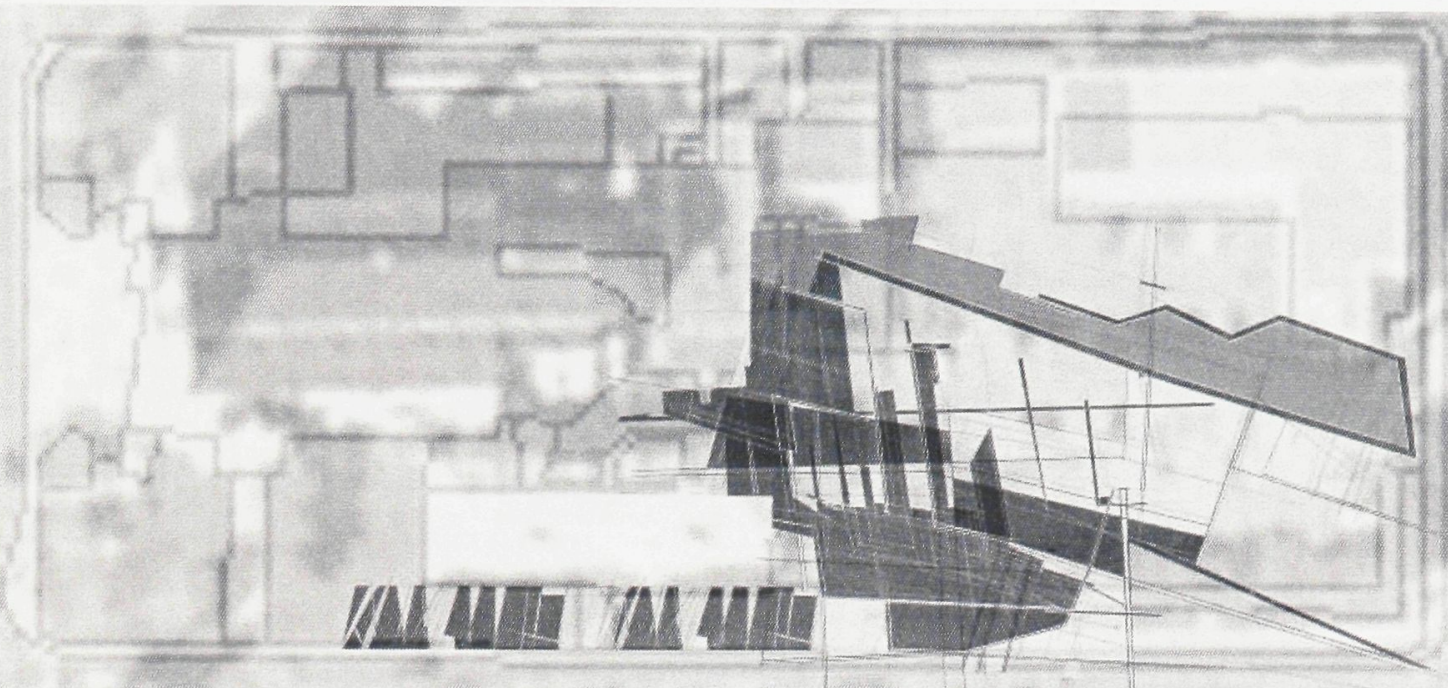

4.4.11 Plan Exploration \#2

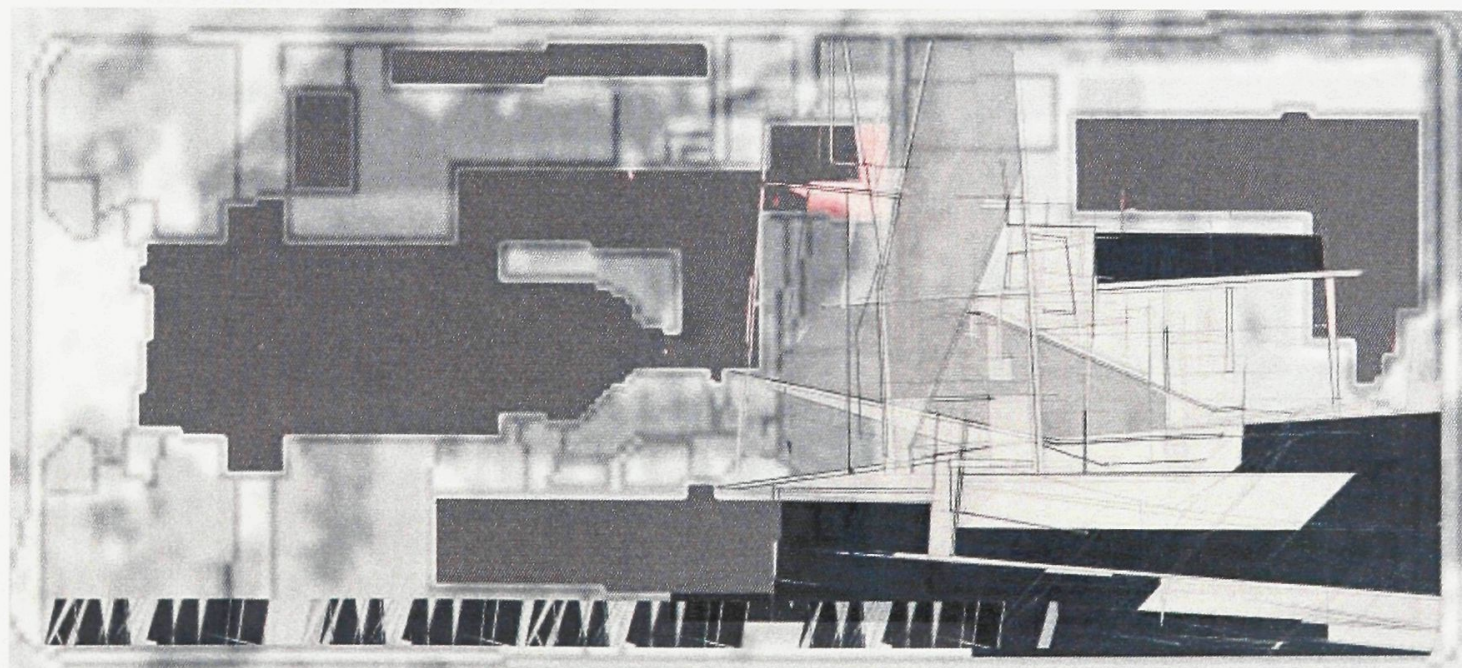

4.4.12 Plan Exploration \#3 


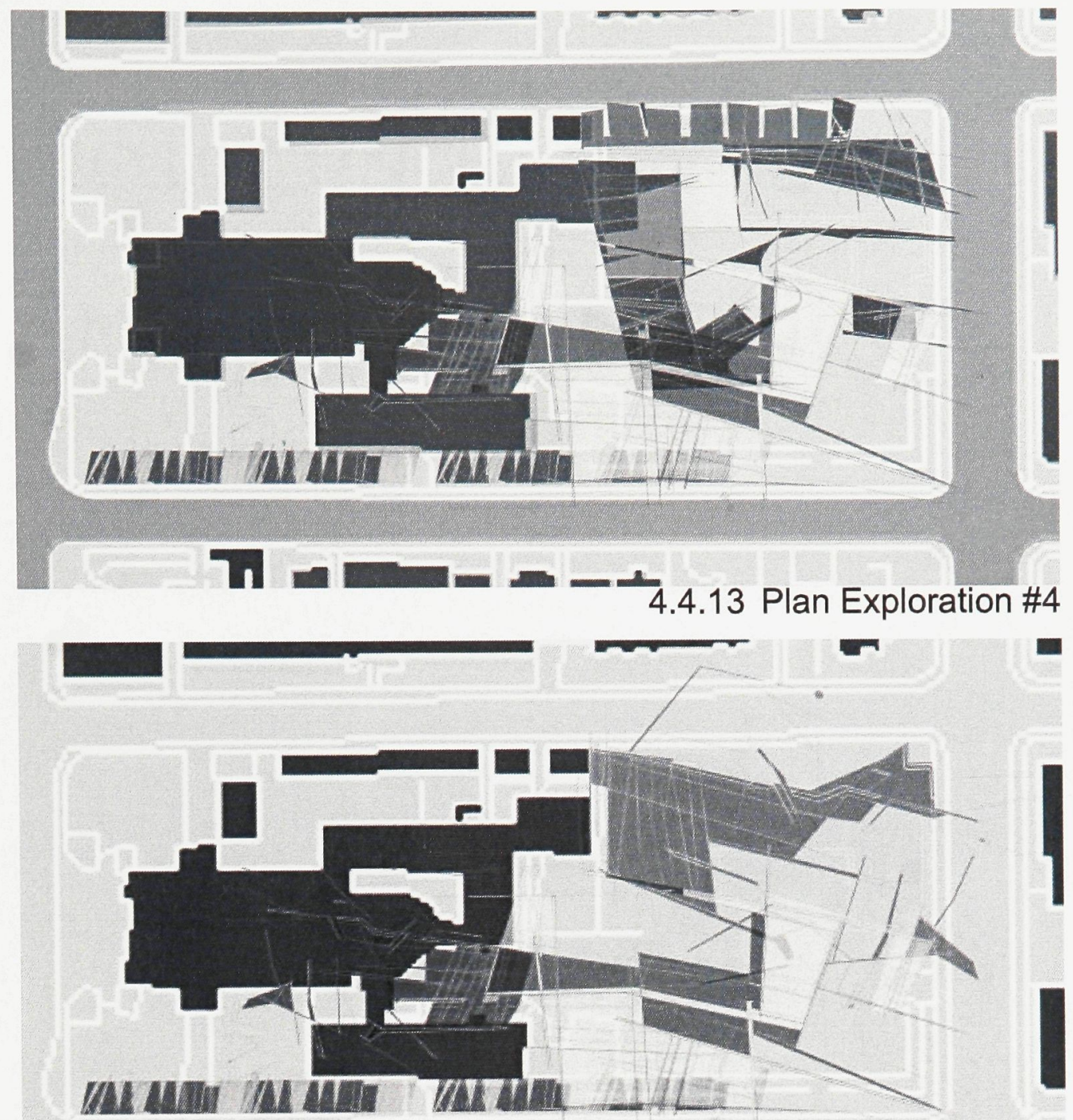

T.

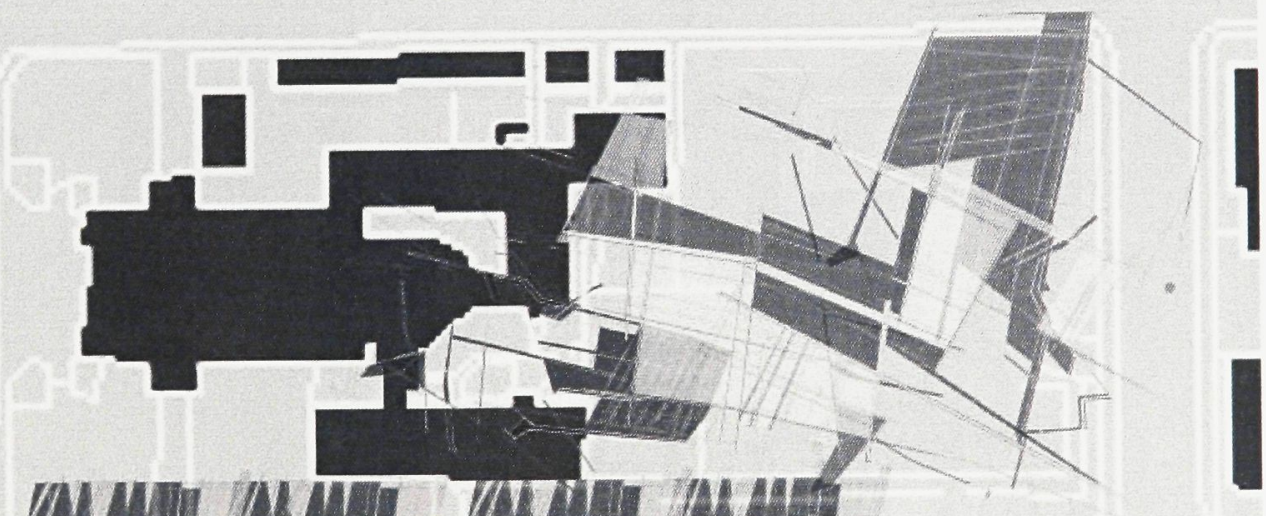

T. $=$ - 


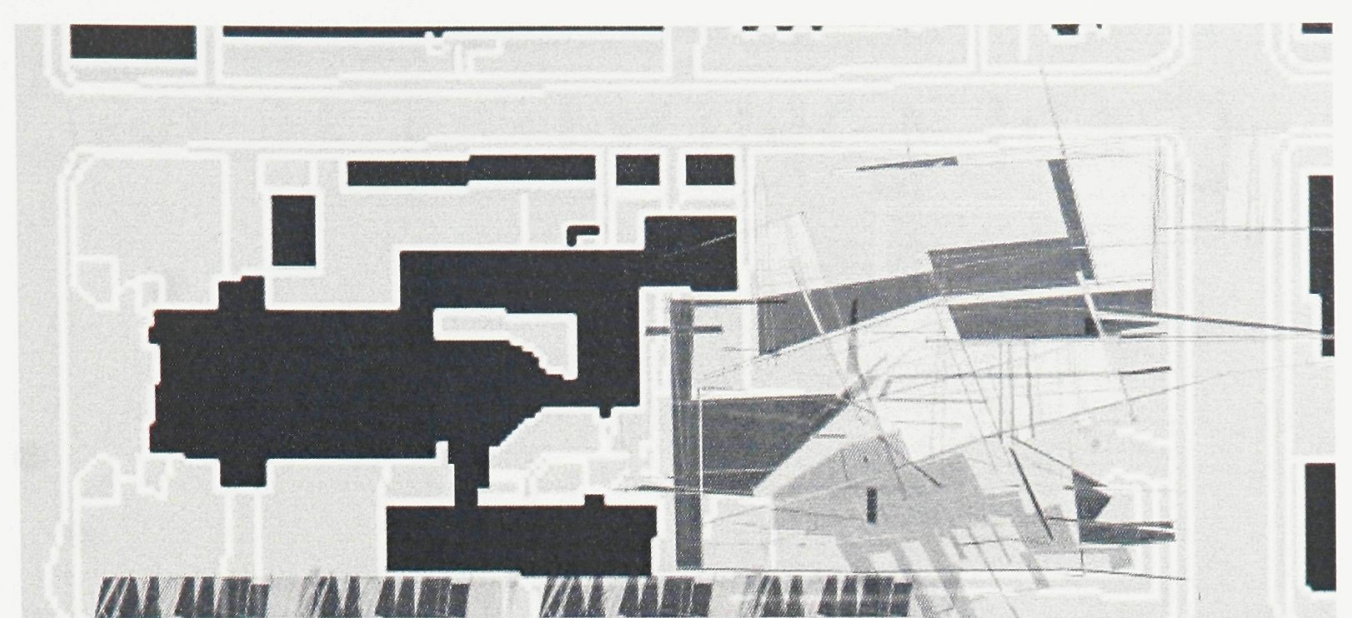

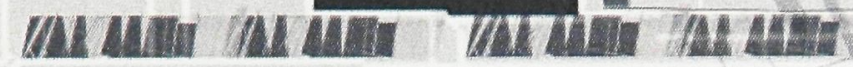
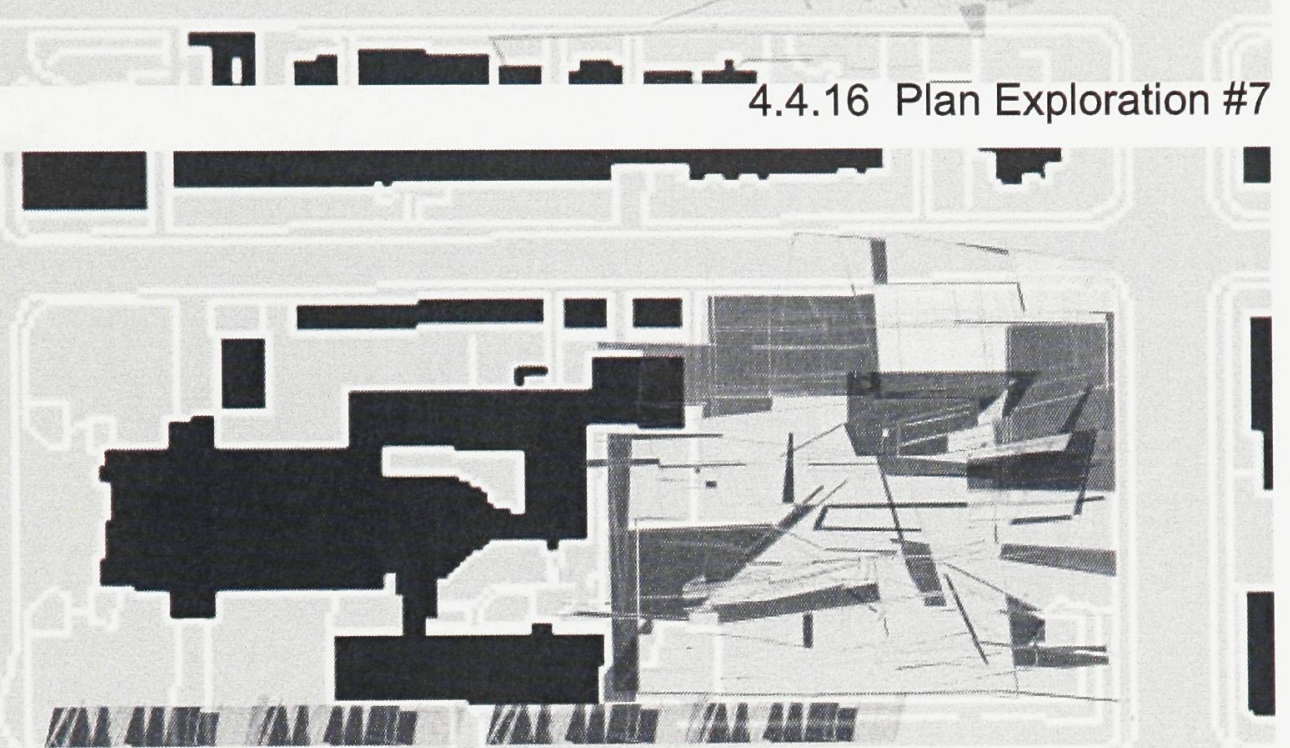

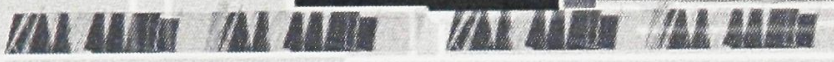
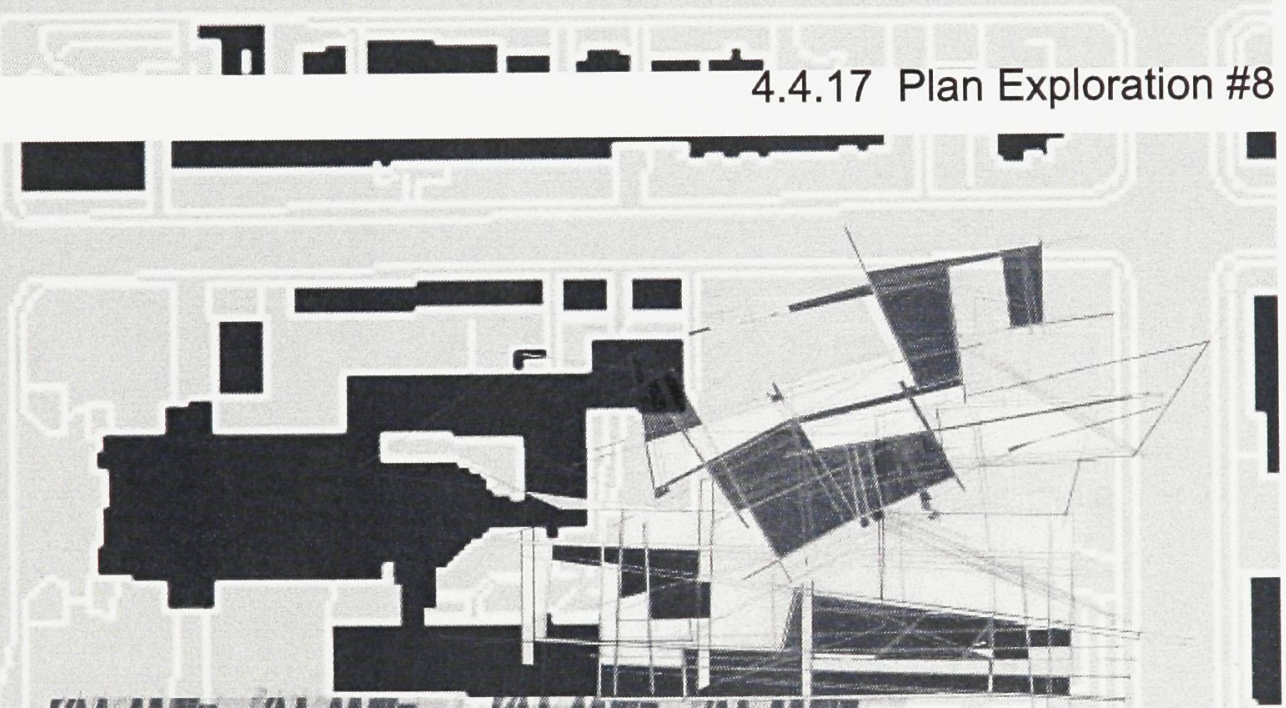

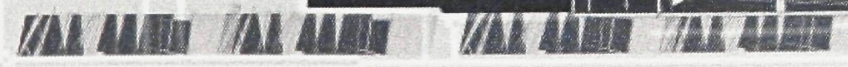

T - $=-\perp_{4.4 .18}$ Plan Exploration \#9 


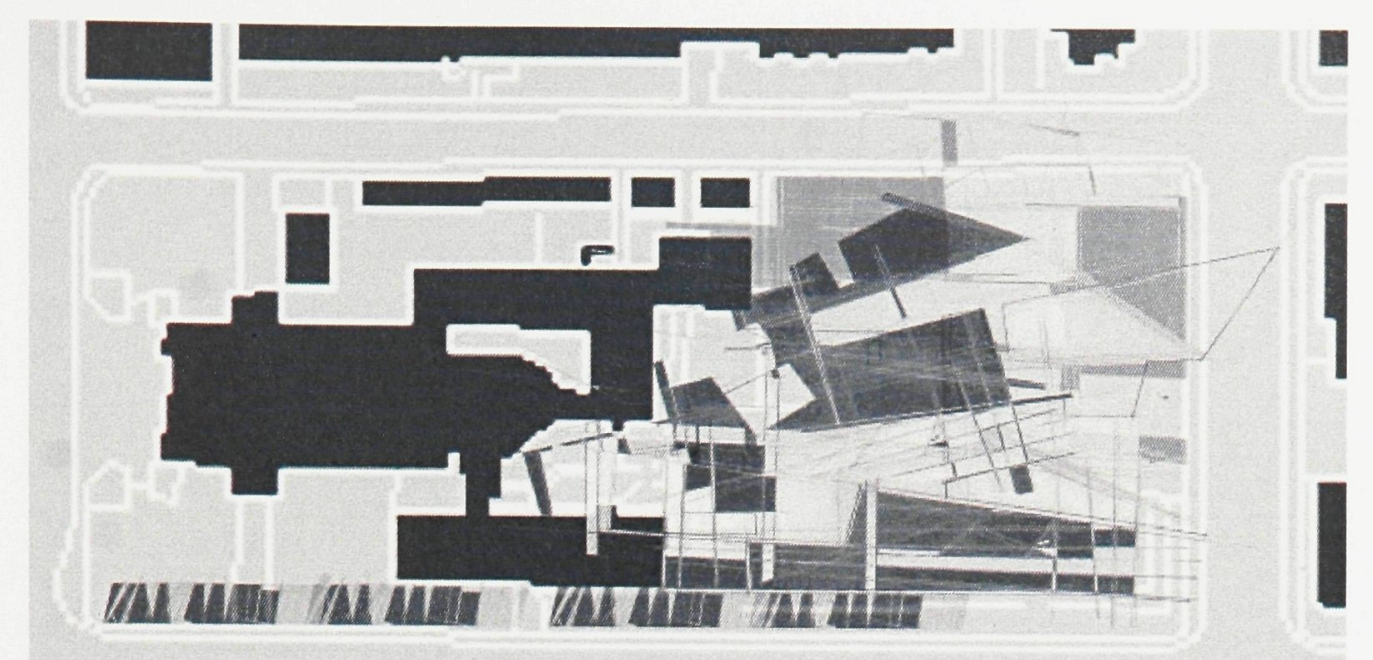

$$
\text { T. }=-\frac{1}{4.4 .19} \text { Plan Exploration \#10 }
$$
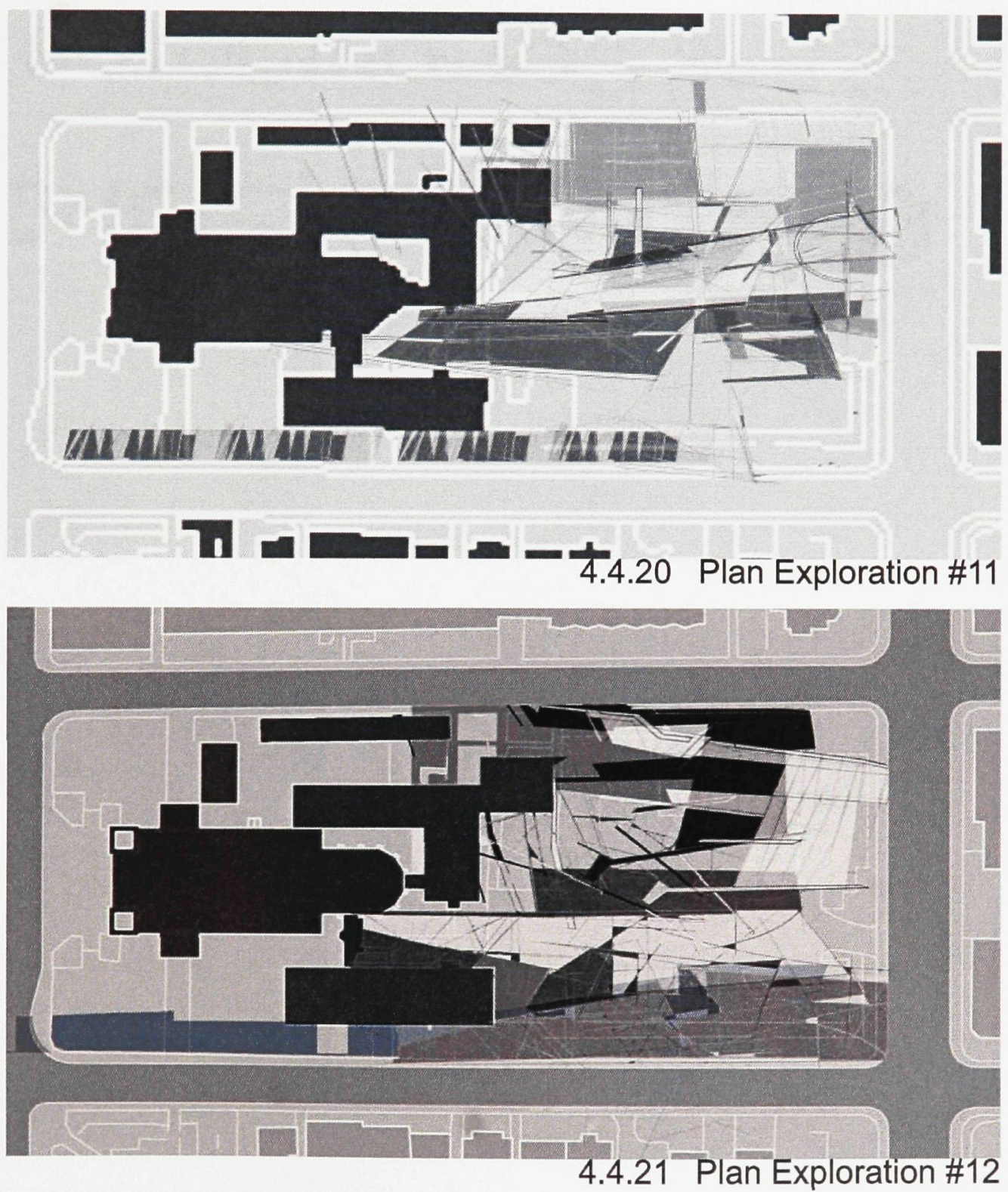

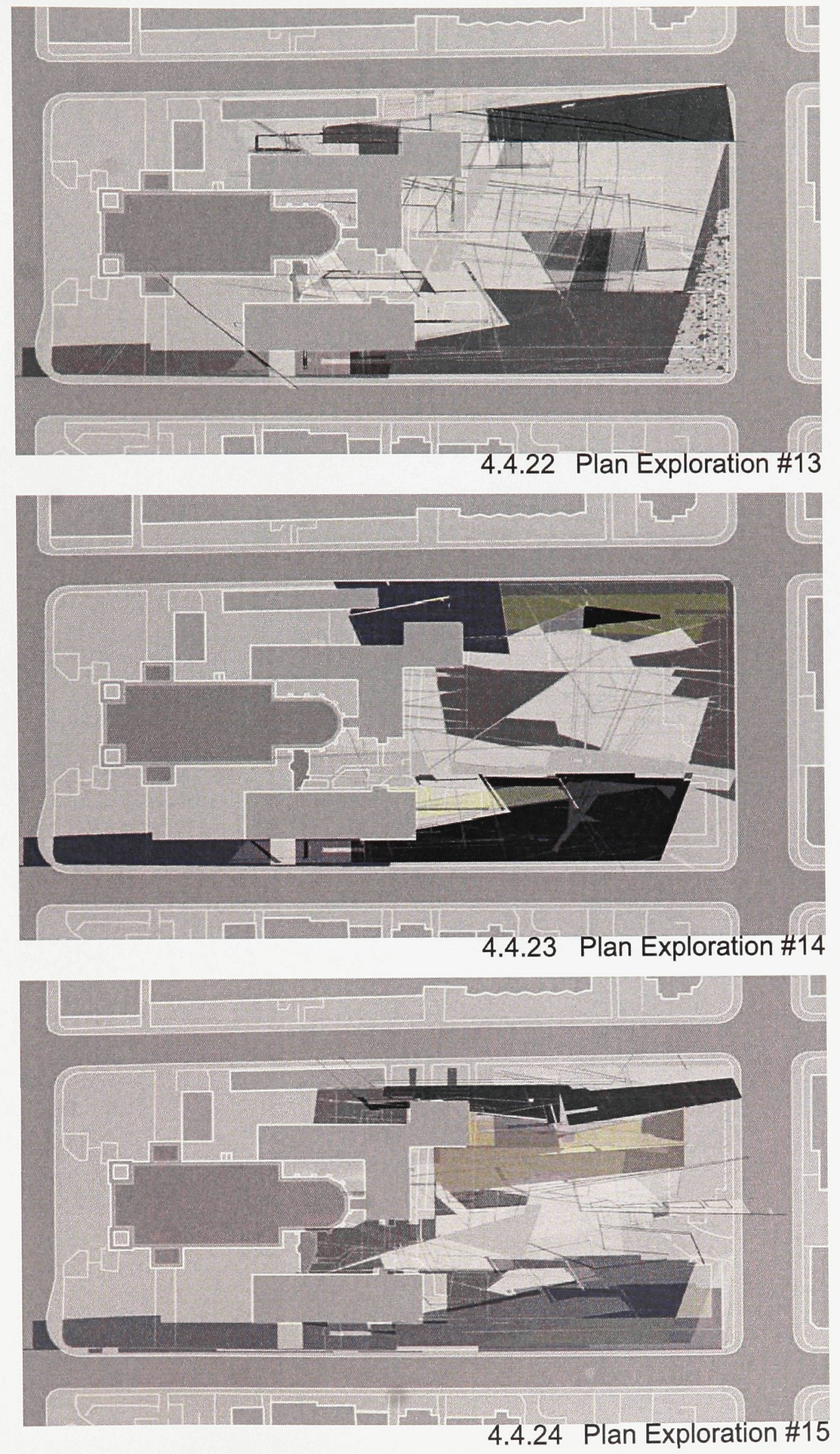

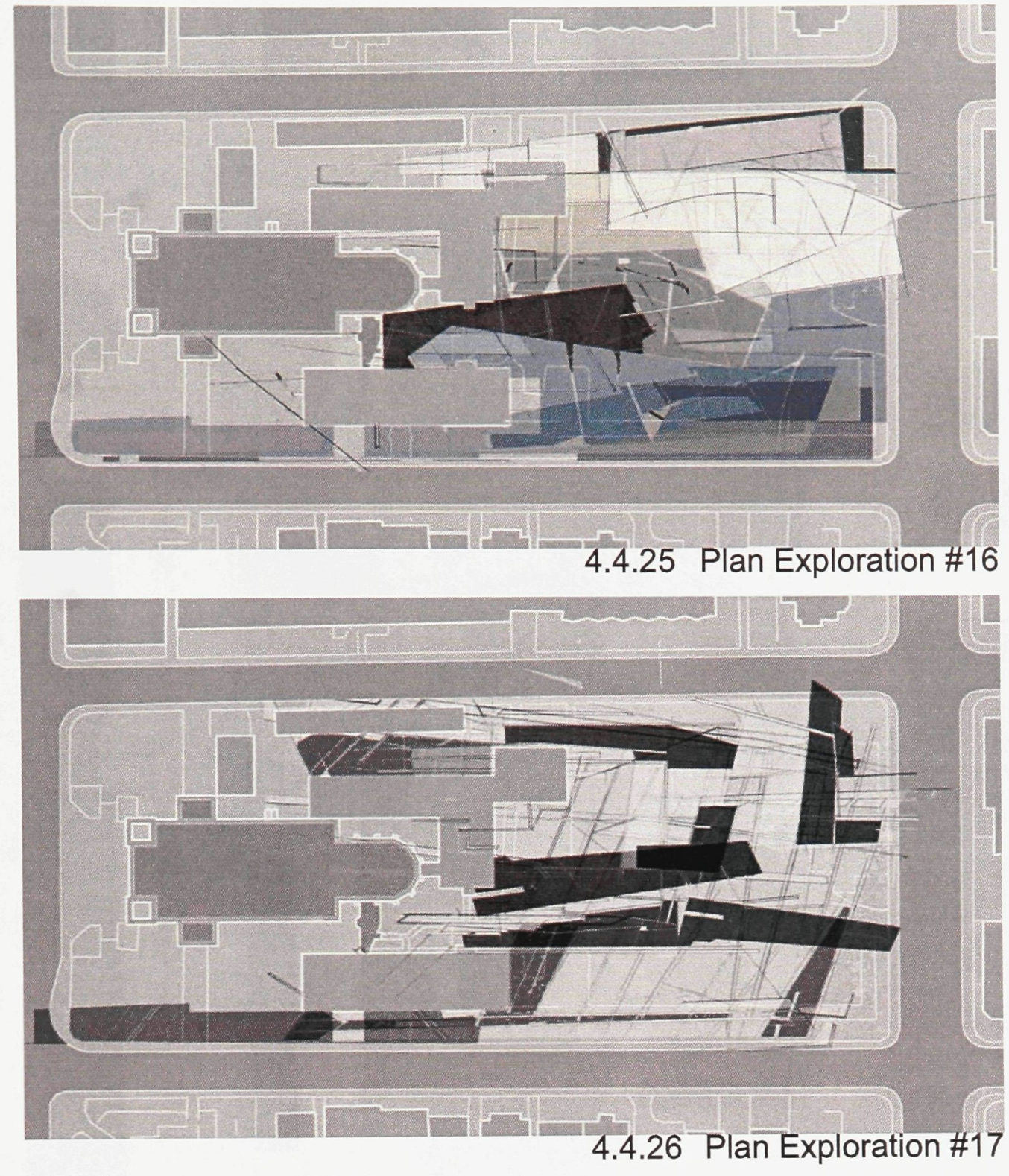


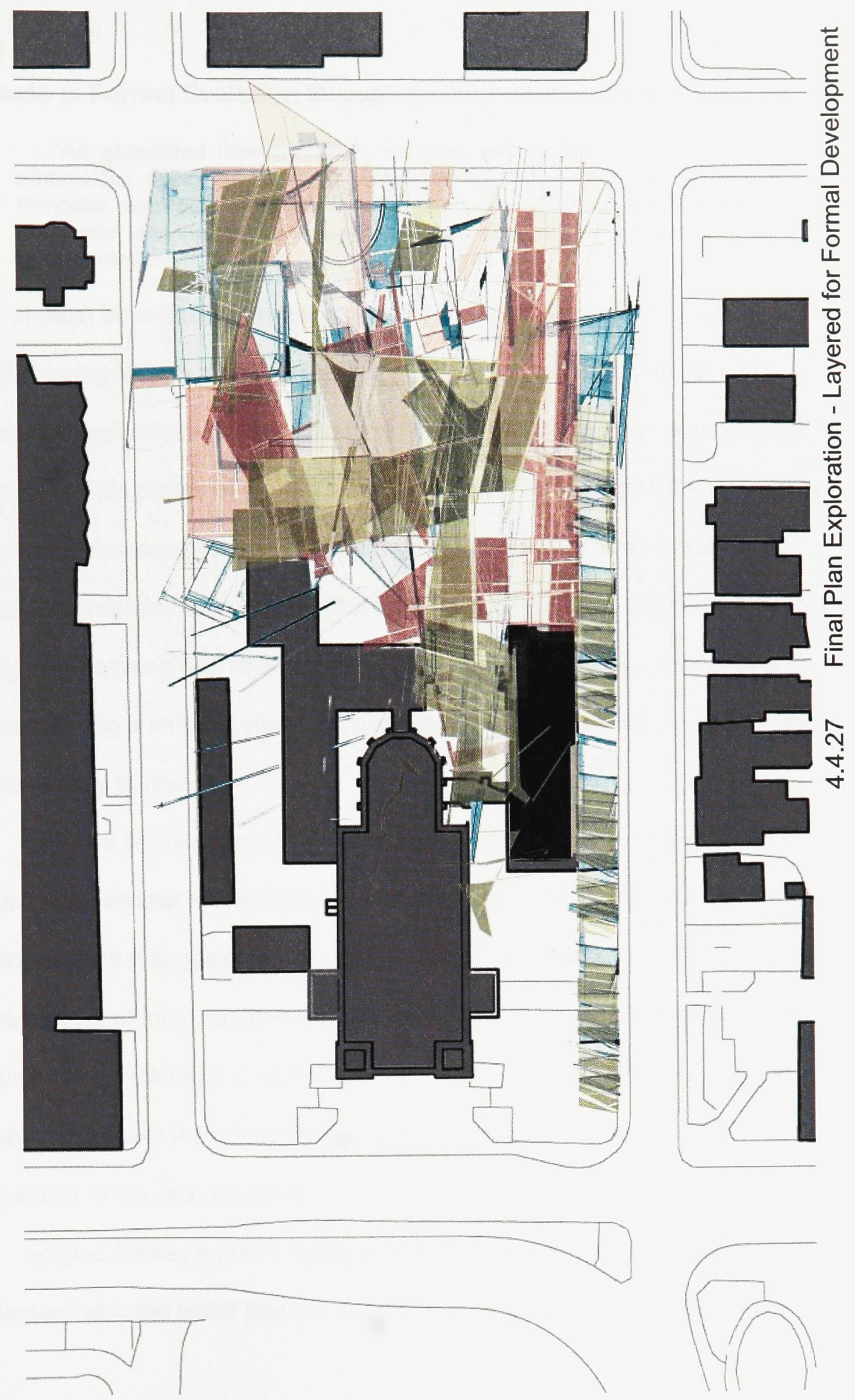




\section{5}

\section{Phase 8: Formal Evolution through Axonometric Projection}

"As objectified representation, isometry and axonometry occupy the ambivalent space opened up between the geometries of Monge \& Poncelet, oscillating between the extremes of self-evident representation (accurate description) and self-referential formulation (freedom from representation)."1

It must be made clear, that the intent of the project was to investigate the role of drawing in "imagining" architecture. In order to do so, the drawings evolved through abstract explorations of "no-thing" to the use of architectural convention. This phase of the project investigates the relationship between the section and plan explorations, attempting to formalize tectonics and the associated programmatic spaces that they begin to suggest. In order to do this, a new type of drawing had to be employed that could clarify this relationship while still maintaining a certain referential distance that would still allow the drawings an opportunity to reveal.

The use of the axonometric or isometric drawing was chosen for this phase. ${ }^{2}$ This schizophrenic drawing allows for an accurate (measurable to scale) development that suggests a possible reading of a building, while still allowing for a certain level of interpretation through its making. This drawing type fractures and unites the building into plan, elevation and section all at once. The drawings are abstracted with the complete removal of the horizon and the natural human perspective at the ground plane.

August Choisy's (1841-1909) comments on drawing and representation, culminated with the belief that the architect, through axonometric projection, 
could have total control in the creation of the world. He believed that it was the one mode of representation that could operate indiscriminately. ${ }^{3}$

"Axonometry implicitly may question the perspectival subject, yet it is also a form of optical representation that flaunts its clarity and freedom from atmospheric distortions. This is the paradox that we must understand in order to engage it critically.".4

Unlike traditional axonometric drawings that are generated from a conventional architectural plan, the project drawings are created by a series of abstracted plan explorations. These were not defined for specific floor levels in the building.

They are, rather, guides for the formalization of the building and program in the horizontal plane. In the spirit of the palimpsest, the axonometric drawings are developed directly over the abstracted plans and, simultaneously, over each other. As the drawings were developed, specific strategies relating to building form, tectonics, possible materiality, and most importantly programmatic relationships were beginning to be suggested. [III. 4.5.1 to 4.5.5] 


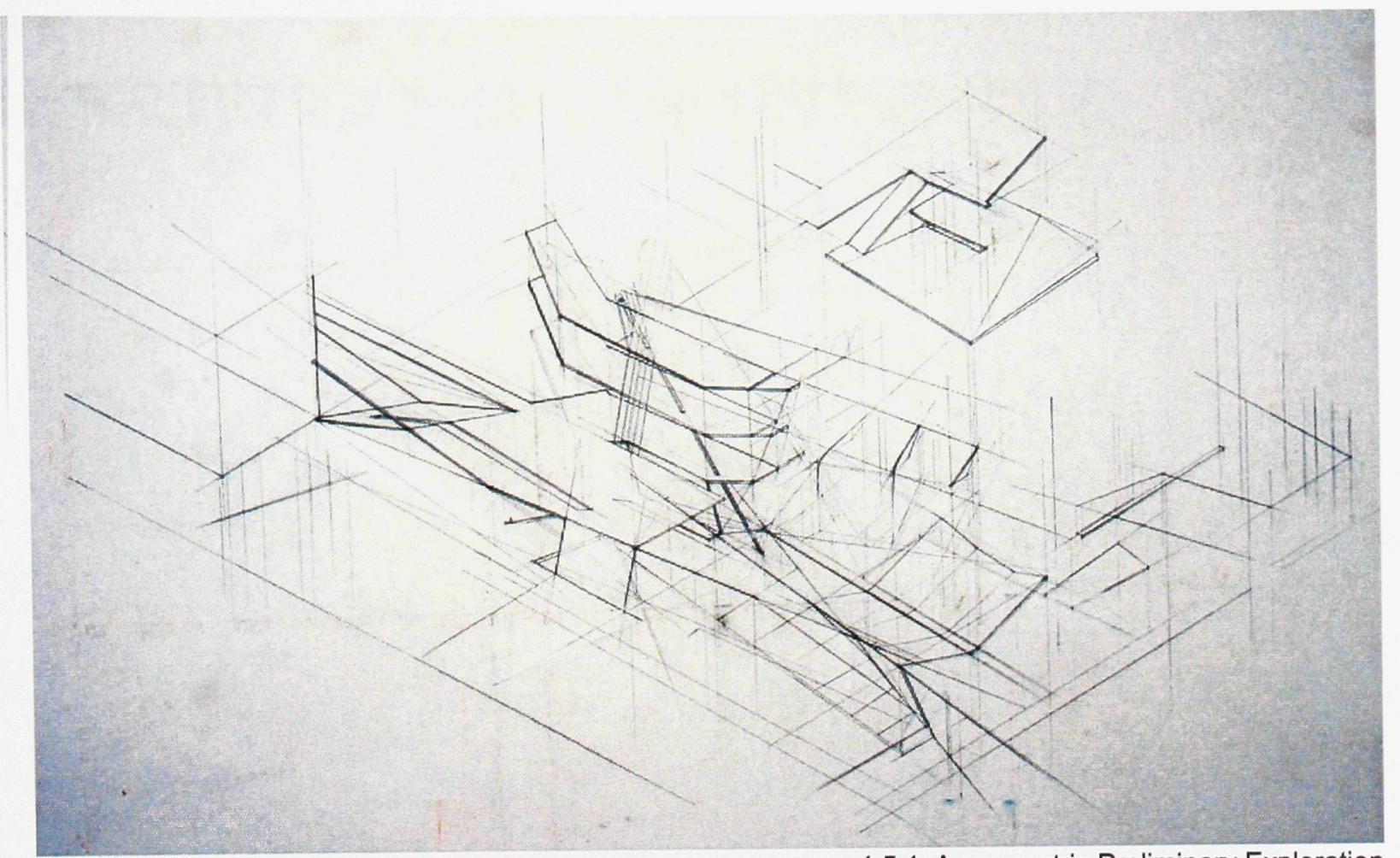

4.5.1 Axonometric Preliminary Exploration

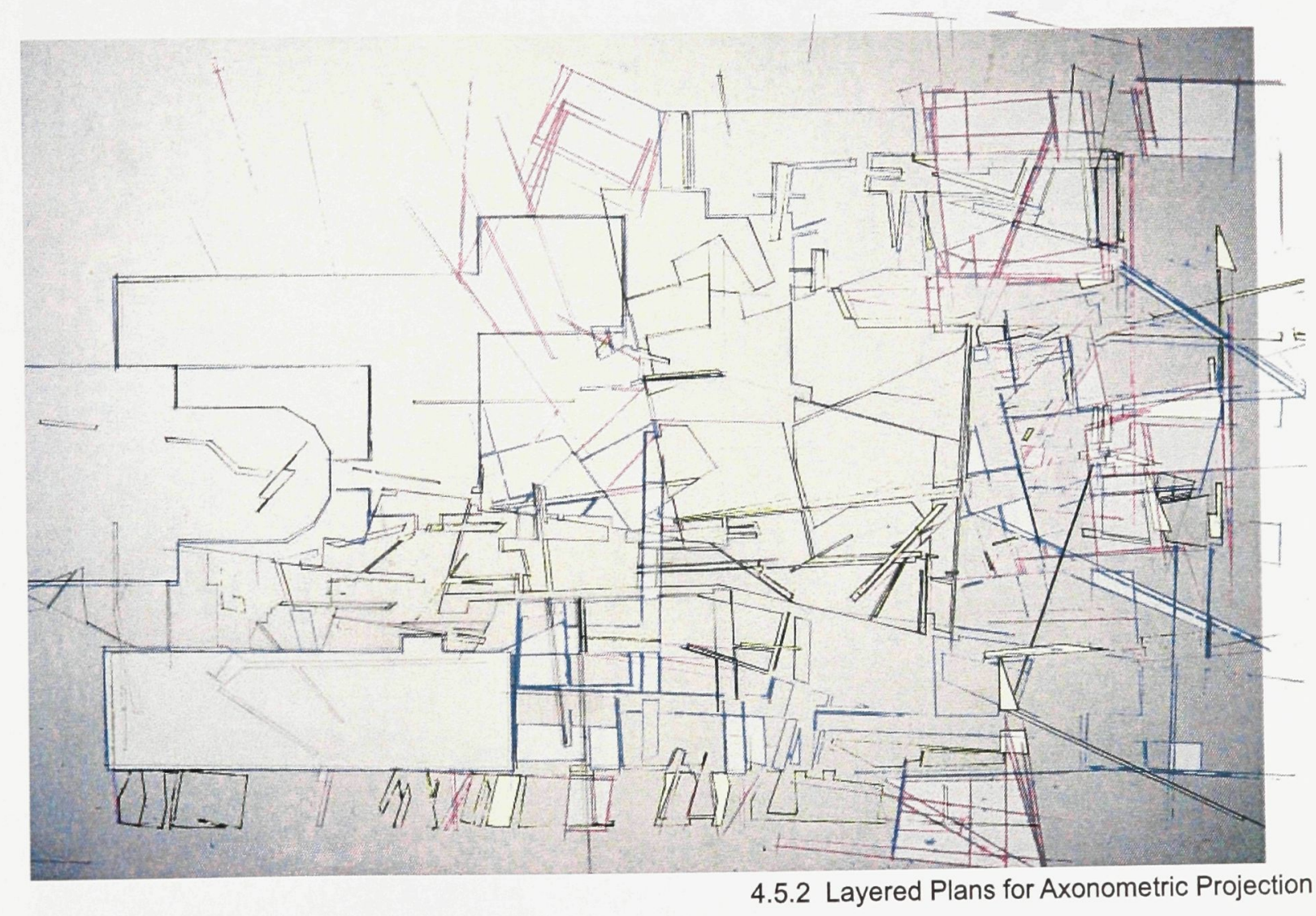




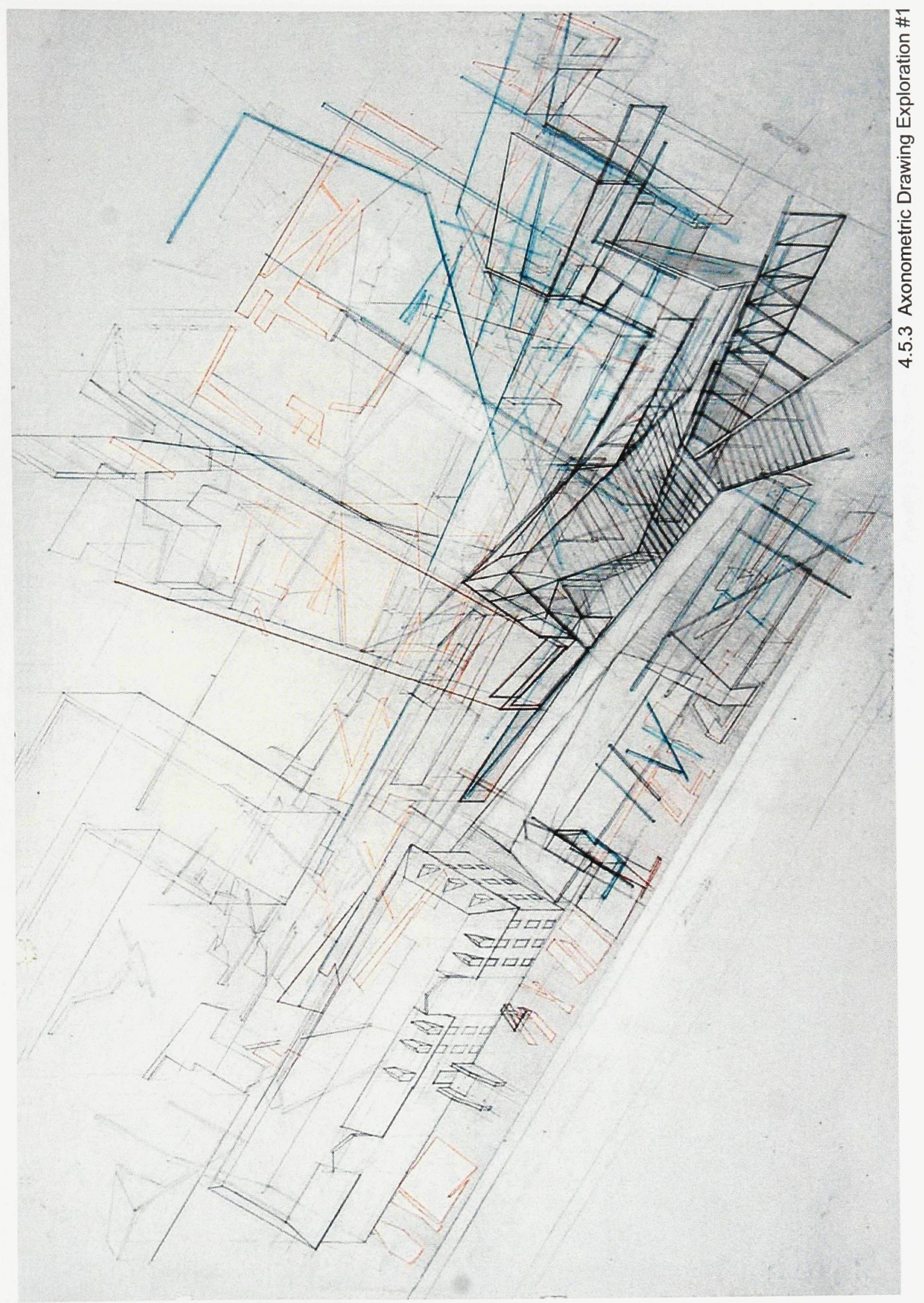




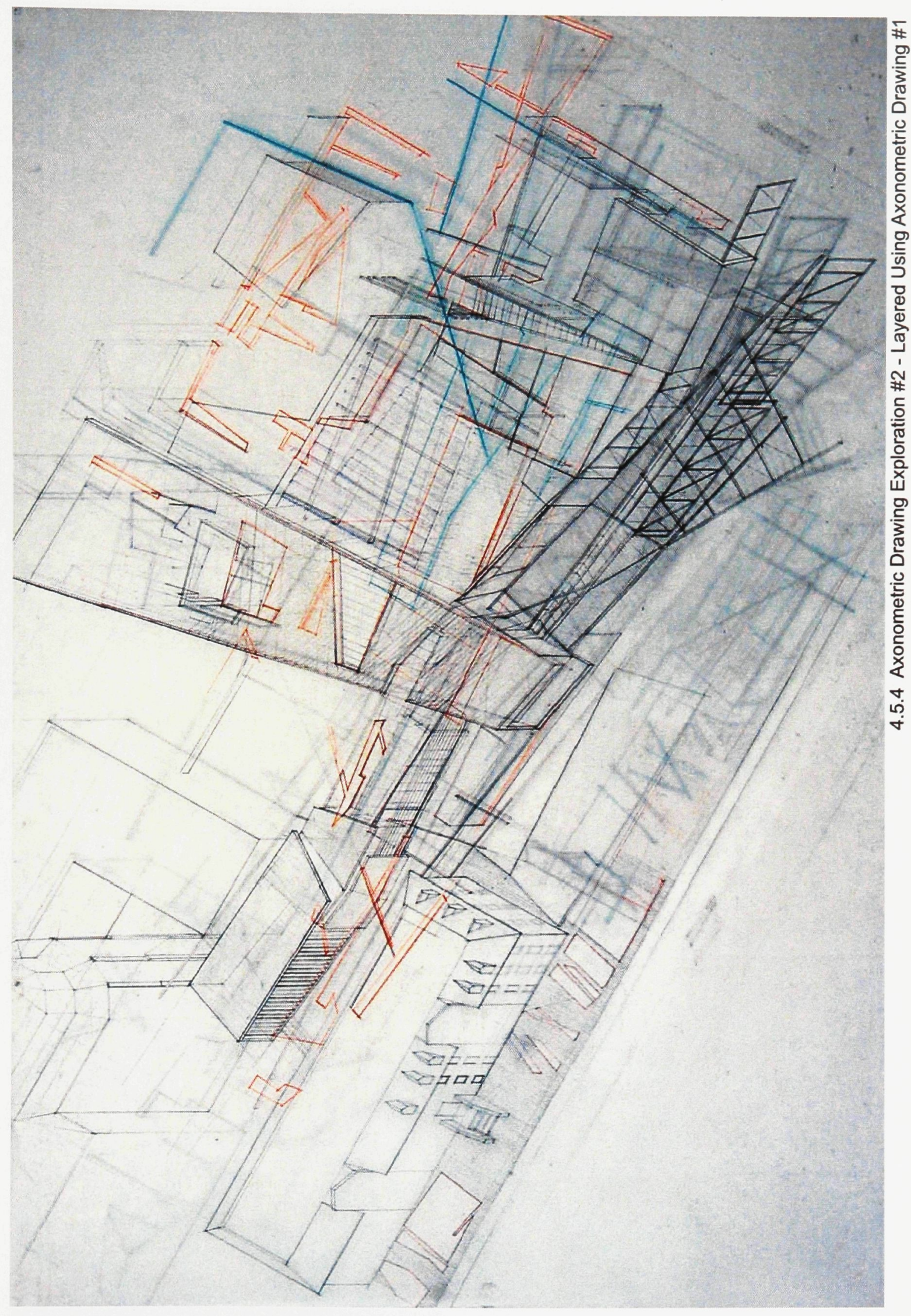




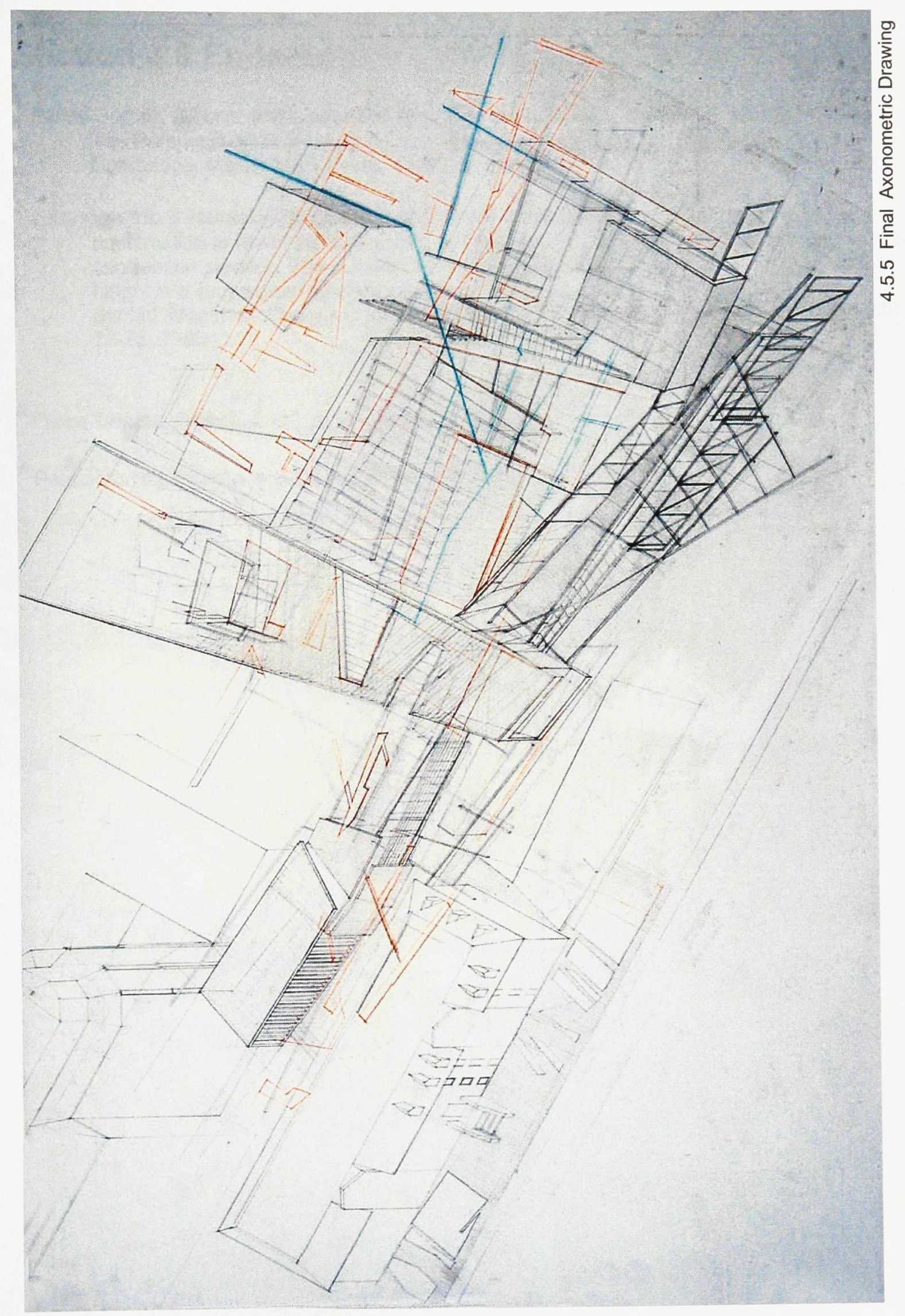




\section{Section 4.5 Endnotes}

1 Perez-Gomez, Alberto, and Louise Pelletier. "Variation Three - The Image without an Observer: The Perspective Hinge". Architectural Representation and the Perspective Hinge.

Cambridge, Mass.: M.I.T Press, c1997. p. 307-08.

${ }^{2}$ Axonometric \& Isometric Projection (the quality of measures or dimensions): A perspective construction in which the converging points are postulated at infinity, so that parallel lines can remain parallel. The axnometric drawing depicts length and width in relationship to height in a single drawing while retaining the constructional Scolari, Massimo. "Elements for a History of Axonometry. Architectural Design 55. (5-6): 73-78. 1985.

2 Perez-Gomez, Alberto, and Louise Pelletier. p. 314-15.

${ }^{4}$ Perez-Gomez, Alberto, and Louise Pelletier. p. 316. 


\section{6}

\section{Phase 9: R.A.I.C. Represented}

This final phase of the project begins to close the gap between interpretive drawings and conventional representation. Developed simultaneously with the axonometric drawings, these drawings consist of "final" project floor plans, elevations and detailed moments in the building. These drawings establish a more defined illustration of the final programmatic layout using a concurrent relationship of orthographic techniques and the plans. [III: 4.6.1 to 4.6.6]

Bearing in mind that these drawings were developed concurrently with the axonometric projections, they did not act as direct "referents" for the other drawings. They were a continuous and simultaneous exploration through drawing that begins to bind the strategies of the project together. These drawings give cohesion to all the drawings produced; from the projected to the axonometric continuously contributing to the imagining of an R.A.I.C. 


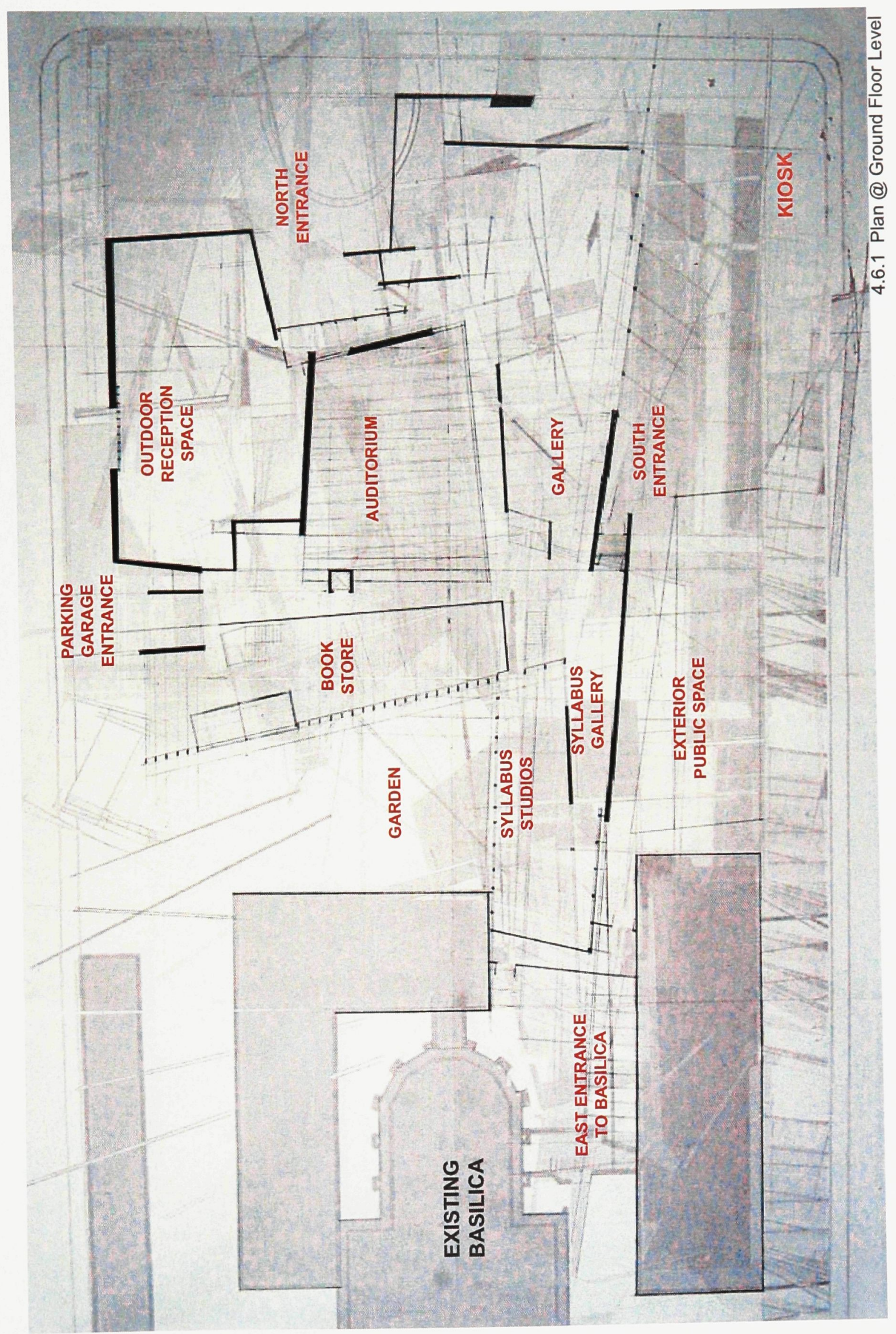




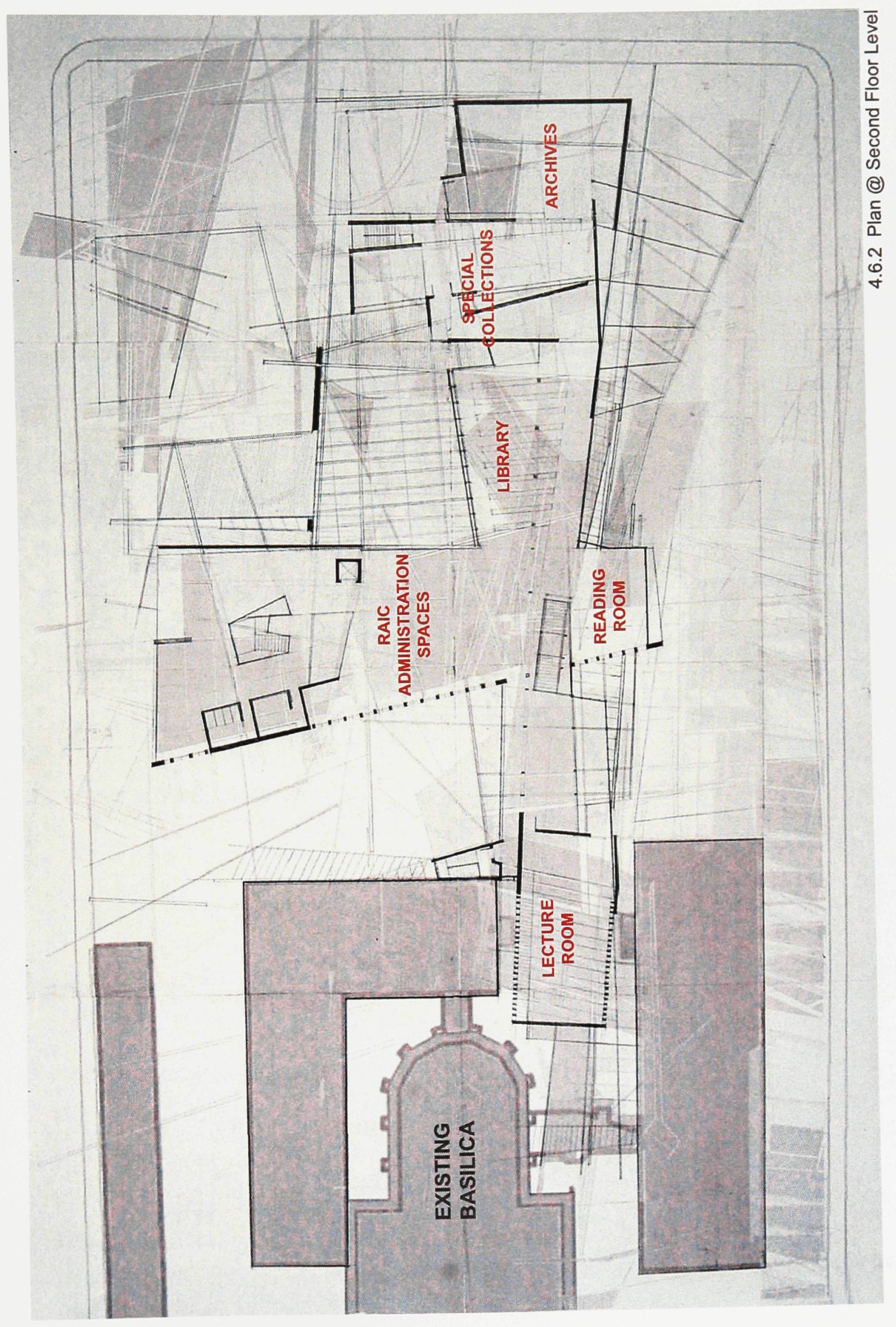




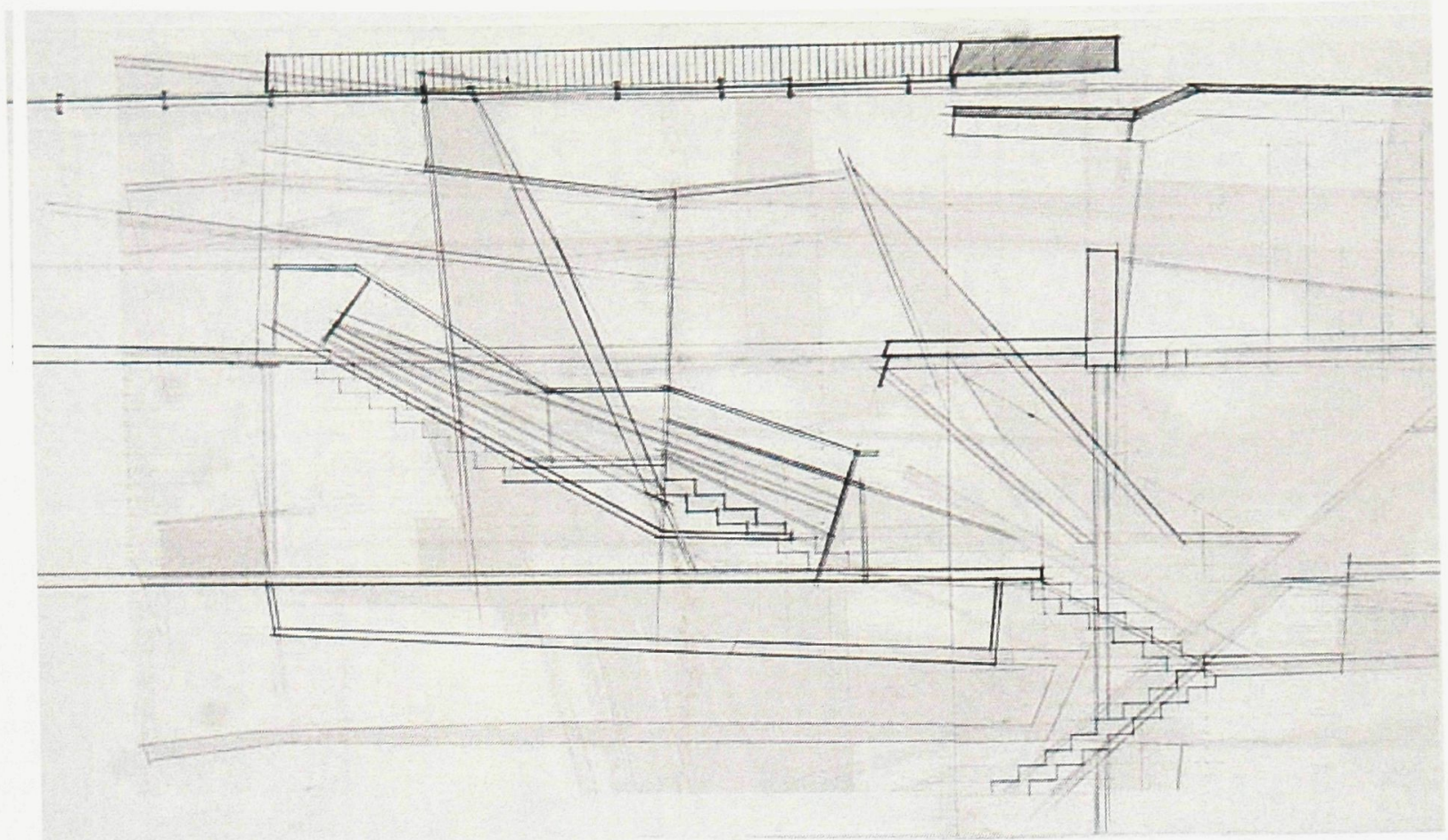

4.6.3 Section @ Main Stair

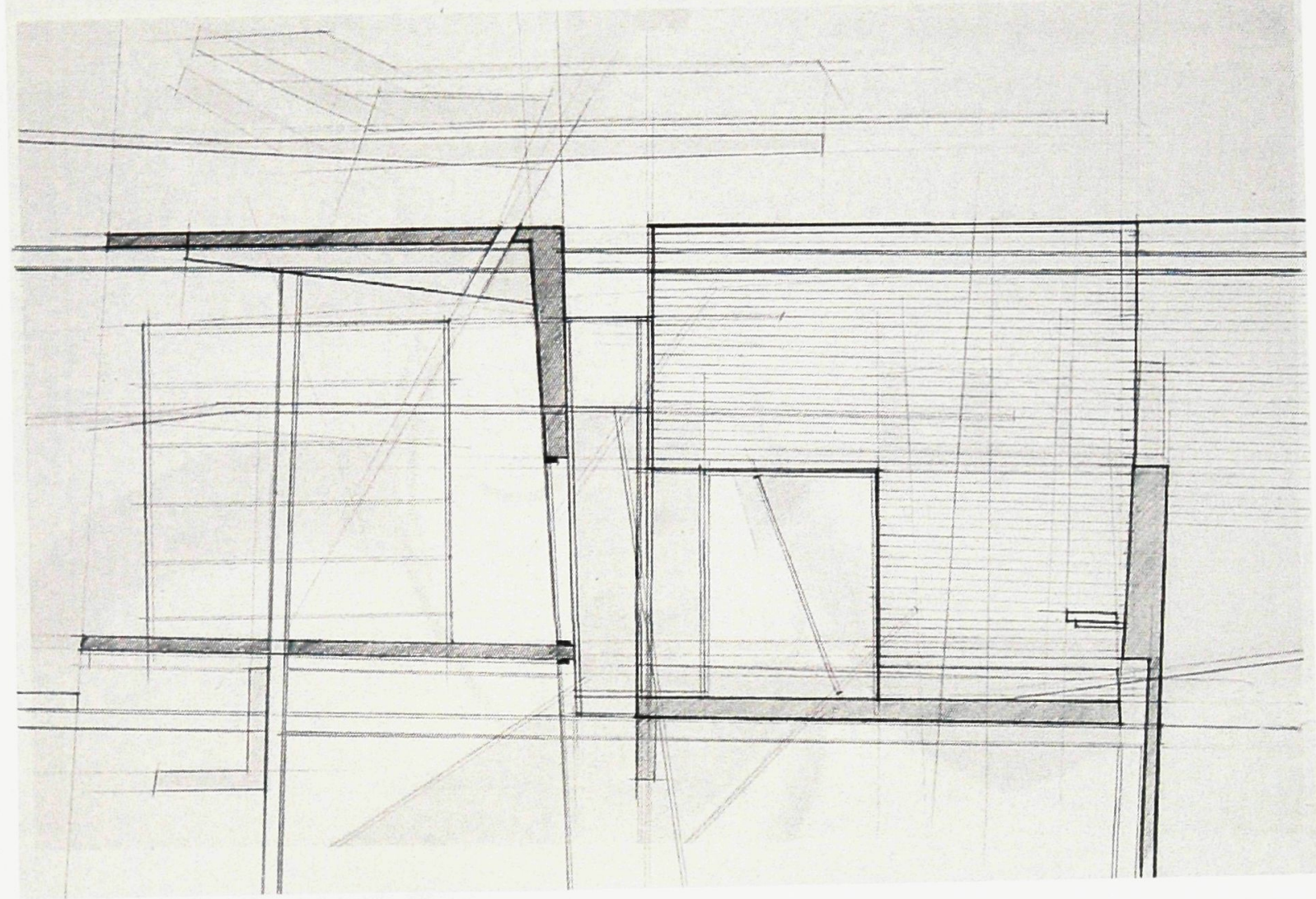

4.6.4 Section@ Library \& Archives Above Gallery 


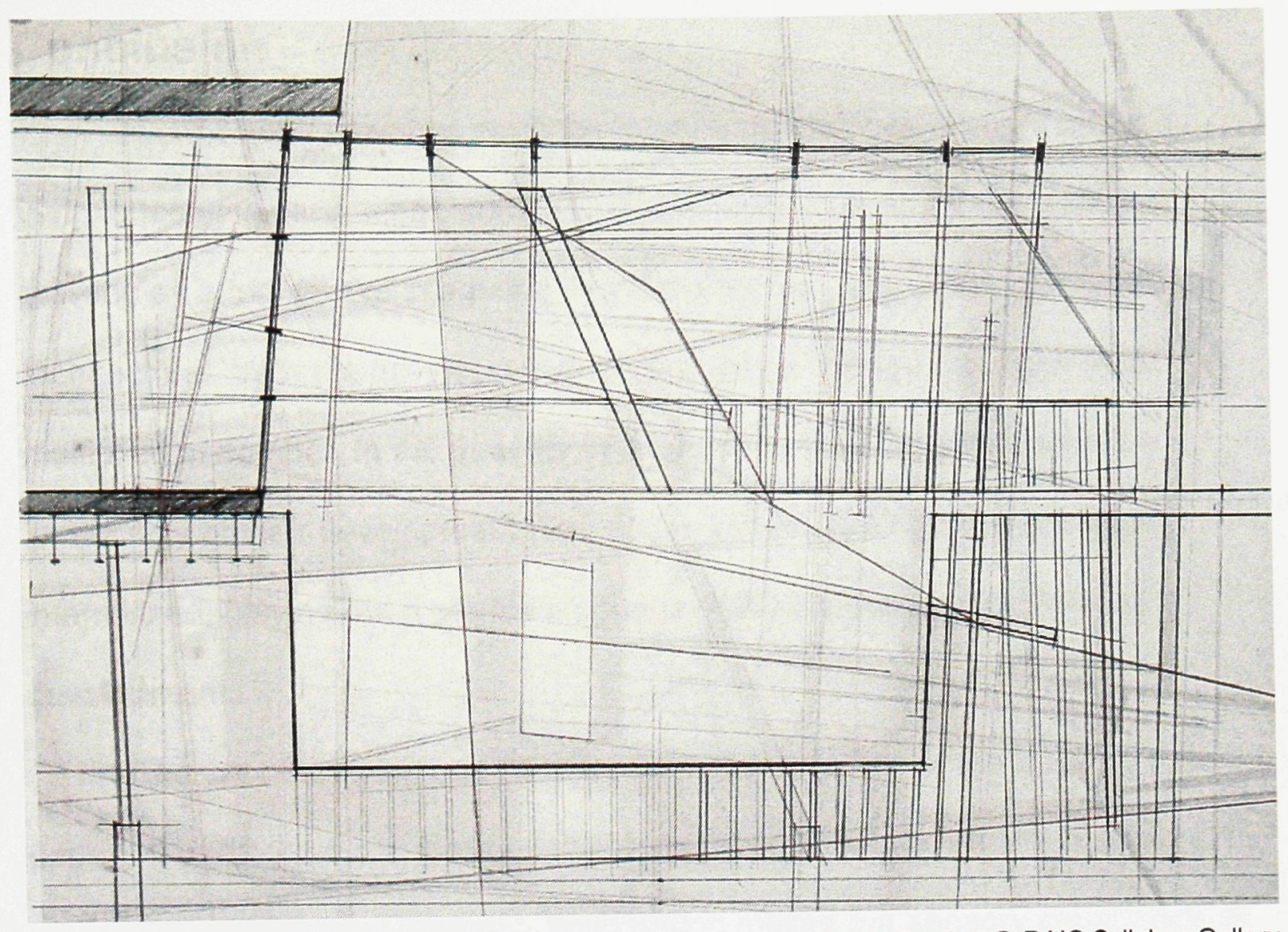

4.6.5 Section @ RAIC Syllabus Gallery

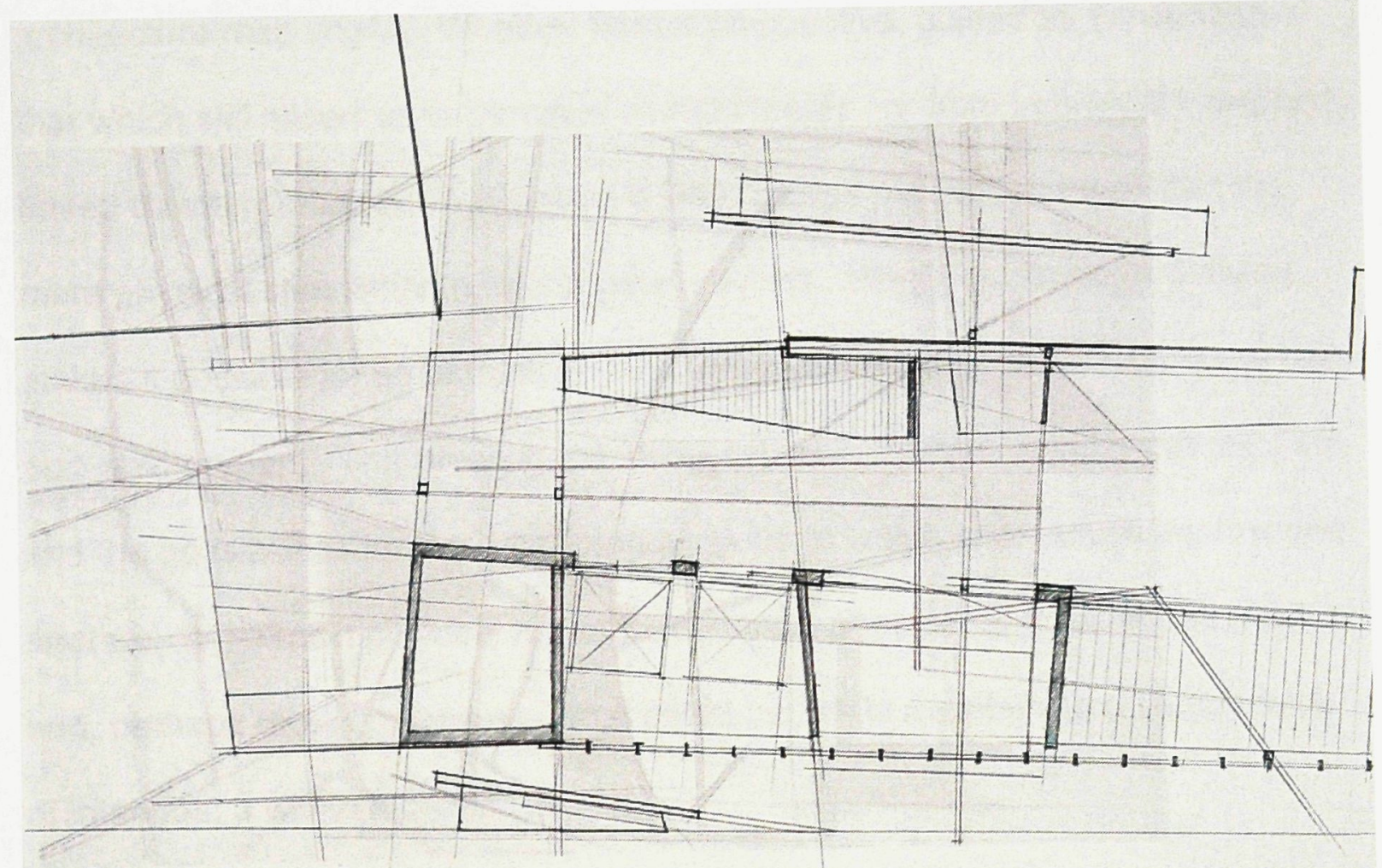

4.6.6 Plan @ St. Patrick Street Kiosk and Underground Parking Garage Pedestrian Entrance 


\section{Conclusion}

Architectural drawings continue to undergo changes brought about by various technological, legal, and cultural demands. This study has explored drawing as a tool for the imagining, the development, and in the representation of architecture. With the developments of new media, design drawings have multiplied in number, in the quantity of information they contain, and in the immediacy of their development. Yet, codes within drawing have become internalized, playing out a private language that excludes non-exploratory development.

The act of drawing can be more than the reduction of the building onto paper. It can be the site for the possibilities of architectural invention and a source for architectural thinking. Imagination makes our sensory experience of architecture meaningful. Whether from a perspective, guided by convention that which still allows us to perceive architecturally - or from individual viewpoints based on interpretation, imagination is what makes perception more than the mere physical stimulation of our sensory organs. Imagining, through drawing, makes it possible for us to think and explore outside the physical realities of our built environment. The drawing can allow us, as architects, to consider the past and the possibilities for the future and allow us to weigh alternatives against one another. It makes it possible for us to be critical about what is, what has been, and, perhaps most importantly, what might be, while maintaining a certain level of intention; a will to architecture. 
A question that has arisen out of this "type" of exploration, including those discussed in the precedent study, is whether we can separate an intellectual synthetic process from the social, cultural and urbanistic conditions or values that guide architecture? The drawings for this thesis have demonstrated that in fact they were never separated. By establishing the program (an R.A.I.C.

headquarters) and a specific site prior to the start of any drawing process, and contributing to my "knowledge" of architecture; [Appendix A] the drawings were constantly being framed by projecting, not only my accumulated understanding of architecture, but also by my understanding of the values of the R.A.I.C, the By Ward Market, and the City of Ottawa. Therefore these drawings can never be of anything else but that of an R.A.I.C.

Understanding the relationships that exist between the making of drawings and the reading of drawings, there is an opportunity to re-evaluate the drawing as an extension of the imagination. The drawings explored and developed in the defence of our thesis have indicated this. Through every phase of the design project, drawing was used to investigate the possibilities for generating new space and form. In order to curtail the abstraction of the drawings, certain parameters were instigated at each phase in order to guide the drawings toward an architectural reading. 


\section{Bibliography}

1 Braham, Allen. "Part Two: Buildings of the 1760s and Their Architects". The Architecture of the French Enlightenment. Berkley and Los Angeles: University of California Press, 1980.

2 Derrida, Jacques. The Truth in Painting. Trans. by Geoff Bennington \& Ian Mcleod. Chicago: University of Chicago Press. 1987.

3 Eisenman, Peter. Diagram Diaries. New York: Universe Publishing. 1999.

4 Evans, Robin. Translation from Drawing to Building. Cambridge, Mass.: MIT Press, 1997.

5 Evans, Robin. "In Front of Lines that Leave Nothing Behind." AA Files 6 (May 1984): 89-96.

6 Fraser, lain, and Rod Hemni. Envisioning Architecture: An Analysis of Drawing. New York: Van Nostrand, 1994.

7 Galofaro, Luca. Digital Eisenman: An Office of the Electronic Era. Berlin: Birkhäuser.

8 Jakobson, Romand. "Linguistics and Poetics: Closing Statement". Style in Language. Ed. Thomas Sebeok. Cambridge: Technology Press of Massachusetts Institute of Technology, 1960.

9 Kahn, Andrea. "Disclosure: Approaching Architecture," Harvard Architectural Review (1992), n. 8, p. 4.

10 Kleinhenz, Christopher. "Palimpsest". Medieval Manuscripts and Textual Criticism. Chapel Hill, N.C.: University of North Carolina Dept. of Romance Languages, 1976.

11 Libeskind, Daniel. Daniel Libeskind: The Space of Encounter. New York: Universe Publishing, 2000.

12 Libeskind, Daniel. Daniel Libeskind: Countersign. New York: Rizzoli International Publications. 1991.

13 Libeskind, Daniel. Jewish Museum Berlin: Architect Daniel Libeskind. Berlin: G+B Arts International. 1999. 
14 Marx, Karl. The Communist Manifesto: Annotated text / Karl Marx; prefaces by Marx and Engels; Edited by Frederic L. Bender. New York: W.W. Norton, 1988.

15 McLuhan, Marshall. Understanding Media: The Extensions of Man. New York: McGraw Hill, 1964.

16 Meissenheimer, Wolfgang. "The Functional and the Poetic Drawing". Daidalos. September 1987.

17 Maurice, Merleau-Ponty, "Eye and Mind". Trans. Colin Smith. Primacy of Perception. New Jersey: Humanities Press, 1976.

18 Perez-Gomez, Architecture and the Crisis of Modern Science. Cambridge, Mass.: M.I.T Press, 1983.

19 Perez-Gomez, Alberto, and Louise Pelletier. Architectural Representation and the Perspective Hinge. Cambridge, Mass.: M.I.T Press, 1997.

20 Picon, Antoine. French Architects and Engineers in the Age of Enlightenment. Trans. Martin Thom. Cambridge: Cambridge University Press. 1992.

21 Sartre, Jean-Paul. "Being and Nothingness". in McNeil and Feldman. Continental Philosophy. London: Blackwell. 1998.

22 Sartre, Jean-Paul. The Imaginary: A Phenomenological Psychology of the Imagination. London: Routledge, 2004.

23 Scolari, Massimo. "Elements for a History of Axonometry. Architectural Design 55. (5-6): 73-78. 1985.

24 Watts, Earle F., and John T. Rule. Descriptive Geometry. Englewood Cliff's, N.J.: Prentice-Hall, Inc., 1946. 


\section{Appendix A}

\section{Imagination}

This chapter will evaluate drawing to be an act of imagining by referencing Jean-Paul Sartre's (1905-1980) explorations on the imagination. As has been already suggested, imagining through drawing is a two fold act: it is a physical act through its making and a psychological act through its reading

Sartre's general theory of the imagination explores the quality of Being, of the imagined object, in the actual absence of that object. In other words, there is an "otherness" in the midst of imaginary representation. The image involved represents or depicts something or someone who is not actually there. In the realm of the mental, an image is that; an image. It is not an object of representation, but an image of an object onto itself. An image, which is a creative act, is always subject to the spontaneity of consciousness. It may sustain certain qualities of a specific object, but through its continuous creative process, the image consciousness "creates" un-real objects. In order to fill in the blanks needed to create the image, consciousness requires pre-given "knowledge" for the completion of its mental materialization, which we will discuss in more depth, further in this section.

The word "image" could only indicate the relationship of consciousness to an object. It is the certain way in which an object appears to consciousness or a certain way in which consciousness presents itself to an object. ${ }^{1}$ Appreciating and sequentially reflecting upon this newly developed image object as another object is an incredibly difficult undertaking and therefore often only understood as 
a representational facet within the mind. This is a similar approach undertaken by architectural drawings guided by convention. These types of drawings, rarely observe beyond the universally associated languages attributed to architecture, preventing them from seeing something new. This is because little ambiguity through representation is required in order for the drawings to be used as instructions for making. This is not to say that it does not happen, those who can suspend disbelief like Robin Evans ${ }^{2}$ suggests, or those with the ability to perceive the depth of the world like Merleau-Ponty ${ }^{3}$ suggests - have the ability to visualize the mental images stemming from any drawing, and possibly triggering a phenomenological experience. When we see the depiction of space in an architectural section it can initiate an imaginative response that convinces us of the possibilities of a scaled space, but in most cases, this is only a reactionary response. One that may be latent in language, symbolism or even metaphor, but still remains in the realm of a development after the fact. Our training and experiences as architects allow us to suspend this disbelief in order to make the transition between drawings or models, and their relationship to depict the possibility of space or a building form. However, to do this, we have established fundamental rules that guide us through this transition, such as scale and the various semantics behind orthographic projection. According to Sartre, there are only three: perception, conception and imagining. ${ }^{4}$

Perception is about the observation of objects, which attempt to enter whole into our consciousness, but because a real object (building) is involved, it can never enter into my consciousness as a whole. It can only reveal itself to me 
as we see it physically. In perception knowledge is formed slowly, as we digest the interludes of an object. Perception posits its object as existing. Without the presence of the object, a building for example, a perception of that building and its' spaces is not possible.

"All this has been said a hundred times: it is characteristic of perception that the object never appears except in a series of profiles, of perceptions...The perception of an object is therefore an affinity of aspects."

Conception is an act of thinking concretely (thought), even though the object is not present. The image is not fully defined and therefore leaves room for progression. It does not recover images like perception as it is an act of thinking. Here, unlike perception, knowledge is defined in a single act of consciousness. ${ }^{6}$ In the case of the thesis explorations, conception can really only happen in mental consciousness, as it is difficult to instantaneously develop an idea through drawing since the act of drawing requires time and effort to develop.

The act of imagining, the third means, has an affinity to both perception and conception. Yet, unlike perception which allows room for an abandonment of the hypothesis, to imagine is about an absolute certainty. Like conception, knowledge is formed immediately but taken to elements more properly representative. Yet, a distinction that the thesis takes in opposition to Sartre is his belief that once the image is revealed to us in consciousness it can no longer teach us anything. If architectural drawings can overlap themselves between the realms of perception and imagination, they can stabilize themselves enough for us to learn and observe from. While still referencing something specific simultaneously, and reveal to us something that did not exist prior to its' making. 
The distinguishing difference between an image - through drawing - and perception is the introduction of self reflection. Thinking and reasoning are a creative act, not a reactionary act such as the way that perception forces itself into consciousness. When I see a building (mentally or through drawing), the object building is thrust, almost uncontrollably, into my consciousness. It is not an act of creation or more appropriately imagining; it is an awareness created only by forced physical observation. The imagining of a building, on the other hand, can be formed regardless of its physical presence. It is an introspective act of creating and associatively becoming an idea. This must be clearly understood in order to fully evaluate the thesis drawings' potential to threshold these moments. Throughout every stage of the process, the drawings will exploit this threshold moment; shifting between imagining and referencing architecture. These verge occurrences are what make the drawings legitimate explorations in abstract ideas while still maintaining an affinity with conventional architectural representation.

"If the intention is taken at the origin, which is to say when it springs from our spontaneity, it already implies, no matter how naked and bare it may seem, certain knowledge: it is hypothetically, the knowledge of the object...In a word, the pure intention is a combination of contradictory terms; since it is always an intention towards something...It must therefore be charged with knowledge (connaissance)."

The production of an image consciousness is to make an 'intentional' synthesis of past moments, which asserts the image object under a specific position (how we see the image). This aspect is inherently intuitive, whose intentions are aimed at the object's corporeality (physicality - not spiritual). This is how we interpret architectural representation. These intuitive intentions are 
guided by the knowledge ${ }^{8}$ that we as humans have accumulated over our individual lives, as architects and students of architecture. It is where a lifetime's worth of memories, experiences and educations are stored until they are needed by consciousness for such things as engaging the imagination. According to Sartre, knowledge is acquired from the sub-conscious. If someone was to ask us to 'imagine' (make the image of) the experience of ecstasy through architecture; these mental images would manifest themselves in different forms. Based on their knowledge someone might visualize their experience of a French Cathedral. Another may visualize light as an architectural metaphor for divinity. Knowledge is dependent on the personal conditions of an individual's subconscious; subjective in the communal realm, but somewhat objective in the personal.

The belief in the image posits the intuition but does not posit the actual object. ${ }^{9}$ Image is defined by its intention. Intention makes the case that the image of an object is consciousness of the object. 'Autonomy' and reflecting upon the imagined object established by this, allows the ability to move beyond nothingness, ${ }^{10}$ and is what Sartre refers to as freedom. This freedom allows us, as human beings, to engage the imagination with individuality; a free will that can give drawing independence.

In the imagination, the distinction between knowledge and intention can only be understood through its abstraction. Intention is defined only by knowledge because we create images based on what we know. It is not solely a static understanding, but an 'act' of that which we represent to ourselves. It is also, not an added element to an already composed image set up to clarify its 
existence, but the active composition that triggers the imagination. Knowledge goes through a radical modification even before it becomes constituted as an image. Knowledge can exist in a free state; creating consciousness through its own existence. Yet, an image cannot exist without knowledge to constitute it.

The progressive role that drawings can have is that of giving the image object a tangible grasp of awareness. They can give to consciousness things that are conceived, perceived or constructed and a way of not only referencing memory and experience, but of potential possibilities. If drawings can begin to exploit the suspension of our disbeliefs, they can begin to reveal another means of imagining for the architect. A way of developing architecture, through drawing, that is inherently tied to its communicative abilities and relating an architectural proposition without having to enclose itself within the boundaries of its own conventions. This not only requires drawings to be primarily antonymous in their making, but require a response to the drawings that can either be subjective or objective, dependent on whether an action or reactionary response is required. Reflection develops autonomy. Are the drawings going to move to the realm of representation, which require an objective response in order to determine things such as scale or structure? Or, are they a means of pro-active thought; continuously revealing an "other".

The imagining of an object through drawing or the mental is a synthetic act; it includes a certain level of knowledge and intention that are at the centre of imagination. It is what makes the object of the image what it is and what can allow the drawing to imagine. 


\section{Appendix A Endnotes}

1 Sartre, "Description - Part 1". Trans. Jonathan Webber. The Imaginary: A Phenomenological Psychology of the Imagination. London: Routledge, c2004 p. 7.

2 Evans, Robin. "Translation from Drawing to Building". Translation from Drawing to Building. Cambridge, Mass.: M.I.T Press, c1997. p. 155.

3 Maurice, Merleau-Ponty. "Eye and Mind". Trans. Colin Smith. Primacy of Perception. New Jersey: Humanities Press, 1976. p. 179.

Reading Depth: According to Merleau-Ponty, depth is an enigma that exists between our natural perception of depth and in the way things are arranged in a drawing or painting, as in the way a perspective is created. It is the understanding that a "thing" is there.

${ }^{4}$ Sartre, "Description - Part 1". p. 8

5 Sartre, "Description - Part 1". p. 8.

6 Sartre, "Description - Part 1". p. 9.

7 Sartre, Jean-Paul. "Description - Part 2. The Probable: The Nature of the Analogon in the Mental Image". Trans. Jonathan Webber. The Imaginary: A Phenomenological Psychology of the Imagination. London: Routledge, c2004.p. 57.

${ }^{8}$ Sartre, "Description - Part 1". p. 13.

${ }^{9}$ Sartre, "Description - Part 1". p. 14.

${ }^{10}$ Sartre, Jean-Paul. "Being and Nothingness". in McNeil and Feldman. Continental Philosophy. London: Blackwell. 1998. p. 154. 